\title{
Petrología de los xenolitos del manto alojados en rocas basálticas del Paleoceno-Eoceno en la zona de Paso de Indios, provincia del Chubut
}

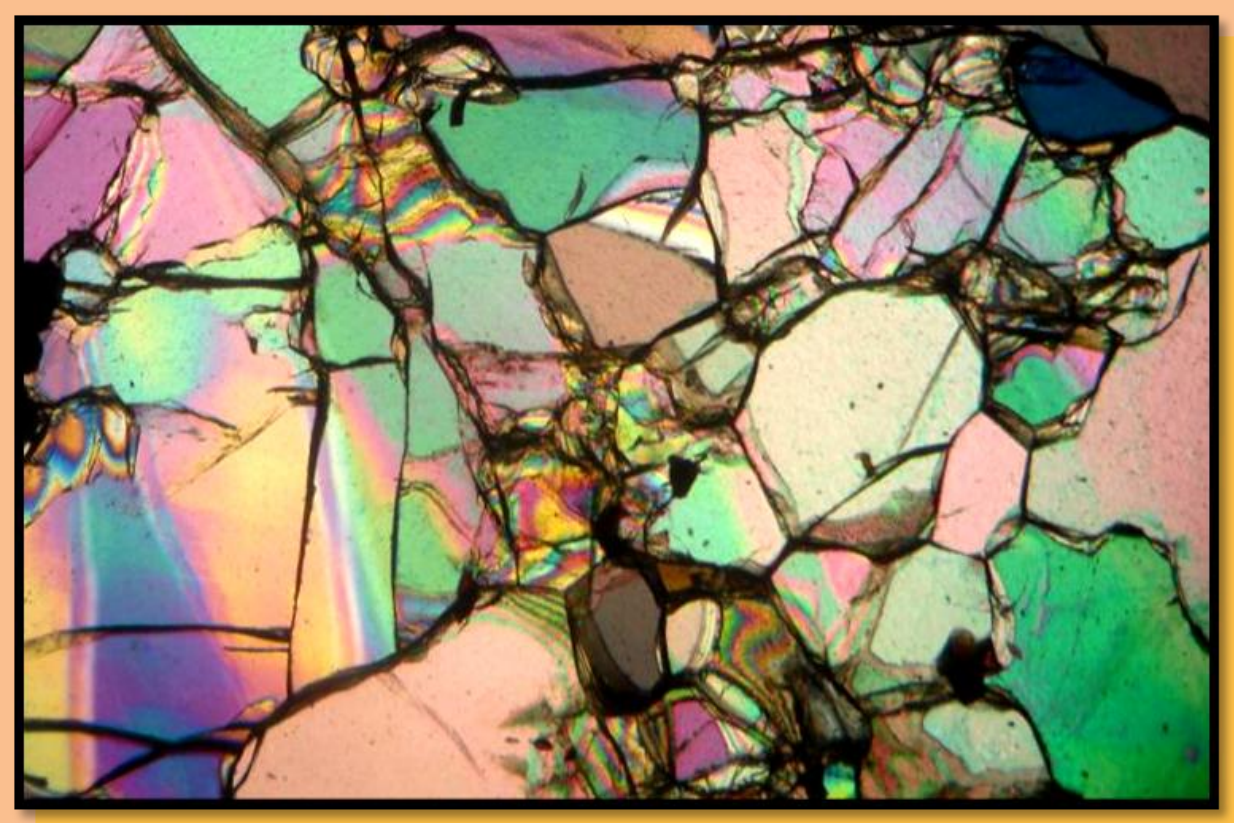

Lic. Alexis Daniel Ponce

Director: Dr. Gustavo Walter Bertotto

Co Director: Dr. Carlos Alberto Cingolani

Facultad de Ciencias Naturales y Museo

Universidad Nacional de La Plata 

A la memoria de mi madre Norma Thome 


\section{AGRADECIMIENTOS}

- A mi director Dr. Gustavo Bertotto por la invalorable colaboración y consejos, en lo profesional y personal, a lo largo de estos años.

- A mi codirector Dr. Carlos Cingolani, a quien le agradezco su colaboración y sugerencias durante el desarrollo de esta tesis.

- Al CONICET por la beca doctoral concedida y por el PIP N 11220110100956 , mediante los cuales se pudo efectuar esta investigación.

- A mi codirector de beca Dr. Miguel Haller, por facilitarme material bibliográfico y por las sugerencias realizadas.

- Agradezco el aporte de la Facultad de Ciencias Exactas y Naturales de la UNLPam a través del plan PI 235 y por brindarme un lugar de trabajo.

- A la Dra. Viviana Alric, por la ayuda al momento de ubicar los afloramientos.

- A la Dra. Gabriela Massaferro.

- A la Facultad de Ciencias Naturales y Museo (UNLP), en especial al personal de la Secretaría de Postgrado.

- Al personal técnico-administrativo y a la dirección del Centro de Investigaciones Geológicas (La Plata), donde se efectuaron trabajos de laboratorio y gabinete.

- A la Università di Modena e Reggio Emilia (Modena, Italia), en especial al Dr. Maurizio Mazzucchelli.

- Al Dr. Alberto Zanetti del Istituto di Geoscienze e Georisorse (CNR), Pavia Italia.

- Al jurado de esta Tesis, doctores: Eugenio Aragón, Ernesto Bjerg y Pablo González.

- Agradezco al INCITAP (UNLPam-CONICET).

- A mis compañeros, amigos y al personal del Pabellón de Geología de la UNLPam.

- Deseo expresar, también, mi reconocimiento y gratitud a Marcela, mi compañera de vida. 


\section{ÍNDICE}

RESUMEN

ABSTRACT

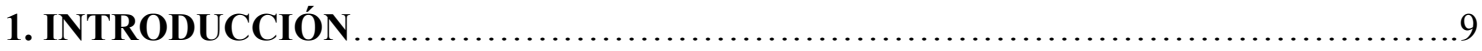

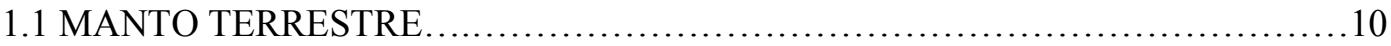

1.1.1 Estructura................................................................ 10

1.1.2 Composición global...........................................................11

1.1.3 Manto litosférico subcontinental...........................................14

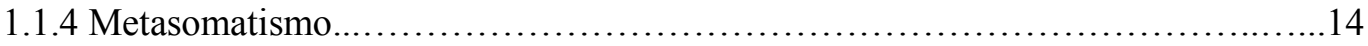

1.2 ESTUDIO DE ROCAS DEL MANTO ........................................ 15

1.2.1 Zona de retroarco patagónico de Argentina....................................16

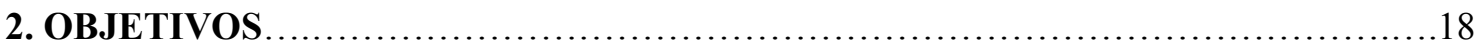

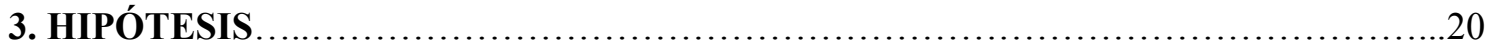

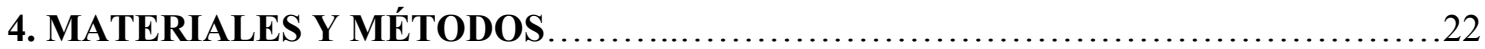

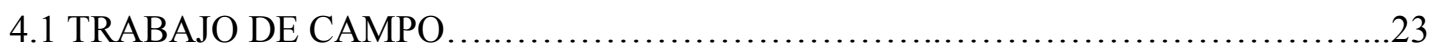

4.2 TRABAJO DE LABORATORIO...................................................23

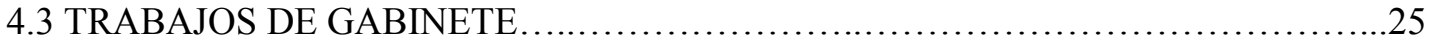

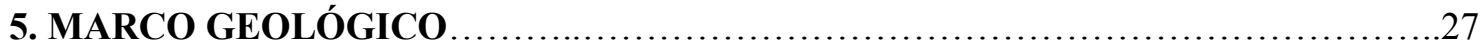

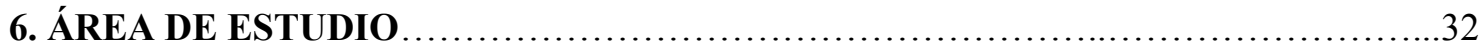

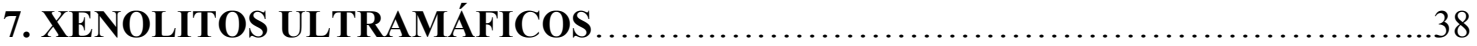

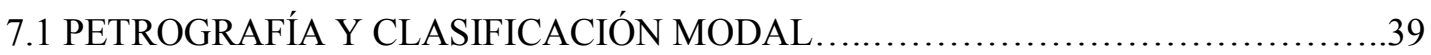

7.1.1- Cerro Chenque..................................................................

7.1.2- Cerro Matilde.................................................................... 46

7.1.3- Cerro León...................................................................... 50

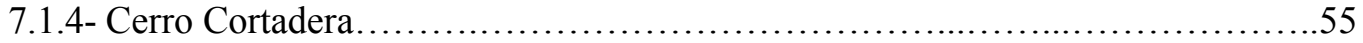

7.1.5- Tapera Marín..........................................................60 
7.1.6- Estancia La Primavera...................................................64

7.2 CARACTERÍSTICAS PETROGRÁFICAS PARTICULARES.......................67

7.2.1 Reemplazo mineral y reacciones.........................................67

7.2.2 Reacciones xenolito-basalto hospedante....................................69

8. GEOQUÍMICA DE LAS FASES MINERALES..................................... 71

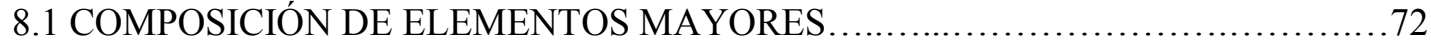

8.2 VARIACIÓN DE ELEMENTOS MAYORES........................................ 74

8.3 GEOQUÍMICA MINERAL DE ELEMENTOS TRAZA.................................78

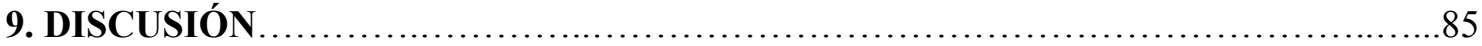

9.1 REEMPLAZO MINERAL Y REACCIONES BASALTO-XENOLITO.................86

9.2 ESTIMACIONES DE TEMPERATURA Y PRESIÓN ................................87

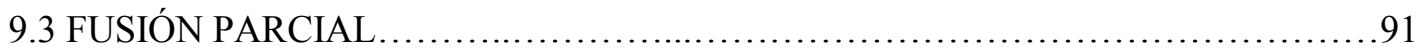

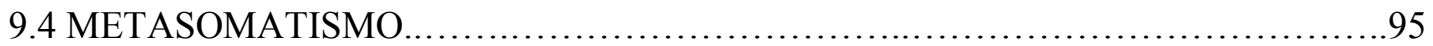

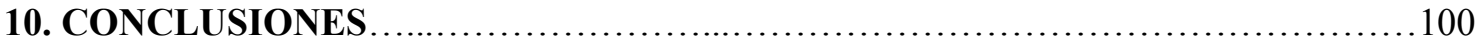

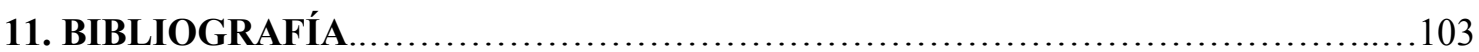

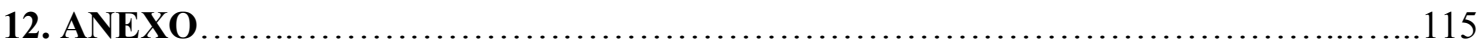




\section{RESUMEN}

Las rocas basálticas eocenas de la región de Paso de Indios (Chubut), son algunas de las varias manifestaciones de basaltos cenozoicos portadores de xenolitos ultramáficos de Patagonia. Los xenolitos analizados presentan una amplia abundancia de harzburgitas y lherzolitas pobres en clinopiroxeno lo que le da un carácter refractario a la columna mantélica del área de estudio. La textura porfiroclástica y la transicional de gruesa a porfiroclástica son las más frecuentes. Las temperaturas de equilibrio están en el orden de $\operatorname{los} 850$ a $1200{ }^{\circ} \mathrm{C}$ y las presiones entre 1,1 y 2,2 GPa, indicando una proveniencia de sectores del manto de aproximadamente 40 a $75 \mathrm{~km}$ de profundidad.

De acuerdo a las composiciones modales, el manto muestreado debajo de Cerro Matilde, Cerro León, Cerro Cortadera y Tapera Marín registra eventos de fusión parcial mayores al 20\%; mientras que los xenolitos con grado de empobrecimiento más variable ocurren en Cerro Chenque, donde se encuentran valores de entre $16 \%$ y $>24 \%$. Tales observaciones son confirmadas por estimaciones de fusión parcial basadas en el \#Cr de la espinela.

El estudio petrográfico evidencia la ocurrencia de dos esquemas de reacción mineralógica principales debido a la percolación de fluidos/fundidos canalizados: 1) disolución de piroxenos y generación de olivinos nuevos en peridotitas ricas en olivino, y 2) reemplazo de olivinos primarios por ortopiroxeno \pm clinopiroxeno en peridotitas ricas en ortopiroxeno. La disolución de piroxenos es atribuida a fundidos subsaturados en sílice, mientras que el reemplazo de olivinos primarios por ortopiroxenoclinopiroxeno es concordante con actividad de fundidos saturados en sílice.

Las reacciones de desequilibrio identificadas en los xenolitos comprenden: la reacción de ortopiroxeno en contacto con basalto alojante y coronas de reacción en ortopiroxeno, clinopiroxeno y espinelas asociadas a venas de vidrio. Tales rasgos están aparentemente relacionados a la inyección de fundido, probablemente durante la interacción con el basalto alojante en el transcurso de su ascenso a la superficie.

El comportamiento de los elementos de tierras raras sugiere eventos de empobrecimiento marcados y enriquecimientos metasomáticos variables por agentes con características similares a fundidos alcalinos (tipo OIB), ultra-alcalinos (tipo kimberlitas) y de composición similar a un fundido en equilibrio con hornblenda. Es notable la impronta de ambiente de subducción en dichos fundidos. 


\begin{abstract}
The Eocene basaltic rocks of the Paso de Indios area (Chubut province), are some of the several manifestations of Cenozoic basalts carrying ultramafic xenoliths in Patagonia. The studied xenoliths present an abundance of harzburgites and poorclinopyroxene lherzolites, giving a refractory character to the mantle column in the sampled area. Dominant textures are coarse and the transition coarse to porphyroclastic. The equilibrium temperatures and pressures are in the range of $850-1200{ }^{\circ} \mathrm{C}$ and $1.1-2.2$ Gpa respectively, indicating provenance from about $40-75 \mathrm{~km}$ depth in the mantle.

According to the modal compositions the mantle beneath Cerro Matilde, Cerro León, Cerro Cortadera and Tapera Marín record events of partial melting greater than $20 \%$; while xenoliths with a more variable degree of depletion occur in Cerro Chenque where values are between $16 \%$ and $>24 \%$. Such observations are confirmed by estimations based on spinel \#Cr.

Petrographic study shows the occurrence of two schemes of mineralogical reactions due to the percolation of channeled melts: 1) dissolution of pyroxene and generation of new olivine in olivine-rich peridotites, and 2) replacement of primary olivine by orthopyroxene \pm clinopyroxene in orthopyroxene-rich peridotites. Dissolution of pyroxene is attributed to silica-undersaturated melts, while the replacement of primary olivine by orthopyroxene-clinopiroxene is consistent with the activity of silica-saturated melts.

Other reactions identified in the xenoliths are dissolution of orthopyroxene in contact with the hosting basalt and reaction rims in pyroxenes and spinels associated with glass veins. Such features are apparently related to the injection of melts, probably by interaction with the hosting basalt during ascent to the surface.

The behavior of rare earth elements suggests strong depletion and enrichment by variables metasomatic agents with characteristics similar to alkaline melts (OIB type), ultra-alkaline melts (kimberlite type) and to melts in equilibrium with hornblende. Also remarkable is the imprint of subduction components in these melts.
\end{abstract}




\section{1- INTRODUCCIÓN}




\subsection{MANTO TERRESTRE}

\subsubsection{Estructura}

El planeta Tierra está dividido en cuatro capas principales, las cuales son conocidas como corteza, manto, núcleo externo y núcleo interno. Por su parte, en base a sus propiedades mecánicas, el manto terrestre está dividido en tres capas principales: manto litosférico (junto a la corteza forman la litósfera), astenósfera y mesósfera. El manto litosférico es la capa más rígida del manto, es de composición peridotítica y se extiende desde la base de la corteza hasta los 100 a $200 \mathrm{~km}$ de profundidad.

El límite entre la litósfera y astenósfera está representado por la isoterma de $1250{ }^{\circ} \mathrm{C}$. La astenósfera se extiende desde los 100-200 km hasta los 350-500 km de profundidad y está caracterizada por presentar un comportamiento plástico causado por la presencia de material parcialmente fundido, que coincide con una zona de baja velocidad de ondas sísmicas (LVZ). Por su parte, la mesosfera se extiende desde la base de la astenósfera hasta el núcleo externo, a aproximadamente $2700-2900 \mathrm{~km}$ de profundidad, y presenta un aumento constante de las velocidades de ondas sísmicas con la profundidad (Figura 1.1) (Helffrich y Wood 2001).

Otras discontinuidades geofísicas han sido detectadas entre los 10 y los $80 \mathrm{~km}$ de profundidad, con un aumento de la velocidad de las ondas sísmicas, explicado por la aparición de rocas más densas (ultramáficas), definiendo el límite corteza-manto, conocida como discontinuidad de Mohorovicic. Los cambios composicionales y las transformaciones de fases que llevan a los rápidos incrementos en las velocidades de ondas sísmicas fueron determinados a partir de ensayos de petrología experimental, los que mostraron que el olivino de la peridotita sufre sucesivas transformaciones de fase dependientes de la presión hacia la estructura de la espinela (ringwoodita) y finalmente se transforma en perovskita + magnesiowustita (Ringwood y Major (1966), Liu (1976), Ito y Takahashi (1989)), según las siguientes reacciones:

$$
\begin{aligned}
& \text { - }(\mathrm{Mg}, \mathrm{Fe})_{2} \mathrm{SiO}_{4}=>(\mathrm{Mg}, \mathrm{Fe})_{2} \mathrm{SiO}_{4} \quad \mathrm{P}=14 \mathrm{GPa} \text {; Prof. }=410 \mathrm{~km} \\
& \text { Olivino Wadsleyita } \\
& \text { - }(\mathrm{Mg}, \mathrm{Fe})_{2} \mathrm{SiO}_{4}=>(\mathrm{Mg}, \mathrm{Fe})_{2} \mathrm{SiO}_{4} \quad \mathrm{P}=18 \mathrm{GPa} \text {; Prof. }=520 \mathrm{~km} \\
& \text { Wadsleyita Ringwoodita } \\
& \text { - }(\mathrm{Mg}, \mathrm{Fe})_{2} \mathrm{SiO}_{4}=>(\mathrm{Mg}, \mathrm{Fe})_{2} \mathrm{SiO}_{3}+(\mathrm{Mg}, \mathrm{Fe}) \mathrm{O} \quad \mathrm{P}=23 \mathrm{GPa} \text {; Prof. }=660 \mathrm{~km} \\
& \text { Ringwoodita Perovskita + Magnesiowustita }
\end{aligned}
$$




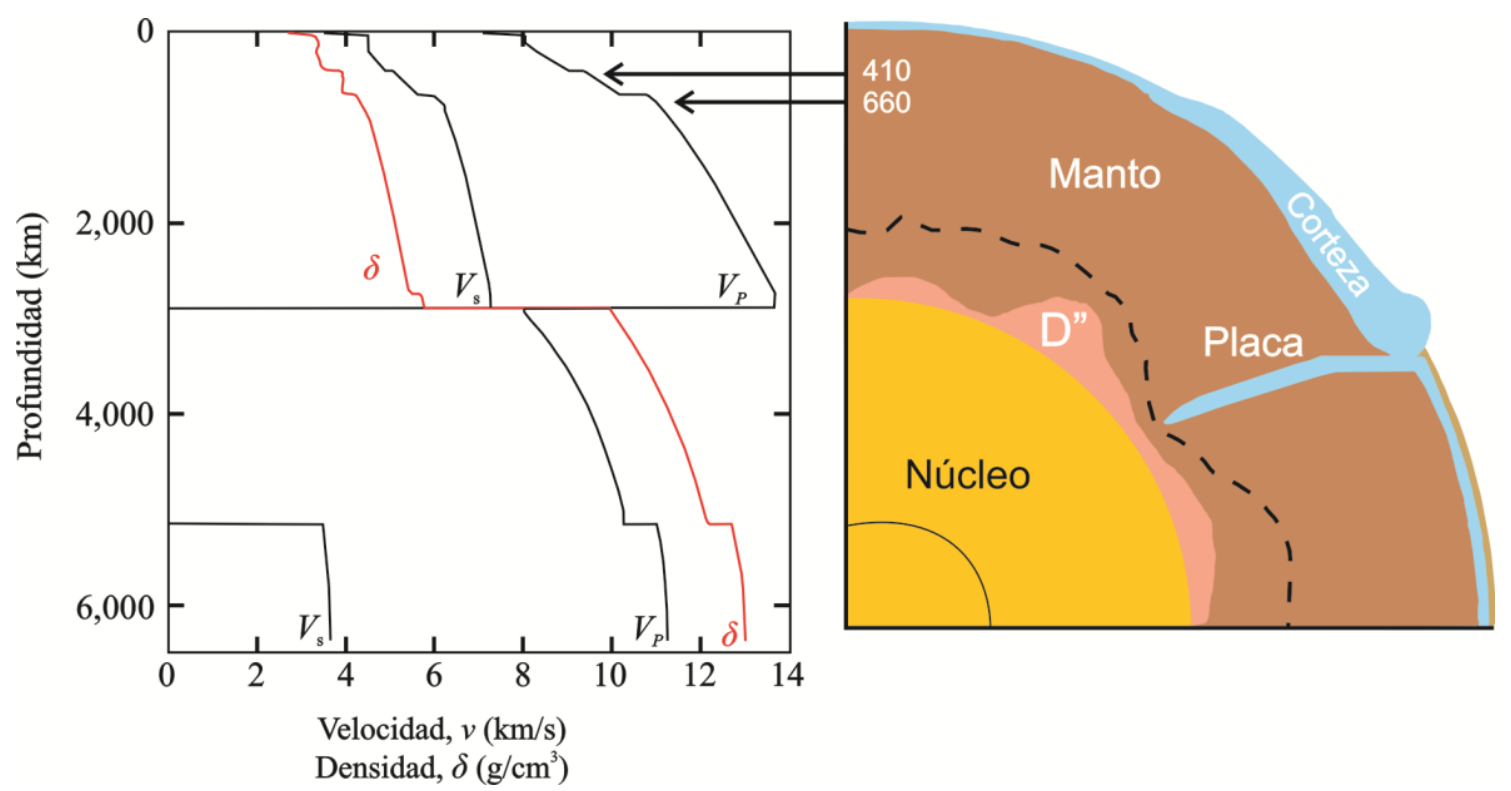

Figura 1.1. Estructura interna de la Tierra en base a evidencias geofísicas. La figura muestra las principales discontinuidades sísmicas a 410 y $660 \mathrm{~km}$ de profundidad, y la capa (D”) en la base del manto. A la derecha se grafica un corte de la Tierra mostrando una región de corteza continental y una placa litosférica subductada hundiéndose en el manto inferior. La capa D" tiene un espesor irregular. Tomado de Helffrich y Wood (2001). Vp: velocidad de onda p; Vs: velocidad de onda s y $\delta$ : densidad.

\subsubsection{Composición Global}

El manto terrestre representa aproximadamente el $83 \%$ del volumen y el $67 \%$ de la masa del planeta y comienza en el límite corteza-manto $(\sim 40 \mathrm{~km})$, extendiéndose hasta el límite manto-núcleo ( 2900 km) (Wilson 1989). El manto está compuesto esencialmente por silicatos de $\mathrm{Fe}, \mathrm{Mg}, \mathrm{Al}$, y óxidos, siendo las rocas ultramáficas ricas en olivino magnesiano $\left(\mathrm{Mg}_{2} \mathrm{SiO}_{4}\right)$ y piroxenos $\left(\mathrm{MgSiO}_{3}\right.$ y $\left.\mathrm{CaMgSi}_{2} \mathrm{O}_{6}\right)$ las más estables en el manto superior.

Manto Superior. Se extiende desde el límite corteza-manto, determinado a partir de la discontinuidad de Mohorovicic, hasta $410 \mathrm{~km}$ de profundidad. Palme y Nickel (1985) sugirieron una composición predominantemente lherzolítica con \#Mg $\sim 90$, donde \#Mg $=100 * \mathrm{Mg} /(\mathrm{Mg}+\mathrm{Fe})$, donde $\mathrm{Fe}$ es $\mathrm{Fe}^{2+}$ total.

El manto superior puede ser dividido en dos partes en base a sus diferentes características geofísicas y geoquímicas. La parte superior, conocida como litosfera, es más rígida que la parte inferior debido a su menor temperatura. Está compuesta fundamentalmente por olivino $(60 \%)$, ortopiroxeno $(30 \%)$, clinopiroxeno $(5 \%)$ y una fase mineral aluminosa (5\%), lo que constituye una composición peridotítica (Rollinson 2007). La fase aluminosa en la litosfera está representada por la gradación desde peridotita en facies de plagioclasa (hasta $\sim 40 \mathrm{~km}$ de profundidad) $\rightarrow$ a peridotita en 
facies de espinela (de $\sim 40$ a $\sim 80 \mathrm{~km}$ de profundidad) $\rightarrow$ y a peridotita en facies de granate (de $\sim 80$ a $\sim 300 \mathrm{~km}$ de profundidad). Esta transición ocurre en función de la presión, a través de las reacciones univariantes en el sistema $\mathrm{CaO}+\mathrm{MgO}+\mathrm{Al}_{2} \mathrm{O}_{3}+$ $\mathrm{SiO}_{2}$. La adición de otros componentes al sistema torna esas reacciones divariantes o multivariantes (Green y Fallon 1998), lo que resulta en presiones y temperaturas levemente diferentes de aquellas definidas para esas reacciones teniendo en cuenta el diagrama de fases. Tales reacciones y las condiciones de equilibrio son representadas a continuación:

$$
\begin{aligned}
& -\mathrm{CaAl}_{2} \mathrm{Si}_{2} \mathrm{O}_{8}+2 \mathrm{Mg}_{2} \mathrm{SiO}_{4} \rightarrow \mathrm{MgAl}_{2} \mathrm{O}_{4}+\mathrm{CaMgSi}_{2} \mathrm{O}_{6}+2 \mathrm{MgSiO}_{3} \\
& \text { Anortita }+ \text { Forsterita } \rightarrow \text { Espinela }+ \text { Diópsido }+ \text { Enstatita } \\
& \left(\mathrm{P}=1-1,2 \mathrm{GPa} ; \mathrm{T}>1100^{\circ} \mathrm{C}\right) \\
& -\mathrm{MgAl}_{2} \mathrm{O}_{4}+4 \mathrm{MgSiO}_{3} \rightarrow \mathrm{Mg}_{2} \mathrm{SiO}_{4}+\mathrm{Mg}_{3} \mathrm{Al}_{2} \mathrm{Si}_{3} \mathrm{O}_{12} \\
& \text { Espinela }+ \text { Enstatita } \rightarrow \text { Olivino }+ \text { Granate } \\
& \left(\mathrm{P}=2-2,8 \mathrm{GPa} ; \mathrm{T}>1000^{\circ} \mathrm{C}\right)
\end{aligned}
$$

La parte inferior del manto superior es la astenosfera, la cual posee composición peridotítica, comportamiento plástico, temperaturas de entre 1400 y $3000{ }^{\circ} \mathrm{C}$ y una densidad de entre $3,4 \mathrm{~g} / \mathrm{cm}^{3}$ y $4,3 \mathrm{~g} / \mathrm{cm}^{3}$ (Green y Falloon 1998).

Zona de Transición. Se sitúa entre $\sim 410 \mathrm{~km}$ a $\sim 660 \mathrm{~km}$ de profundidad y está delimitada por dos discontinuidades marcadas por los cambios en las velocidades de las ondas sísmicas (Figura 1.2). Estas discontinuidades son debidas a cambios de fase polimórficas de la estructura cristalina de determinados minerales causados por variaciones en las condiciones de presión (Anderson 1967). A partir de los $300 \mathrm{~km}$ hasta los $460 \mathrm{~km}$ de profundidad, ya en la zona de transición, ocurre la transformación de fase del ortopiroxeno a granate majorítico (fase de mayor densidad del granate). A los 400 $\mathrm{km}$ de profundidad (14 GPa), el olivino sufre un cambio en su estructura, pasando de una forma $\alpha$ de presión más baja, a una más densa $\beta-\mathrm{Mg}_{2} \mathrm{SiO}_{4}$ (wadsleyita). Ambas transiciones de fases representan un aumento significativo en la densidad del manto. Una transición gradual del piroxeno a majorita representa un aumento de $10 \%$ de la densidad, mientras que la transición de olivino $\alpha$ a $\beta$ incrementa un $8 \%$ la densidad. Cerca de los $500 \mathrm{~km}$ de profundidad, tiene lugar un nuevo cambio de fase en el olivino, desde $\beta-\mathrm{Mg}_{2} \mathrm{SiO}_{4}$ a una estructura de espinela $\gamma-\mathrm{Mg}_{2} \mathrm{SiO}_{4}$ (ringwoodita), siendo una 
transición más gradual con un aumento del 2\% de la densidad del manto (Rollinson 2007).

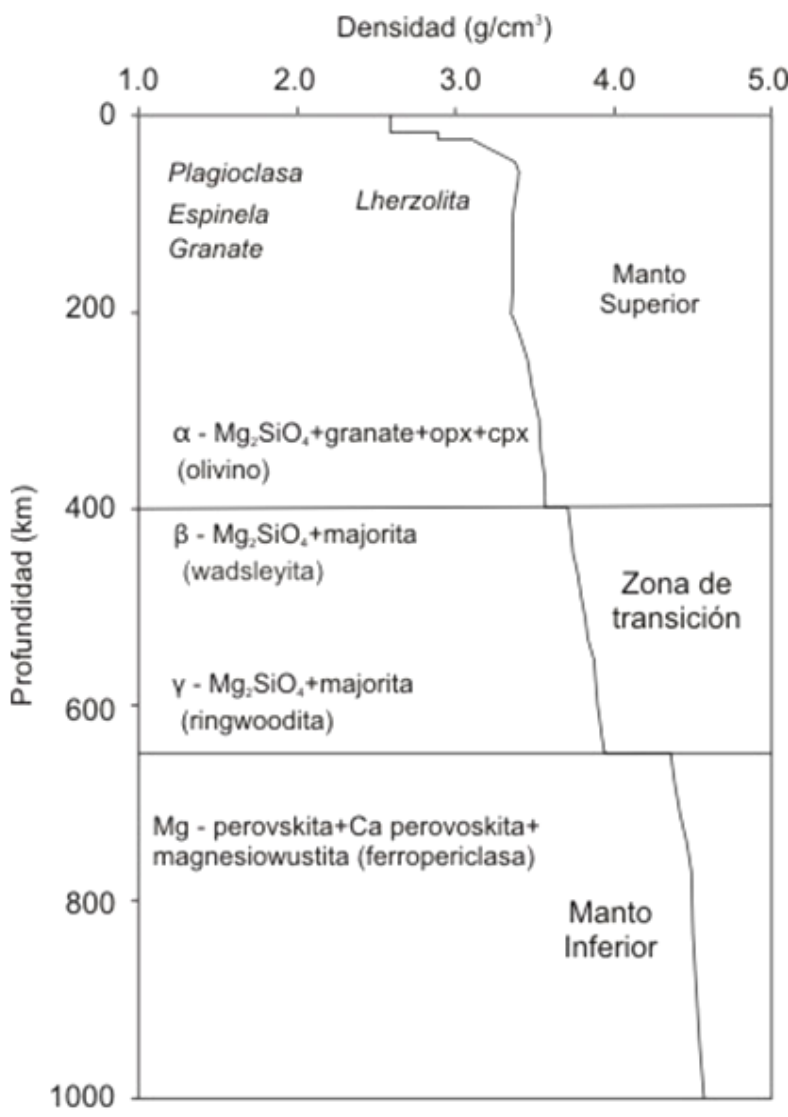

Figura 1.2. Diagrama de profundidad $(\mathrm{km}) v s$. densidad $\left(\mathrm{g} / \mathrm{cm}^{3}\right)$, de los primeros $1000 \mathrm{~km}$ del manto terrestre, mostrando las principales fases minerales en las distintas capas (Rollinson 2007).

Manto inferior. El manto inferior constituido por la mesosfera (de $\sim 660 \mathrm{~km} \mathrm{a} 2900$ $\mathrm{km}$ ), es una porción del manto que se extiende desde la base de la zona de transición hasta el núcleo. Su temperatura media es de $3000^{\circ} \mathrm{C}$ y su densidad está entre $4,3 \mathrm{~g} / \mathrm{cm}^{3}$ y $5,4 \mathrm{~g} / \mathrm{cm}^{3}$. El manto inferior tiene una composición del \#Mg ( 90) similar a la del manto superior. Una discontinuidad debido al aumento de la velocidad sísmica y de la densidad en el manto ocurre a los $660 \mathrm{~km}$ definiendo el límite inferior de la zona de transición del manto. Aquí ocurre la disociación de ringwoodita $\left(\gamma-\mathrm{Mg}_{2} \mathrm{SiO}_{4}\right)$ en perovskita magnésica $\left((\mathrm{Mg}, \mathrm{Fe}) \mathrm{SiO}_{3}\right)$ y magnesiowustita o ferropericlasa $((\mathrm{Mg}, \mathrm{Fe}) \mathrm{O})$. Además, el granate majorita se transforma en perovskita cálcica $\left(\mathrm{CaSiO}_{3}\right)$. El manto inferior contiene 77-83\% (molar) de perovskita magnésica, 13-18\% de magnesiowustita y 4-5\% de perovskita cálcica. La perovskita magnésica es el mineral dominante en el manto inferior, siendo consecuentemente el mineral más abundante en el planeta (Hama y Suito 2001, Rollinson 2007). 


\subsubsection{Manto Litosférico Subcontinental (MLSC).}

El MLSC representa el residuo luego de los eventos de extracción de fundidos del manto primordial o primitivo, siendo empobrecido y más refractario, con alta relación $\mathrm{Mg} / \mathrm{Fe}$ y bajos contenidos de $\mathrm{Al}_{2} \mathrm{O}_{3}$ en relación al manto astenosférico subyacente. Posee una composición heterogénea y, comparativamente, es más espeso, más frío, más diferenciado químicamente y más antiguo que la corteza y el manto litosférico oceánico (Menzies y Hawkesworth 1987). El MLSC es un dominio del manto que está prácticamente aislado del resto del manto y por eso ha resistido a la homogenización. En el caso de las litosferas arqueanas, éstas preservan dominios aislados desde el inicio de la formación de la Tierra y proveen importante información sobre los procesos iniciales de formación del planeta (Rollinson 2007).

El MLSC posee gradaciones verticales de los contenidos de $\mathrm{Ca}$, donde harzburgitas refractarias superficiales gradan a lherzolitas refractarias más profundas. Estas características refractarias derivan de la constante fusión del manto astenosférico. Cerca de la astenósfera, las características de las lherzolitas litosféricas se aproximan a las lherzolitas astenosféricas (más ricas en $\mathrm{Ca}$ ), dificultando la determinación del límite litosfera/astenósfera. Su composición ha sido estimada principalmente a partir de estudios del comportamiento geoquímico de suites de xenolitos peridotíticos mantélicos que son reflejos de la composición de su fuente en el manto. Estas suites están representadas predominantemente por lherzolitas, harzburgitas y dunitas, que poseen \#Mg normalmente >85 (McDonough 1990).

\subsubsection{Metasomatismo}

El manto superior es composicionalmente heterogéneo a escala espacial y temporal. Los procesos metasomáticos son las principales causas del re-enriquecimiento mantélico, generando numerosas heterogeneidades. Estos procesos fueron clasificados en dos principales tipos: metasomatismo críptico (Dawson 1984) y metasomatismo modal (Harte 1983). El metasomatismo críptico ocurre con el re-enriquecimiento en la roca, visto principalmente para los elementos traza, no acompañado de la formación de nuevas fases minerales; lo que cambia esencialmente es la composición de los minerales originales de la roca (Dawson, 1984, Menzies y Hawkesworth 1987). Se denomina metasomatismo modal a la formación de nuevos minerales en las peridotitas además de los minerales comunes (Harte 1983, Menzies y Hawkesworth 1987). 
Algunos fenómenos metasomáticos en el manto son consecuencias naturales del ascenso de magmas ricos en volátiles a través de las fracturas presentes en la litosfera (Menzies y Hawkesworth 1987). Al ascender, estos magmas pierden calor y tienden a su estancamiento, ocurriendo la cristalización de minerales como olivino, piroxenos, granate y feldespatos, dejando al magma residual saturado en volátiles y enriquecido en elementos incompatibles. El continuo enfriamiento de esos magmas da lugar a la cristalización de fases volátiles como kaersutita, apatito, flogopita y sulfuros en el manto. El ascenso de los volátiles restantes dependerá de la estabilidad de las fases en el manto. Por ejemplo, en caso de que las temperaturas locales fueran mayores que la estabilidad de los carbonatos, pero menores que las fases $\mathrm{OH}^{-}$, el fluido que continuará percolando será rico en $\mathrm{CO}_{2}$.

Sin embargo, el enfriamiento del magma con liberación concomitante de volátiles es sólo uno de los factores responsables del metasomatismo mantélico. En zonas de subducción, por ejemplo, ocurre la entrada de cantidades significativas de $\mathrm{H}_{2} \mathrm{O}$ en el manto superior liberada por el proceso de deshidratación de la placa subductante. Ito et al. (1983) observaron que la tasa de retorno de agua en el manto a través de la subducción es de 3 a 10 veces mayor que la cantidad liberada por el magmatismo (Menzies y Hawkesworth 1987). La percolación de estos fluidos acuosos en los intersticios de peridotitas causa la concomitante reacción y difusión en los minerales originales, produciendo mica y anfíbol intersticial (metasomatismo modal) (Menzies y Hawkesworth 1987).

\subsection{ESTUDIO DE ROCAS DEL MANTO}

Las rocas y los fragmentos de roca del manto de la Tierra se encuentran en varios marcos geológicos como: 1) secciones del manto en ofiolitas representando la litosfera suboceánica; 2) peridotitas masivas, diversamente conocidas como peridotitas alpinas, orogénicas, o simplemente peridotitas de alta temperatura; 3) peridotitas abisales, extraídas desde el fondo del océano (residuo de la extracción de fundidos de corteza oceánica); 4) xenolitos peridotíticos con espinela (raramente granate) en basaltos alcalinos, en su mayoría de la litosfera subcontinental, pero con muestras prácticamente idénticas a las correspondientes a la litosfera suboceánica; y 5) xenolitos de peridotita con granate provenientes de kimberlitas, lamproítas y menos frecuentemente de basaltos alcalinos, estos fragmentos muestrean niveles más profundos de la litosfera subcontinental y por lo general se limitan a antiguas regiones cratónicas. Además, los 
diamantes incluidos en kimberlitas a veces contienen inclusiones de minerales del manto profundo, pero estos casos son inusuales (Walter et al. 2011, Palme y O’Neill 2014).

El ascenso de los xenolitos a la superficie de la Tierra contenidos en los basaltos es tan rápido que los minerales no tienen tiempo para adaptarse a presiones y temperaturas más bajas. Debido a su abundancia, la mayoría de la información utilizada para la estimación de la composición química del manto deriva de xenolitos de lherzolita con espinela procedentes de profundidades de 40-60 km. Las lherzolitas de granate, mucho más raras, aportan información valiosa sobre el manto hasta profundidades de aproximadamente $200 \mathrm{~km}$ y temperatura de $1400{ }^{\circ} \mathrm{C}$.

\subsubsection{Zona de retroarco patagónico de Argentina}

En el sur de Sudamérica, al sur de $\operatorname{los} 35^{\circ} \mathrm{S}$, múltiples episodios volcánicos fueron originados durante el Cenozoico vinculados a movimientos extensionales desarrollados en el retroarco extraandino. Estos episodios están caracterizados por erupciones de basaltos alcalinos (Stern et al. 1990) que en numerosos afloramientos contienen xenolitos mantélicos. Inclusiones mantélicas de la región de Comallo (Río Negro) y Los Adobes (Chubut) fueron señaladas en primera instancia por Gelós y Hayase (1979). Luego, Bjerg et al. (1991, 2005), Barbieri et al. (1999) y Rivalenti et al. (2004) realizaron trabajos regionales basados en xenolitos en facies de espinela colectados en las provincias de Río Negro, Chubut y Santa Cruz. De todas esas localidades (más de 20), sólo dos contienen peridotitas portadoras de granate: Pali Aike localizada en la Patagonia sur (Skewes y Stern 1979, Douglas et al. 1987, Stern et al. 1989, Kempton et al. 1999, Vannucci et al. 2002) y Prahuaniyeu, localizada en la Patagonia norte (Ntaflos et al. 2001, Bjerg et al. 2005, Ntaflos y Bjerg 2006, Bjerg et al. 2009). Por su parte, al norte del Río Colorado se indicaron tres localidades con xenolitos del manto (Bertotto 2000, 2002a, 2002b, Jalowitzki et al. 2010) y una localidad en el extremo sur de Argentina (Tierra del Fuego, Acevedo y Quartino 2004), en ambos sectores se trata de peridotitas en facies de espinela.

En el área de Paso de Indios, zona central de la provincia del Chubut, existen varios afloramientos de basaltos Paleógenos portadores de xenolitos ultramáficos. Esos xenolitos fueron mencionados inicialmente por Gelós y Hayase (1979), Alric et al. (1993), Labudía (1994) y Alric (1996). Más tarde, Rivalenti et al. (2004) y Bjerg et al. 
(2005) incluyeron microanálisis obtenidos en muestras del área de Paso de Indios en sus trabajos regionales sobre el manto de Patagonia.

Rivalenti et al. (2004) registraron una extrema heterogeneidad geoquímica en los xenolitos del manto de esta área, cuyos clinopiroxenos muestran una variabilidad en elementos traza que casi cubre el rango composicional entero exhibido por xenolitos del manto del retroarco patagónico extraandino. En particular, Paso de Indios es una de las pocas localidades de Patagonia en la cual los clinopiroxenos de las peridotitas en facies de espinela muestran patrones con una depresión en HREE que sugiere pronunciados eventos de fusión parcial. A pesar de estos estudios, la información petroquímica reportada es insuficiente para caracterizar en detalle la composición del manto litosférico y los procesos petrológicos asociados. Prueba de ello es la reducida cantidad de muestras de Paso de Indios analizadas en los trabajos regionales de Rivalenti et al. (2004) y Bjerg et al. (2005), la mayoría de los cuales pertenecen a Cerro Chenque.

Por último, Castro et al. (2011) estudiaron xenolitos granulíticos de corteza inferior hallados en basaltos alcalinos Paleógenos de Cerro Chenque, indicando que estas muestras probablemente constituyan residuos generados a partir de la segregación de fundidos silícicos por fusión parcial de una fase sólida o cristalización incompleta de magma parental de composición intermedia. Asimismo, obtuvieron una edad de 175,9 \pm 4,9 Ma en circones lo que estaría indicando que la formación de la corteza residual ocurrió en un momento de compleja evolución litosférica en un contexto geodinámico previo a la ruptura del Gondwana a esta latitud. 


\section{2- OBJETIVOS}


El objetivo de este trabajo es incrementar el conocimiento del manto litosférico subcontinental (MLSC) debajo de la región de Paso de Indios, basado en el análisis petrográfico-modal y la geoquímica mineral de elementos mayores y traza de xenolitos ultramáficos en facies de espinela alojados en rocas basálticas paleógenas de los afloramientos denominados Cerro Chenque, Cerro Matilde, Cerro León, Cerro Cortadera, Tapera Marín y Estancia La Primavera. Los datos son utilizados para intentar restringir una sección del manto mediante la estimación de las condiciones de temperatura y presión en el Paleógeno e inferir los procesos petrológicos y geoquímicos experimentados a través del tiempo.

Los objetivos particulares comprenden: la definición de las condiciones físicoquímicas del manto; la interpretación de los procesos petrológicos que predominan en esta porción del manto litosférico; la identificación de los agentes metasomáticos y la naturaleza de los procesos de refertilización inducidos en la cuña litosférica sobre la zona de subducción. 


\section{3- HIPÓTESIS}


Las hipótesis de trabajo sobre las que se basó esta tesis son:

Los xenolitos ultramáficos fueron muestreados por los basaltos a distintas profundidades dentro del manto litosférico en el campo de estabilidad de la espinela.

El manto litosférico, representado por los xenolitos, exhibe empobrecimientos variables por extracción de fundidos.

Los xenolitos registran cambios químicos a partir de la circulación de fundidos/líquidos (metasomatismo) a niveles del manto.

$>$ Los xenolitos, en su viaje a superficie, sufrieron cambios químicos a partir del ingreso de vetillas del basalto hospedante. 


\section{4- MATERIALES Y MÉTODOS}




\subsection{TRABAJOS DE CAMPO}

El trabajo de campo se dividió en dos campañas (Diciembre de 2011 y Octubre de 2013), y se extendió por un total de 20 días. Las tareas se concentraron en la zona de Paso de Indios (Chubut), se relevaron los afloramientos denominados: Cerro Chenque, Cerro Matilde, Cerro León, Cerro Cortadera, Tapera Marín, Estancia La Primavera, Corral de Piedra y El Pajarito. En cada localidad se colectaron muestras representativas de xenolitos ultramáficos (excepto en Corral de Piedra y El Pajarito donde no se hallaron), sobre las cuales se realizaron análisis petrográficos y geoquímicos. También se realizó el relevamiento fotográfico de los afloramientos y de las muestras colectadas. El acceso a los sitios de muestreo fue posible gracias a las menciones de Alric (1996) y Alric (2011, comunicación personal) sobre los basaltos portadores de xenolitos ultramáficos en basaltos paleoceno-eocenos de la zona de Paso de Indios.

\subsection{TRABAJOS DE LABORATORIO}

\subsubsection{Cortes delgados}

En el laboratorio de rocas de la Facultad de Ciencias Exactas y Naturales (UNLPam) se confeccionaron aproximadamente 500 secciones delgadas a partir de las muestras de roca colectadas en el campo. De éstas, se seleccionaron 326 para las descripciones petrográficas y conteos modales. Para el montaje de las secciones se empleó una preparación de 80\% Resina Epoxi DICAST 751 (Distraltec) + 20\% de Endurecedor DICURE 365 (Distraltec); mientras que para el corte de rocas y desbaste se utilizó una sierra Struers Discoplan-TS. Por último, el pulido final de las secciones delgadas se realizó sobre placas de vidrio con abrasivos en polvo (carburo de silicio y óxido de aluminio) de diferentes granulometrías, hasta alcanzar el espesor deseado. Aquellos cortes delgados destinados a análisis químicos se pulieron a "espejo" con pastas de diamante Prazis mediante una pulidora a disco Struers Planopol-V.

\subsubsection{Análisis por microsonda electrónica}

La composición química de elementos mayores de olivinos, ortopiroxenos, clinopiroxenos y espinelas fue determinada mediante análisis de microsonda electrónica por dispersión de longitud de onda (WDS) en dos laboratorios distintos.

-En el departamento de Ciencias de La Tierra de la Universidad de Milán, Italia, se utilizó una microsonda JEOL JXA-8200 usando un voltaje de aceleración de $15 \mathrm{kv}$, corriente del haz de 15 nA y diámetro de haz de 1-3 micrones, con 30 segundos de 
conteo en el pico y 10 segundos en el fondo. Los estándares utilizados fueron minerales naturales (olivino para $\mathrm{Mg}$, onfacita para $\mathrm{Na}$, ilmenita para $\mathrm{Ti}$, rodonita para $\mathrm{Mn}$, feldespato potásico para $\mathrm{K}$, anortita para $\mathrm{Ca}$ y $\mathrm{Al}$, wollastonita para $\mathrm{Si}$, fayalita para $\mathrm{Fe} \mathrm{y}$ niquelina para $\mathrm{Ni}$ ) y cromita sintética para $\mathrm{Cr}$.

-En el Laboratorio de Microscopía Electrónica y Análisis por Rayos X, perteneciente a la Facultad de Matemática, Astronomía y Física de la Universidad Nacional de Córdoba, se utilizó una microsonda JEOL JXA-8230 usando un voltaje de aceleración de $15 \mathrm{kv}$, corriente del haz de $20 \mathrm{nA}$ y diámetro de haz de 1-3 micrones, con 15 segundos de conteo en el pico y 10 segundos en el fondo. Los estándares utilizados fueron minerales naturales; olivino para $\mathrm{Mg}$, anortoclasa para $\mathrm{Na}$ y $\mathrm{Al}$, titanita para $\mathrm{Ti}$, rodonita para $\mathrm{Mn} \mathrm{y} \mathrm{Si}$, ortoclasa para $\mathrm{K}$, wollastonita para $\mathrm{Ca}$, fayalita para $\mathrm{Fe}$, niquelina para Ni y cromita de Bushveld para Cr.

Los resultados obtenidos en ambas microsondas fueron corregidos por efecto matriz utilizando el método convencional ZAF provisto por el paquete de programas de JEOL. Los resultados tienen una exactitud del 94 a 98\%. Además, se analizaron 11 muestras en ambos laboratorios con el fin de controlar los datos y poder emplearlos en conjunto.

\subsubsection{Análisis por ablación láser}

Los datos de elementos traza de las fases minerales se obtuvieron mediante laser ablation microprobe-inductively coupled plasma-mass spectrometry (LAM-ICP-MS) en el Instituto de Geociencias y Georecursos del Consiglio Nazionale per le Ricerche y la Universidad de Pavia, Italia. La configuración básica del instrumento y el protocolo de análisis han sido descritos por Bottazzi et al. (1999). La precisión y exactitud de los análisis de elementos traza se evaluaron a partir de análisis repetidos en una muestra estándar (BCR2-G), resultando en aproximadamente $>93 \%$ y $>90 \%$, respectivamente. Los valores del estandar fueron tomados de la base de datos de Materiales de Referencia Geoquímica del USGS, http://minerals.cr.usgs.gov/ geo_chem_stand/; los valores de referencia para Nb, Ta, Dy y Er son datos ICP-MS inéditos de la Universidad Memorial de St. John, Terranova, Canadá). Los límites de detección de los análisis por LAM-ICPMS son, en gran parte, función del volumen de ablación y el tiempo de recuento por elemento. El volumen de ablación varía dependiendo en gran medida de la configuración instrumental, y por lo tanto los límites de detección se calculan para cada análisis. 


\subsection{TRABAJO DE GABINETE}

\subsubsection{Mapa geológico}

En base al mapa de Alric et al. (2002) y las hojas geológicas Paso de Indios (Anselmi et al. (2004) y Los Altares (Silva Nieto 2005), se confeccionó un mapa geológico de síntesis del área de estudio (Figura 5.1). Para esto se utilizaron los programas GV-SIG, Corel Draw y Photoshop. En este mapa se puede observar la geología local y la ubicación de los afloramientos estudiados.

\subsubsection{Clasificación modal y petrografía}

El análisis petrográfico de las muestras de xenolitos se realizó empleando un microscopio petrográfico Nikon Eclipse E400 Pol, propiedad de la UNLPam.

Se realizó la descripción petrográfica y análisis modal de 131 muestras de xenolitos ultramáficos en facies de espinela de Cerro Chenque, 63 de Cerro Matilde, 65 de Cerro León, 26 de Cerro Cortadera, 36 de Tapera Marín y 5 de Estancia La Primavera.

El contenido modal de las fases minerales se estimó por conteo de puntos mediante el empleo de dos métodos: a) conteo de puntos a partir de imágenes escaneadas de secciones delgadas utilizando el programa Rock.Ar (Larrea et al. 2010); b) conteo de minerales en secciones delgadas empleando un contador Prior modelo G. La cantidad de puntos obtenidos en cada muestra varió entre 2000 y 12000. A modo de control se repitieron conteos con uno y otro método sobre 20 muestras, no hallándose diferencias significativas. Para la clasificación modal de los xenolitos ultramáficos se utilizó el diagrama triangular olivino-ortopiroxeno-clinopiroxeno de Le Maitre et al. (2002).

Si bien en la literatura existen varias clasificaciones texturales de rocas ultramáficas (por ejemplo Mercier y Nicolas (1975) y Nielson-Pike y Schwarzman (1977)), se siguió la propuesta de Harte (1977) ya que es una clasificación descriptiva y no hace énfasis en la génesis.

\subsubsection{Tratamiento de datos geoquímicos}

Para evitar reiterar los nombres de los minerales se utilizarán, cuando se crea necesario, las abreviaturas de los mismos según lo consignado en la Tabla 4.1.

\begin{tabular}{|c|c|c|c|c|c|c|c|}
\hline \multicolumn{7}{|c|}{ Minerales } \\
\hline Cpx & Clinopiroxeno & Fa & Fayalita & Ol & Olivino & Spl & Espinela \\
Di & Diópsido & Fo & Forsterita & Opx & Ortopiroxeno & Wo & Wollastonita \\
En & Enstatita & Fs & Ferrosillita & Pl & Plagioclasa & Grt & Granate \\
\hline
\end{tabular}

Tabla 4.1. Abreviaturas de los nombres de minerales tomada de Whitney y Evans (2010). 
A partir de la información geoquímica obtenida de las fases minerales (ol, opx, cpx y spl) se calcularon los componentes iónicos y moleculares presentes en las mismas y se clasificaron mediante programas específicos, utilizando plataforma Excel. Para esto se emplearon las ecuaciones disponibles en la página de internet de la Universidad de Padova (Italia) (www.geoscienze.unipd.it).

En piroxenos se determinó el contenido relativo de Enstatita, Ferrosillita y Wollastonita; además se calculó el parámetro número de magnesio (\#Mg) $\left[=100 * \mathrm{Mg} /(\mathrm{Mg}+\mathrm{Fe})\right.$, donde $\mathrm{Fe}$ es $\mathrm{Fe}^{2+}$ total $]$. La clasificación de piroxenos se realizó con el diagrama triangular de Morimoto et al. (1988), empleando el diagrama Triplot (software libre).

En olivinos se obtuvo el parámetro número de magnesio $(\# \mathrm{Mg})$ y los contenidos relativos de Forsterita, Fayalita y Tefroíta; mientras que sobre las espinelas se calcularon los parámetros número de magnesio $(\# \mathrm{Mg})$ y de cromo (\#Cr) $[=100 * \mathrm{Cr} /(\mathrm{Cr}+\mathrm{Al})]$.

Por otro lado, con las concentraciones de elementos mayores obtenidos con microsonda electrónica se realizaron cálculos de temperaturas y presiones de equilibrio con el fin de inferir el estado termobarométrico del manto litosférico muestreado. Las temperaturas de equilibrio se estimaron siguiendo la metodología indicada por Brey y Köhler (1990), Taylor (1998) y Nimis y Taylor (2000) sobre el par opx-cpx. Por su parte, las condiciones de presión se estimaron según Köhler y Brey (1990) mediante el intercambio de Ca entre ol y cpx y mediante el barómetro de Mercier (1980) sobre clinopiroxeno y ortopiroxeno. Para poder realizar estas estimaciones se realizaron análisis tanto en borde y núcleo de cada mineral.

Las estimaciones de fusión parcial se realizaron en primer lugar mediante la información de la composición modal; para esto se utilizó la relación cpx/opx vs cpx en comparación con la composición del manto primitivo propuesta por Johnson et al. (1990).

El grado de fusión parcial (F) se estimó, también, en base al número de cromo (\#Cr) de las espinelas utilizando la ecuación empírica de Hellebrand et al. (2001), donde $\mathrm{F}=\left[0,1 * \ln \left(\# \mathrm{Cr}_{\mathrm{spl}}+0,24\right)\right]$. Ello fue corroborado con la ecuación alternativa desarrollada por Batanova et al. (1998), donde $\mathrm{F}=\left[9,71 * \ln \left(\# \mathrm{Cr}_{\mathrm{spl}}\right)+25,8\right]$, y con modelos de fusión teóricos ploteados en los gráficos generados con la composición de los elementos de tierras raras en cpx. 


\section{5- MARCO GEOLÓGICO}


A continuación se describen brevemente las unidades aflorantes en el área de estudio. Se tomaron como base las hojas geológicas a escala 1:250.000 Paso de Indios (Silva Nieto 2005), Los Altares (Anselmi et al. 2004) y Gastre (Lizuain y Silva Nieto 1993). Además, el trabajo de tesis de Alric (1996) permitió ubicar los afloramientos de interés y acotar la edad de los mismos (Figura 5.1).

El área de estudio abarca $2000 \mathrm{~km}^{2}$ y se encuentra emplazada dentro de la provincia geológica de los Patagónides (Ramos 1999, Giacosa y Márquez 1999). Las rocas más antiguas aflorantes en este sector pertenecen a la secuencia volcánica denominada Formación Lonco Trapial (Turner 1983). Estas rocas comprenden una facies volcánica, compuesta de andesitas, andesitas brechosas y brechas andesíticas, y una facies piroclástica integrada por tobas primarias y retrabajadas, tobas dacíticas $\mathrm{y}$ andesíticas, areniscas tobáceas medianas y finas y aglomerados volcánicos; ambas facies son típicas de estratovolcanes de arcos magmáticos (Page y Page 1993). Esta formación aflora principalmente en el sector oeste y fue incluida en el Jurásico medio (Aaleniano-Calloviano) por Silva Nieto (2005) en base a una datación K/Ar sobre una andesita.

Durante el Jurásico medio a superior (Calloviano-Oxfordiano) tuvo lugar la depositación de la Formación Cañadón Asfalto (Stipanicic et al. 1968), cuyos afloramientos se encuentran principalmente a lo largo del valle del río Chubut, con un espesor máximo de 400 metros. Las rocas que la componen comprenden areniscas, areniscas y limolitas calcáreas, areniscas tobáceas, calizas e intercalaciones de basaltos olivínicos, y son el resultado de una sedimentación lagunar, que permitió la precipitación de calizas. Esta unidad se encuentra expuesta en el sector norte del área de estudio, en ambas márgenes del río Chubut.

El Cretácico se encuentra representado por el Grupo Chubut (Lesta 1968). Esta unidad está dividida en dos formaciones, Fm. Los Adobes y Fm. Cerro Barcino (Codignotto et al. 1978).

La Formación Los Adobes aflora al oeste de la estancia La Primavera y en cercanías del paraje El Pajarito y comprende conglomerados polimícticos de grano grueso a mediano, con clastos mal seleccionados de granitos, andesitas y basaltos; areniscas tobáceas de grano medio a grueso con intercalaciones de arcilitas y tobas medianas. La sedimentación de estas rocas es propia de un medio fluvial con alternancia de baja y alta energía. En base a la asociación de microorganismos hallados en esta unidad, 
Codignotto et al. (1978) le asignaron una edad barremiana (Cretácico inferior) (Anselmi et al. 2004).

La Formación Cerro Barcino está compuesta por litologías piroclásticas aflorantes en proximidades a estancia La Primavera, Tapera Marín, Corral de Piedra, cerro León, cerro Negro, cerro Matilde y en el sector este del área de estudio. Los afloramientos incluyen tobas, tobas arenosas, areniscas tobáceas y arcilitas bien estratificadas con algunos bancos macizos; se interpretan como sedimentación de cenizas volcánicas sobre planicies de tipo fluvial. Estudios micropaleontológicos le permitieron a Panza (1981) y Proserpio (1987), entre otros, asignarle una edad barremiana-cenomaniana (Cretácico inferior-superior) a esta Formación (Anselmi et al. 2004).

En discordancia levemente angular sobre las sedimentitas Cretácicas del Grupo Chubut, se deposita la secuencia Supra-Cretácica de las areniscas de la Fm. Paso del Sapo y de las limolitas de la Fm. Lefipan de un ambiente litoral maritimo (limite sur de la hoja Gastre). Este dato es muy importante pues marca la gran extension y subsidencia de la zona en los momentos previos a la extrusion de lo basaltos portadores de xenolitos.

Con la instauración de un margen divergente durante gran parte del Paleógeno (Somoza y Ghidella 2005), se inicia el Rift Paleógeno de los Patagónides (Aragón et al, 2015) en el cual tuvo lugar la efusión del volcanismo de retroarco ampliamente representado en en esta región de la Patagonia. En esta zona del retroarco extraandino se encuentran rocas basálticas paleocenas-eocenas que intruyen y/o cubren sedimentos del Grupo Chubut. Estas rocas se agrupan en la Formación El Buitre (Ardolino y Franchi 1993) e incluyen basaltos alcalinos, gabros, basanitas y volcanitas con afinidad química de intraplaca (De Ignacio et al. 2001; Kay 2002; Kay et al. 2004 y Kay et al. 2007). Alric et al. (2002) realizaron 14 dataciones Ar/Ar sobre estas rocas, arrojando edades desde 62,5 \pm 0,26 a 49,6 $\pm 0,77$ Ma., lo que permitió reconocer dos secuencias volcánicas; la secuencia paleocena aflorante en cerro Negro y meseta Pagarzuntudúa, y la secuencia eocena aflorante en los cerros Chenque, Matilde, León, Cortadera, Mesa, Corral de Piedra, Tapera Marín, Estancia La Primavera y al sur del establecimiento El Pajarito. Las rocas basálticas de esta última secuencia son portadoras de xenolitos ultramáficos, objeto de estudio de este trabajo.

En el lapso Eoceno superior-Oligoceno inferior se depositó el Grupo Sarmiento; denominación dada por Simpson (1941) al conjunto de sedimentitas portadoras de mamíferos que afloran en proximidades del paraje El Pajarito, en forma paralela a la ruta nacional 25. Este grupo se caracteriza por la presencia de tobas, tobas arenosas, 
areniscas y limolitas tobáceas de color gris; el ambiente depositacional continental está relacionado a fenómenos magmáticos explosivos, de carácter dacítico y/o andesítico, cuyos piroclastos provienen del arco magmático andino. Lesta y Ferello (1972), Nullo (1983) y Turner (1983) le asignaron la edad correspondiente a esta unidad (Silva Nieto 2005).

En el Mioceno, con la reinstalación de un margen fuertemente convergente (Placa de Nazca), se produce la inversión tectónica de las fallas extensionales que habian afectado a los Patagónides durante el Paleógeno (Giacosa y Marquez 1999), dando lugar asi a la finalizacion del Rift Paleogeno de los Patagonides (Aragón et al. 2015).

Esta inversión tectónica Miocena da lugar a la configuracion topográfica actual, con el levantamiento de las Sieras de Taquetren, Lonco Trapial y del $C^{\mathbf{o}}$ Negro (Giacosa y Márquez 1999).

El Cuaternario en el área de estudio está caracterizado por una amplia cubierta sedimentaria. Se distinguen los depósitos sedimentarios denominados del primer nivel “depósitos pleistocenos antiguos" y del segundo nivel, diferenciados por su ubicación topográfica. Estos niveles involucran potentes acumulaciones de gravas, fanglomerados y areniscas gruesas, compuestos de clastos redondeados subesféricos, de granitos, andesitas y basaltos. Estos sedimentos son los más abundantes en la zona de estudio, ocupando hasta un tercio de su superficie. Nullo (1983) le asignó una edad pleistocena a estos depósitos (Silva Nieto 2005).

Alrededor del cruce de la ruta nacional 25 y la ruta provincial 12 aflora la Formación Valenzuela que involucra depósitos psefíticos con intercalaciones de areniscas y areniscas conglomerádicas. Estos pueden presentar restos de troncos silicificados retransportados y corresponderían a un ambiente continental fluvial en facies de canal. Cortés (1988) incluyó tentativamente en el Pleistoceno a la Formación Valenzuela (Anselmi et al. 2004).

También durante el Pleistoceno se formaron los siguientes depósitos: a) depósitos de remoción en masa, compuestos por grandes bloques irregulares de basalto desarrollados en los bordes de las mesetas basálticas que le dan origen; b) depósitos de cobertura de pedimentos. Son afloramientos delgados y tabulares de poca pendiente, constituidos fundamentalmente por psefitas y/o psamitas cuya composición varía según la roca de donde derivan; c) depósitos de terrazas fluviales del río Chubut. De estos últimos, se encuentran cinco diferentes niveles de terrazas fluviales en las márgenes del río, separados por escalones o escarpas. En mayor medida se corresponden con 
acumulaciones inconsolidadas de grava y arena gruesa de composición volcánica y piroclástica. La edad de este último depósito llega hasta la actualidad (Anselmi et al. 2004).

Finalmente, en el transcurso del Holoceno se originaron los depósitos aluviales y coluviales presentes en el lecho del río Chubut y cauces temporarios tributarios del mismo. Están compuestos por material de granulometría variada: grava, arena, limo y arcilla. También están presentes depósitos de planicies aluviales, compuestos por niveles arenosos con intercalaciones conglomerádicas en cauces permanentes y acumulaciones arenosas y limosas en otros cauces efímeros (Silva Nieto 2005).

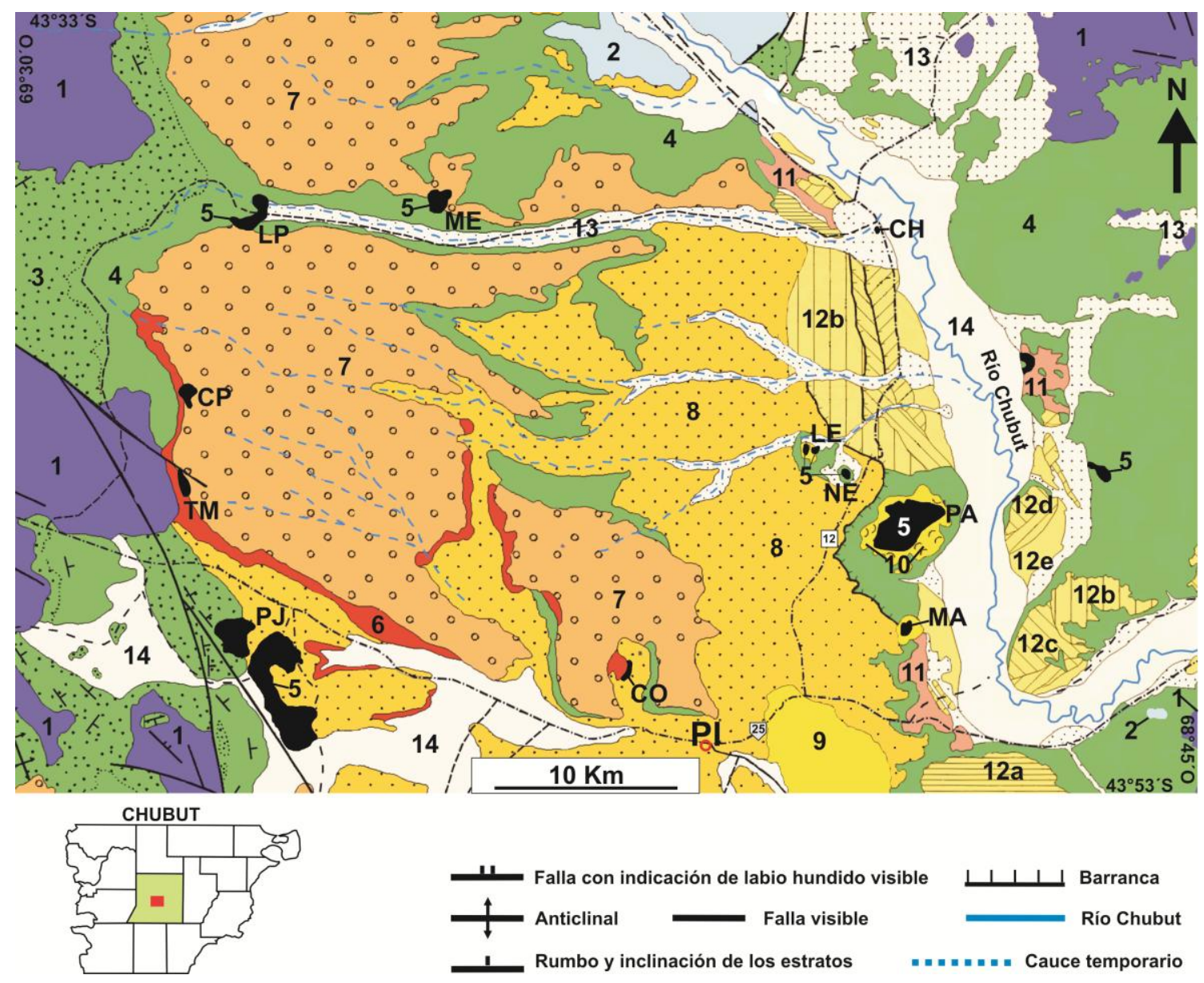

Figura 5.1. Mapa geológico con las principales unidades estratigráficas que afloran en el área de estudio. Referencias: 1- Fm. Lonco Trapial (Jurásico medio), 2- Fm. Cañadón Asfalto (Jurásico medio-superior), 3- Fm. Los Adobes (Cretácico inferior), 4- Fm. Cerro Barcino (Cretácico inferior-superior), 5- Fm. El Buitre (Paleoceno-Eoceno), 6- Grupo Sarmiento (Eoceno superior-Oligoceno), 7- depósitos del primer nivel (Pleistoceno), 8- depósitos del segundo nivel (Pleistoceno), 9- Fm. Valenzuela (Pleistoceno superior), 10- depósitos de remoción en masa (Pleistoceno), 11 - Cobertura de pedimento, 12 a, b, c, d, edepósitos de terrazas fluviales (Pleistoceno-Holoceno), 13-depósitos aluviales y coluviales (Holoceno), 14- depósitos de planicies aluviales (Holoceno). LP- Estancia La Primavera, ME- $\mathrm{C}^{\circ} \mathrm{Mesa}, \mathrm{CH}^{-} \mathrm{C}^{\circ}$ Chenque, LE- $\mathrm{C}^{\circ}$ León, NE- $\mathrm{C}^{\circ}$ Negro, PA- meseta Pagarzuntudúa, MA- $\mathrm{C}^{\circ}$ Matilde, CO- $\mathrm{C}^{\circ}$ Cortadera, TM- Tapera Marín, CP- $\mathrm{C}^{\circ}$ Corral de Piedra, PJ- El Pajarito. PI- localidad de Paso de Indios. 


\section{6- ÁREA DE ESTUDIO}


El área de estudio está ubicada en la zona extraandina del centro de la provincia del Chubut, en cercanías de la localidad de Paso de Indios. El área incluye los afloramientos del Cerro Chenque, Cerro Matilde, Cerro León, Cerro Cortadera, Tapera Marín y Estancia La Primavera y se encuentra emplazada dentro de la provincia geológica de los Patagónides (Ramos 1999, Giacosa y Márquez 1999). Los afloramientos estudiados son relictos de coladas y diques de composición basáltica alcalina que cubren e intruyen respectivamente, a sedimentitas cretácicas del Grupo Chubut y se encuentran parcialmente cubiertos por detritos cuaternarios (Alric et al. 2002, Anselmi et al. 2004, Silva Nieto 2005). Estos basaltos eocenos pertenecen a la Formación El Buitre (Ardolino y Franchi 1993) y están relacionados al Rift Paleógeno de los Patagónides (Aragón et al 2015); a su vez estos basaltos son correlacionables con el volcanismo bimodal sin-extensional Paleógeno del complejo volcánico Piedra Parada (Aragón et al. 2005). El Rift de los Patagónides está vinculado a la tectónica extensional generada por el episodio de margen de placa transformante que afectó el margen activo del sur de América del Sur desde el Paleoceno al Oligoceno (Aragón et al. 2011). Durante esta etapa se desprendió la placa de Farallón-Aluk y se generó una ventana de subducción (slab window) por debajo del área estudiada.

Cerro Chenque: está ubicado $26 \mathrm{~km}$ al nor-noreste de la localidad de Paso de Indios a la vera de la ruta provincial $\mathrm{N}^{\circ} 12$, en proximidades de Paso Berwyn $\left(68^{\circ} 56^{\prime} 37,1^{\prime \prime} \mathrm{O} ; 43^{\circ}\right.$ $\left.38^{\prime} 36,6^{\prime \prime} \mathrm{S}\right)$. El afloramiento principal corresponde a un dique basáltico de unos 50 metros de longitud (Figura 6.1). Los xenolitos ultramáficos de mayor tamaño alcanzan $20 \mathrm{~cm}$ de diámetro, son friables (meteorizados) y se encuentran sueltos o en el contacto entre bloques (Figura 6.7A). En cambio, los xenolitos de aspecto más "fresco" no superan los $5 \mathrm{~cm}$ de diámetro y fueron obtenidos de lajas verticales de basalto masivo. Los afloramientos de Cerro Chenque también incluyen una importante cantidad de xenolitos de granulitas de corteza inferior, de hasta $25 \mathrm{~cm}$ de diámetro, del período Jurásico medio (Castro et al. 2011). Se aclara que esta localidad es diferente de la denominada Cerro de los Chenques (Rivalenti et al. 2007) que está localizada aproximadamente unos $160 \mathrm{~km}$ al suroeste a los $70^{\circ} 4^{\prime} 9,9^{\prime \prime} \mathrm{O}$ y $44^{\circ} 52^{\prime} 2,9^{\prime \prime} \mathrm{S}$. 


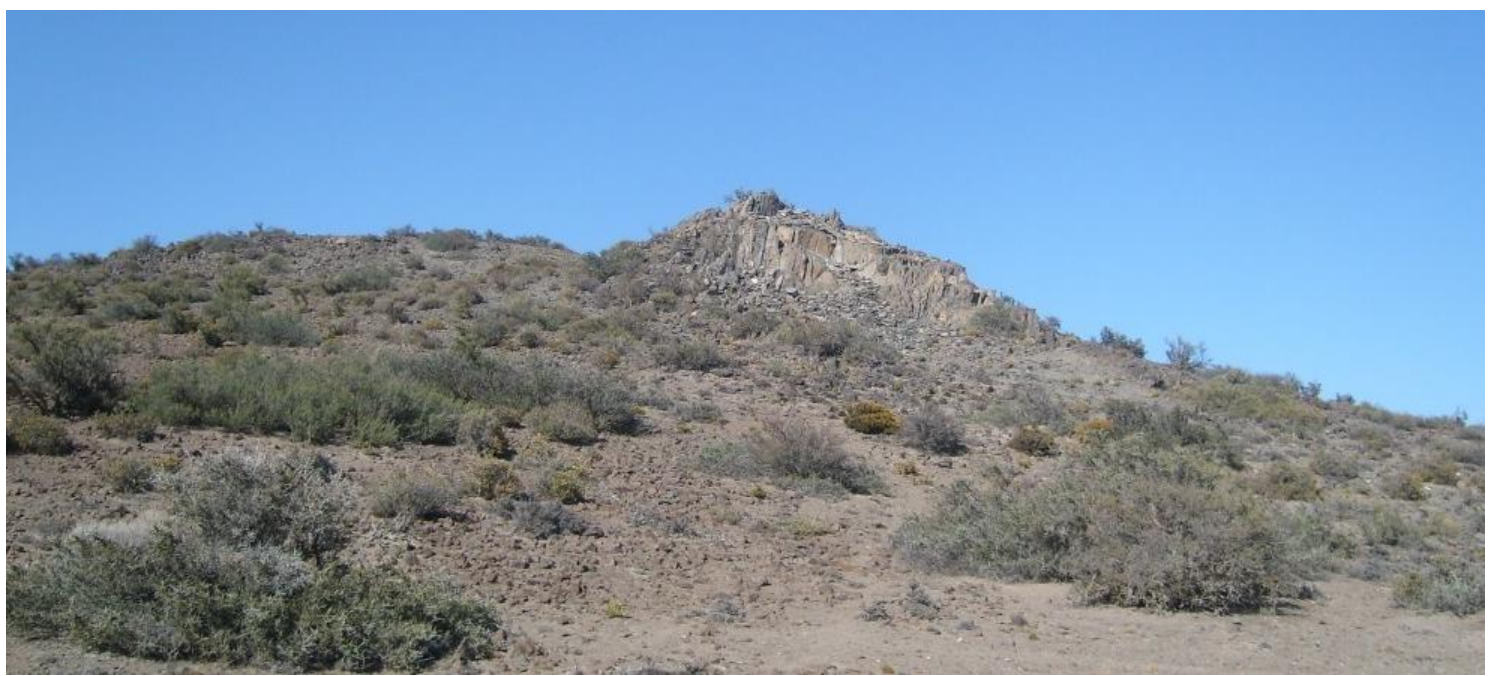

Figura 6.1. Cerro Chenque visto desde la ruta provincial $n^{\circ} 12$. Fotografía tomada desde el sur.

Cerro Matilde: está ubicado $12 \mathrm{~km}$ al noreste de la localidad de Paso de Indios, dentro de la Estancia Los Manantiales (a los $68^{\circ} 55^{\prime} 26,6^{\prime \prime} \mathrm{O}$ y $43^{\circ} 48^{\prime} 41,8^{\prime \prime} \mathrm{S}$ ). Este cerro es un remanente de una colada de lava de geoforma semicircular en planta de unos $700 \mathrm{~m}$ de diámetro (Figura 6.2). Los xenolitos alcanzan $7 \mathrm{~cm}$ de diámetro y se obtuvieron de bloques de lava in situ de diferentes tamaños (de hasta $60 \mathrm{~cm}$ de diámetro), hallándose hasta 5 xenolitos por bloque, algunos con evidente alteración meteórica (Figura 6.7B).

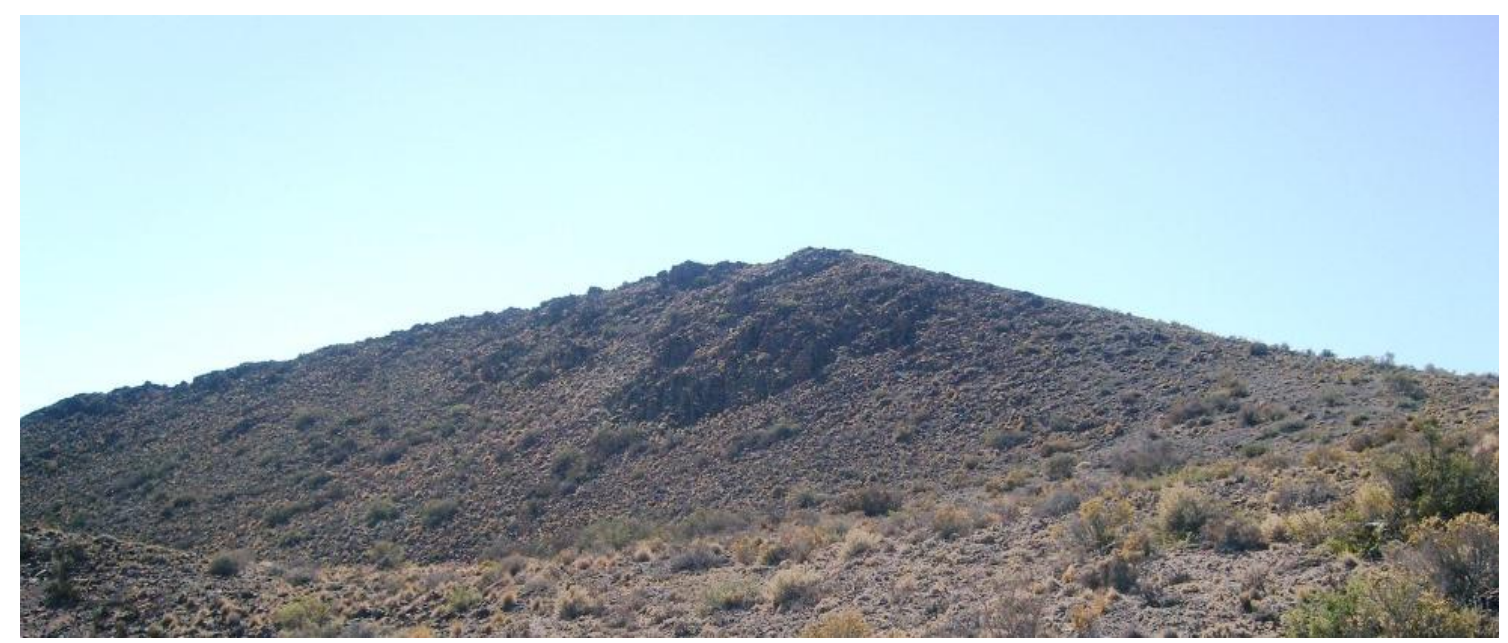

Figura 6.2. Cerro Matilde. Fotografía tomada desde el oeste.

Cerro León: está localizado $18 \mathrm{~km}$ al norte de Paso de Indios, dentro del establecimiento perteneciente a la Sra. Zaira Reguera (69 $\left.69^{\circ} 14,2^{\prime \prime} \mathrm{O} ; 43^{\circ} 42^{\prime} 8,9^{\prime \prime} \mathrm{S}\right)$. Los afloramientos se presentan como suaves lomadas, en parte cubiertos por derrubios basálticos y sedimentos recientes (Figura 6.3). Los xenolitos ultramáficos hallados son de difícil extracción por estar alojados en el centro de bloques de basalto masivo, de 
hasta $80 \mathrm{~cm}$ de diámetro (Figura 6.7C). El tamaño máximo de los xenolitos colectados alcanza los $10 \mathrm{~cm}$ de diámetro.

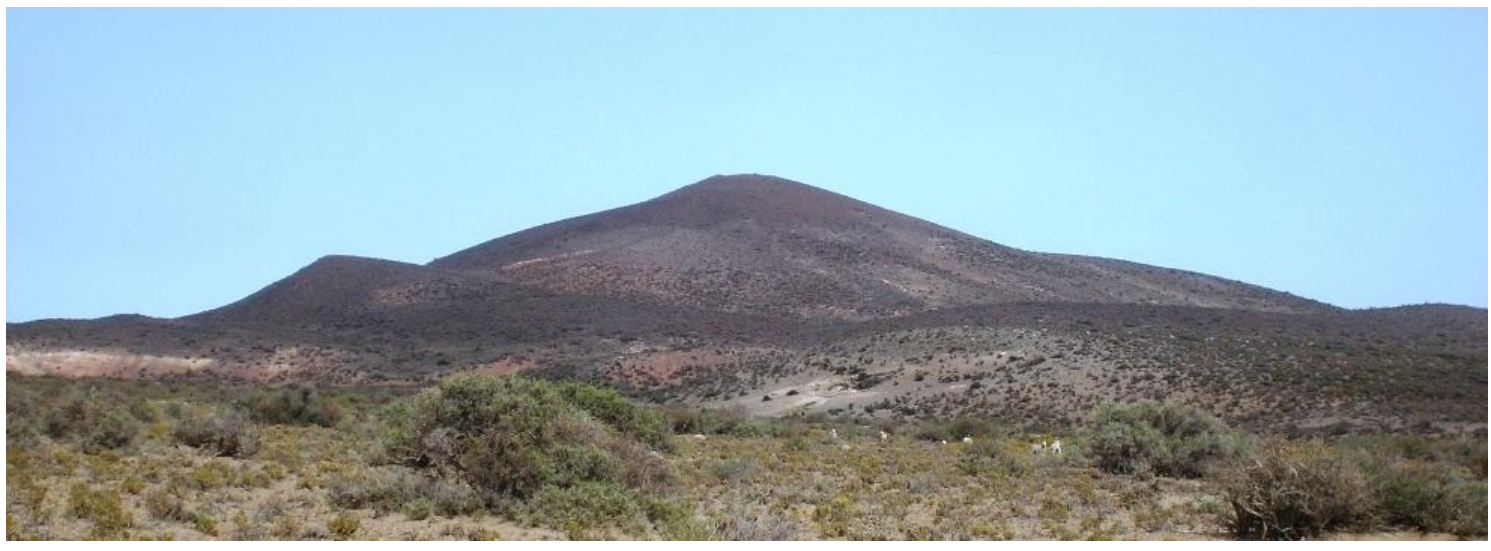

Figura 6.3. Vista panorámica de Cerro León. Fotografía tomada desde el sureste.

Cerro Cortadera: se ubica $6 \mathrm{~km}$ al oeste de la localidad de Paso de Indios, en el

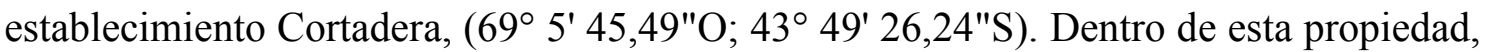
$3 \mathrm{~km}$ al norte de la ruta nacional 25 aflora un cuerpo basáltico que cubre sedimentitas del Grupo Chubut. Este cuerpo se presenta como una suave elevación de unos $1000 \mathrm{~m}$ de diámetro, elongada en sentido NO-SE (Figura 6.4). No se observa el contacto entre el basalto y el Grupo Chubut debido a la cobertura de detritos basálticos y sedimentos modernos. Los xenolitos ultramáficos se encuentran alojados en bloques de basalto masivo color gris acerado y alcanzan los $4 \mathrm{~cm}$ de diámetro máximo (Figura 6.7D).

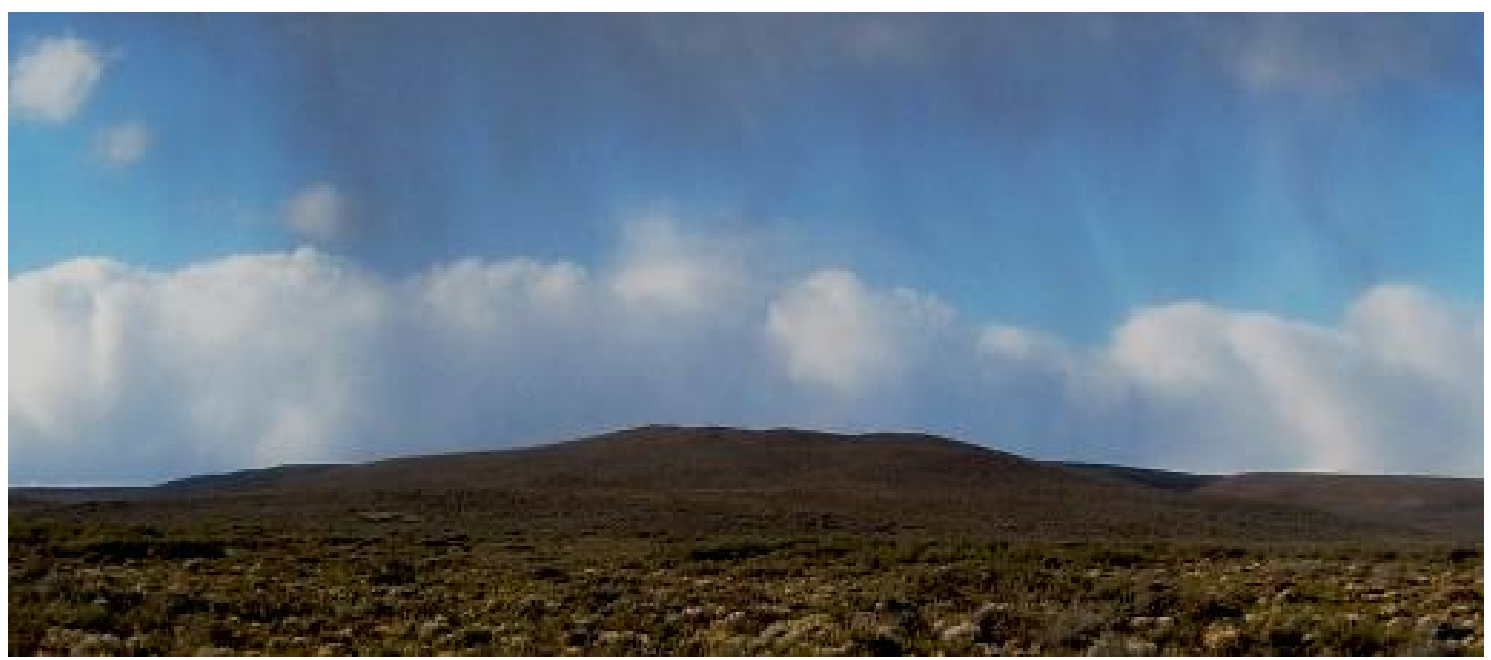

Figura 6.4. Cerro Cortadera. Fotografía tomada desde el este. 
Tapera Marín: se encuentra dentro del establecimiento Guatraché unos $31 \mathrm{~km}$ al NO de la localidad de Paso de Indios. En el afloramiento (69 21' 40,40"O; 43 44' 20,60"S) se visualiza una colada basáltica que se extiende en dirección NNE-SSO por unos 4,5 km (Figura 6.5). En el nivel superior de esta colada se hallaron nódulos ultramáficos, mayormente peridotíticos, de hasta $4 \mathrm{~cm}$ de diámetro y de difícil extracción (Figura $6.7 \mathrm{E})$.

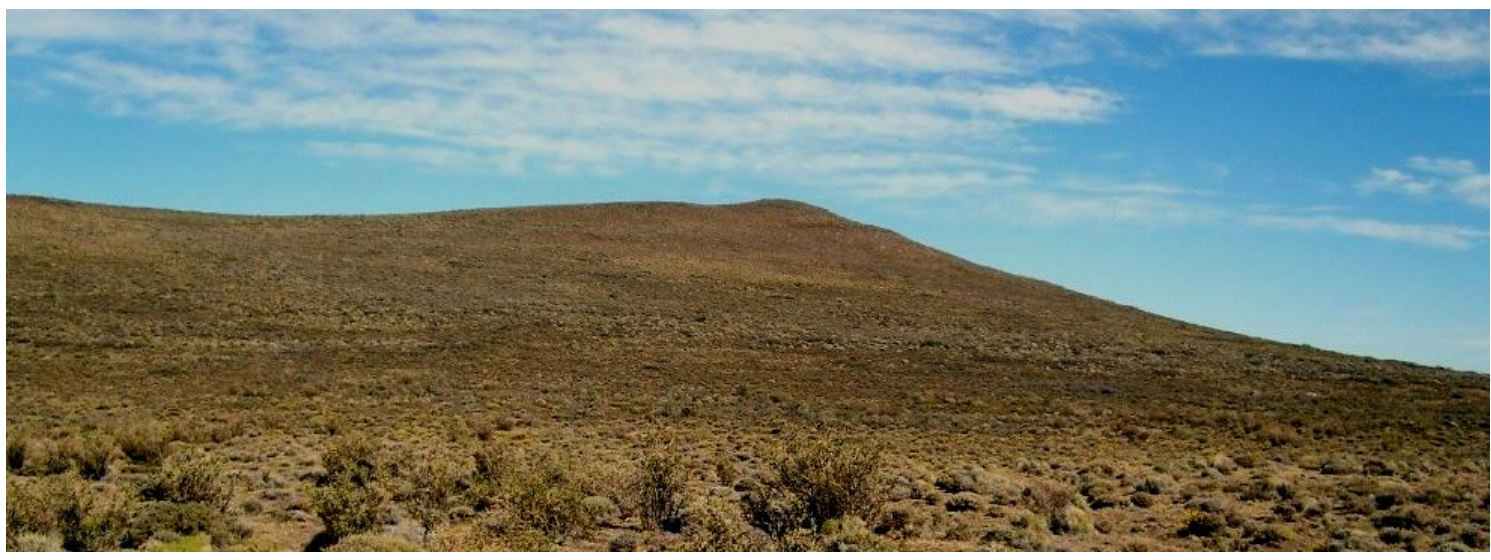

Figura 6.5. Vista parcial de la colada de Tapera Marín. Fotografía tomada desde el noroeste.

Estancia La Primavera: es un conjunto de afloramientos basálticos ubicados unos 30 $\mathrm{km}$ al oeste de Cerro Chenque, dentro de la estancia homónima (69¹8'5,57"O; $43^{\circ} 37^{\prime} 51,81^{\prime \prime S}$ ) (Figura 6.6). Al lugar se accede por un camino que bordea un arroyo temporario desde la ruta provincial $\mathrm{N}^{\circ} 12$. Los afloramientos se corresponden con restos de coladas que se encuentran diaclasadas y disgregadas en bloques y columnas. Aparecen también pequeños morros de hasta 5 metros de altura diaclasados en bloques de 10 por $15 \mathrm{~cm}$. Principalmente se encontraron xenolitos granulíticos de hasta $3 \mathrm{~cm} \mathrm{y}$ escasos xenolitos piroxeníticos (Figura 6.7F).

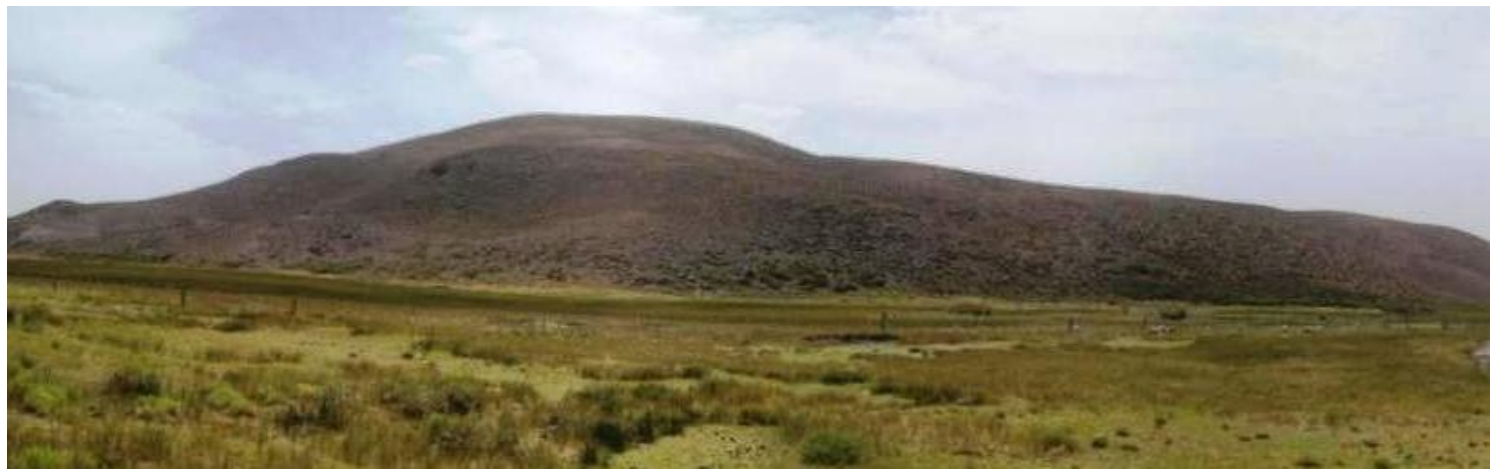

Figura 6.6. Vista panorámica de los afloramientos de Estancia la Primavera. Fotografía tomada desde el sur. 

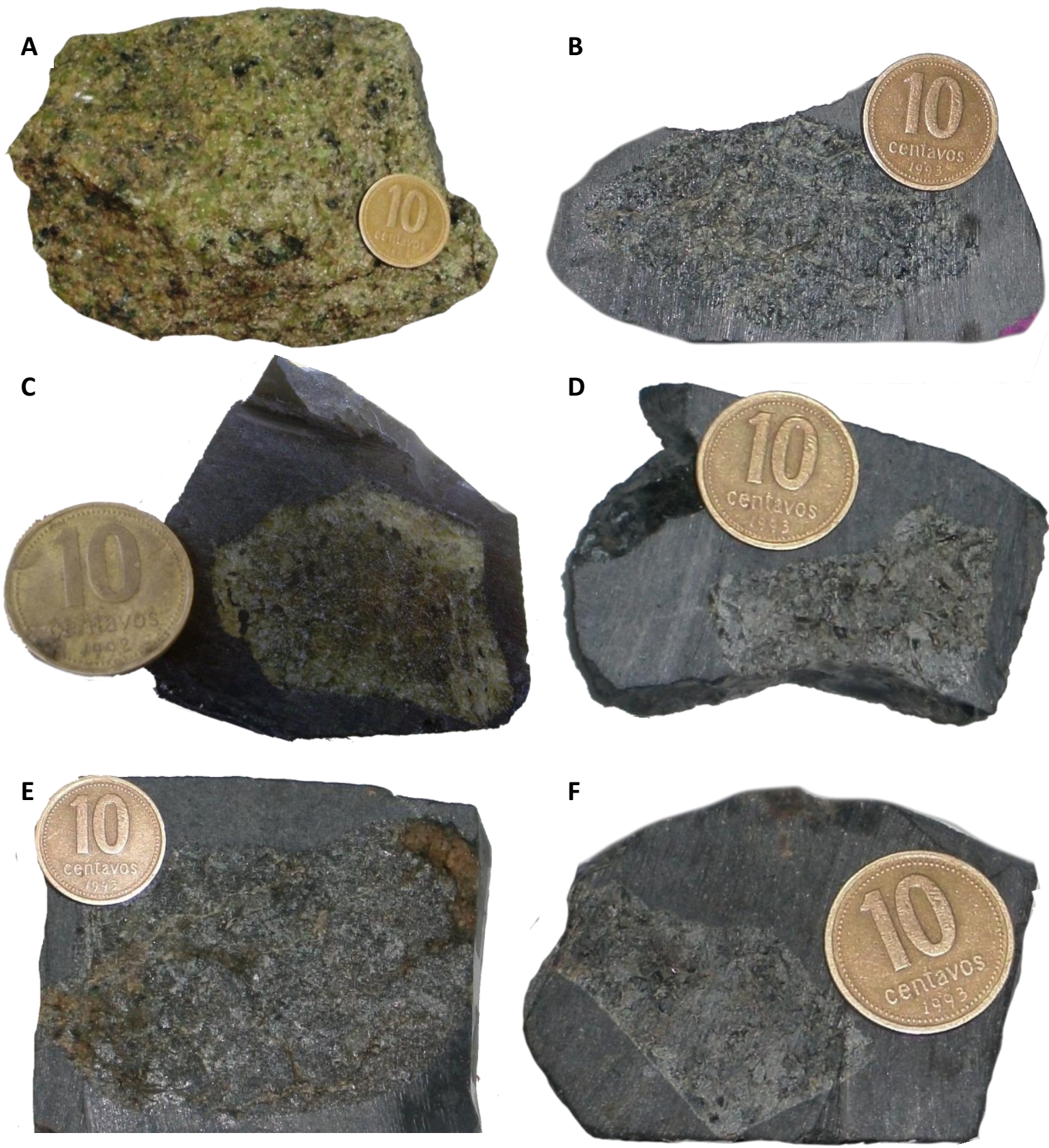

Figura 6.7. Muestras de mano de algunos xenolitos ultramáficos de la región de Paso de Indios. A: lherzolita Q-Eug de Cerro Chenque; B: dunita M-G de Cerro Matilde; C: harzburgita L82 de Cerro León; D: webterita C23 de Cerro Cortadera; E: Harzburgita T18 de Tapera Marín; F: webterita P13 de Estancia La Primavera. 


\section{7- XENOLITOS ULTRAMÁFICOS}




\subsection{PETROGRAFÍA Y CLASIFICACIÓN}

Los porcentajes indicados en las descripciones corresponden a los valores obtenidos a partir de los conteos de puntos y no al recálculo efectuado para clasificar cada roca. Para la descripción textural se seguirá la nomenclatura de Harte (1977), resumida en la tabla 7.1.

\begin{tabular}{|c|c|c|c|c|}
\hline Textura & Porfiroclastos & Tamaño de grano & Límite de grano & Subtipos \\
\hline Gruesa & Ausentes & En promedio $>2 \mathrm{~mm}$ & $\begin{array}{l}\text { Variable. } \\
\text { Mayormente rectos } \\
\text { o suavemente } \\
\text { curvos. }\end{array}$ & $\begin{array}{l}\text { - Ecuante } \\
\text { - Tabular }\end{array}$ \\
\hline Porfiroclástica & $\begin{array}{l}\mathrm{Si},>10 \% \text { de } \mathrm{Ol} \\
\text { son porfiroclastos }\end{array}$ & $\begin{array}{l}2 \text { poblaciones principales: } \\
\text { 1) porfiroblastos; } \\
\text { 2) matriz de grano fino }\end{array}$ & $\begin{array}{l}\text { Irregular en } \\
\text { porfiroblastos y } \\
\text { recto en neoblastos. }\end{array}$ & $\begin{array}{l}\text { - Ni disturbado ni } \\
\text { laminado } \\
\text { - Disturbado } \\
\text { - Fluidal }\end{array}$ \\
\hline $\begin{array}{l}\text { Porfiroclástica } \\
\text { en mosaico }\end{array}$ & $\begin{array}{l}\mathrm{Si},<10 \% \text { de } \mathrm{Ol} \\
\text { son porfiroclastos }\end{array}$ & $\begin{array}{l}2 \text { poblaciones principales: } \\
\text { 1) porfiroblastos; } \\
\text { 2) matriz de grano fino }\end{array}$ & $\begin{array}{l}\text { Irregular en } \\
\text { porfiroblastos y } \\
\text { recto en neoblastos }\end{array}$ & $\begin{array}{l}\text { - Ni disturbado ni } \\
\text { laminado } \\
\text { - Fluidal } \\
\text { - Laminado y } \\
\text { disturbado }\end{array}$ \\
\hline Granuloblástica & $\begin{array}{l}\text { Ausentes o raros } \\
\text { para todas las } \\
\text { especies } \\
\text { minerales }\end{array}$ & $\begin{array}{l}\text { Pequeño rango de tamaño } \\
\text { para c/especie (exc. raros } \\
\text { porfiroclástos). Granos en } \\
\text { gral. }<2 \mathrm{~mm}\end{array}$ & $\begin{array}{l}\text { Granos poligonales } \\
\text { o poligonales- } \\
\text { tabulares limitados } \\
\text { por bordes rectos o } \\
\text { suavemente curvos }\end{array}$ & $\begin{array}{l}\text { - Ecuante } \\
\text { - Tabular }\end{array}$ \\
\hline
\end{tabular}

Tabla 7.1. Texturas de rocas ultramáficas y sus características según Harte (1977).

A continuación se presenta la información referida a la cuantificación de tipo de roca y de textura de los xenolitos de cada localidad, junto con la descripción de cada tipo de roca hallado. La descripción de cada litología está ilustrada con una fotomicrografía tomada con luz polarizada, nicoles paralelos de una muestra ejemplo, donde la escala roja representa $1 \mathrm{~mm}$. Por último la tabla 7.2 presenta un resumen de la información que perimite comparar los xenolitos de las diferentes localidades.

\subsubsection{Cerro Chenque}

Los xenolitos muestreados en Cerro Chenque clasifican como peridotitas y piroxenitas en facies de espinela (Figura 7.1, Tabla 12.1). Harzburgita es el tipo de roca más frecuente (70 muestras, 53,4\%), seguida de lherzolita (40 muestras, 30,5\%), websterita (13 muestras, 9,9\%), dunita (3 muestras, 2,3\%), websterita olivínica (2 muestras, 1,5\%), ortopiroxenita ( 1 muestra, $0,8 \%$ ), ortopiroxenita olivínica (1 muestra, $0,8 \%$ ) y clinopiroxenita olivínica (1 muestra, 0,8\%). Por su parte, la textura predominante es la porfiroclástica $(48,1 \%) \mathrm{y}$, menos frecuente, la transicional gruesa a 
porfiroclástica $(20,6 \%)$, porfiroclástica en mosaico y granuloblástica $(13,0 \%)$ y la textura gruesa $(5,3 \%)$ (Figura 7.2$)$.

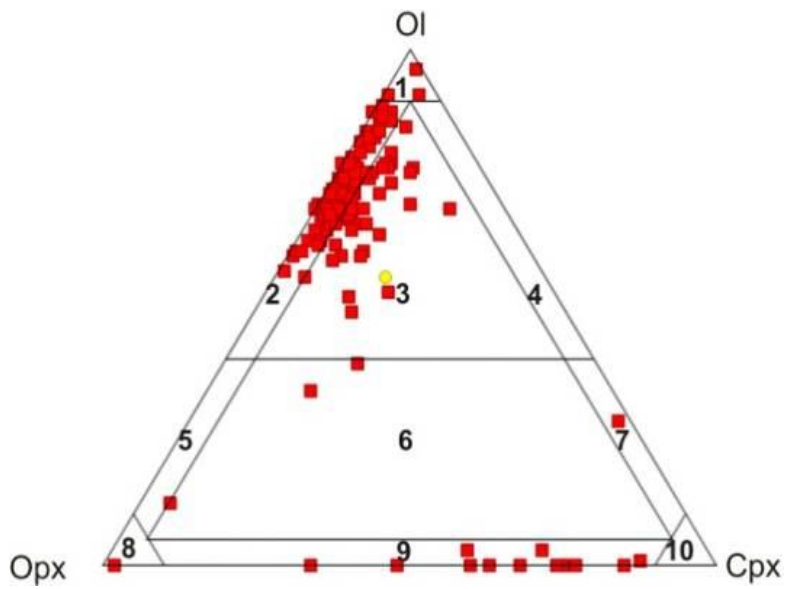

Figura 7.1. Clasificación de peridotitas y piroxenitas de Cerro Chenque. El círculo amarillo representa la composición del manto primitivo de Johnson et al. (1990). 1 dunita, 2 harzburgita, 3 lherzolita, 4 wehrlita, 5 ortopiroxenita olivínica, 6 websterita olivínica, 7 clinopiroxenita olivínica, 8 $\begin{array}{lllll}\text { ortopiroxenita, } & 9 & \text { websterita } & \text { y } & 10\end{array}$ clinopiroxenita.

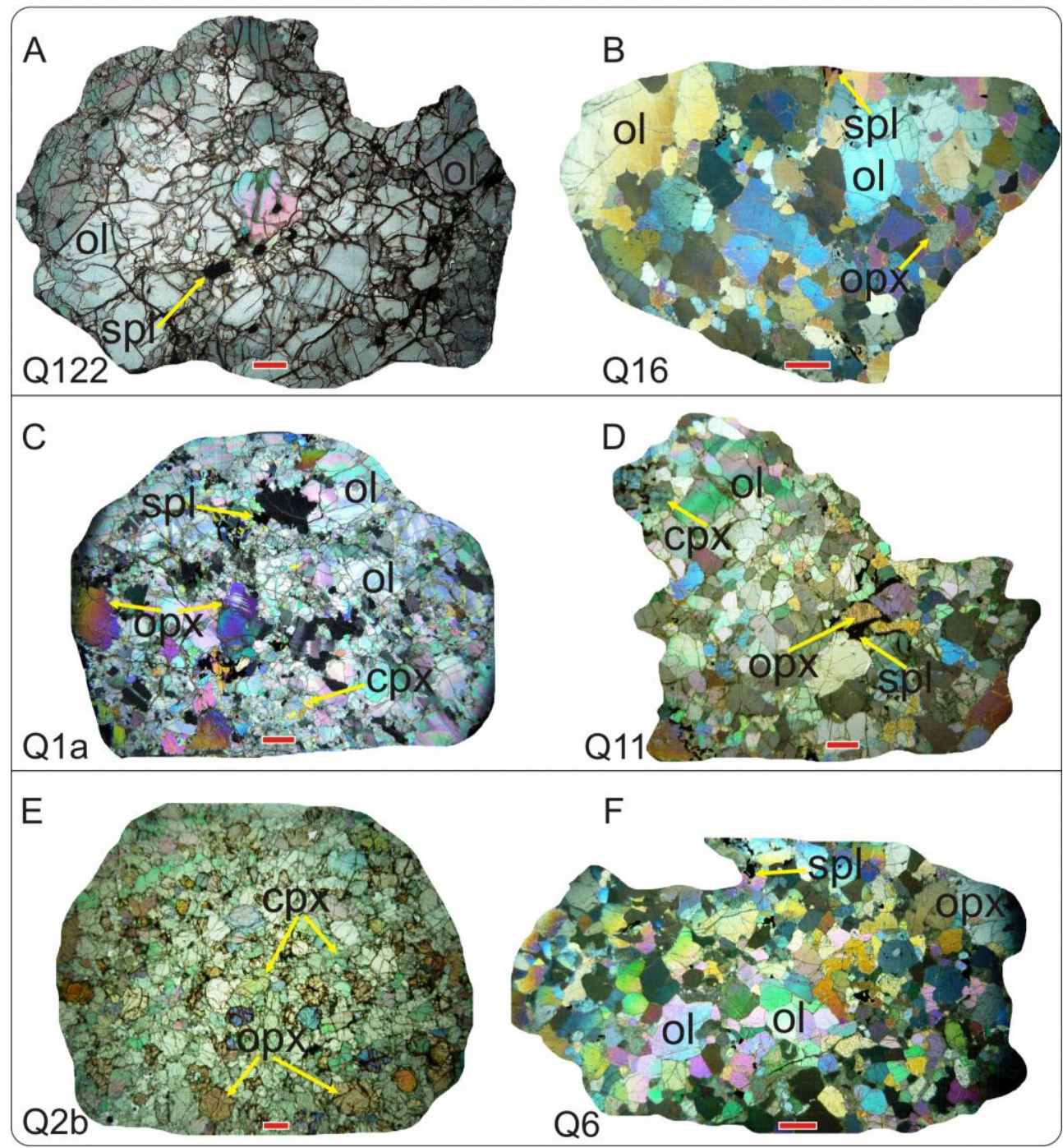

Figura 7.2. Texturas presentes en peridotitas y piroxenitas de Cerro Chenque. A: textura gruesa; B: textura transicional gruesa a porfiroclástica; $\mathrm{C}$ : textura porfiroclástica; D: textura porfiroclástica en mosaico; E y F: textura granuloblástica. La línea roja representa $2 \mathrm{~mm}$. Fotomicrografías de cortes delgados con luz polarizada, nicoles cruzados. 


\section{Harzburgitas}

Las harzburgitas (ej. Q117) contienen olivino en proporciones modales que van

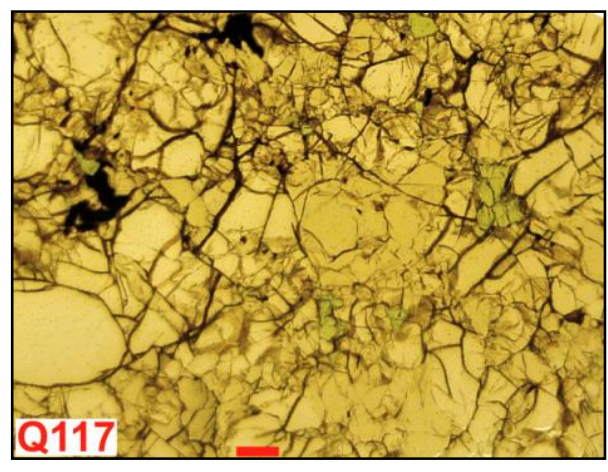
desde el 52 al 87\%. El tamaño de los cristales de olivino varía entre 3 y $12 \mathrm{~mm}$ y presentan frecuentes kink bands. Los cristales de mayor tamaño se presentan anhedrales a subhedrales, con frecuentes bordes irregulares y suturas entre ellos. Los cristales del orden de 1-2 mm pueden desarrollar formas poligonales y ocasionales contactos en puntos triples. También es posible encontrar olivinos poligonales dentro de cristales de opx (ver sección 7.2) y, menos frecuentemente, iddingsita en fracturas y bordes de olivinos.

El contenido modal de ortopiroxeno está comprendido entre 9 y 39\%. El tamaño máximo de los cristales de opx es de 10,5 mm. Los cristales de mayor tamaño muestran finos patrones regulares de lamelas de exsolución de clinopiroxeno $\mathrm{y}$, en algunos casos, kink bands menos desarrolladas que en el caso de los cristales de olivino. En el contacto con basalto, los opx desarrollan coronas de reacción, compuestas principalmente por cpx, ol, vidrio, opx, minerales del grupo de la $\mathrm{spl} \pm$ pl. En algunas muestras se puede observar opx vermicular dentro de cristales de olivino (ver sección 7.2).

El volumen de clinopiroxeno en estas rocas es de entre 0,2 y 4,7\% y en su mayoría son cristales subhedrales. En algunas muestras, los cristales de cpx se presentan con texturas de desequilibrio, exhibiendo centros cribados o una fina corona de reacción, en varios casos asociados a venillas que se conectan con el basalto hospedante. También pueden aparecer clinopiroxenos como agregados finos dentro de parches de reacción. Se puede observar, asimismo, la presencia de lamelas de exsolución e inclusiones fluidas dentro de los cpx. El tamaño máximo de los clinopiroxenos en las harzburgitas es de 3 $\mathrm{mm}$.

La espinela representa hasta un 7,4\% del volumen de las harzburgitas de Cerro Chenque. Los cristales mayores se presentan en forma anhedral tipo holly leaf (Mercier y Nicolas 1975), subhedral asociada a olivino o, en forma simplectítica vermicular asociada a opx. También aparece diseminada en parches de reacción. El tamaño máximo de las espinelas es de $2,6 \mathrm{~mm}$.

Las harzburgitas presentan vetillas de vidrio alterado (serpentinizado) que pueden ocupar hasta el 6,9\% del volumen de la muestra. Estas venas, suelen estar conectadas al 
basalto hospedante de los xenolitos o simplemente conectan parches de reacción entre sí. Los parches de reacción están presentes en pocas muestras y ocupan un máximo de $1,3 \%$ del volumen de las mismas. Estos parches se encuentran rellenos de ol $+\mathrm{cpx}+\mathrm{spl}$ + minerales opacos \pm pl; la pl está presente en los parches de las muestras Q13, Q18, Q19, Q30 y Q31. Generalmente, estos parches conservan la forma de los cristales que reemplazaron.

\section{$\underline{\text { Lherzolitas }}$}

Las lherzolitas (ej. Q51) presentan un contenido modal de olivino que varía entre 38,9 y 79,4\%. Los cristales mayores pueden alcanzar los $15 \mathrm{~mm}$ de diámetro y se

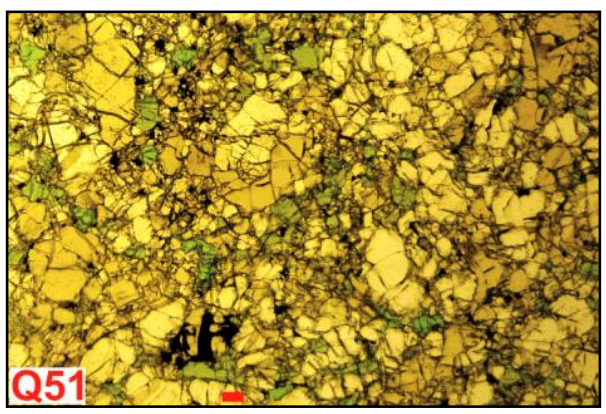
presentan anhedrales a subhedrales, con frecuentes bordes irregulares y suturados con otros olivinos. Estos cristales también presentan kink bands. Por su parte, algunos de los cristales menores a $1 \mathrm{~mm}$ presentan formas poligonales y ocasionales iddingsita en fracturas y bordes de olivinos. También se hallan cristales de olivino poligonales dentro de cristales mayores de opx u ocupando engolfamientos de cristales de ortopiroxeno (ver sección 7.2).

El contenido de ortopiroxeno varía entre 7,1 y 37,4\%. Los cristales de mayor tamaño (6,6 mm máximo) muestran lamelas de exsolución de clinopiroxeno. Al contacto con el basalto, los cristales de opx desarrollan coronas de reacción formadas principalmente por cpx, ol, vidrio, opx, minerales del grupo de la spl y, en algunos casos, pl. En algunas muestras se puede observar la presencia de opx insterticial vermicular entre o dentro de cristales de olivino (ver sección 7.2). Algunos ortopiroxenos de mayor tamaño exhiben engolfamientos que están ocupados por olivinos subhedrales (ver sección 7.2).

La proporción de clinopiroxeno en las lherzolitas de Cerro Chenque varía entre 4,7 y 20,9\% y en su mayoría son cristales subhedrales. En algunas muestras, los cristales de cpx presentan reacciones que dan lugar al desarrollo de cristales cribados o, a la presencia de coronas de grano fino. También se los pueden encontrar como agregados dentro de parches de reacción. El tamaño máximo de los cpx identificados es de $7 \mathrm{~mm}$.

La espinela representa un 0,9 a 4,7\% del volumen, excepto la muestra Q42 que contiene $24 \%$ de espinela. Los cristales se presentan en forma anhedral tipo holly leaf o vermicular con tamaño máximo de $2,2 \mathrm{~mm}$. 
Las vetillas ocupan hasta un $7,1 \%$ de las lherzolitas y suelen estar conectadas al basalto hospedante. El relleno de estas vetillas es generalmente vidrio amarillento (serpentinizado) y minerales opacos.

\section{$\underline{\text { Websteritas }}$}

Se encontró olivino en sólo 3 de las 13 websteritas estudiadas con contenido variable entre 0,4 y $3 \%$. El olivino hallado en estas rocas se presenta de forma subhedral con

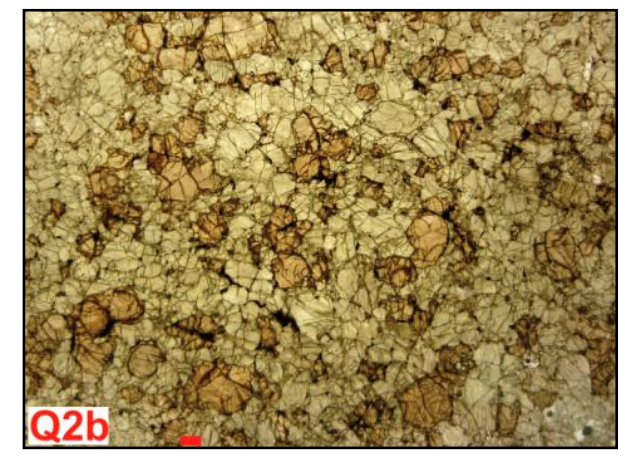
bordes irregulares, tamaños de hasta $6 \mathrm{~mm}$ y kink bands.

El ortopiroxeno representa entre un 7,4 y $65,9 \%$ del volumen de las websteritas. Los cristales se presentan anhedrales a subhedrales, con tamaños de hasta $10,5 \mathrm{~mm}$ y pueden presentar lamelas de exsolución de clinopiroxeno. En contacto con el basalto hospedante, los cristales de ortopiroxeno desarrollan un borde de reacción, el cual está compuesto por vidrio, ol, cpx y minerales opacos. También se encuentran cristales de opx totalmente reemplazados, que forman parches de reacción, los cuales se conectan entre sí por medio de venillas. Las websteritas Q67 y Q165 presentan, entre los granos de opx, cristales de plagioclasa subhedrales y con maclas polisintéticas.

El contenido modal de clinopiroxeno varía entre 34 y 81,7\%. Los cristales se presentan principalmente subhedrales con diámetro máximo de $6 \mathrm{~mm}$. Algunos cristales, de mayor tamaño, tienen lamelas de exsolución y pueden contener inclusiones de ortopiroxenos y espinelas. La espinela se encuentra en una proporción de hasta el $3 \%$, con excepción de la muestra Q141 que posee un 23,3\% en volumen. Los cristales de espinela son anhedrales a subhedrales, ubicándose entre los cristales de piroxenos. El tamaño máximo es de $0,9 \mathrm{~mm}$.

El volumen de las vetillas y parches es del 6,2 y 2,9\% respectivamente. Generalmente las venillas conectan parches con el basalto hospedante, dando lugar a reacciones de reemplazo de grano fino.

\section{Dunitas}

En las dunitas (ej. Q14) el contenido modal de olivino varía entre 87 y 92\%. Este mineral se presenta en cristales de hasta $7,5 \mathrm{~mm}$ de diámetro, y puede presentar los bordes suturados en contacto con otros olivinos. Los cristales de mayor tamaño son 


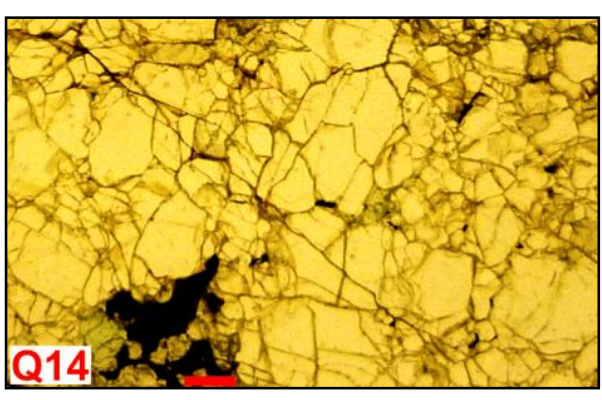

anhedrales a subhedrales y muestran kink bands, mientras que aquellos de hasta $1 \mathrm{~mm}$ presentan caras poligonales con frecuentes contactos en puntos triples.

El contenido de ortopiroxeno varía entre 1 y $7 \%$ y los cristales pueden alcanzar los $5,7 \mathrm{~mm}$ de diámetro. Los ortopiroxenos son principalmente anhedrales, y al contacto con el basalto hospedante desarrollan finas coronas de reacción. Dicha reacción está compuesta por cpx, ol, vidrio, opx y minerales del grupo de la spl.

El clinopiroxeno ocupa entre el 1 y $6 \%$ del volumen de las dunitas. Los cristales se presentan en formas anhedrales a subhedrales con bordes irregulares y alcanzan un tamaño de hasta 1,7 mm. Los clinopiroxenos encontrados en la dunita Q29 exhiben exsoluciones de espinela.

Las muestras de dunita también contienen hasta un 4\% de espinela, de 1,2 $\mathrm{mm}$ de diámetro máximo. Los cristales de espinela se presentan en formas anhedrales y subhedrales, asociados a opx o dentro de cristales de olivino.

Por último, el contenido de vetillas relacionadas al basalto hospedante no supera el $3 \%$ del volumen de las dunitas analizadas.

\section{Websteritas olivínicas}

Del total de las 131 muestras de Cerro Chenque estudiadas, sólo se han encontrado 2 websteritas olivínicas (Q120 y Q144) las cuales contienen entre un 30,8 y 37,1\% de

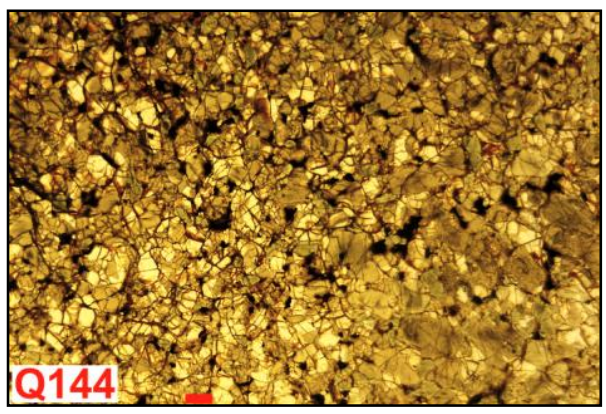
olivino modal. Los cristales de olivino son subhedrales y presentan alguno de sus bordes rectos, con ocasionales contactos en puntos triples. El tamaño máximo es de $2,5 \mathrm{~mm}$.

Los cristales de ortopiroxeno son subhedrales y alcanzan a ocupar entre 37 y 45,2\% del volumen.

Tienen tamaño máximo de $3,8 \mathrm{~mm}$ y presentan reacción al contacto con el basalto hospedante.

El contenido de clinopiroxeno varía entre 15,6 y 21,4\%. Se presentan con formas subhedrales, desarrollando una fina corona de reacción.

La espinela se encuentra en proporción variable entre 2,8 y 4,7\%; se presenta de forma subhedral o anhedral tipo holly leaf. El contenido de venillas varía de 1,5 a 2,1\%; 
mientras que los parches de reacción se encuentran en torno a ortopiroxenos y ocupan entre 0,2 y $1,6 \%$.

Estas dos websteritas olivínicas presentan texturas equigranulares; granuloblástica (Q144) y porfiroclástica en mosaico (Q120).

\section{Ortopiroxenita olivínica}

La ortopiroxenita olivinica Q111 presenta un contenido de olivino de 10,8\%; éste es subhedral y alcanza hasta $1,2 \mathrm{~mm}$ de diámetro máximo.

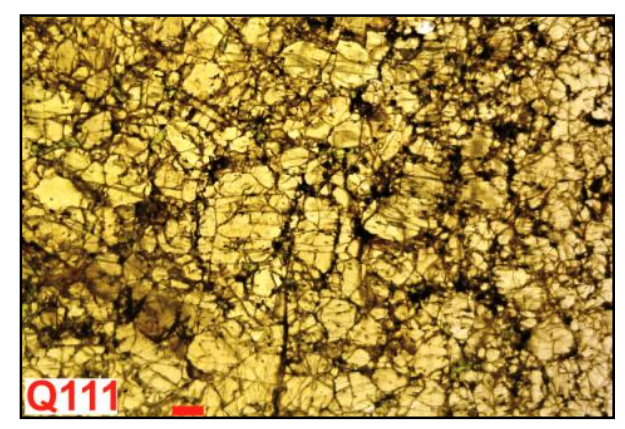

El contenido de ortopiroxeno es de 78,6\%. Los cristales son subhedrales de hasta $6 \mathrm{~mm}$ y presentan pleocroísmo en tonos marrones rosados.

Los cristales de clinopiroxeno ocupan el $4,2 \%$ del volumen y desarrolla forma subhedral con diámetros menores a $1 \mathrm{~mm}$. El contenido modal de espinela es de $1,7 \%$ y se encuentra dispersa por toda la muestra en forma intersticial.

Las vetillas que atraviesan la muestra representan el 4,4\% en volumen.

\section{Clinopiroxenita olivínica}

El único ejemplar de clinopiroxenita olivínica corresponde a una vena dentro de la harzburgita Q98 (ver foto). Esta vena tiene un ancho de $5 \mathrm{~mm}$. El contenido de olivino es de $24,8 \%$, es subhedral, de hasta $2 \mathrm{~mm}$ de diámetro y presenta kink bands.

El contenido modal de ortopiroxeno es de 1,2\%, se presenta en forma subhedral con diámetro máximo de $2,2 \mathrm{~mm}$.

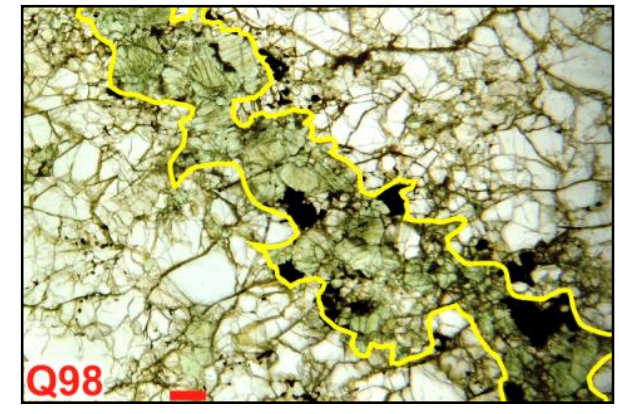

El clinopiroxeno ocupa el 61,2\% del volumen. Se presenta como cristales subhedrales a euhedrales de bordes rectos. La mayoría de los cristales de cpx exhiben lamelas de exsolución de espinela. El diámetro máximo es de $2,5 \mathrm{~mm}$.

Los cristales de espinela ocupan $11,5 \%$ del volumen de la muestra. Los mismos presentan una sección circular pero de bordes irregulares y tienen hasta $1,8 \mathrm{~mm}$ de diámetro. Las vetillas presentes en esta muestra ocupan un $1,2 \%$ del volumen. 


\section{Ortopiroxenita}

El contenido de ortopiroxeno en la ortopiroxenita Q50 es de 91,9\%. Los cristales alcanzan un diámetro máximo de $9 \mathrm{~mm}$. Los mismos presentan bordes redondeados y

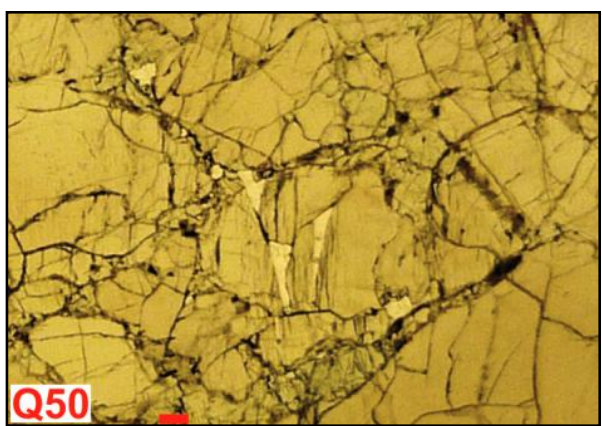
fina reacción al contacto con el basalto hospedante. La muestra se encuentra atravesada por numerosas fracturas y venillas que alcanzan el $1,5 \%$ en volumen.

El clinopiroxeno representa el $1,8 \%$ del irregulares y contienen lamelas de exsolución. El contenido de espinela llega al 1,2\%; se presenta en forma intersticial mayormente en vetas que atraviesan la muestra.

\subsubsection{Cerro Matilde}

Los xenolitos de cerro Matilde están, en su mayoría, representados por harzburgitas (51 muestras, $80,9 \%$ ) y, en menor medida por lherzolitas (8 muestras, 12,7\%) y dunitas (4 muestras, 6,4\%) (Figura 7.3, Tabla 12.1). La textura dominante es la porfiroclástica $(58,7 \%)$, seguida de la transicional gruesa a porfiroclástica $(22,2 \%)$, gruesa $(15,9 \%)$ y porfiroclástica en mosaico (3,2\%) (Figura 7.4).

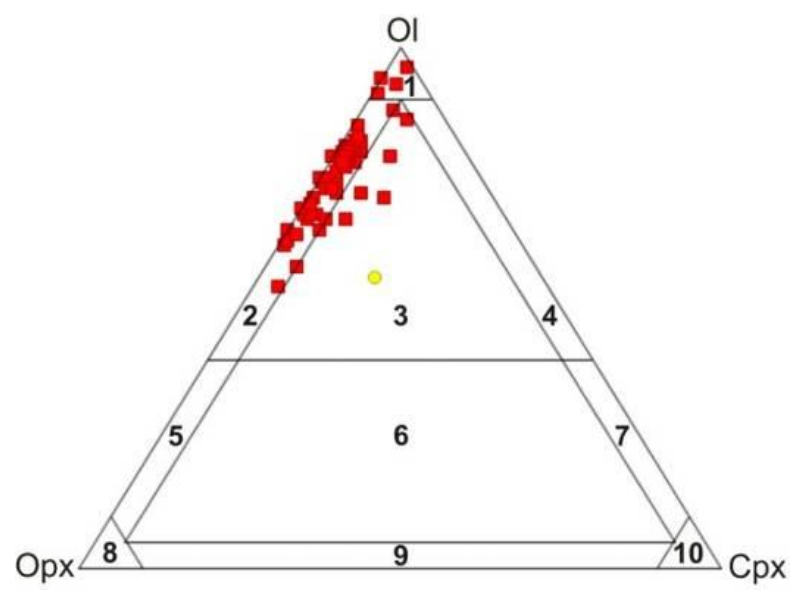

Figura 7.3. Clasificación de peridotitas y piroxenitas de Cerro Matilde. El círculo amarillo representa la composición del manto primitivo de Johnson et al. (1990). 1 Dunita, 2 harzburgita, 3 lherzolita, 4 wehrlita, 5 ortopiroxenita olivínica, 6 websterita olivínica, 7 clinopiroxenita olivínica, 8 ortopiroxenita, 9 websterita y 10 clinopiroxenita. 


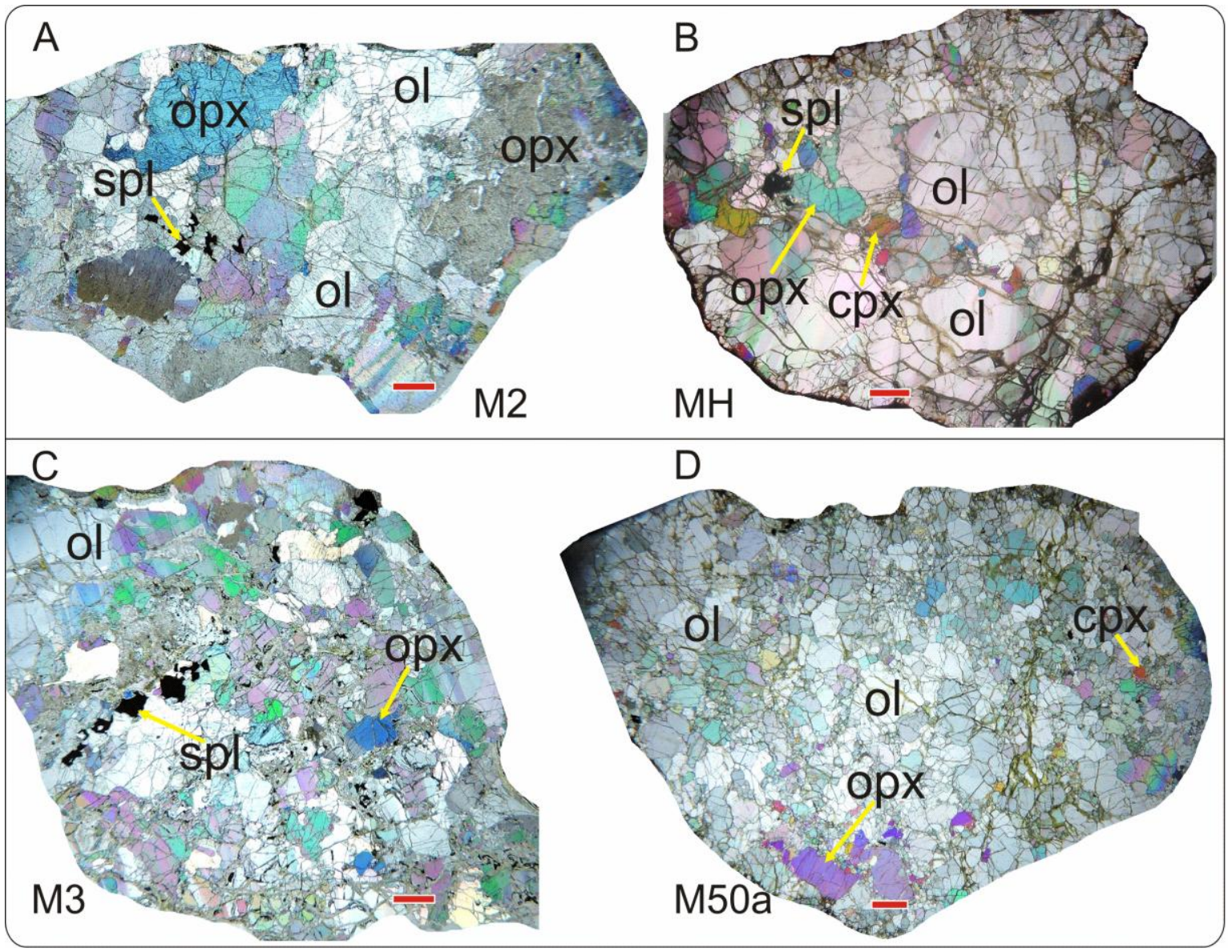

Figura 7.4.Texturas presentes en peridotitas y piroxenitas de Cerro Matilde. A: Textura gruesa; B: textura transicional gruesa a porfiroclástica; C: textura porfiroclástica y D: textura porfiroclástica en mosaico. La linea roja representa $2 \mathrm{~mm}$. Fotomicrografías de cortes delgados con luz polarizada, nicoles cruzados.

\section{Harzburgitas}

Las harzburgitas (ej. M22) contienen olivino en proporciones modales que van desde

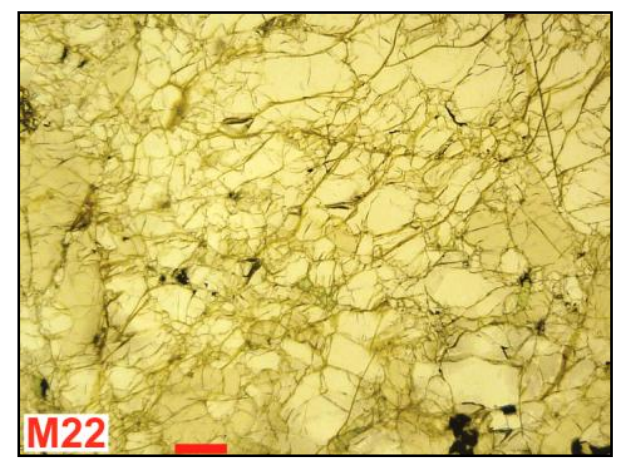
52,9 a $81,4 \%$. El tamaño máximo de los cristales de olivino es de 10,8 $\mathrm{mm}$. Los cristales de mayor tamaño se presentan anhedrales a subhedrales, con frecuentes bordes irregulares y bordes suturados entre grandes olivinos. Los cristales del orden de 1-2 mm suelen desarrollar formas poligonales y ocasionales contactos en puntos triples. En un tercio de las muestras, los olivinos mayores presentan kink bands. En algunos casos se observan olivinos poligonales dentro de cristales de opx (ver sección 7.2). Menos frecuente es la presencia de iddingsita en fracturas y bordes de olivinos.

El contenido modal de ortopiroxeno está comprendido entre 13,1 y 40,3\%. El tamaño máximo de cristales es de $9,5 \mathrm{~mm}$. Los de mayor tamaño muestran finos patrones 
regulares de lamelas de exsolución de clinopiroxeno y, a veces, kink bands menos desarrolladas que en olivino. Al contacto con el basalto, los ortopiroxenos presentan coronas de reacción, formadas principalmente por cpx, ol, vidrio, opx y minerales del grupo de la spl. En algunas muestras se puede observar la presencia de ortopiroxeno vermicular dentro de cristales mayores de olivino (ver sección 7.2).

El volumen de clinopiroxeno en estas rocas es de hasta $4,7 \%$; en su mayoría son cristales subhedrales de hasta $3 \mathrm{~mm}$ de diámetro. En algunos casos tienen lamelas de exsolución e inclusiones fluidas. En algunas muestras los clinopiroxenos presentan cristales cribados. También aparecen asociados a parches de reacción como agregados de garano fino.

La espinela representa hasta un 5,5\% del volumen de las harzburgitas y desarrolla un tamaño máximo de $2 \mathrm{~mm}$. Los cristales mayores tienen forma anhedral holly leaf, subhedral asociada a olivino o asociada a ortopiroxeno en forma simplectítica vermicular. También aparece diseminada en parches de reacción.

Las harzburgitas presentan vetillas de vidrio alterado (serpentinizado) que pueden ocupar hasta el $11,7 \%$ del volumen de muestra, estas venas suelen estar conectadas al basalto hospedante de los xenolitos. En pocas muestras aparecen parches de reacción, los que pueden representar hasta un 3,2\% del volumen. Estos parches se encuentran rellenos de ol, cpx, minerales del grupo de la spl, y vidrio.

\section{$\underline{\text { Lherzolitas }}$}

Las lherzolitas (ej. M30b) exhiben un contenido modal de olivino que varía entre 62,4 y $83,2 \%$. Los cristales mayores alcanzan $8,5 \mathrm{~mm}$ de diámetro, tienen formas anhedrales a subhedrales, con frecuentes bordes irregulares, contactos suturados entre

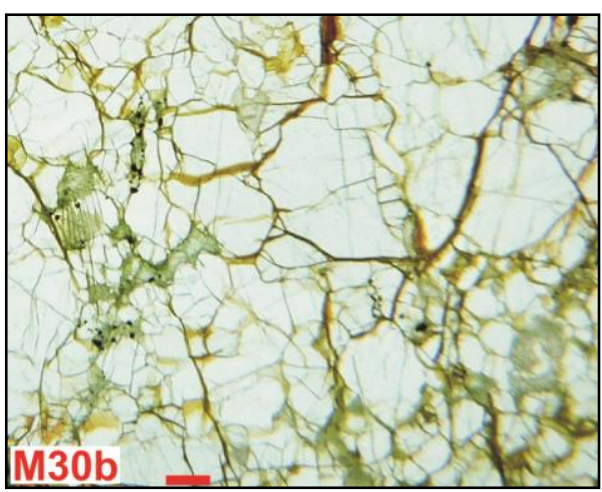
grandes olivinos y kink bands. Los cristales menores a $1 \mathrm{~mm}$ pueden desarrollar formas poligonales y puntos triples de contacto. En ocasiones, se observan olivinos subhedrales dentro de cristales de ortopiroxeno. Es posible encontrar iddingsita en las fracturas de los olivinos.

El contenido de ortopiroxeno varía entre 4,6 y $28,8 \%$. Los cristales de mayor tamaño $(8,1 \mathrm{~mm}$ máximo) muestran lamelas de exsolución de clinopiroxeno. Al contacto con el basalto, los ortopiroxenos desarrollan coronas de reacción, formada principalmente por cpx, ol, vidrio, opx y, minerales del 
grupo de la spl. Algunos ortopiroxenos mayores presentan engolfamientos ocupados por olivinos subhedrales (ver sección 7.2).

La cantidad de clinopiroxeno en estas lherzolitas varía entre 4,9 y 10,8\%; en su mayoría son cristales subhedrales de $2,7 \mathrm{~mm}$ de tamaño máximo. En algunas muestras presentan cristales cribados o con una fina corona de reacción. También pueden aparecer como agregados finos en parches de reacción.

La espinela constituye del 1,5 a 6,6\% del volumen. Los cristales se presentan en forma anhedral (holly leaf) y vermicular con tamaño máximo de 1,6 mm.

Las vetillas alcanzan a ocupar hasta un $8,3 \%$ y suelen estar conectadas al basalto hospedante. El relleno de estas vetillas es generalmente vidrio amarillo "serpentinizado".

\section{Dunitas}

En las dunitas (ej. MG), el contenido modal de olivino varía entre 85,8 y $90,9 \%$ y se presenta en cristales de hasta $6 \mathrm{~mm}$ de diámetro. Los de mayor tamaño son anhedrales a

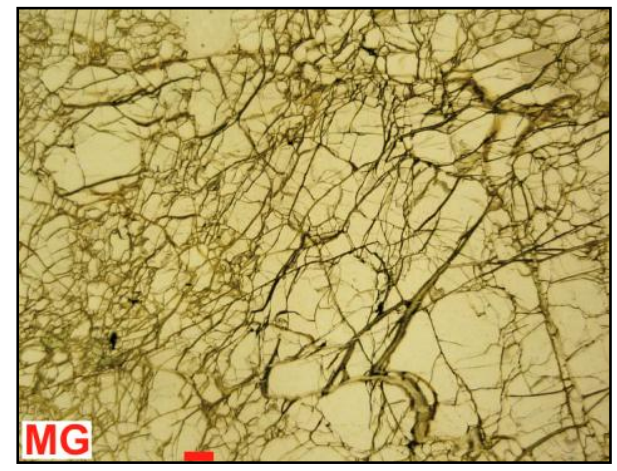
subhedrales y muestran kink bands. Estos olivinos mayores tienen los bordes suturados con otros olivinos mientras que aquellos cristales de hasta 1 $\mathrm{mm}$ de diámetro presentan caras poligonales con frecuentes contactos en puntos triples. El contenido de ortopiroxeno varía entre 1,0 y 7,4\%, los cristales son anhedrales y pueden alcanzar 1,8 mm de diámetro. Al contacto con el basalto presentan coronas de reacción compuestas por cpx, ol, vidrio, opx y minerales del grupo de la spl.

El clinopiroxeno ocupa entre 0,5 y $2,9 \%$ del volumen de las dunitas. Se presenta en formas anhedrales de hasta $0,7 \mathrm{~mm}$ de diámetro y con bordes irregulares.

Por su parte, las dunitas contienen hasta un 1,3\% de espinela, con 1,1 mm de diámetro máximo. Los cristales de espinela se presentan en formas anhedrales y subhedrales, pudiéndosela encontrar asociada a opx o dentro de cristales de ol (ver sección 7.2). Las dunitas pueden contener una cantidad variable de vetillas, ocupando hasta un máximo de $6,3 \%$ de su volumen. El contenido de parches de reacción es de $3,4 \%$ y se encuentran vinculados a la vetillas. 


\subsubsection{Cerro León}

En Cerro León, la mayoría de los xenolitos clasifican como harzburgitas (35 muestras, 53,8\%) y dunitas (21 muestras, $32,3 \%)$ y, en menor medida, corresponden a lherzolitas (4 muestras, 6,2\%), wehrlitas (2 muestras, 3,1\%), websteritas olivínicas (2 muestras, 3,1\%) y ortopiroxenita (1 muestra, 1,5\%) (Figura 7.5; Tabla 12.1). Las texturas en orden decreciente de abundancia son: porfiroclástica $(52,3 \%)$, gruesa $(20,0 \%)$, gruesa a porfiroclástica $(13,8 \%)$, porfiroclástica en mosaico $(10,8 \%)$ y granuloblástica $(3,1 \%)$ (Figura 7.6).

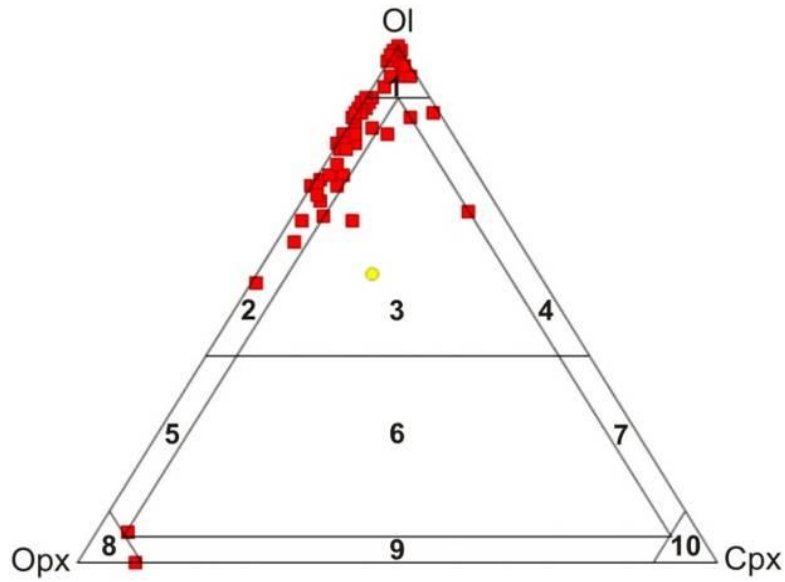

Figura 7.5. Clasificación de peridotitas y piroxenitas de Cerro León. El círculo amarillo representa la composición del manto primitivo de Johnson et al. (1990). 1 Dunita, 2 harzburgita, 3 lherzolita, 4 wehrlita, 5 ortopiroxenita olivínica, 6 websterita olivínica, 7 clinopiroxenita olivínica, 8 ortopiroxenita, 9 websterita y 10 clinopiroxenita. 


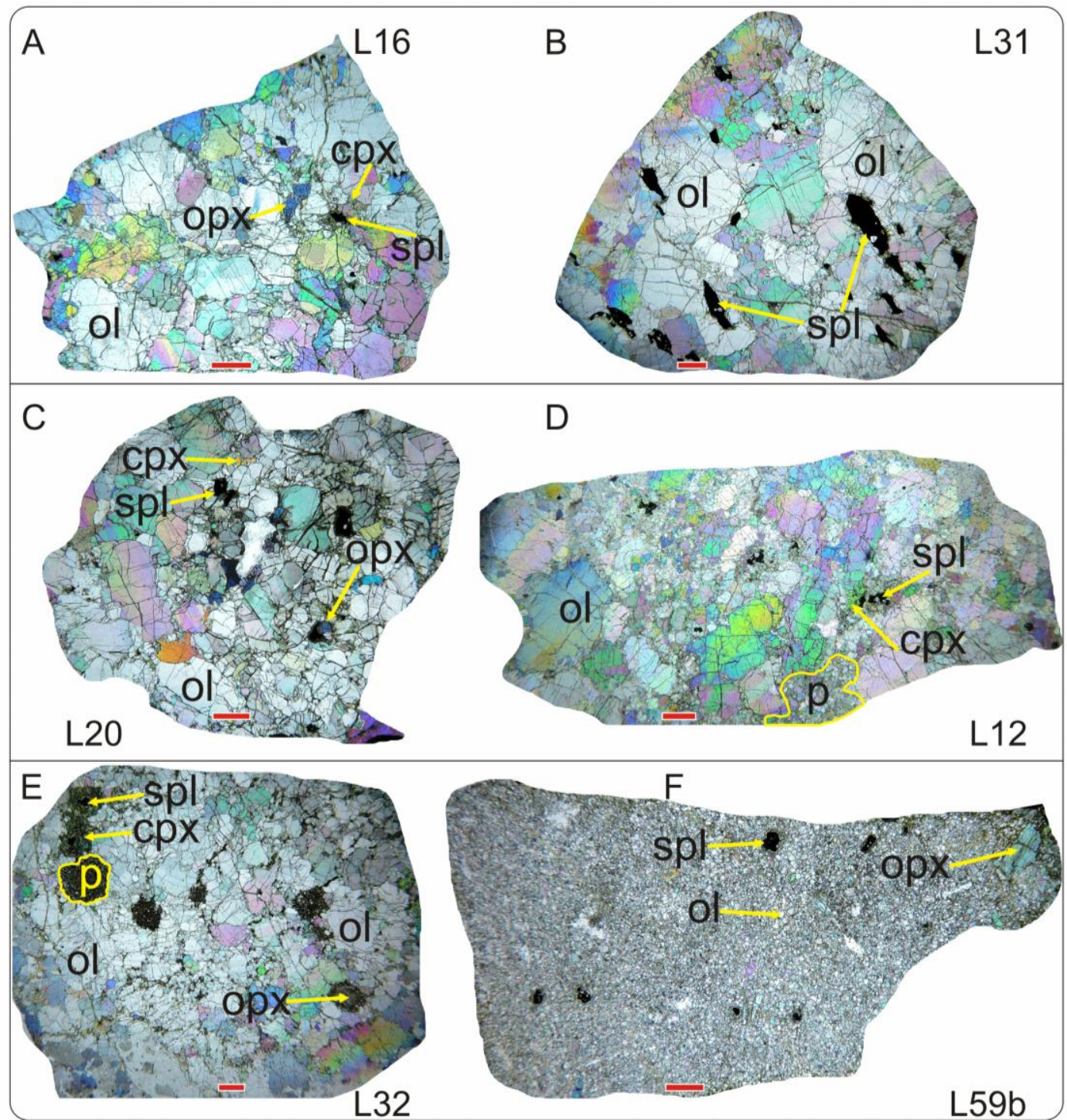

Figura 7.6. Texturas presentes en xenolitos de Cerro León. A y B: textura gruesa; C: textura transicional gruesa a porfiroclástica; D: textura porfiroclástica; E: textura porfiroclástica en mosaico y $\mathrm{F}$ : textura granuloblástica. La linea roja representa $2 \mathrm{~mm}$. Fotomicrografías de cortes delgados con luz polarizada, nicoles cruzados.

\section{Harzburgitas}

Las harzburgitas (ej. L82a) contienen olivino en proporciones modales que van desde 53,0 a $87,3 \%$. Los cristales de mayor tamaño se presentan anhedrales a subhedrales con

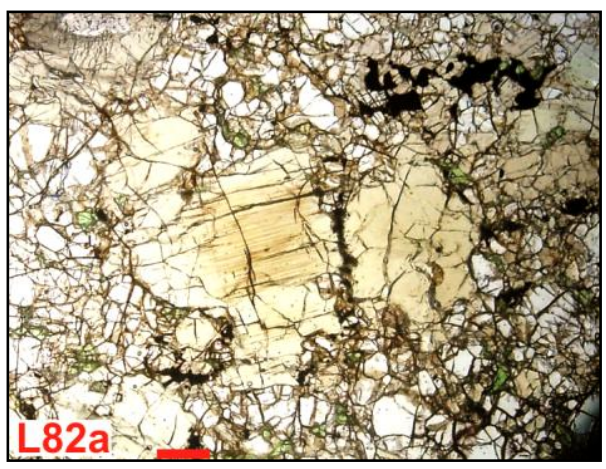
frecuentes bordes irregulares y suturas entre grandes olivinos. Los cristales del orden de 1-2 $\mathrm{mm}$ pueden desarrollar formas poligonales $\mathrm{y}$ ocasionales puntos triples de contacto. El tamaño de los olivinos alcanza los $10 \mathrm{~mm}$ como máximo. Es frecuente que los cristales mayores presenten kink bands. En ocasiones, se observan olivinos 
poligonales dentro de cristales de ortopiroxeno (ver sección 7.2).

El contenido modal de ortopiroxeno está comprendido entre 9,7 y $43,5 \%$ y tiene un tamaño máximo de $8 \mathrm{~mm}$. Los cristales mayores muestran finos patrones regulares de lamelas de exsolución de clinopiroxeno. Al contacto con el basalto, los ortopiroxeno presentan coronas de reacción, formada principalmente por cpx, ol, vidrio, opx y minerales del grupo de la spl. En algunas muestras se puede observar la presencia de ortopiroxeno vermicular dentro o entre los cristales mayores de olivino (ver sección 7.2).

El volumen de clinopiroxeno en estas rocas es de entre 0 y $4 \%$; en su mayoría son cristales subhedrales. En algunas muestras se presentan reaccionados, mostrando cristales cribados. También pueden aparecer como agregados finos en parches de reacción. El tamaño máximo de los clinopiroxenos es de $6 \mathrm{~mm}$.

La espinela representa hasta un 5,5\% del volumen de las harzburgitas. Los cristales mayores se presentan en forma anhedral holly leaf o en forma simplectítica vermicular asociada a ortopiroxeno. El tamaño máximo de los cristales es de 2,5 mm. También aparece diseminada en parches de reacción.

Las harzburgitas presentan vetillas de vidrio alterado (serpentinizado) que pueden ocupar hasta el 7,4\% del volumen de muestra, estas venas suelen estar conectadas al basalto hospedante de los xenolitos. En pocas muestras aparecen parches de reacción, representando hasta un 4,2\% del volumen. Estos parches se encuentran rellenos de ol, cpx, spl y vidrio.

\section{Dunitas}

En las dunitas (ej. L31), el contenido modal de olivino varía entre 79,8 y 96,2\%, con cristales de hasta 13,5 mm de diámetro, los cuales presentan los bordes suturados con

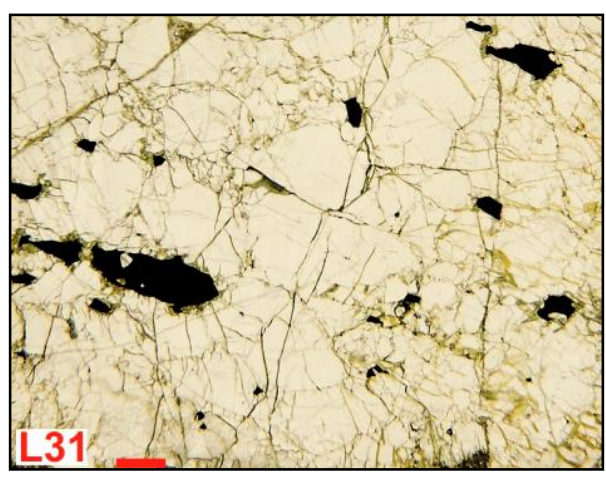
otros olivinos. Los cristales de mayor tamaño son anhedrales a subhedrales y muestran kink bands, mientras que aquellos cristales de hasta $1 \mathrm{~mm}$ presentan caras poligonales con frecuentes contactos en puntos triples. El contenido de ortopiroxeno varía entre 0 y $9,5 \%$ y los cristales pueden alcanzar los $6 \mathrm{~mm}$. Los ortopiroxenos son 
principalmente anhedrales, y al contacto con el basalto presentan coronas de reacción. Dicha reacción forma $\mathrm{cpx}$, ol, vidrio, opx, minerales del grupo de la spl y, eventualmente $\mathrm{pl}$.

El clinopiroxeno ocupa entre 0 y 4,9\% del volumen de las dunitas. Se presenta con formas anhedrales y bordes irregulares, de hasta $1,2 \mathrm{~mm}$.

Las muestras de dunita contienen hasta $6 \%$ de espinela, de 2,4 $\mathrm{mm}$ de diámetro máximo. Los cristales se presentan en formas anhedrales y subhedrales, pudiéndoselos encontrar asociados a ortopiroxeno. En dos dunitas (L32 y L47) las espinelas presentes en parches de reacción exhiben centros cribados. Las dunitas pueden contener vetillas hasta en un $6,3 \%$ de su volumen y parches de reacción hasta 3,4\%.

\section{$\underline{\text { Lherzolitas }}$}

Las lherzolitas (ej. L73) presentan un contenido modal de olivino que varía entre 65,0 y $84,1 \%$. Los cristales mayores alcanzan $9,5 \mathrm{~mm}$ de diámetro máximo y se

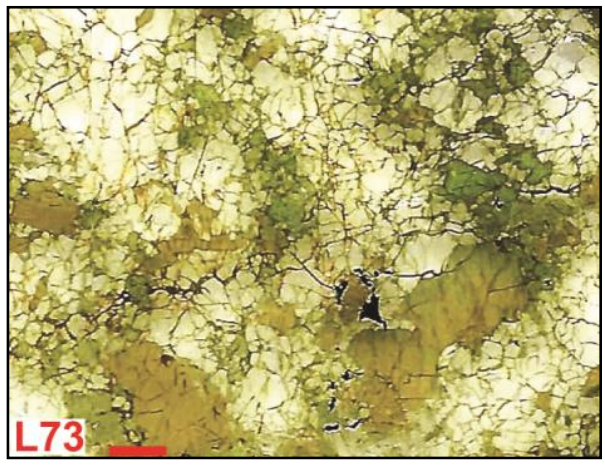
presentan anhedrales a subhedrales, con frecuentes bordes irregulares y suturas entre grandes olivinos. Estos cristales también presentan kink bands. Los cristales menores a $1 \mathrm{~mm}$, con frecuencia, desarrollan formas poligonales.

El contenido de ortopiroxeno varía entre 5,0 y $27,9 \%$. Los cristales de mayor tamaño $(3,6 \mathrm{~mm}$ máximo) muestran lamelas de exsolución de clinopiroxeno. Al contacto con el basalto, los ortopiroxenos presentan reacción, formada principalmente por $\mathrm{cpx}$, ol, vidrio, opx y spl.

La cantidad de clinopiroxeno en estas lherzolitas varía entre 5,1 y 9,4\%; en su mayoría son cristales subhedrales. En algunas muestras se presentan reaccionados, mostrando cristales cribados. También pueden aparecer como agregados finos en parches de reacción. El tamaño máximo de los clinopiroxenos es de 7,2 mm.

La espinela abarca de 0,8 a 2,8\% del volumen. Los cristales son subhedrales con tamaño máximo de hasta $2,8 \mathrm{~mm}$.

Las vetillas ocupan hasta $1,3 \%$ y suelen estar conectadas al basalto hospedante. El relleno de estas venillas es generalmente vidrio alterado color amarillo. 


\section{Wehrlitas}

En las wehrlitas (ej. L12), el contenido de olivino varía entre 64,5 y 82,5\%. Los cristales de mayor tamaño alcanzan los $9 \mathrm{~mm}$, tienen bordes suturados con otros olivinos y presentan kink bands. Por otro lado, los olivinos menores a $1 \mathrm{~mm}$ de diámetro se presentan en forma subhedral con bordes rectos.

El volumen de ortopiroxeno está comprendido entre 1,3 y 4,7\%, los cristales

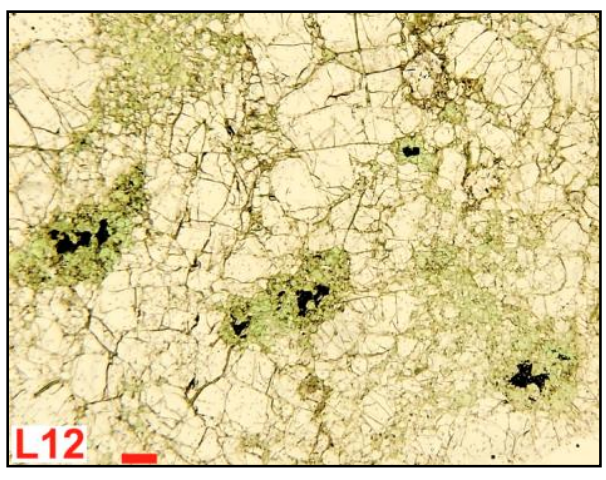
alcanzan un máximo de $2 \mathrm{~mm}$ y se presentan de forma subhedral. En cuanto al contenido de clinopiroxeno, el mismo varía entre 11,9 y $25,8 \%$. Los cristales mayores alcanzan los $1,8 \mathrm{~mm}$ y muestran bordes irregulares.

Las wehrlitas de Cerro León contienen espinelas en una proporción que varía entre 1,3 y $1,7 \%$. Se presentan como cristales anhedrales.

El contenido de vetillas es de hasta $3,6 \%$ y se las halla distribuidas por toda la muestra. En el caso de los parches de reacción, estos se encuentran conectados con vetillas y están rellenos de espinelas, clinopiroxenos finos y algunos cristales de plagioclasa (L12).

\section{Websteritas olivínicas}

Del total de muestras estudiadas se han encontrado dos websteritas olivínicas (L61 y L64) las cuales contienen 5,6 y 5,3\% de olivino modal respectivamente. Los cristales de

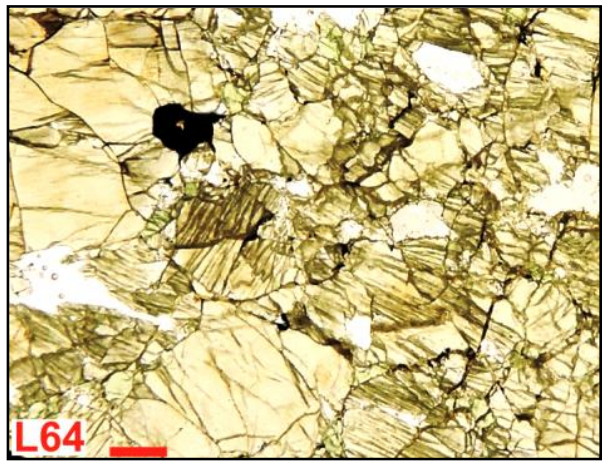
olivino son subhedrales y presentan alguno de sus bordes rectos, con ocasionales contactos en puntos triples. El tamaño máximo es de $9 \mathrm{~mm}$.

La proporción de ortopiroxeno alcanza el $86,7 \%$ en volumen. Se presentan como cristales subhedrales con reacción al contacto con el basalto. El tamaño máximo de los cristales es de 4 $\mathrm{mm}$.

El contenido de clinopiroxeno es de 5,2\%. Se presenta subhedral, y con $1 \mathrm{~mm}$ de diámetro máximo.

La espinela se encuentra en una proporción modal de entre 0,7 y 1,4\%, es subhedral, con tamaños de hasta 1,2 mm. El contenido modal de vetillas varía de 1,4 a 1,9\%. 


\section{Ortopiroxenita}

La única ortopiroxenita hallada en Cerro León (L51) presenta un contenido de ortopiroxeno de 79,1\%. Los cristales mayores son subhedrales. El clinopiroxeno representa el 7,7\% en volumen con cristales de bordes irregulares. El contenido de espinela llega al 7,9\% y se presenta en forma intersticial. La muestra se encuentra

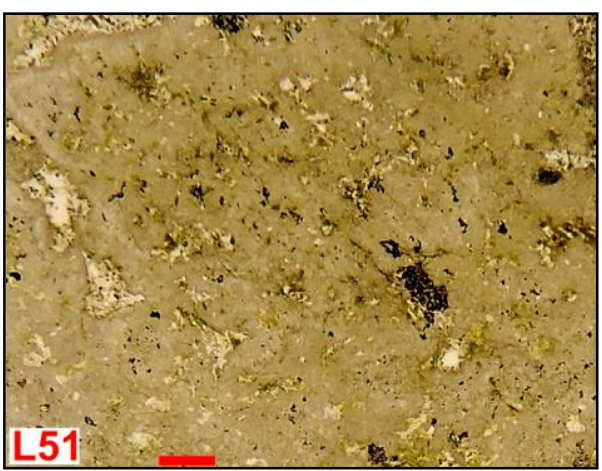
completamente fracturada y atravesada por numerosas vetillas. Éstas ocupan 5,3\% del volumen y se encuentran distribuidas por toda la muestra.

\subsubsection{Cerro Cortadera.}

Los xenolitos de Cerro Cortadera son mayoritariamente websteritas (14 muestras, $53,8 \%$ ) y le siguen en orden de abundancia, harzburgitas (5 muestras, 19,2\%), lherzolitas y websteritas olivínicas ( 2 muestras de cada una, 7,8\% en cada caso) y, wehrlitas, ortopiroxenitas y ortopiroxenitas olivínicas ( 1 muestra de cada una, 3,8\% en cada caso) (Figura 7.7; Tabla 12.1). La textura porfiroclástica es la dominante en las muestras de Cerro Cortadera (42,3\%), seguida de la transicional gruesa a porfiroclástica $(26,9 \%)$, gruesa $(15,4 \%)$, porfiroclástica en mosaico $(7,7 \%)$ y granuloblástica $(7,7 \%)$ (Figura 7.8).

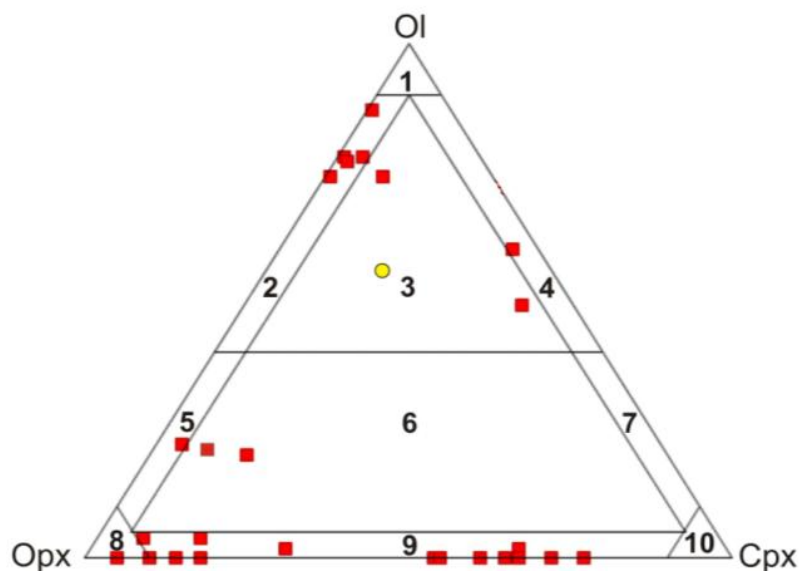

Figura 7.7. Clasificación de peridotitas y piroxenitas de Cerro Cortadera. El círculo amarillo representa la composición del manto primitivo de Johnson et al. (1990). 1 dunita, 2 harzburgita, 3 lherzolita, 4 wehrlita, 5 ortopiroxenita olivínica, 6 websterita olivínica, 7 clinopiroxenita olivínica, 8 ortopiroxenita, 9 websterita y 10 clinopiroxenita. 


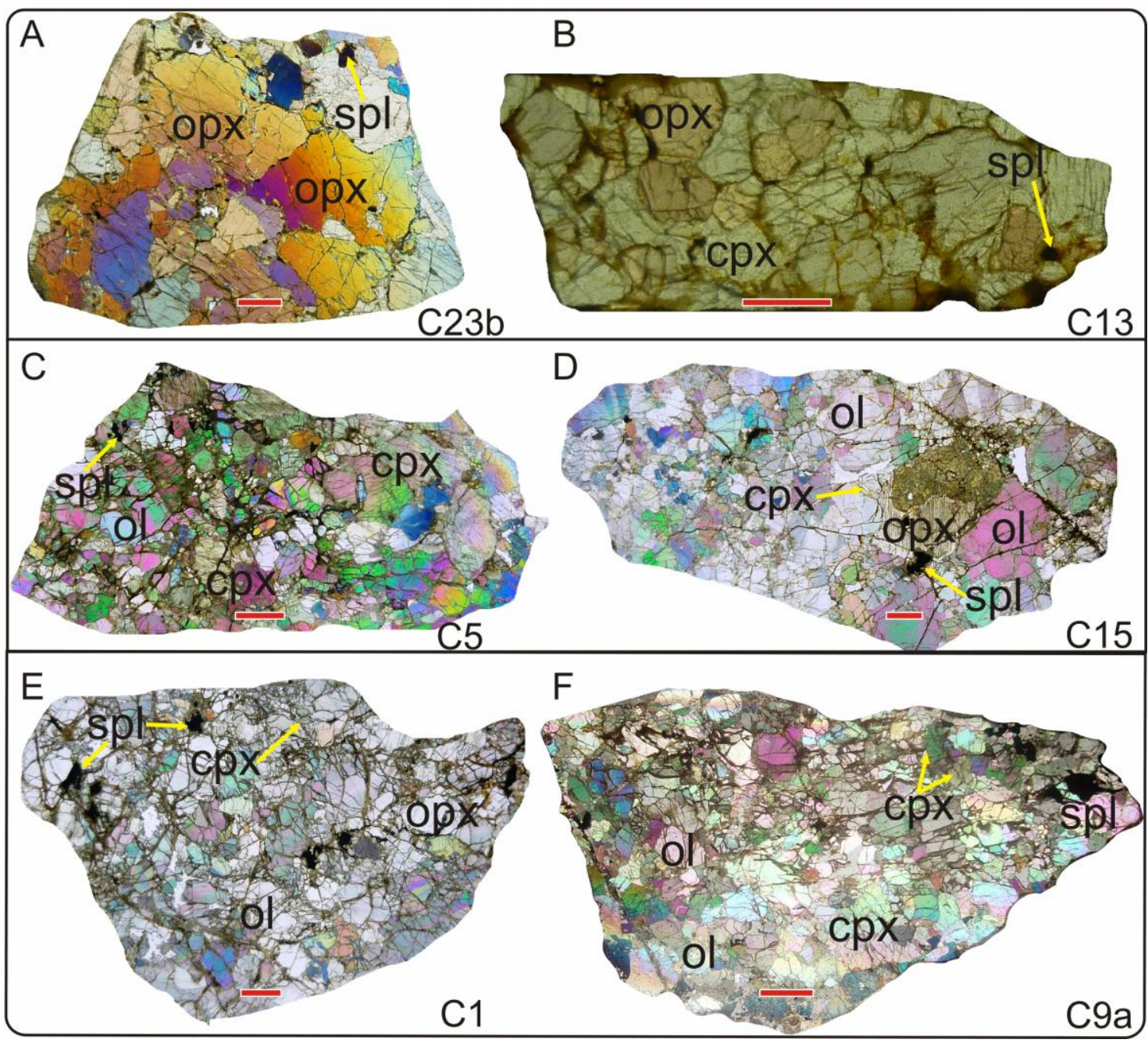

Figura 7.8. Texturas presentes en xenolitos de Cerro Cortadera. A y B: textura gruesa; C: textura transicional gruesa a porfiroclástica; D: textura porfiroclástica; E: textura porfiroclástica en mosaico y F: textura granuloblástica. La linea roja representa $2 \mathrm{~mm}$. Fotomicrografías de cortes delgados con luz polarizada, nicoles cruzados, excepto $\mathrm{B}$, que se exhibe con nicoles paralelos.

\section{Websteritas}

El contenido de olivino en las websteritas varía entre 0 y 4,5\%. El olivino hallado en estas rocas es subhedral y presenta bordes irregulares, con tamaños de hasta 3,4 mm. El

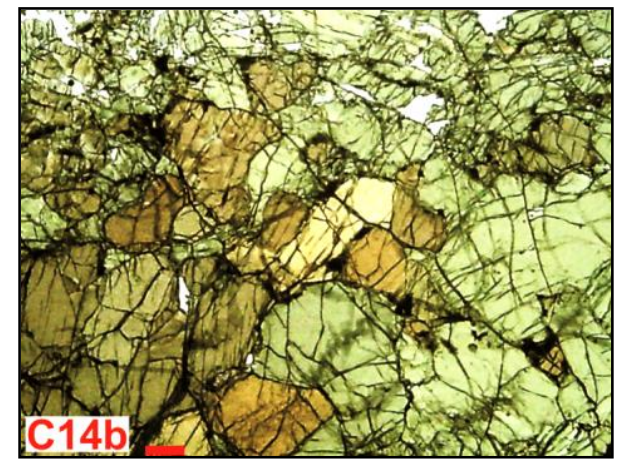
ortopiroxeno representa entre 22,7 y $86,5 \%$ del volumen de las websteritas estudiadas. Los cristales se presentan anhedrales a subhedrales, con tamaños de hasta $13 \mathrm{~mm}$. En contacto con el basalto desarrollan un borde de reacción, compuesto por vidrio, ol, cpx y minerales opacos. Algunas muestras presentan fracturas que afectan los cristales de opx. Se hallaron ortopiroxenos subhedrales dentro de cristales de olivino (ver sección 7.2). El contenido modal de clinopiroxeno varía entre 7,0 y 72,9\%. Los 
cristales principalmente se presentan subhedrales con diámetro máximo de $9 \mathrm{~mm}$ y se observan exsoluciones. También se observaron inclusiones de ortopiroxenos y espinelas dentro de cristales mayores.

La espinela se encuentra en una proporción de hasta 2,4\%. Se presentan entre los cristales de piroxenos, de forma anhedral a subhedral, con tamaño máximo de 0,8 $\mathrm{mm}$. El contenido de vetillas y parches es del 0,7 y 5,9\% respectivamente. Generalmente las vetillas se encuentran conectando parches con el basalto alojante, dando lugar a reacciones de reemplazo de grano fino.

\section{Harzburgitas}

El contenido de olivino en las harzburgitas de Cerro Cortadera (ej. C1) varía entre 65,8 y $78,2 \%$. Los cristales de mayor tamaño se presentan anhedrales a subhedrales, con frecuentes bordes irregulares y suturas entre ellos. Los cristales menores a 1,5 mm con frecuencia desarrollan formas poligonales. El tamaño de los cristales de olivino alcanza los $10 \mathrm{~mm}$ de diámetro máximo. En forma frecuente los olivinos mayores presentankink

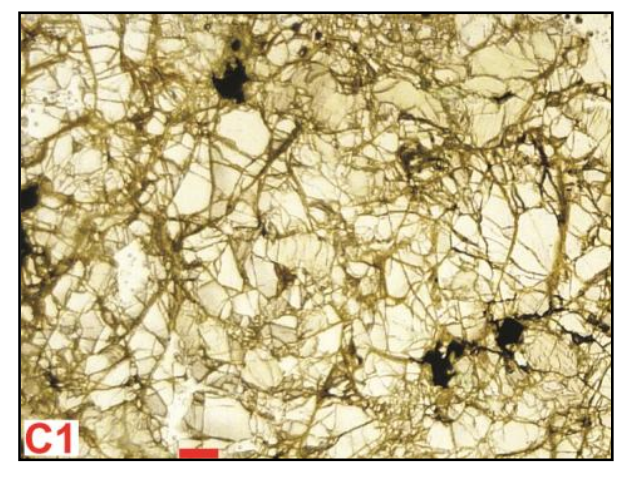

hospedante desarrollan una corona de reacción, formada principalmente por cpx, ol, vidrio, opx y spl.

El volumen de clinopiroxeno en estas rocas es de entre 1,1 y 4,0\%; en su mayoría son cristales subhedrales. En algunas muestras se presentan reaccionados, mostrando corona de reacción. También pueden aparecer como agregados finos en parches de reacción. El tamaño máximo de los cristales de clinopiroxeno es de 2,2 mm.

La espinela representa hasta un 2,9\% del volumen de las harzburgitas. Los cristales mayores exhiben forma anhedral a subhedral y están asociados a ortopiroxeno. El tamaño máximo de los cristales es de $2 \mathrm{~mm}$.

Las harzburgitas presentan venillas de vidrio alterado (serpentinizado) que pueden ocupar hasta un 9,4\% del volumen de las muestras, estas venas suelen estar conectadas con el basalto hospedante. 
Los parches de reacción ocupan hasta un 4,5\% del volumen. Estos se encuentran rellenos de ol, cpx, sy minerales del grupo de la spl. Generalmente estos parches conservan la forma de los ortopiroxenos que han reemplazado.

\section{Lherzolitas}

En Cerro Cortadera se estudiaron dos lherzolitas (C5 y C17b). Estas presentan un contenido modal de olivino que varía entre 49,3 y 68,9\%. Los cristales mayores alcanzan $5 \mathrm{~mm}$ de diámetro máximo y son anhedrales a subhedrales. Los cristales menores a $1 \mathrm{~mm}$ pueden desarrollar formas subhedrales con bordes rectos. Estos olivinos menores se encuentran dentro de cristales de clinopiroxeno (ver sección 7.2).

El contenido de ortopiroxeno varía entre 6,9 y $16,3 \%$. Los cristales de mayor tamaño

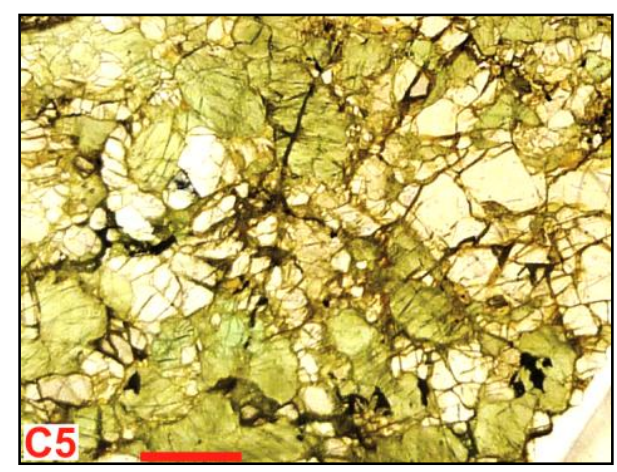
(4,5 mm máximo) muestran lamelas de exsolución de clinopiroxeno. La cantidad de clinopiroxeno en estas lherzolitas varía entre 9,2 y $42,5 \%$ y en su mayoría son subhedrales. Algunos cristales presentan exsoluciones de espinela. El tamaño máximo de los cpx es de 4,6 $\mathrm{mm}$.

El contenido de espinela representa de un 0,8 a $1,6 \%$ del volumen. Los cristales se presentan en forma subhedral, con tamaño máximo de hasta $0,8 \mathrm{~mm}$.

Las vetillas alcanzan hasta un 3,6\% modal y suelen estar conectadas al basalto hospedante. Por su parte el contenido de parches de reacción es de hasta $0,3 \%$.

\section{Websteritas olivínicas}

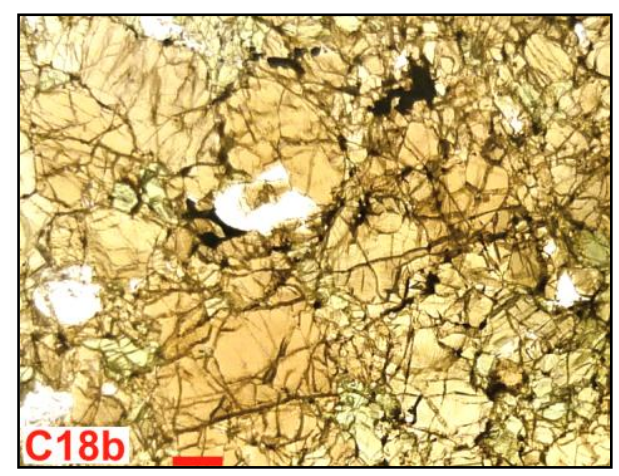

Del total de xenolitos de Cerro Cortadera estudiados se han encontrado sólo dos websteritas olivínicas (C18b y C28b) las cuales contienen 18,8 y $19,6 \%$ de olivino modal respectivamente. Los cristales de olivino son subhedrales, con ocasionales contactos en puntos triples. El tamaño máximo es de $3 \mathrm{~mm}$.

El contenido de ortopiroxeno es de 59,6 y $65,2 \%$ en volumen. Se presentan como cristales subhedrales con reacción al contacto con el basalto. El tamaño máximo de los cristales es de 7,5 mm. El contenido de clinopiroxeno es de 8,0 y 14,8\%. Se presenta 
como cristales subhedrales con un diámetro máximo de 1,7 $\mathrm{mm}$. La muestra está atravesada por fracturas y vetillas.

La espinela se encuentra en una proporción de entre 1,5 y $3,7 \%$, se presenta subhedral, con tamaños de hasta 0,6 mm. El contenido de vetillas varía de 3,1 a 3,4\% en volumen. Los parches de reacción se encuentran en torno a ortopiroxenos y ocupan entre 0,1 y $2,2 \%$.

\section{Wehrlita}

Se encontró una única muestra de wehrlita (C9a) con un contenido de olivino de $53,9 \%$. Los cristales de mayor tamaño alcanzan los 3,7 mm y exhiben bordes suturados

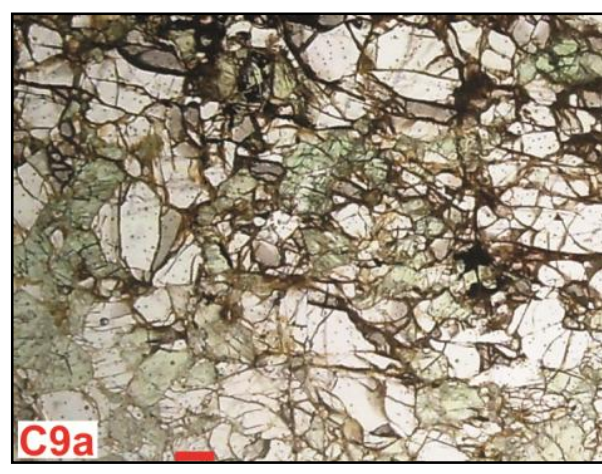
con otros olivinos. Algunos cristales de olivino se encuentran dentro de ortopiroxeno (ver sección 7.2). El volumen de ortopiroxeno es de 3,6\%, los cristales son subhedrales y alcanzan un máximo de 1,4 mm. El contenido modal de clinopiroxeno es de $32,9 \%$. Los cristales mayores alcanzan 3,4 $\mathrm{mm}$ de diámetro máximo, muestran bordes irregulares y presentan lamelas de exsolución. Los cristales menores alcanzan como máximo $1 \mathrm{~mm}$ y se encuentran dentro de parches de reacción. La wehrlita de Cerro Cortadera contiene 2,9\% de espinela modal. Se presenta como cristales irregulares de centro cribado, con tamaño máximo de 1,2 mm.

El contenido de vetillas es de hasta $6,3 \%$ y se las halla distribuidas por toda la muestra. En el caso de los parches de reacción $(0,4 \%)$, estos se encuentran conectados con vetillas y están rellenos de espinelas y clinopiroxenos finos.

\section{Ortopiroxenita olivínica}

El volumen de olivino en la muestra C28a es de 20,6\% y los cristales mayores

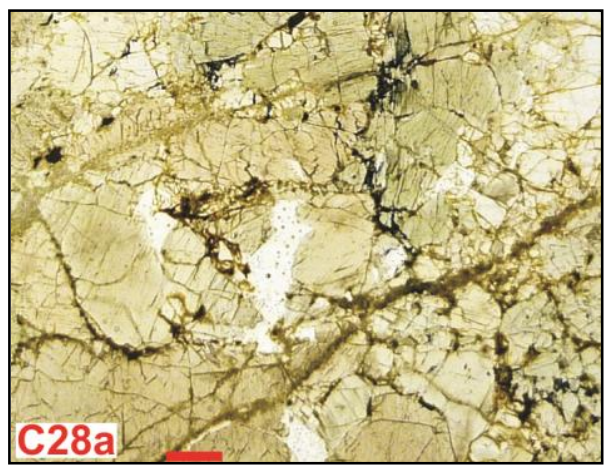
alcanzan un desarrollo de $3 \mathrm{~mm}$ con bordes irregulares. Los olivinos menores a $1 \mathrm{~mm}$ se presentan subhedrales y con bordes rectos. Los cristales de olivino están atravesados por numerosas fracturas en toda la muestra.

El contenido de ortopiroxeno es de $68,5 \%$, los cristales mayores alcanzan los $15 \mathrm{~mm}$ y presentan 
bordes curvos y lamelas de exsolución. Los ortopiroxenos menores a $1 \mathrm{~mm}$ presentan hábito vermicular y se encuentran entre cristales de olivino (ver sección 7.2).

Los clinopiroxenos exhiben una proporción modal de 3,6\% y se presentan como cristales subhedrales.Las espinelas ocupan el $2 \%$, son anhedrales y no superan los 0,5 $\mathrm{mm}$. El contenido de vetillas y parches de reacción es del 3,2 y 2,1\% respectivamente.

\section{$\underline{\text { Ortopiroxenita }}$}

El contenido de ortopiroxeno en la muestra C23b es del 85,1\%. Los cristales mayores

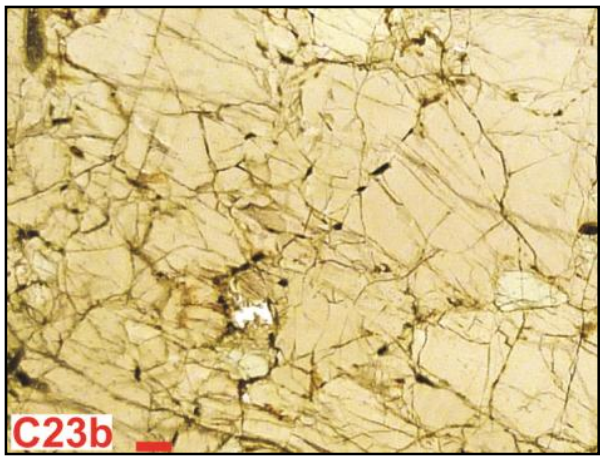
se presentan subhedrales. El clinopiroxeno representa el $5,3 \%$ con cristales de bordes irregulares. El contenido de espinela llega al 0,3\% y se presenta en forma intersticial. La muestra se encuentra atravesada por numerosas vetillas $\mathrm{y}$ fracturas. El contenido de vetillas es del 3,3\% del volumen, mientras que los parches de reacción ocupan el 5,9\%.

\subsubsection{Tapera Marín}

En Tapera Marín, la mayoría de los xenolitos clasifican como harzburgitas (28 muestras, 77,7\%); en menor medida se hallaron lherzolitas (5 muestras, 13,9\%), dunitas (2 muestras, 5,6\% y una muestra de websterita (2,8\%) (Figura 7.9, Tabla 12.1). Por su parte las texturas presentes corresponden principalmente a porfiroclástica $(63,9 \%)$ y gruesa a porfiroclástica $(22,2 \%)$, seguidas de las texturas granuloblástica $(8,3 \%)$, gruesa $(2,8 \%)$ y porfiroclástica en mosaico $(2,8 \%)$ (Figura 7.10$)$.

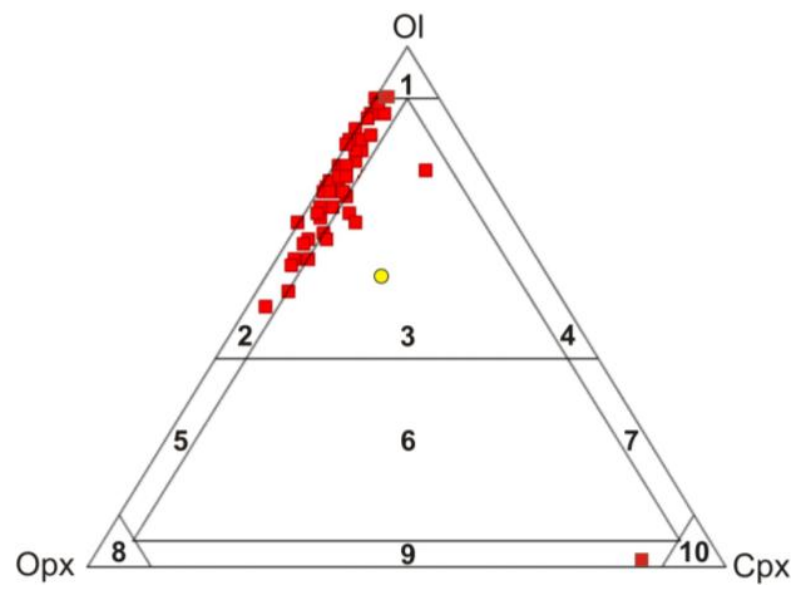

Figura 7.9. Clasificación de peridotitas y piroxenitas de Tapera Marín. El círculo amarillo representa la composición del manto primitivo de Johnson et al. (1990). 1 dunita, 2 harzburgita, 3 lherzolita, 4 wehrlita, 5 ortopiroxenita olivínica, 6 websterita olivínica, 7 clinopiroxenita olivínica, 8 $\begin{array}{llll}\text { ortopiroxenita, } 9 \text { websterita y } 10 & 0\end{array}$ clinopiroxenita. 


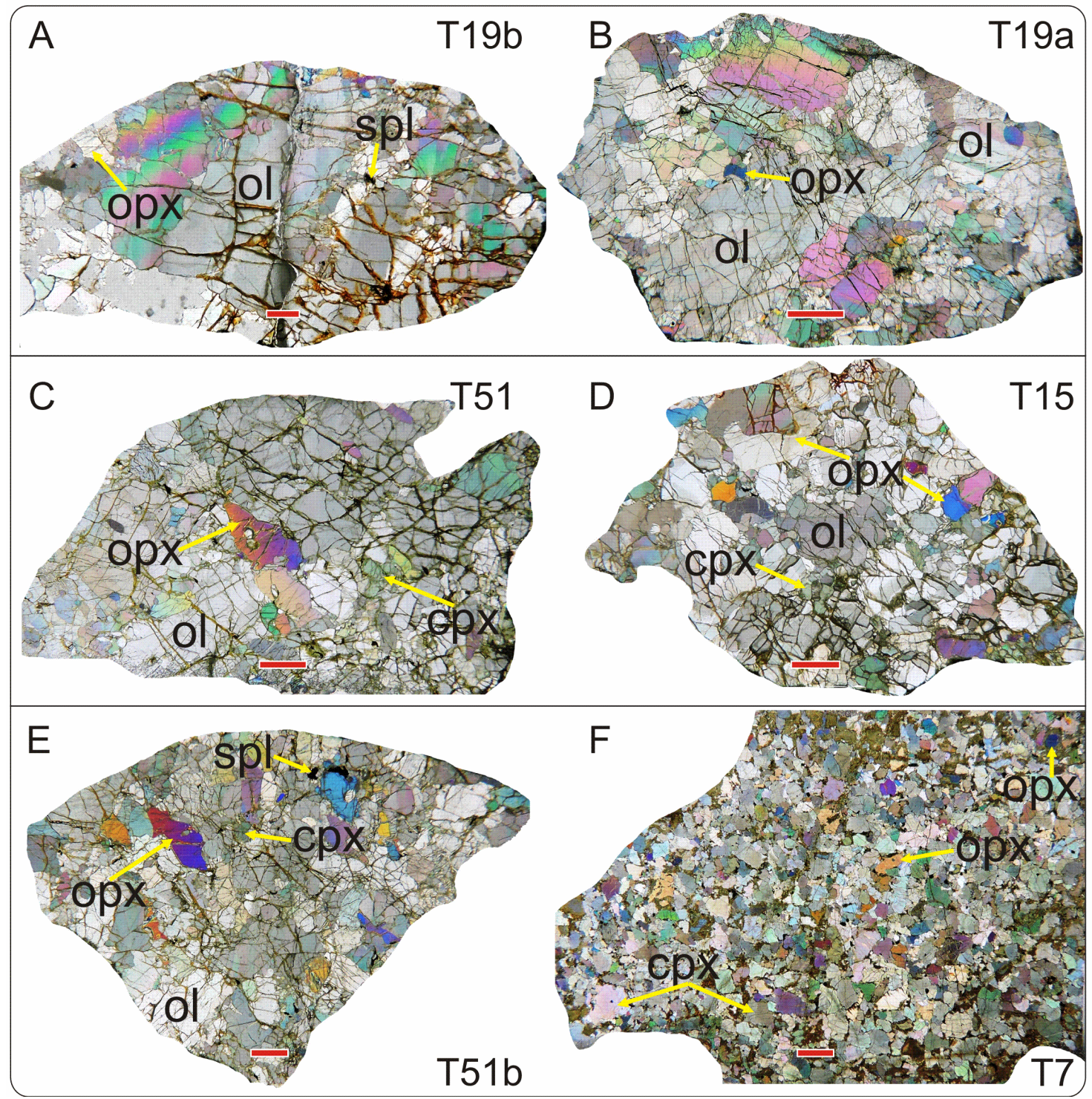

Figura 7.10. Texturas presentes en xenolitos de Cerro Tapera Marín. A: textura gruesa; B y C: textura transiciona gruesa a porfiroclástica; D: textura porfiroclástica; $\mathrm{E}$ : textura porfiroclástica en mosaico y $\mathrm{F}$ : textura granuloblástica. La linea roja representa $2 \mathrm{~mm}$. Fotomicrografías de cortes delgados con luz polarizada, nicoles cruzados.

\section{Harzburgitas}

En las harzburgitas (ej. T31) el contenido de olivino varía entre 55,9 y 83,3\%, se presenta como cristales subhedrales y con frecuentes bordes suturados al contacto con

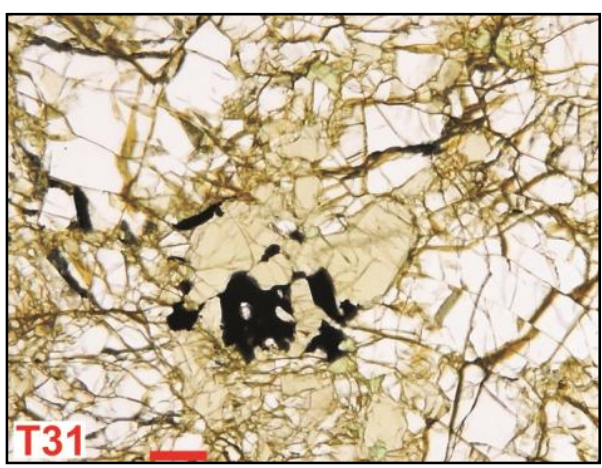

otros olivinos. También se pueden observar kink bands. Los olivinos menores $(\approx 1 \mathrm{~mm})$ presentan formas poligonales, con desarrollo de contactos en puntos triples. Se observan olivinos intersticiales en ortopiroxenos y en algunos casos, olivinos poligonales en bordes de ortopiroxeno (ver sección 
7.2). El tamaño máximo alcanzado por los olivinos es de $13,5 \mathrm{~mm}$.

El contenido de opx varía entre 9,4 y $39,1 \%$. Los cristales mayores alcanzan un diámetro de 8,2 $\mathrm{mm}$ y se presentan subhedrales con bordes irregulares. Es frecuente observar lamelas de exsolución de cpx y reacción al contacto con el basalto hospedante. Dicha reacción está compuesta por cpx, ol, spl y vidrio. Por su parte, también es posible observar ortopiroxenos vermiculares entre cristales de olivino (ver sección 7.2).

El clinopiroxeno ocupa entre el 0,1 y $4,4 \%$ del volumen de las muestras. Estos cristales son subhedrales y algunos presentan coronas de reacción. Los clinopiroxenos alcanzan un tamaño máximo de 1,7 mm. Los cristales menores (de unos $0,7 \mathrm{~mm}$ ) se presentan con bordes irregulares y formas redondeadas.

El contenido de espinela varía entre 0,3 y 3,6\% y se presenta en formas variadas: vermiculares y holly leaf en torno a ortopiroxeno y vermicular entre cristales de olivino. El tamaño máximo de cristales es de $2,1 \mathrm{~mm}$.

Las vetillas y parches de reacción pueden alcanzar los 7,2 y 6,3\% respectivamente. Los parches están rellenos de vidrio, spl y cpx.

\section{Lherzolitas}

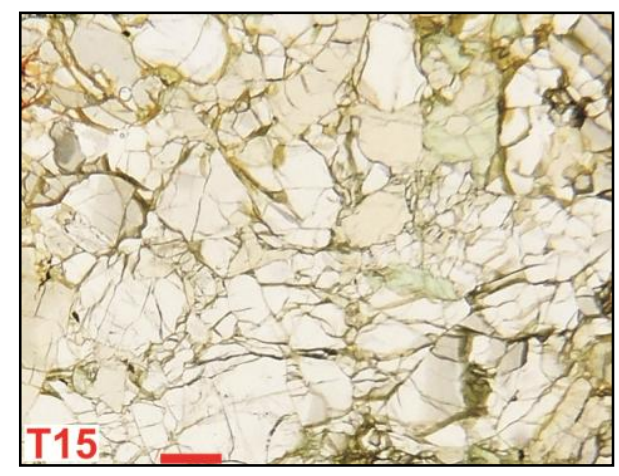

Las lherzolitas (ej. T15) contienen olivino entre 59,9 y $69,2 \%$. Los cristales mayores (hasta 7,5 $\mathrm{mm}$ ) son subhedrales y desarrollan kink bands. Los bordes frecuentemente son curvos y redondeados. Los olivinos menores son poligonales. Se hallaron algunos olivinos subhedrales dentro de ortopiroxeno (ver secc. 7.2).

El contenido de ortopiroxeno varía entre 8,0 y 30,4\%. Se presentan subhedrales (de hasta $7 \mathrm{~mm}$ ) y desarrollan una zona de reacción cuando se encuentran en contacto con el basalto hospedante. Otra característica común es la presencia de pequeños ortopiroxenos dentro de cristales de olivinos (ver sección 7.2).

El clinopiroxeno está presente en proporciones de entre 5,1 y 13,7\%. Los cristales alcanzan un desarrollo de hasta 2,2 $\mathrm{mm}$, son subhedrales $\mathrm{y}$, en algunos casos desarrollan coronas de reacción.

La espinela representa entre el 0,8 y 2,6\%, con cristales que pueden alcanzar los 1,5 $\mathrm{mm}$ de diámetro máximo. Se presentan vermiculares, holly leaf o subhedrales. 
Las lherzolitas presentan hasta un $4,4 \%$ de vetillas distribuidas por toda la muestra. Las mismas están rellenas de vidrio y con algunos minerales opacos dentro.

Dos de las lherzolitas contienen parches de reacción, ocupando hasta un 3,3\%.

\section{Dunitas}

Las dunitas (ej. T19b) presentan un contenido de olivino que varía entre 83,3 y 90,0\%. Los cristales de mayor tamaño son anhedrales a subhedrales, con bordes

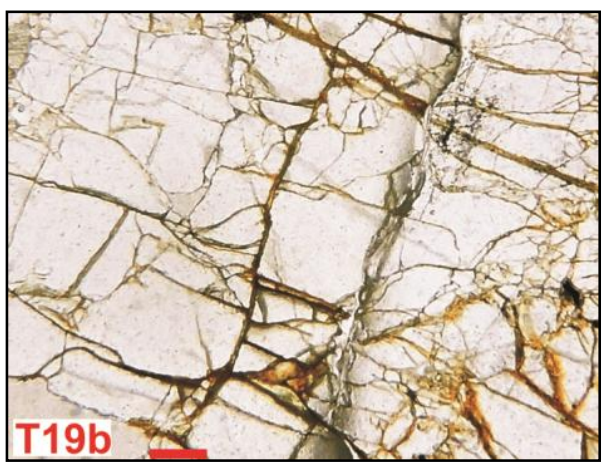
irregulares y en sutura con otros cristales de olivino. Los olivinos menores a $1 \mathrm{~mm}$ se presentan poligonales. También se hallan olivinos euhedrales dentro de ortopiroxeno. El tamaño máximo de olivino es de $13,5 \mathrm{~mm}$.

El contenido de ortopiroxeno llega hasta el 9,5\% del volumen. Se presenta como cristales subhedrales que contienen lamelas de exsolución. La dunita T19a contiene un cristal grande de ortopiroxeno con abundantes exsoluciones que desarrolla un extremo de ortopiroxeno límpido (ver sección 7.2). Los ortopiroxenos mayores alcanzan 3,7 mm de diámetro.

El volumen de clinopiroxeno es del $0,5 \%$, con tamaños de cristales de no más de 0,6 $\mathrm{mm}$, que se presentan de forma subhedral.

Las espinelas presentes en Tapera Marín, ocupan un volumen de entre 0 y $0,7 \%$, se presentan anhedrales, de forma holly leaf y con un tamaño máximo de 1,6 mm. El contenido de vetillas alcanza $5,1 \%$ en la dunita T19a y la misma contiene también $0,9 \%$ de parches de reacción.

\section{Websterita}

Se encontró un solo xenolito de websterita en Tapera Marín (T7), el cual presentaun

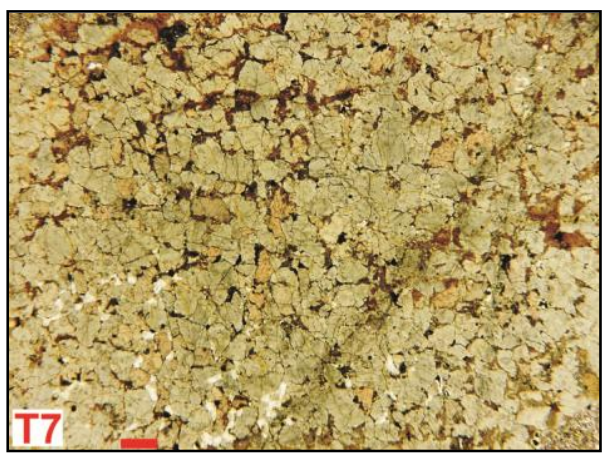
contenido de cpx de $80 \%$. Los cristales de cpx se presentan con forma subhedral, bordes irregulares y tamaño máximo de $3 \mathrm{~mm}$. El contenido de opx alcanza el 15\%. Los cristales también presentan formas subhedrales, con tamaño de hasta $2 \mathrm{~mm}$.

La espinela se encuentra en una proporción de hasta el 3\%. Los cristales de espinela son anhedrales a subhedrales, con un tamaño máximo es de $0,9 \mathrm{~mm}$. 
El contenido de vetillas y parches es del $2 \%$. Generalmente las vetillas cortan tanto cristales de opx como de cpx.

\subsubsection{Estancia La Primavera}

En Estancia La Primavera se hallaron 5 xenolitos ultramáficos que corresponden a piroxenitas en facies de espinela. Según los contenidos modales de ol, opx y cpx, estos xenolitos clasifican como websteritas (4 muestras, $80 \%$ ) y ortopiroxenita (1 muestra, 20\%) (Figura 7.11, Tabla 12.1). Por su parte las texturas presentes corresponden principalmente a gruesa y granuloblástica ( $40 \%$ de cada una) y, en menor medida, la textura transicional gruesa a porfiroclástica $(20 \%)$.

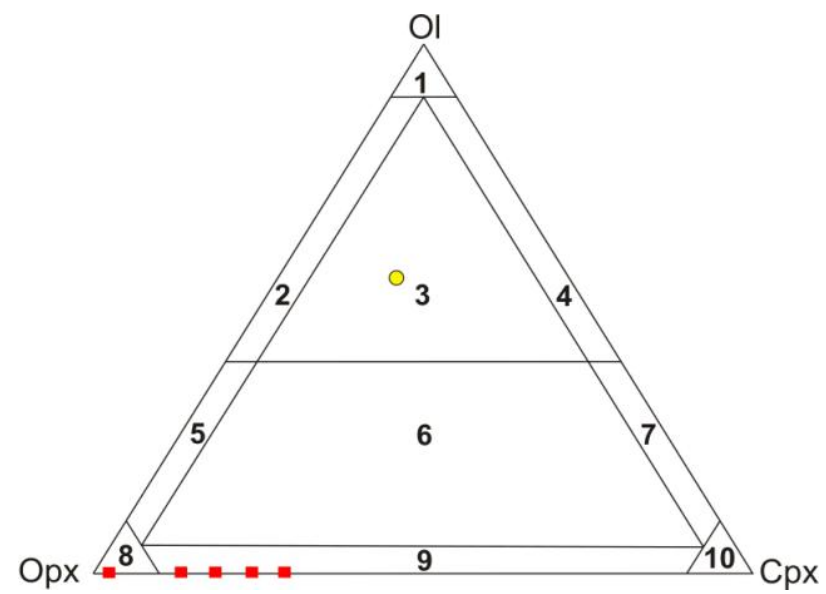

Figura 7.11. Clasificación de peridotitas y piroxenitas de Estancia La Primavera. El círculo amarillo representa la composición del manto primitivo de Johnson et al. (1990). 1 dunita, 2 harzburgita, 3 lherzolita, 4 wehrlita, 5 ortopiroxenita olivínica, 6 websterita olivínica, 7 clinopiroxenita olivínica, 8 ortopiroxenita, 9 websterita y 10 clinopiroxenita. 


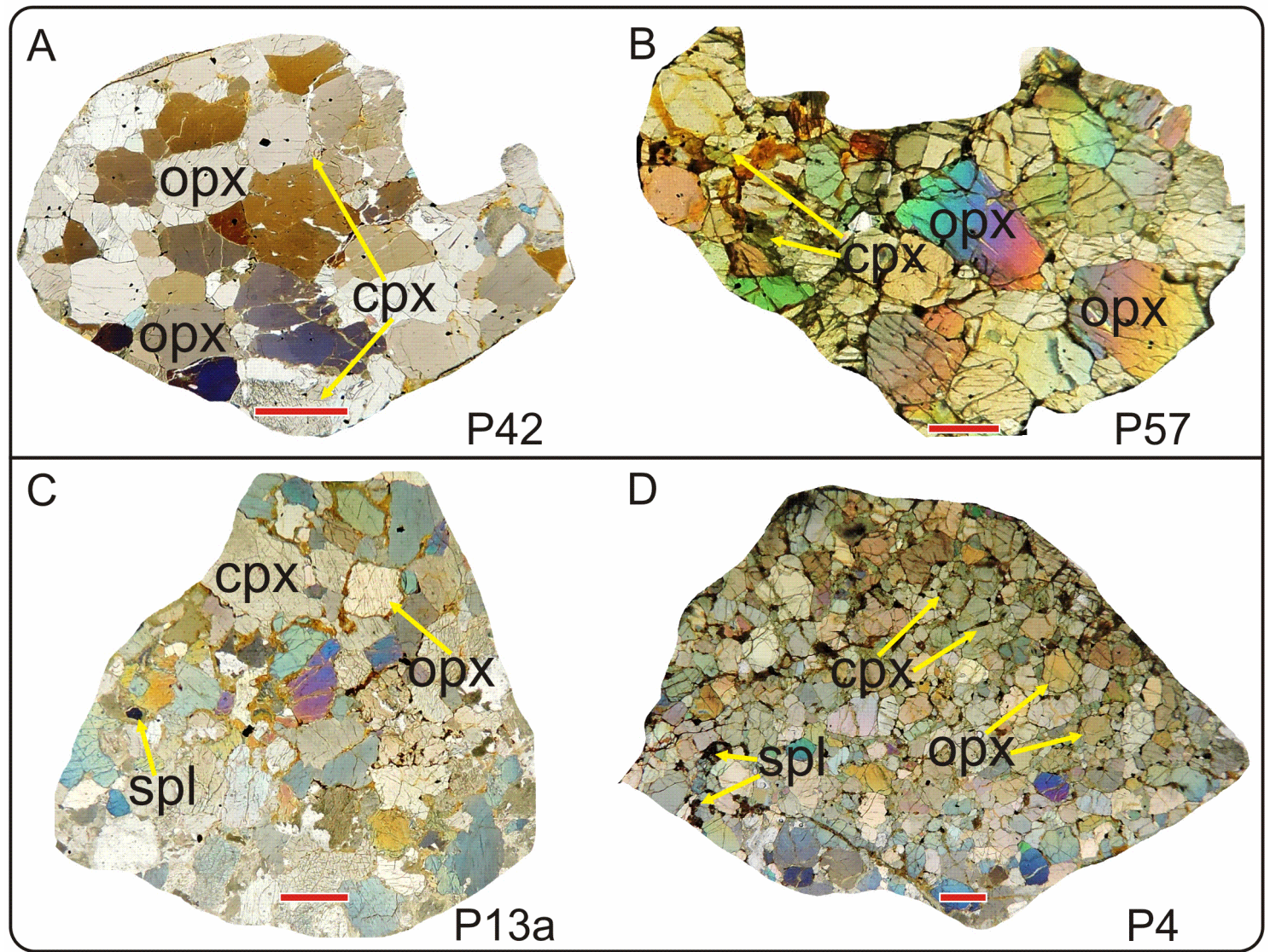

Figura 7.11. Texturas presentes en piroxenitas de Tapera Marín. A y B: textura gruesa; C: textura transicional gruesa a porfiroclástica y D: textura granuloblástica. La linea roja representa $2 \mathrm{~mm}$. Fotomicrografías de cortes delgados con luz polarizada, nicoles cruzados, con excepción de A, que se exhibe con nicoles paralelos.

\section{Websteritas}

El contenido modal de ortopiroxeno en las websteritas de Ea. La Primavera (ej. P4) varía entre 63,9 y $81,6 \%$. Los cristales se presentan subhedrales, con tamaños de hasta

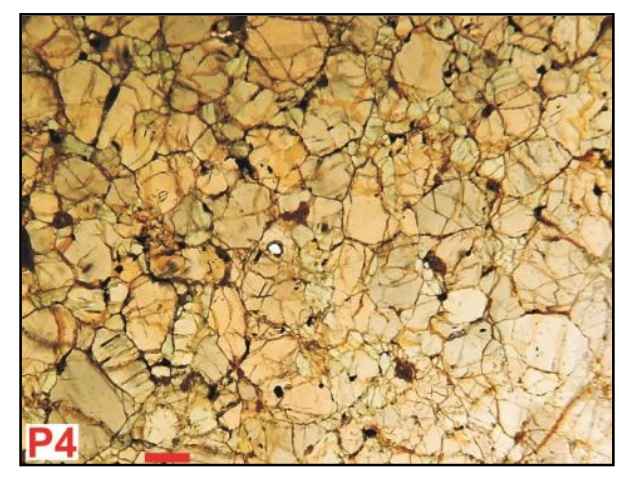

4,2 $\mathrm{mm}$. Suelen presentar exsoluciones y una fina zona de reacción cuando el ortopiroxeno está en contacto con el basalto hospedante. Aquellos cristales menores a $1 \mathrm{~mm}$ se presentan con bordes rectos y desarrollan contactos en puntos triples; además presentan incipientes kink bands.

El contenido modal de clinopiroxeno varía entre 14,2 y 29,9\%. Los cristales se presentan subhedrales con bordes redondeados, con un diámetro máximo de $1 \mathrm{~mm}$. En algunas muestras, los cristales de clinopiroxeno ocupan engolfamientos de ortopiroxeno o se encuentran de manera intersticial entre ortopiroxenos (ver sección 7.2). 
La espinela se encuentra en una proporción de hasta el 3,4\%. Se presentan entre los cristales de piroxenos, de forma subhedral, con tamaño máximo de 0,6 mm.

El contenido de vetillas varía entre 0,4 y $2,8 \%$. Generalmente las vetillas se encuentran presentes de forma homogénea en toda la muestra y puede presentar rellenos afaníticos.

\section{$\underline{\text { Ortopiroxenita }}$}

La muestra P42 es la única ortopiroxenita hallada, la cual contiene un 94,3\% de ortopiroxeno. Los cristales mayores alcanzan $4 \mathrm{~mm}$ de diámetro y son subhedrales con

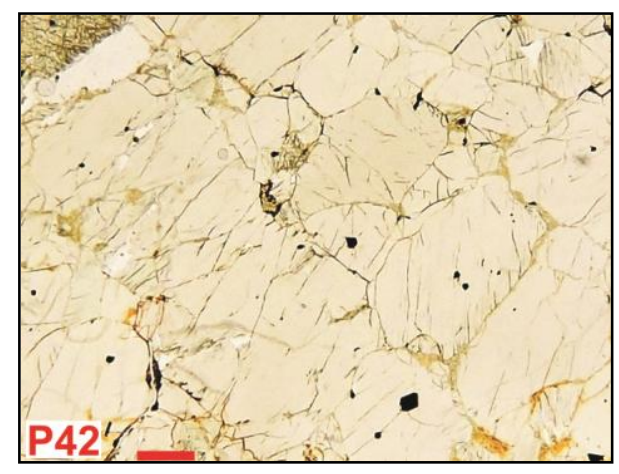
bordes suaves. Los cristales menores de $1 \mathrm{~mm}$ son poligonales y desarrollan contactos en puntos triples. En contacto con el basalto hospedante, los cristales de ortopiroxeno exhiben una corona de reacción poco desarrollada.

El contenido de clinopiroxeno es de 1,5\%. Los cristales se presentan subhedrales con bordes redondeados y con un tamaño que no supera los $0,9 \mathrm{~mm}$.

La espinela es escasa $(0,2 \%$ modal $)$, es euhedral y se encuentra dentro de cristales de ortopiroxeno. La muestra presenta $1,3 \%$ de vetillas diseminadas.

\begin{tabular}{|c|c|c|c|c|c|c|}
\hline Roca & \multicolumn{7}{c|}{ Chenque Matilde León Cortadera Tapera Marín Ea. La Primavera } \\
\hline \hline Dunita & 2,3 & 6,4 & 32,3 & & 5,6 & \\
Harzburgita & 53,4 & 80,9 & 53,8 & 19,2 & 77,7 & \\
Lherzolita & 30,5 & 12,7 & 6,2 & 7,8 & 13,9 & \\
Wherlita & & & 3,1 & 3,8 & & \\
Ortopiroxenita olivínica & 0,8 & & & 3,8 & & \\
Websterita olivínica & 1,5 & & 3,1 & 7,8 & & \\
Clinopiroxenita olivínica & 0,8 & & & & & \\
Ortopiroxenita & 0,8 & & 1,5 & 3,8 & & 20,0 \\
Websterita & 9,9 & & & 53,8 & 2,8 & 20,0 \\
\hline Total & 100,0 & 100,0 & 100,0 & 100,0 & 100,0 & 100,0 \\
\hline
\end{tabular}

\begin{tabular}{|c|c|c|c|c|c|c|}
\hline Textura & \multicolumn{6}{c|}{ Chenque Matilde León Cortadera Tapera Marín Ea. La Primavera } \\
\hline \hline Gruesa & 5,3 & 15,9 & 20,0 & 15,4 & 2,8 & 40,0 \\
Gruesa a porfiroclástica & 20,6 & 22,2 & 13,8 & 26,9 & 22,2 & 20,0 \\
Porfiroclástica & 48,1 & 58,7 & 52,3 & 42,3 & 63,9 & \\
Porfiroclástica en mosaico & 13,0 & 3,2 & 10,8 & 7,7 & 2,8 & \\
Granuloblástica & 13,0 & & 3,1 & 7,7 & 8,3 & 40,0 \\
\hline Total & 100,0 & 100,0 & 100,0 & 100,0 & 100,0 & 100,0 \\
\hline
\end{tabular}

Tabla 7.2. Arriba resumen de clasificación modal y abajo, resumen de las texturas de los xenolitos ultramáficos de cada localidad estudiada. Valores expresados en porcentaje. 


\subsection{CARACTERÍSTICAS PETROGRÁFICAS PARTICULARES}

\subsubsection{Reemplazo mineral y reacciones}

Los xenolitos ultramáficos muestreados en la zona de Paso de Indios presentan evidencias de reemplazo mineral y desequilibrios, vinculadas con reacciones ocurridas a nivel del manto. A continuación se describen cada una de las reacciones halladas en orden decreciente de abundancia.

\section{Ortopiroxenos dentro y entre cristales de olivino}

Este tipo de reemplazo está presente en la mayoría de los xenolitos de todos los afloramientos estudiados. Se caracteriza por la presencia de cristales de ortopiroxeno irregulares, sin deformación, que se encuentran rodeando grandes cristales de olivino; también se pueden encontrar ortopiroxenos con formas vermiculares penetrando en olivinos de gran tamaño con kink bands. Con menos frecuencia, se encuentran ortopiroxenos en forma de "Y" creciendo en puntos triples de contacto entre olivinos, como un estadio incipiente de reemplazo (Figura 7.12 a-d).

Olivinos entre y dentro de cristales de ortopiroxeno

Este reemplazo está presente en al menos un xenolito ultramáfico de todos los muestreados en cada localidad. Se caracteriza por la presencia de cristales de olivino poligonales creciendo dentro de cristales mayores de ortopiroxeno que presentan lamelas de exsolución. También es posible encontrar cristales de olivinos subhedrales rodeando piroxenos, formando difusas coronas (Figura $7.12 \mathrm{e}-\mathrm{i}$ ).

$\underline{\text { Simplectitas de espinela-ortopiroxeno }}$

Tres muestras de harzburgitas de Cerro Chenque presentan intercrecimiento simplectítico de cristales de espinela y ortopiroxeno \pm clinopiroxeno (Figura 10.3). Esta textura ha sido descripta previamente en xenolitos de Laguna Fría y Prahuaniyeu en Patagonia norte (Bjerg et al. 2005) y en Pali Aike en el extremo sur de Patagonia (Selverstone 1982). Las espinelas aparecen con morfología de holly leaf y vermiculares (Figura $7.12 \mathrm{j}-\mathrm{k}$ ).

\section{$\underline{\text { Sobrecrecimiento de ortopiroxeno }}$}

En un xenolito de Cerro Chenque (Q117) se encontró un cristal de ortopiroxeno con lamelas de exsolución e incipiente deformación (kink bands), el cual presenta una apófisis de ortopiroxeno límpido sin exsoluciones a modo de un sobrecrecimiento de ortopiroxeno. Este sobrecrecimiento es notorio del resto del cristal (Figura 7.12 1). 

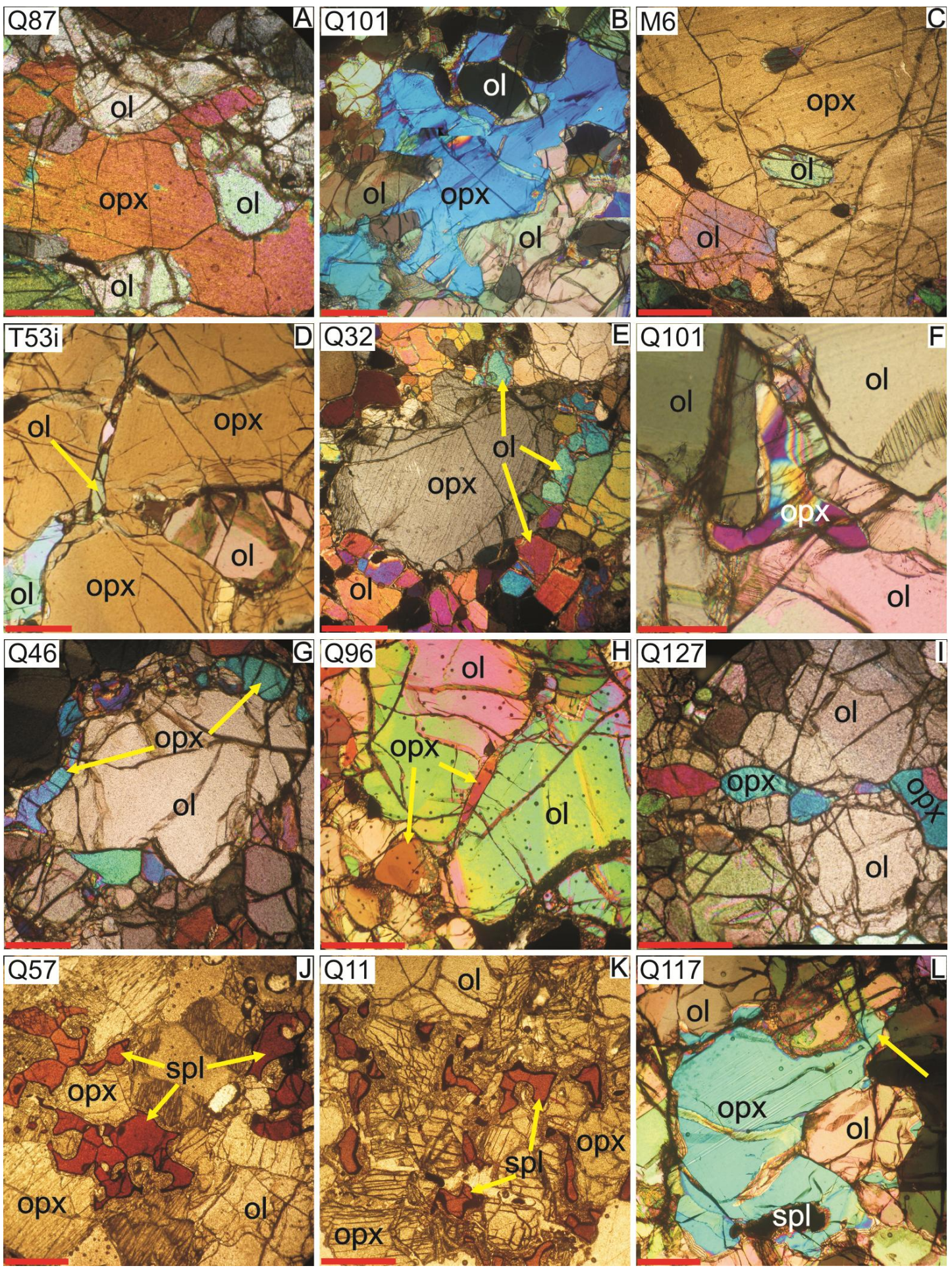

Figura 7.12. Reacciones a nivel mantélico. Ortopiroxenos reemplazando ol: a) opx elongados y sin exsoluciones rodeando un porfiroclasto de olivino, b) cristales de opx vermiculares rodeando e ingresando dentro de un cristal de olivino con kind bands, c) cristal de olivino atravesado por cristales de opx con forma de gotas vermiculares, d) opx en forma de $\mathrm{Y}$ en un contacto triple de olivinos. Olivinos reemplazando opx: e y f) porfiroclastos de opx con bordes engolfados, ocupados por olivinos neoformados, g) olivinos euhedrales dentro de porfiroclastos de opx exsuelto, h) gran porfiroclasto de opx con ingreso de ol en venilla y engolfamientos ocupados por ol límpidos, i) olivinos poligonales sin deformación, rodeando un porfiroclasto de opx con lamelas de exsolución. Simplectitas de espinela y ortopiroxeno: j) espinela vermicular alrededor de opx, k) y l) ortopiroxeno con lamelas de exsolución con sobrecrecimiento de opx límpido, señalado con la flecha amarilla. La linea roja representa $1 \mathrm{~mm}$ en todos los casos. Fotomicrografías de cortes delgados con luz polarizada, nicoles cruzados, con excepción de j, $\mathrm{k}$, que se exhiben con nicoles paralelos. 


\subsubsection{Reacciones xenolito-basalto hospedante}

Cuando los cristales que componen los xenolitos ultramáficos se encuentran en contacto con el basalto hospedante desarrollan reacciones de distintas características. Esta interacción roca/fundido puede generarse directamente en el contacto del basalto con los cristales (preferentemente opx) del borde de los xenolitos, o bien en minerales internos, cuando venillas de fundido ingresan al interior de los xenolitos. En el caso donde el basalto hospedante interacciona con cristales de ortopiroxeno, la mayoría de las veces, éstos desarrollan una textura de desequilibrio generalmente de poco espesor y de grano muy fino, la cual está compuesta por olivinos, piroxenos, vidrio y minerales opacos. Por su parte, hacia el basalto el desequilibrio generado puede dar lugar a una aglomeración de plagioclasas y feldespatos o, un aglomerado de clinopiroxenos zonados (Figura 7.13 a-f). La diferencia de composición mineralógica de la zona de reacción podría estar en relación con la composición de la roca hospedante y/o con la presión a la que tiene lugar esta reacción.

Es frecuente que los xenolitos ultramáficos estén atravesados por numerosas venillas, las cuales conectan el basalto con los cristales del interior de los xenolitos. Generalmente estas venas se encuentran rellenas de vidrio serpentinizado, piroxenos, minerales opacos y, en ocasiones, plagioclasa (Figura $7.13 \mathrm{~g}$ ). Si bien las venillas atraviesan a todos los minerales constituyentes de los xenolitos, los piroxenos y las espinelas son las fases minerales que desarrollan mayor reacción al contacto. Una de las reacciones vinculadas a venillas es la documentada por cristales de clinopiroxenos con desarrollo de una fina corona de reacción o textura de borde esponjosa (spongy rim) (Figura 7.13 h). Por último, los fundidos que ingresan a los xenolitos a través de las venillas, en ocasiones generan la reacción de ortopiroxenos los cuales son reemplazados en forma parcial o total, dando lugar a parches o bolsillos de reacción (Figura 7.13 i). Estos parches están compuestos mayoritariamente por clinopiroxeno, minerales opacos y relictos del mineral reemplazado. 

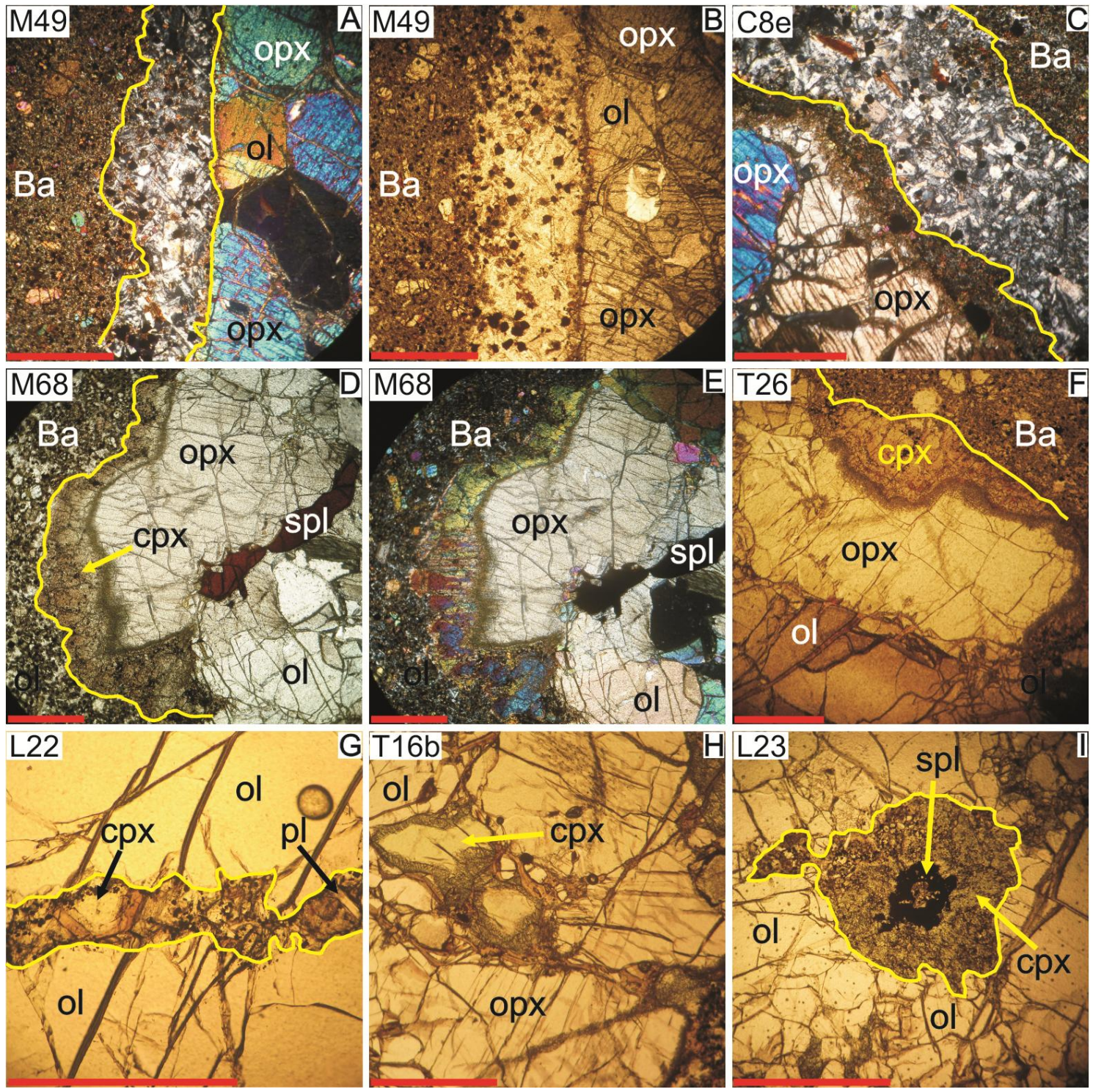

Figura 7.13. Reacciones por interacción xenolito-basalto halojante: a, b y c) contacto opx-basalto, desarrollando un aglomerado de plagioclasas + vidrio + minerales opacos, d, e y f) contacto opx-basalto desarrollando un aglomerado de cpx + vidrio + minerales opacos, g) vena de fundido $+\mathrm{cpx}+\mathrm{pl}$ atravesando cristal de olivino, h) clinopiroxeno desequilibrado, con desarrollo de corona de reacción. El mismo está rodeado de venillas de fundido que se comunican con el basalto, i) parche de reacción producto del reemplazo de opx y espinela. La línea roja en cada imagen representa $1 \mathrm{~mm}$. Fotomicrografías de cortes delgados con luz polarizada. a, c, e con nicoles cruzados y b, d, f, g, h e i con nicoles paralelos. 


\section{8- GEOQUÍMICA DE LAS FASES MINERALES}




\subsection{COMPOSICIÓN DE ELEMENTOS MAYORES}

Los resultados de los análisis por microsonda electrónica de olivinos, ortopiroxenos, clinopiroxenos y espinelas están detallados en las Tablas 12.2a, b, c y d (anexo 12). Los análisis representan el valor medio calculado a partir de análisis puntuales (2 a 3 ) dentro de un mismo cristal. Cabe aclarar que no se analizaron muestras de Estancia La Primavera.

\subsubsection{Cerro Chenque}

El contenido de forsterita (Fo) en olivinos varía entre 90,1 (Q90) y 92,5 (Q109). Los ortopiroxenos analizados son enstatitas (Figura 8.1) con una composición de En $_{86,8-92,2}$, $\mathrm{Fs}_{6,9-12,5}$ y $\mathrm{Wo}_{0,1-1,7} ;$ mientras que los clinopiroxenos son diópsidos con contenidos relativos de $\mathrm{En}_{46,9-50,7}, \mathrm{Fs}_{2,3-4,8}$ y $\mathrm{Wo}_{45,6-48,1}$.

En el caso de las espinelas, el parámetro \#Mg $[100 * \mathrm{Mg} /(\mathrm{Mg}+\mathrm{Fe})$, donde $\mathrm{Fe}$ es $\mathrm{Fe}^{2+}$ total] varía entre 67,6 (Q58) y 80,8 (Q104); mientras que el parámetro \#Cr $[100 * \mathrm{Cr} /(\mathrm{Cr}+\mathrm{Al})]$ varía entre 16,5 (Q90) y 44,6 (Q108).

\subsubsection{Cerro Matilde}

Los olivinos de los xenolitos de Cerro Matilde muestran un contenido de Fo entre 90,2 (M57) y 92,7 (M67). Los ortopiroxenos analizados son enstatitas, con contenidos de $\mathrm{En}_{89,8-91,4}, \mathrm{Fs}_{7,7-8,6} \mathrm{y} \mathrm{Wo}_{0,7-1,8}$. Los clinopiroxenos clasifican como diópsidos, excepto uno de la muestra M67 que presenta un contenido de Wo $=50,7 \%$. La composición relativa de los clinopiroxenos es $\mathrm{En}_{37,1-50,0}, \mathrm{Fs}_{12,2-2,7}$ y $\mathrm{Wo}_{46,4-50,7}$.

Las espinelas de Cerro Matilde presentan \#Mg entre 62,1 (M57) y 71,0 (MH) y \#Cr entre 37,8 (M53) y 44,7 (M55), excepto la muestra M57 que presenta una espinela rica en $\mathrm{Cr}$, con $\# \mathrm{Cr}=77,0$.

\subsubsection{Cerro León}

Los olivinos de xenolitos de Cerro León presentan un contenido de Fo que varía entre 86,9 y 91,9. Los ortopiroxenos son de la especie enstatita con contenidos de $\operatorname{En}_{89,8-}$ 91,4, $\mathrm{Fs}_{7,7-8,6}$ y $\mathrm{Wo}_{0,7-1,8}$; mientras que los clinopiroxenos clasifican como diópsido excepto el de la muestra L37 que clasifica en el campo de la augita. Las composiciones correspondientes son $\mathrm{En}_{48,9-49,9}, \mathrm{Fs}_{3,4-7,0}$ y $\mathrm{Wo}_{43,7-47,6}$. Las espinelas presentan \#Mg entre 66,5 y 85,6 y \#Cr varíable entre 17,9 y 43,5. 


\subsubsection{Cerro Cortadera}

Los olivinos analizados presentan un contenido de Fo de entre 89,2 y 90,9. Además se analizaron sólo dos cristales de ortopiroxeno de la muestra C30A (websterita). Estos clasifican como enstatitas con un contenido medio de $\mathrm{En}_{84,5-84,7}, \mathrm{Fs}_{14,7-14,8}$ y $\mathrm{Wo}_{0,6-0,8}$. Los clinopiroxenos analizados muestran un contenido de $\mathrm{En}_{44,3-49,1}, \mathrm{Fs}_{3,6-5,6} \mathrm{y} \mathrm{Wo}_{46,4-50,2}$ y clasifican como diópsidos excepto uno de la muestra C30a que posee un contenido de $\mathrm{Wo}=50,2 \%$.

Por su parte las espinelas estudiadas presentan valores de \#Mg variables entre 57,1 y 63 y de \#Cr entre 19,7 y 54,9.

\subsubsection{Tapera Marín}

El contenido de Fo en olivinos varía entre 89,7 y 91,4. Los ortopiroxenos son enstatitas con composiciones de $\mathrm{En}_{90.6-90.7}, \mathrm{Fs}_{8.1-8.2} \mathrm{y}_{\mathrm{Wo}_{1.0-1.1}}$. El único clinopiroxeno analizado es un diópsido con contenidos de $\mathrm{En}_{50}, \mathrm{Fs}_{4} \mathrm{y} \mathrm{Wo}_{46}$. Mientras que la única espinela analizada tiene \#Mg de 66,5 y \#Cr de 50,4.

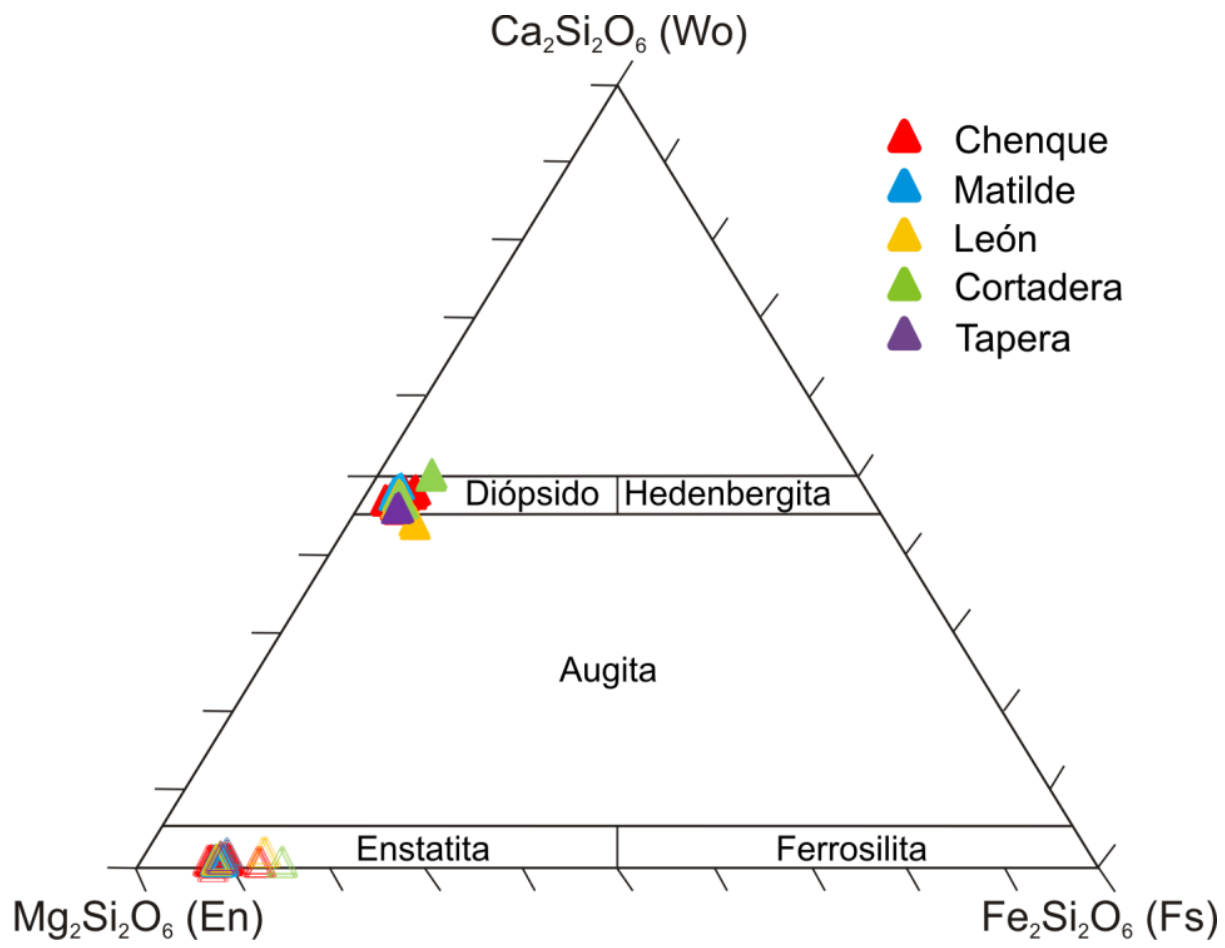

Figura 8.1. Clasificación de ortopiroxenos (símbolos vacíos) y clinopiroxenos (símbolos llenos). 


\subsection{VARIACIÓN DE ELEMENTOS MAYORES}

Los diagramas de variación de elementos mayores de las fases minerales de Paso de Indios se graficaron junto con muestras de minerales de xenolitos ultramáficos de Patagonia (Rivalenti et al. 2004a, 2004b; Bjerg et al. 2005 y Ntaflos et al. 2007) y de xenolitos del volcán Agua Poca (Bertotto et al. 2013) con el fin de realizar diferentes comparaciones. En cada diagrama, el campo en color celeste representa las muestras de Patagonia y el campo en color rosa representa a las muestras de Agua Poca.

\subsubsection{Olivino}

Los olivinos presentes en los xenolitos muestreados en todos los afloramientos tienen un contenido de Fo que varía entre 86,9 y 92,4 y se ubican dentro del rango de variación descripto por Rivalenti et al. (2004a). Estos olivinos tomados en conjunto no presentan una clara correlación con su contenido de $\mathrm{SiO}_{2}$, pero muestran una leve correlación positiva con el contenido de NiO, más evidente, a su vez, para las lherzolitas de Cerro Chenque (Figura 8.2). En ambos casos encontramos que los olivinos de Paso de Indios plotean cerca del campo de las muestras de Patagonia, excepto las lherzolitas de cerro Chenque que muestran composiciones más refractarias.

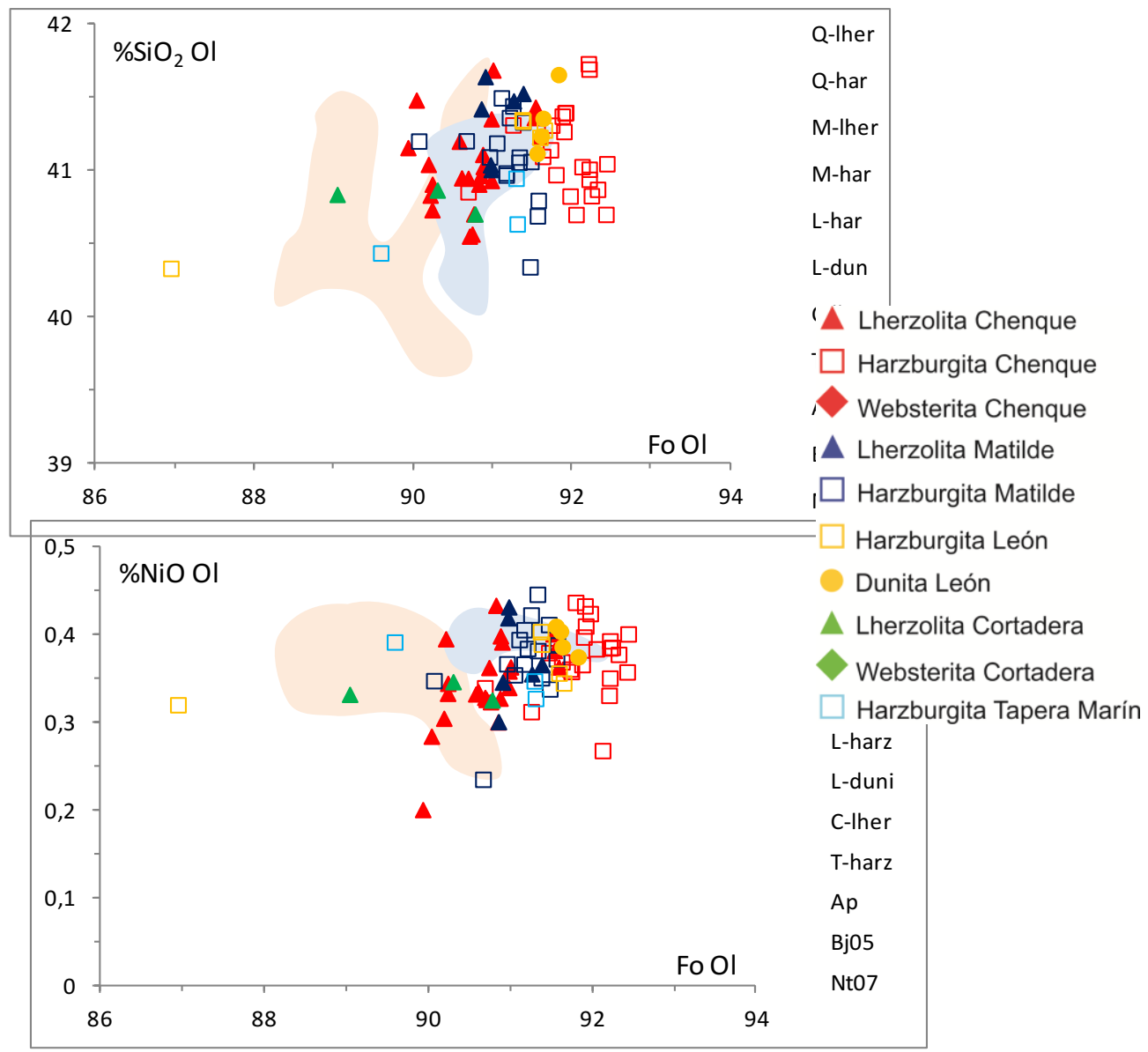

Figura 8.2. Variación del contenido $\mathrm{SiO}_{2}$ y NiO versus el valor de Fo de olivinos de Paso de Indios. 


\subsubsection{Clinopiroxeno}

En los clinopiroxenos de los cerros Chenque, Matilde y León el contenido de $\mathrm{Na}_{2} \mathrm{O}$ se incrementa mientras que el contenido de $\mathrm{CaO}$ decrece con el incremento del contenido de $\mathrm{Al}_{2} \mathrm{O}_{3}$. En el resto de las localidades no se alcanza a verificar dicha correlación por la escasa cantidad de clinopiroxenos analizados (Figura 8.3). Los clinopiroxenos de los cerros Chenque y León muestran un rango de variación de $\mathrm{Na}_{2} \mathrm{O}$ y $\mathrm{CaO}$ similar al del resto de Patagonia, varias muestras del cerro Matilde (al igual que las de Tapera Marín) presentan bajos contenidos de $\mathrm{Al}_{2} \mathrm{O}_{3}$ para el valor de $\mathrm{Na}_{2} \mathrm{O}$ y las de Cortadera concentraciones de $\mathrm{Al}_{2} \mathrm{O}_{3}$ algo más altas para el valor de $\mathrm{Na}_{2} \mathrm{O}$.

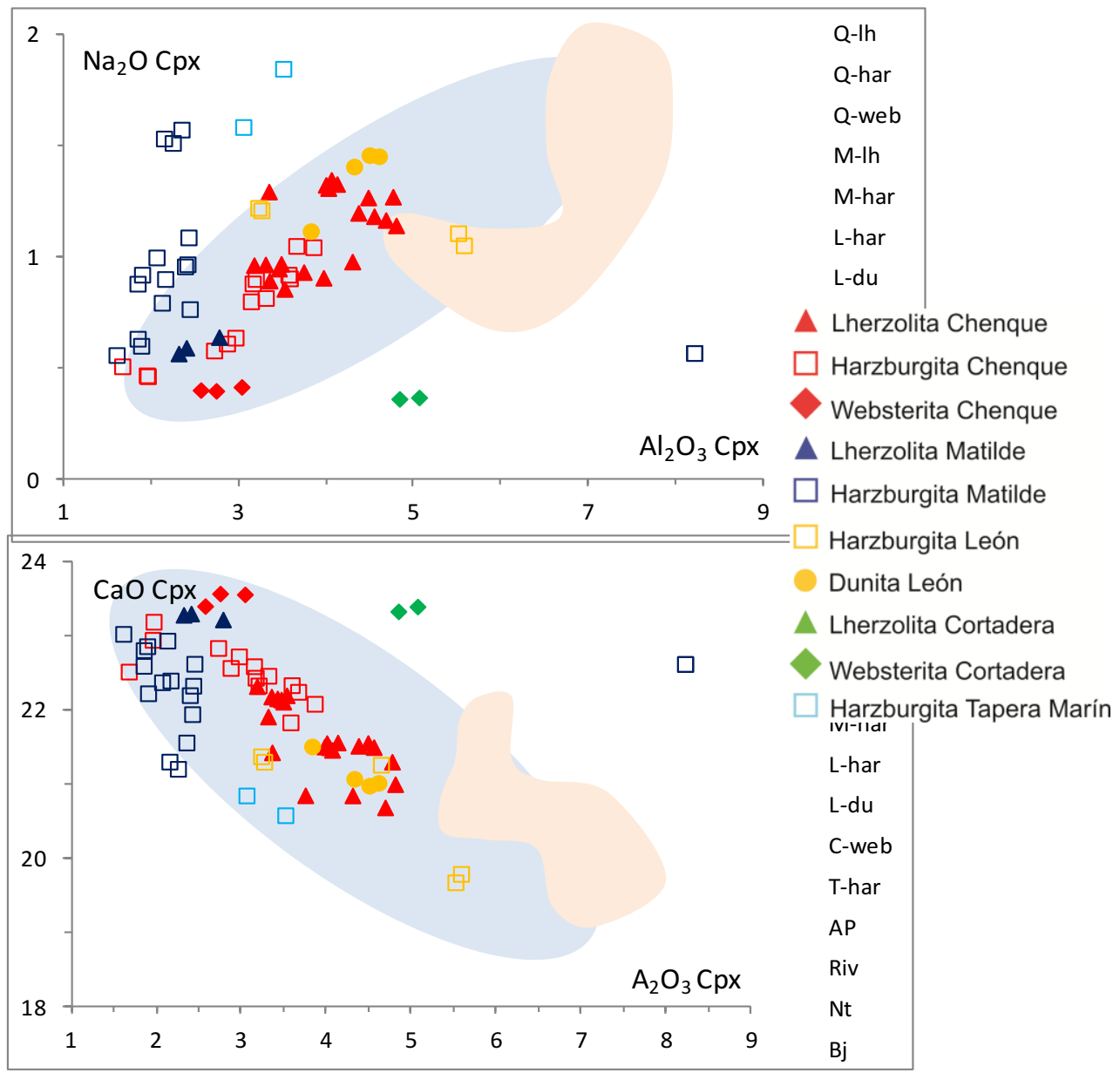

Figura 8.3. Trenes de variación de $\mathrm{Na}_{2} \mathrm{O}$ y $\mathrm{CaO}$ respecto del $\mathrm{Al}_{2} \mathrm{O}_{3}$ en clinopiroxenos. La muestra que se desvía es pobre en $\mathrm{SiO}_{2}$

\subsubsection{Ortopiroxeno}

En los ortopiroxenos, si se observan todos los datos en conjunto, y en particular los de los cerros Chenque y Matilde, el contenido de $\mathrm{Al}_{2} \mathrm{O}_{3}$ presenta correlación negativa con el MgO (Figura 8.4). Los ortopiroxenos de las harzburgitas de cerro León y los de Cortadera tienen valores de $\mathrm{MgO}$ bajos diferenciándose del valor promedio de las muestras de Patagonia y Agua Poca. 


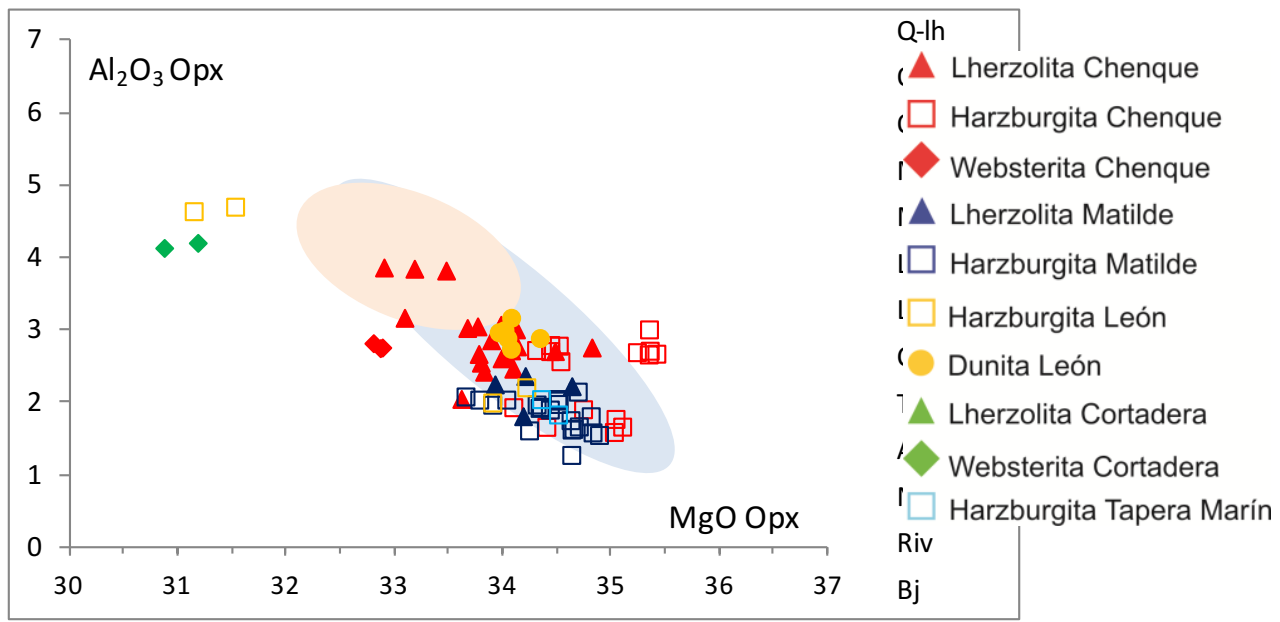

Figura 8.4. Diagrama de variación de $\mathrm{Al}_{2} \mathrm{O}_{3}$ vs $\mathrm{MgO}$ en ortopiroxenos

\subsubsection{Espinelas}

Las espinelas de Cerro Chenque presentan correlación negativa del parámetro \#Mg respecto del parámetro \#Cr. Si bien las espinelas de las demás localidades no muestran una correlación definida, si hay una correlación negativa considerando las muestras en conjunto. Además espinelas se ubican dentro o muy próximas al campo de las espinelas de Patagonia (Figura 8.5).
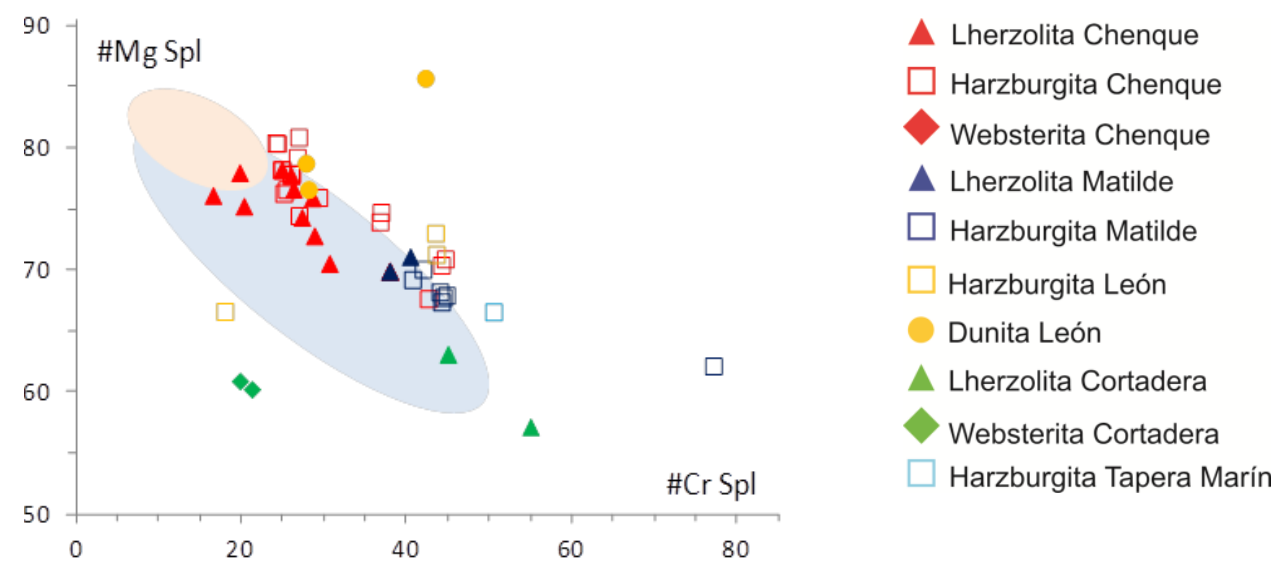

Figura 8.5. Diagrama de correlación \#Cr vs. \#Mg en espinelas de Paso de Indios.

Las espinelas y olivinos se ubican dentro del ámbito de variación de los olivinos y espinelas del manto (olivine-spinel mantle array, OSMA) propuesto por Arai (1994). En este diagrama, todas las muestras de Matilde y Cortadera, algunas harzburgitas de cerro Chenque y las harzburgitas de León y Tapera Marín se ubican próximas a las muestras más refractarias de Patagonia. Por otra parte, se distingue un grupo de muestras de cerro León y algunos otros xenolitos de cerro Chenque con valores de $\# \mathrm{Cr}<30$ que se localizan junto a muestras poco empobrecidas de Patagonia (Figura 8.6). 
Los diagramas de variación expuestos dejan en evidencia que los xenolitos de Cerro Matilde tienen los piroxenos con los más bajos contenidos de $\mathrm{Al} 2 \mathrm{O} 3$ y las espinelas con los contenidos más altos de \#Cr de este muestreo.

Los valores de $\mathrm{CaO}, \mathrm{Na} 2 \mathrm{O}$ y $\mathrm{A} 12 \mathrm{O} 3$ en clinopiroxenos y \#Mg y \#Cr en espinelas, muestran un rango de variación comparable con valores previos de peridotitas de Paso de Indios (Bjerg et al. 2005 y Rivalenti et al. 2004a) y están significativamente empobrecidos comparados con el manto fértil debajo de la región de Agua Poca (xenolitos del grupo 1 de Bertotto et al. 2013) y de cerro de los Chenques (muestra CD61 de Rivalenti et al. 2004, 2007), las cuales son de las pocas muestras de lherzolitas en facies de espinela fértiles encontradas en el retroarco extraandino argentino (Rivalenti et al. 2007, Bertotto et al. 2013).
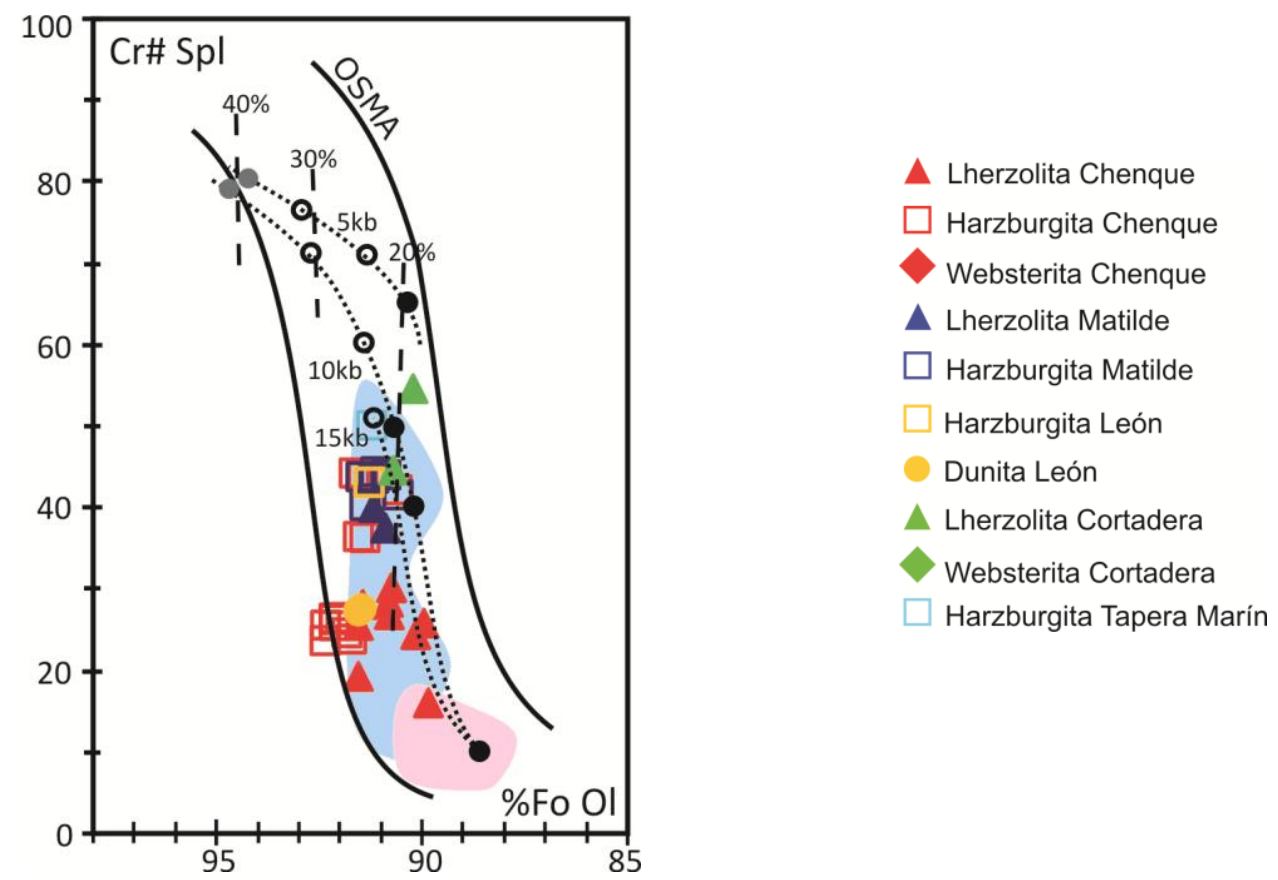

Figura 8.6. Diagrama de variación de \#Cr de la espinela vs. el contenido de Fo del olivino. Las líneas de puntos representan trenes residuales de fusión. Círculos negros completos: lherzolitas, círculos negros vacios: harzburgitas y círculos completos grises: dunitas. OSMA: Olivine-Spinel Mantle Array (Arai 1994).

Las relaciones texturales opx-cpx y la correlación positiva de los valores de \#Mg, $\mathrm{Al}_{2} \mathrm{O}_{3}$ (Figura 8.7) y $\mathrm{TiO}_{2}$ sugieren que esas dos fases se encuentran próximas al equilibrio químico. De manera similar, las relaciones texturales sp-ol y la correlación negativa de su \#Mg sugieren equilibrio químico entre estas dos fases en litologías que experimentan diferentes grados de fusión parcial. Sin embargo, las harzburgitas de cerro Chenque forman una tendencia, en la cual los \#Mg correlacionan positivamente (Figura $8.8)$. 


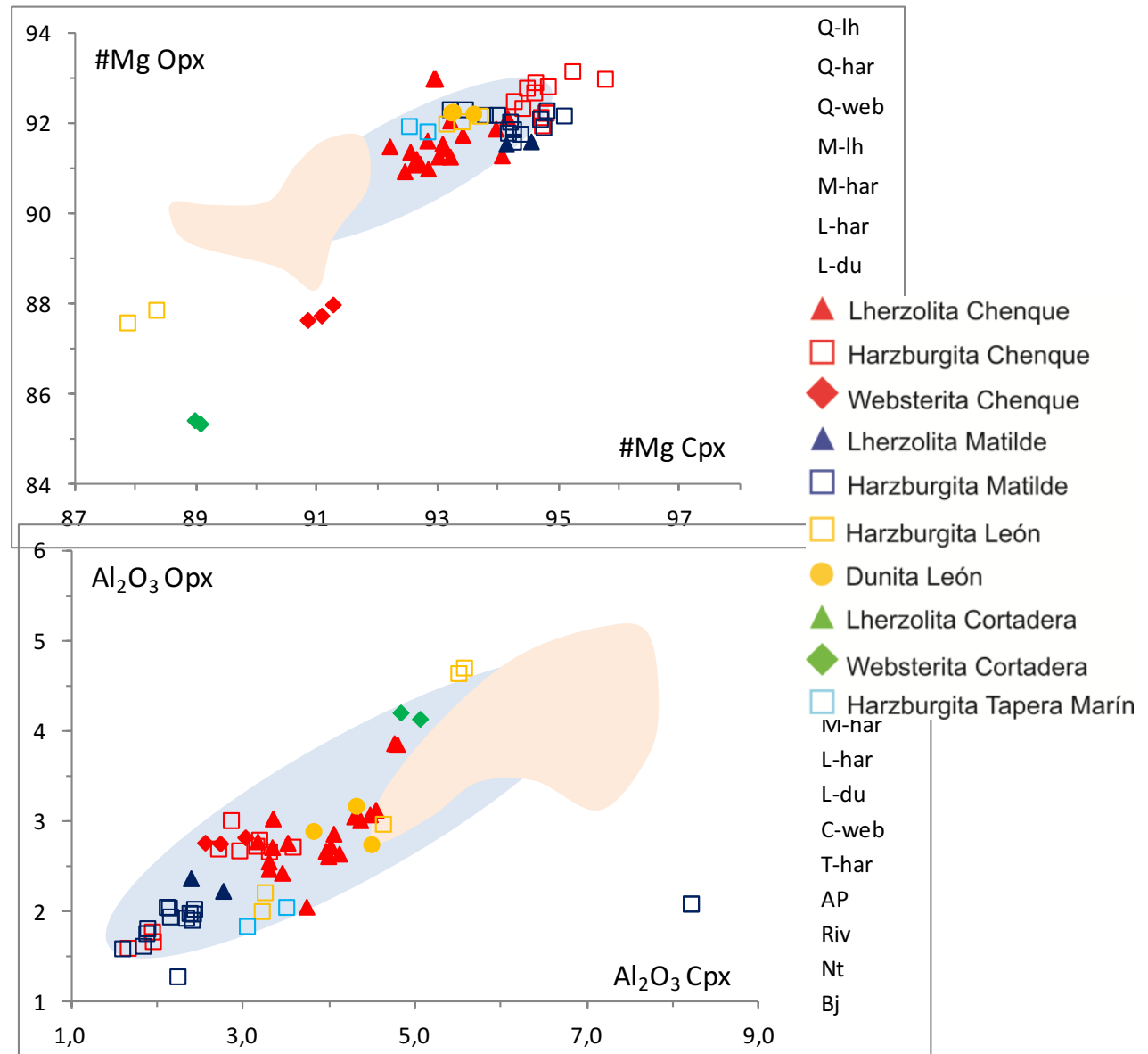

Figura 8.7. Diagrama de variación entre opx y cpx, respecto a sus \#Mg y al contenido de $\mathrm{Al}_{2} \mathrm{O}_{3}$.

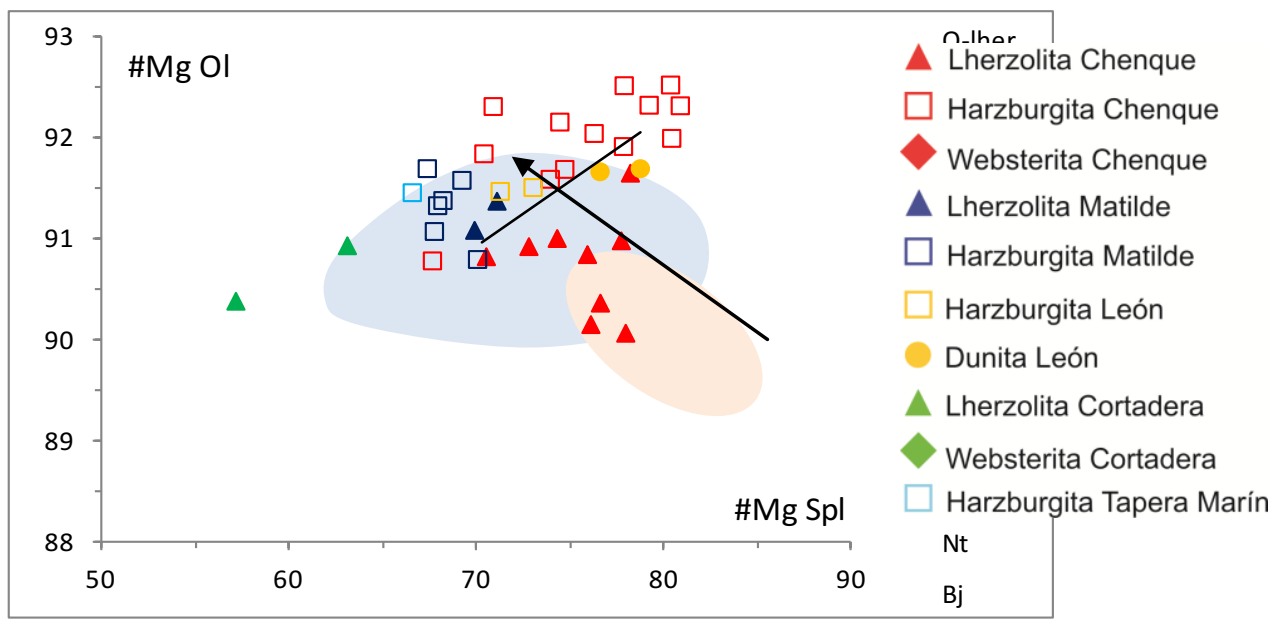

Figura 8.8. Diagrama de variación entre \#Mg del olivino vs. \#Mg de la espinela. La flecha indica la evolución de olivinos y espinelas por fusión parcial. La línea negra contínua muestra un tren local para harzburgitas de cerro Chenque.

\subsection{GEOQUÍMICA MINERAL DE ELEMENTOS TRAZA}

Los análisis de elementos traza realizados sobre clinopiroxenos de los xenolitos de los cerros Chenque, Matilde y León se presentan en la Tabla 12.3. Los valores fueron normalizados a condrito C1 de Anders y Grevesse (1989) para representar los 
correspondientes patrones, en especial los de elementos traza extendidos y las tierras raras (REE) y el ítrio (Y).

Los patrones de elementos traza muestran un amplio rango de variación (Figura 8.9). Al analizarlos, se los separó, de forma general, en dos grupos; por un lado aquellos patrones que muestran características típicas de arco volcánico, como ser anomalías negativas de Nb-Ta, Zr-Hf y Ti (MH, M55, M67, M79, Q101, M69, M57, Q77, Q80, Q108, M53) (Figura 8.10). Un segundo grupo presenta características no tan similares a típicos arcos volcánicos, donde las muestran carecen de alguno de esos rasgos o, los presentan menos marcados (Q65, QEUG, L82, Q105, Q107, Q109) (Figura 8.11).

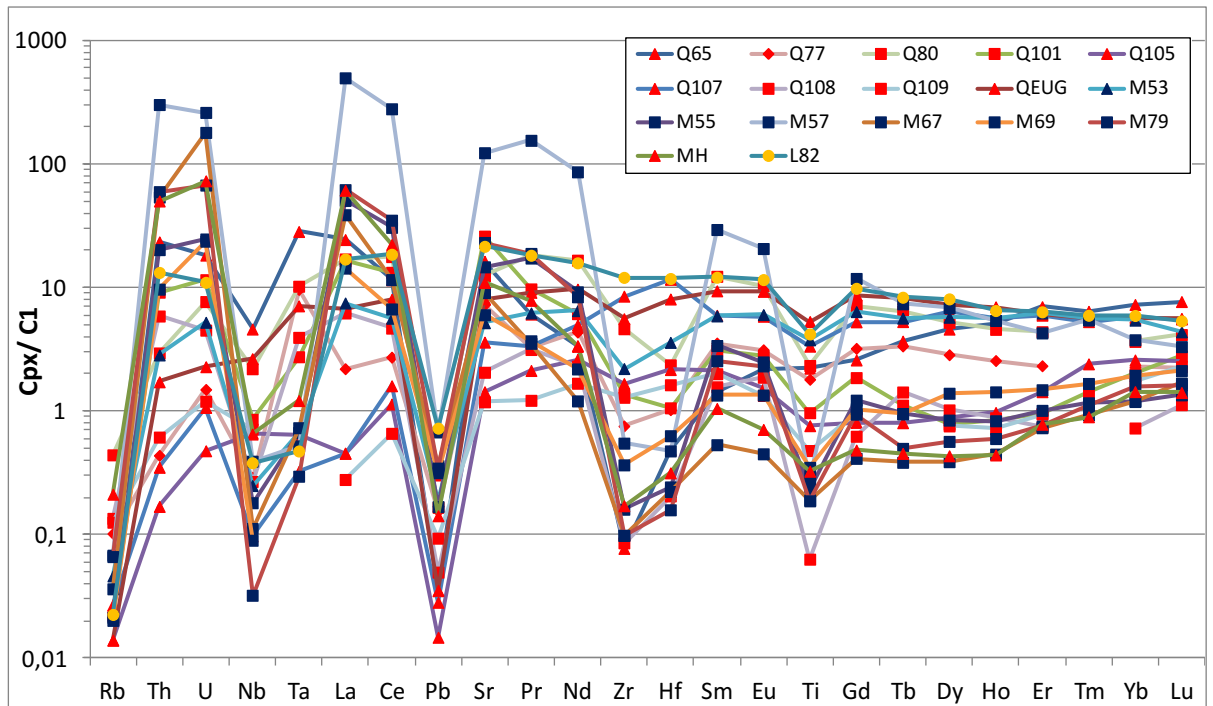

Figura 8.9. Patrones de elementos traza extendidos de clinopiroxenos de xenolitos de Paso de Indios. Q: Chenque; M: Matilde; L: León. Triángulo: lherzolita; cuadrado: harzburgita, círculo: dunita y rombo: websterita.

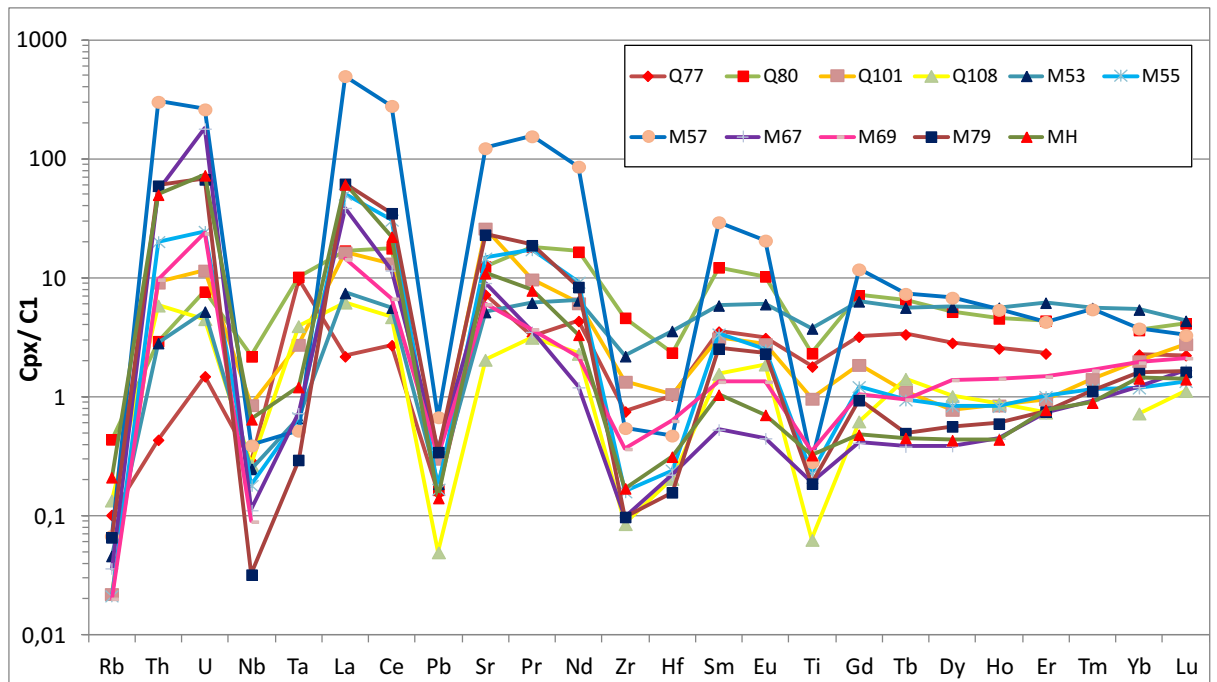

Figura 8.10. Patrones de elementos traza extendidos de clinopiroxenos de xenolitos con características de arco volcánico. Q: Chenque; M: Matilde; L: León. Triángulo: lherzolita; cuadrado: harzburgita, círculo: dunita y rombo: websterita. 


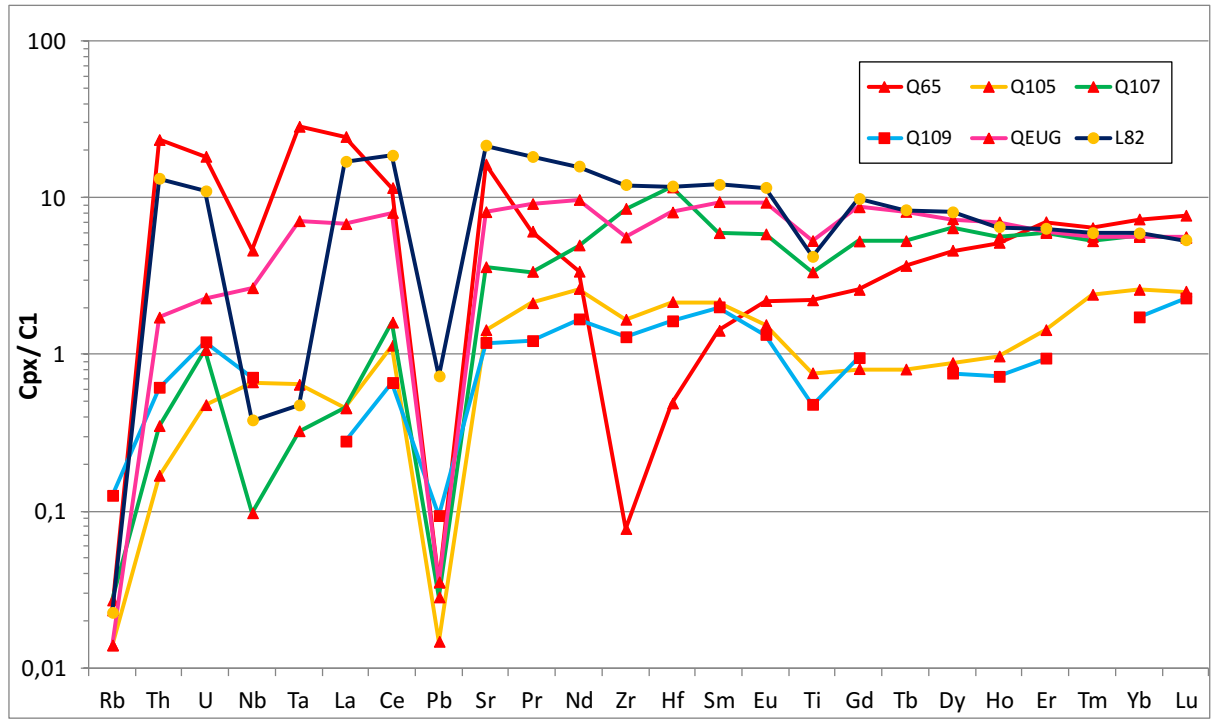

Figura 8.11. Patrones de elementos traza extendidos de clinopiroxenos de xenolitos sin características claras de arco volcánico. Q: Chenque; M: Matilde; L: León. Triángulo: lherzolita; cuadrado: harzburgita, círculo: dunita y rombo: websterita.

En la Figura 8.12 se grafican todos los patrones de REE en forma conjunta, para tener una visión general de su variación, en los gráficos siguientes se presentan los mismos patrones reagrupados según su comportamiento. En todos estos gráficos también se incluyeron aquellos valores de REE de rocas de Paso de Indios de Rivalenti et al. (2004a) y Barbieri et al. (1999). Estas muestras son: M-PI14, M-PI16, M-PI18, M-PI23, M-PI29, Q-PI41, Q-PI46, Q-PI48 y Q-PI52. Además, en los gráficos con patrones reagrupados se incluyó (en línea continua) el patrón correspondiente a un cpx del manto primitivo de Sun y McDonough (1989) y los patrones teóricos (líneas negras punteadas) de este cpx luego de 1, 5, 10, 15, y 20\% de empobrecimiento por fusión parcial no modal.

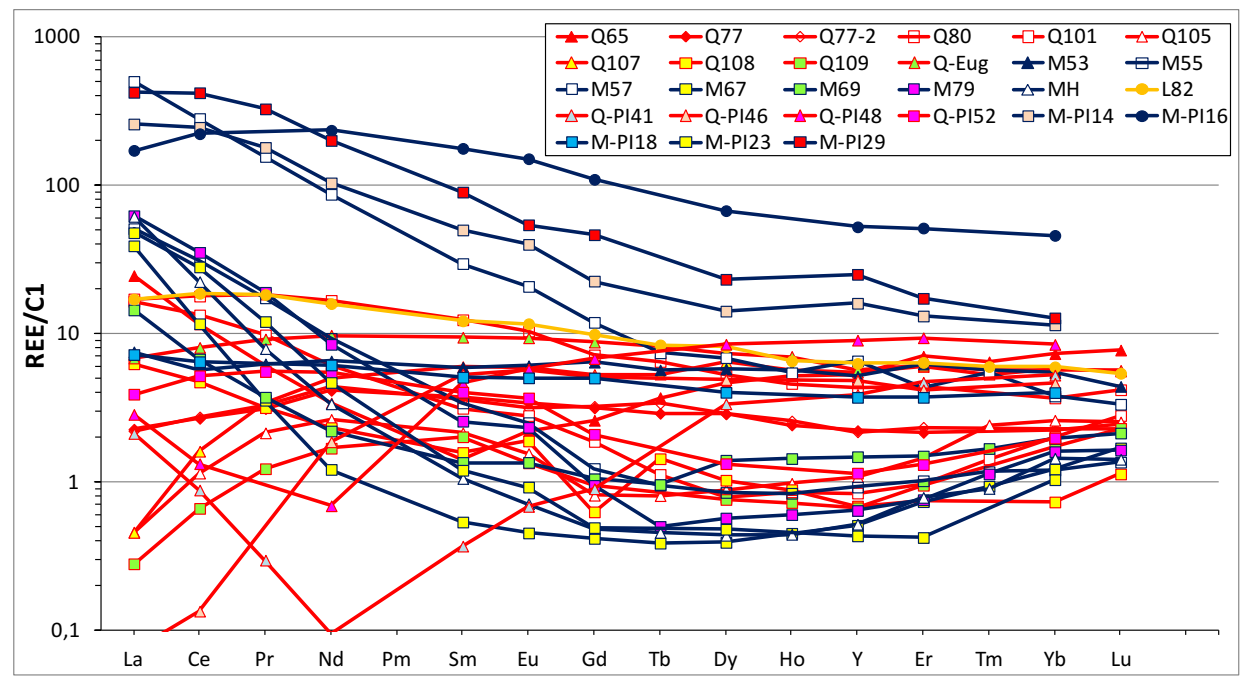

Figura 8.12. Patrones de REE normalizados a condrito C1 de Anders y Grevesse (1989). 
Al reagrupar los patrones podemos diferenciar los siguientes grupos:

Grupo I. Patrones empobrecidos en LREE. Las lherzolitas Q107 y Q-PI46 de Cerro Chenque presentan patrones de MREE-HREE planos y empobrecidos en LREE. Desde Gd a Lu siguen los patrones de empobrecimiento por fusión del MP de entre 10 y $12 \%$ desde el Eu hacia los LREE se desvían (por leve enriquecimiento) de los patrones modelo de fusión (Figura 8.13).

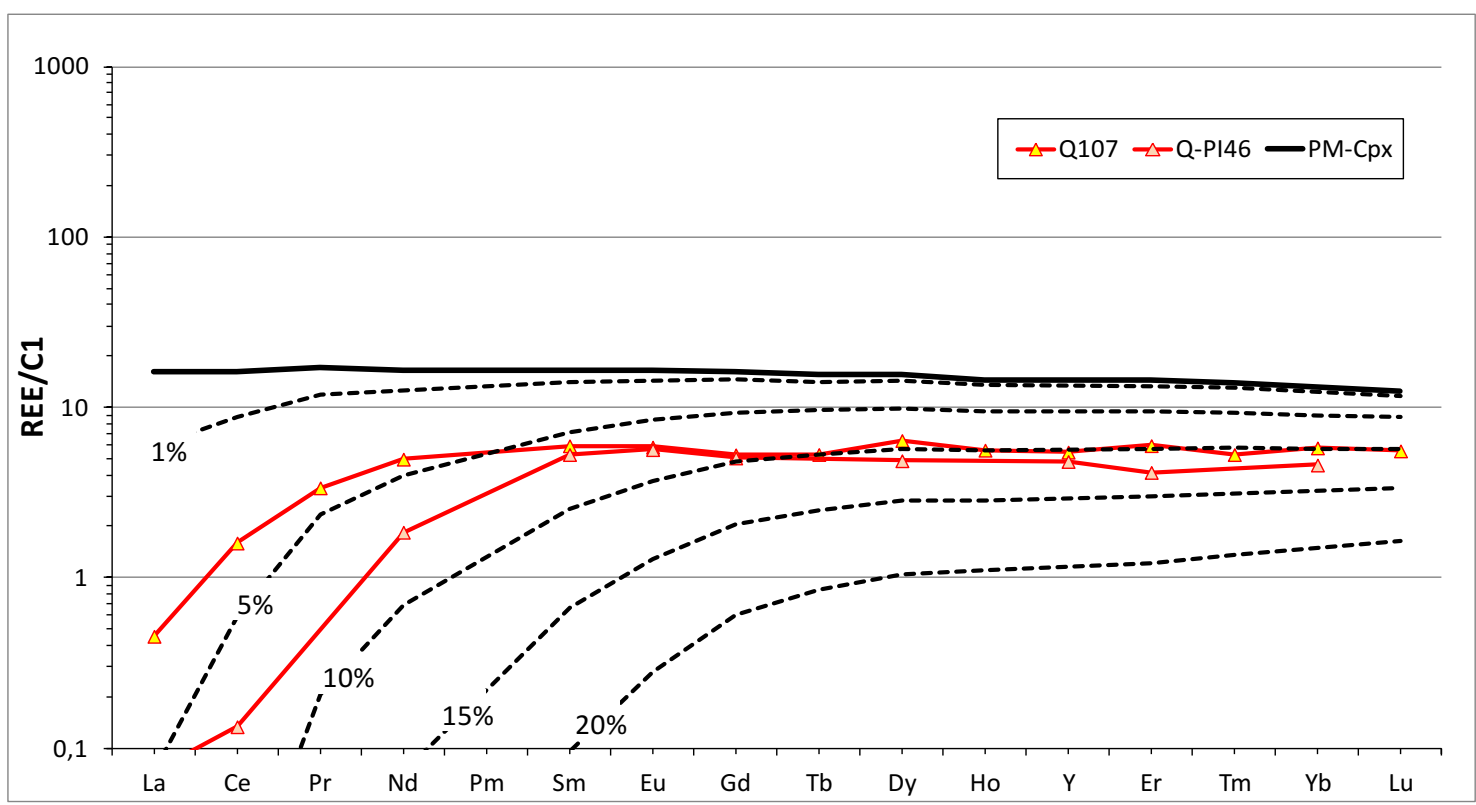

Figura 8.13. Patrones de REE con empobrecimientos en LREE.

Grupo II. Patrones Planos. Existen una serie de muestras de los cerros Chenque, Matilde y León que presentan patrones de REE relativamente plano $(\mathrm{La} / \mathrm{Yb}$ 1,01 a 1,88), paralelos entre sí. Los HREE siguen comportamientos propios de empobrecimiento por fusión parcial (entre 10 y 17\%), en cambio los MREE y LREE se alejan de estos patrones modelo debido a enriquecimiento (Figura 8.14).

Grupo III: Patrones enriquecidos en elementos de tierras raras livianas (LREE). Los patrones de REE correspondientes a clinopiroxenos de 9 muestras de Cerro Matilde y 2 de Cerro Chenque, están enriquecidos en LREE respecto del C1. Las tierras raras medias (MREE) y pesadas (HREE), tienen patrones que se corresponden a empobrecimientos variables de 0 a $>20 \%$ de fusión. Excepto la lherzolita $\mathrm{MH}$, todas las muestras enriquecidas en LREE son harzburgitas (Figura 8.15). 


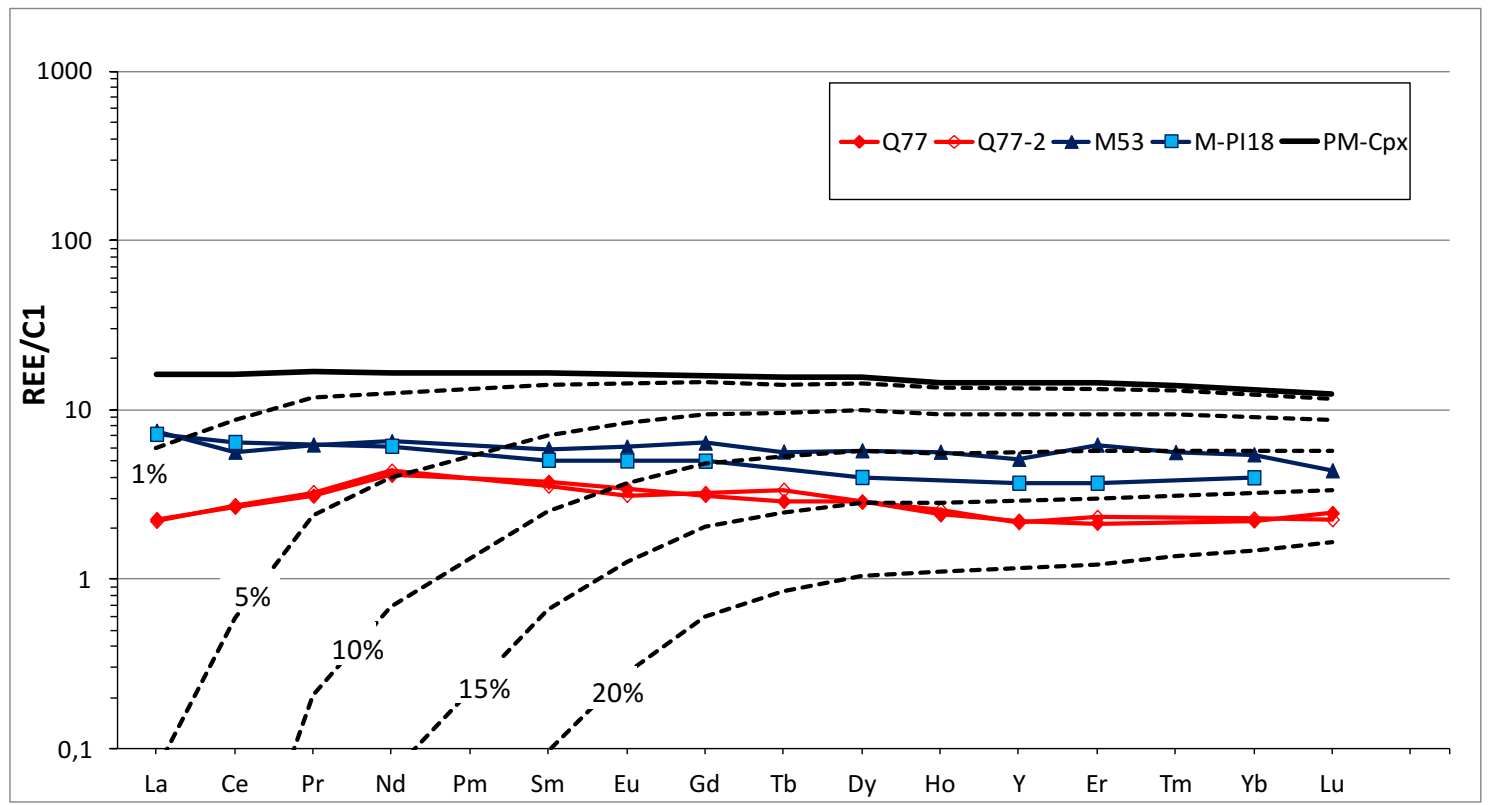

Figura 8.14. Patrones de REE con disposición plana.

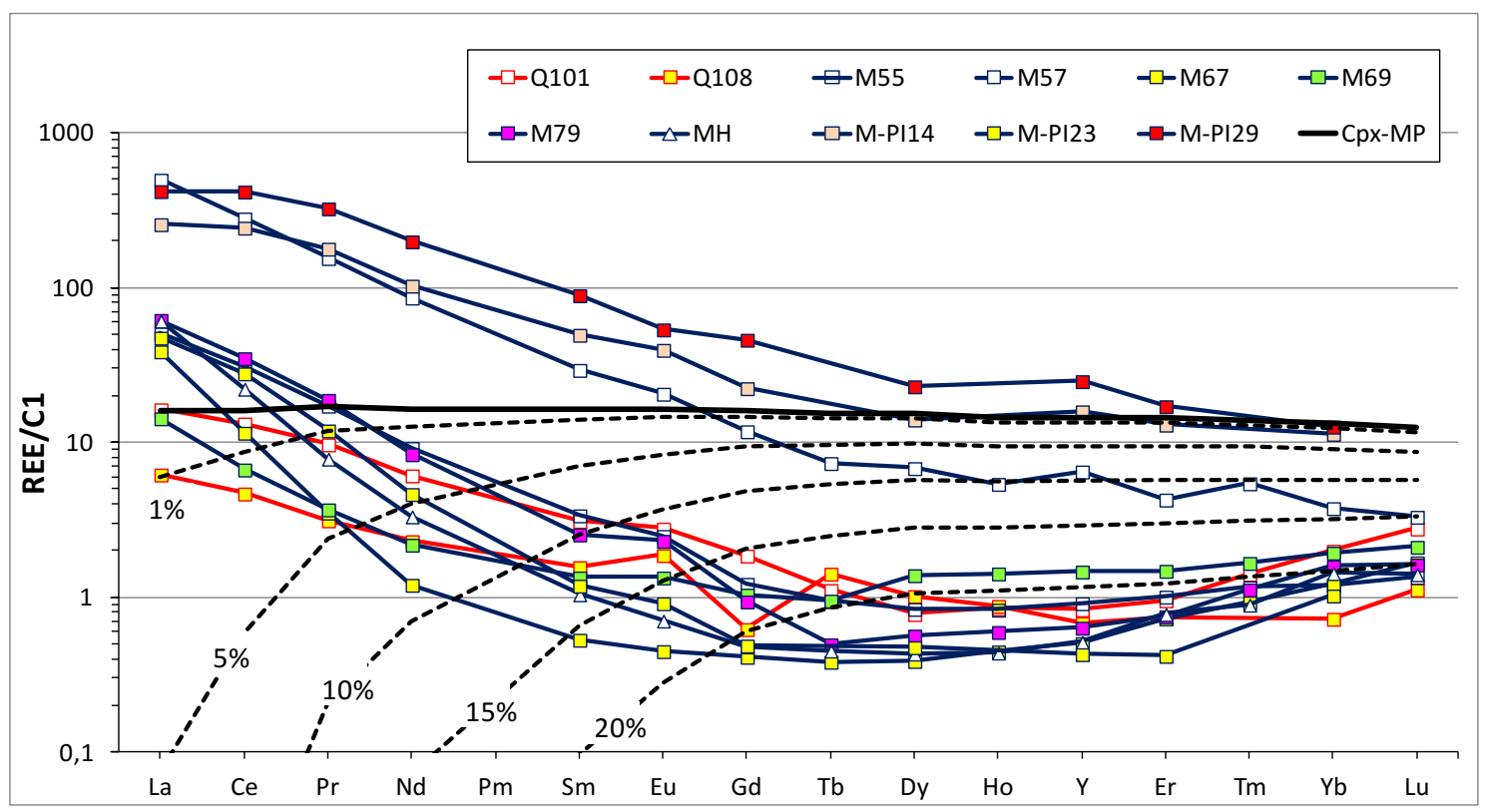

Figura 8.15. Patrones de REE enriquecidos en elementos de tierras raras livianas.

Grupo IV: Patrones de REE en forma de "U". Varias de las mismas muestras del grupo anterior (excepto Q108, M57, M-PI14 y M-PI29) muestran clinopiroxenos con patrones de REE en forma de "U". Las mismas presentan fraccionamiento muy fuerte de LREE, con enriquecimiento en La de hasta $62 \mathrm{xC}$, exhibiendo además un patrón relativamente plano en los elementos MREE (ej. Tb $=0,4-1,1 \times C 1$ ) y un leve enriquecimiento en los HREE $(\mathrm{Lu}=1,4-2,8)$ (Figura 8.16). El contenido de HREE es consistente con $\approx 16-23 \%$ de fusión parcial de un manto primitivo en facies de espinela. 
Grupo V. Patrones en forma de "V". Las lherzolitas de Cerro Chenque Q65, Q-PI41 y Q-PI48 muestran patrones con un mínimo en Sm o Nd y fuertes enriquecimientos hacia $\mathrm{La}(\mathrm{La} / \mathrm{Sm}-\mathrm{Nd}=4,1-23,4)$ y Lu (Figura 8.17). Los enriquecimientos hacia los HREE se corresponden con extracción de fundidos de entre 5 y $11 \%$.

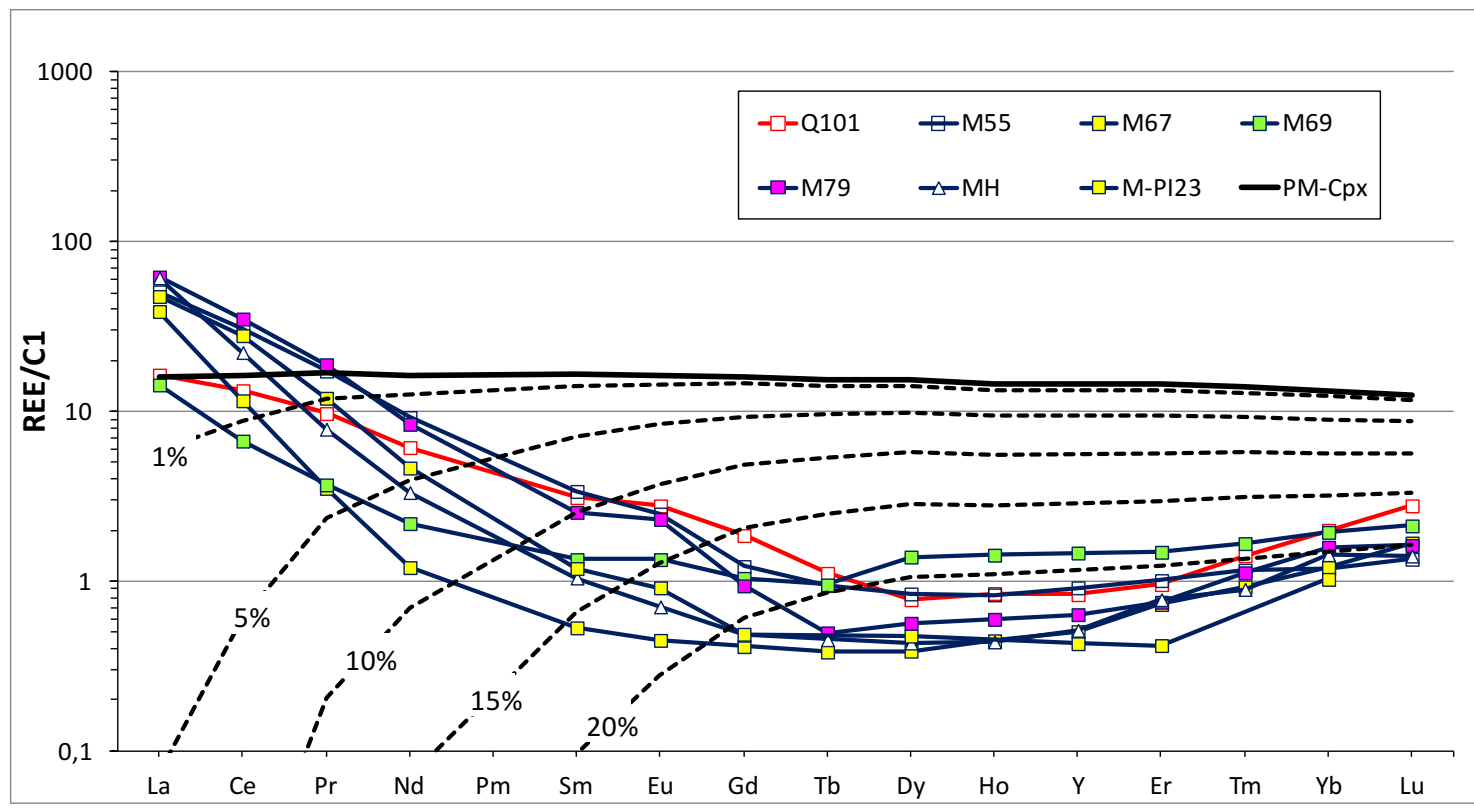

Figura 8.16. Patrones de REE en forma de "U".

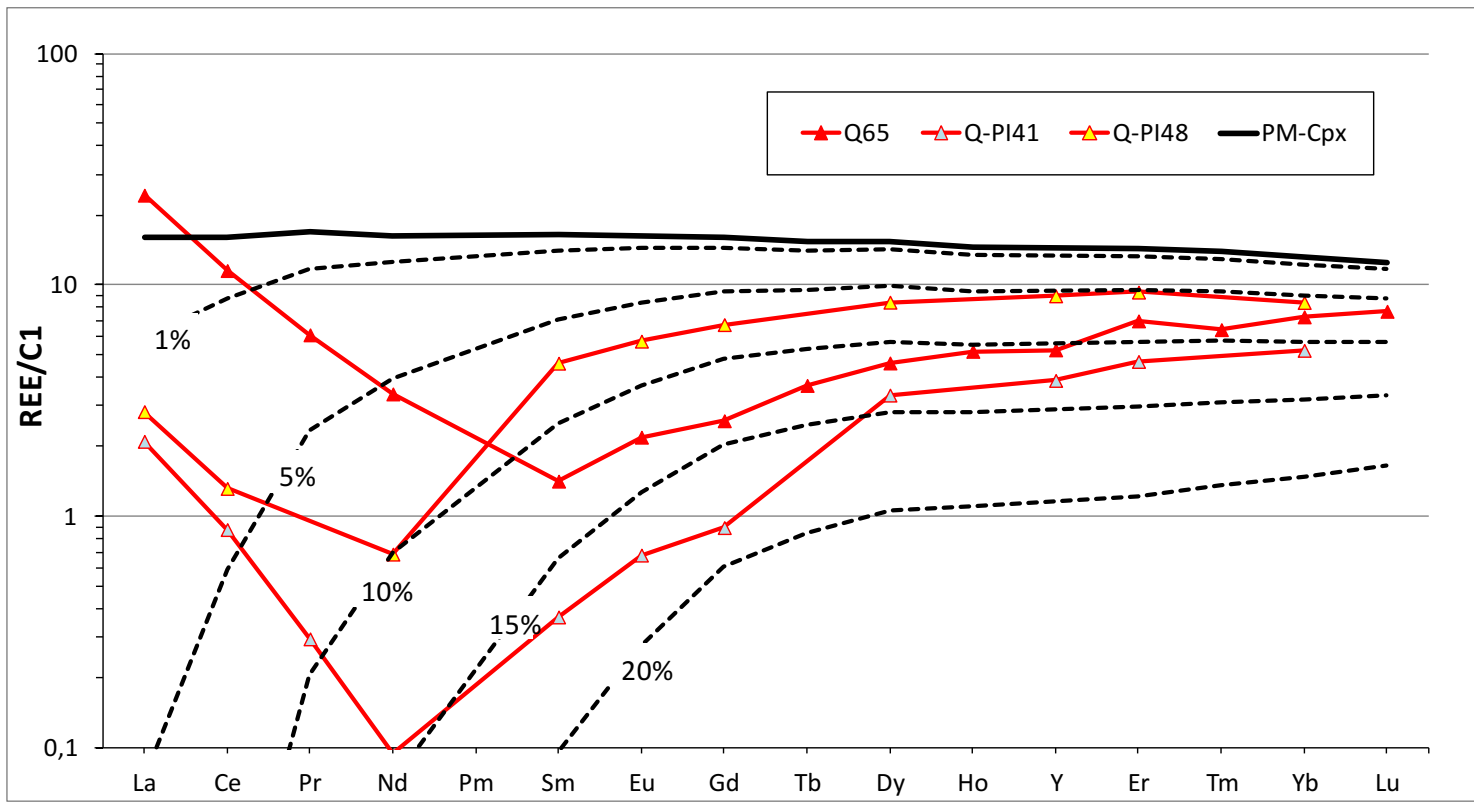

Figura 8.17. Patroenes de REE en forma de "V".

Grupo VI. Patrones sinusoidales. Cinco clinopiroxenos de 2 dunitas (M-PI16 y L82), 2 lherzolitas (Q105 y Q-Eug) y una harzburgita (Q-PI52) presentan este tipo de patrones con relaciones $\mathrm{La} / \mathrm{Ce}$ de 0,40 a 0,85. La dunita de Cerro Matilde M-PI16 es la más enriquecida, con valores de REE entre 45 y 234 veces el C1 (Figura 8.18). E resto de los 
clinopiroxenos exhiben fraccionamientos de HREE propios de patrones de manto primitivo empobrecido por entre un 5 y $20 \%$ de fusión.

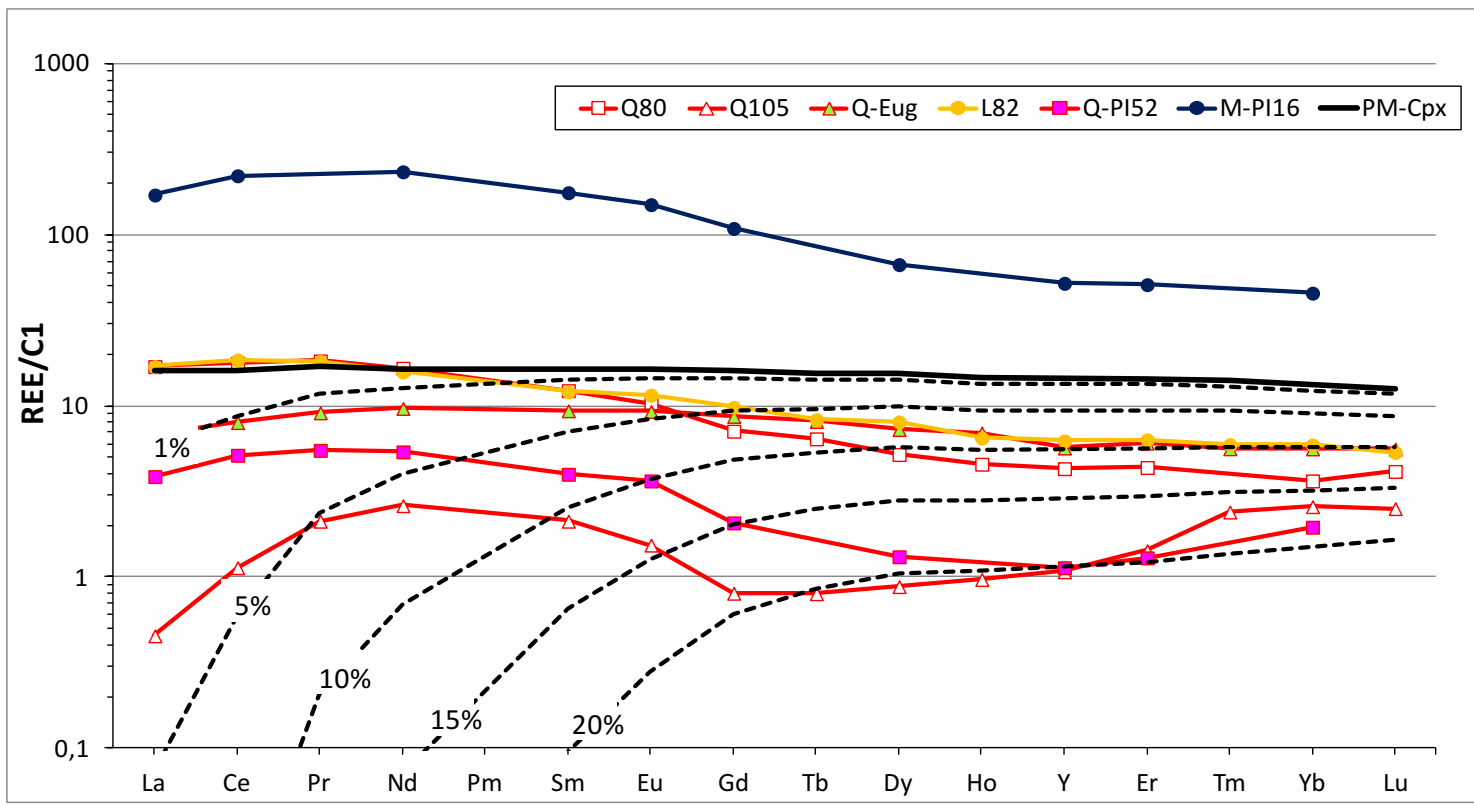

Figura 8.18. Patrones de REE con disposición sinusoidal. 


\section{9- DISCUSIÓN}




\subsection{REEMPLAZO MINERAL Y REACCIONES BASALTO-XENOLITO}

Los xenolitos ultramáficos de Paso de Indios presentan diferentes evidencias de reemplazo mineral y reacciones que están vinculadas a la interacción de estas rocas mantélicas con fundidos, tanto circulantes en el manto litosférico, como aquellos fundidos basálticos hospedantes que permitieron su ascenso hasta la superficie. Algunas de las muestras analizadas (ej. Q1-a y Q132, entre otras) presentan evidencias petrográficas de más de un proceso de reemplazo a nivel del manto, lo que indica una superposición de al menos dos eventos metasomáticos, con la eventual modificación de las características prístinas del manto muestreado.

La presencia de ortopiroxenos con morfologías vermiculares dentro o alrededor de grandes cristales de ol son microtexturas que indican corrosión y disolución de olivinos del manto por reacción con líquidos circulantes saturados en sílice y la cristalización de ortopiroxenos magmáticos (Piccardo et al. 2004). Estos líquidos ricos en sílice también son los responsables del sobrecrecimiento magmático, de ortopiroxenos con lamelas de exsolución e incipiente deformación (kink bands), evidenciado por el desarrollo de una apófisis de ortopiroxeno límpido sin exsoluciones (ej. muestra Q117 de Cerro Chenque).

Por su parte, la disolución de ortopiroxeno y cristalización de nuevos olivinos estaría asociada a eventos de fusión parcial de peridotitas en condiciones de baja presión (facies de espinela), y a la interacción de la columna de rocas ultramáficas del manto con fundidos percolantes subsaturados en sílice (Hirose y Kushiro 1993, Niu 1997, Kelemen et al. 1995). Existen casos extremos (documentados por petrografía y afloramientos), en los cuales los cristales de olivino ocupan un gran volumen de los engolfamientos de piroxenos; los olivinos se presentan con formas vermiculares y conectados entre sí, generando canales de dunita (ej. Alpes, Piccardo et al. 2004).

El intercrecimiento simplectítico de cristales de espinela y ortopiroxeno \pm clinopiroxeno, como se observa en tres muestras de harzburgitas de Cerro Chenque (Q11, Q57 y Q94), representaría el producto de la descomposición de granates al pasar a condiciones de facies de espinela (Smith 1977, Piccardo et al. 2004, entre otros). Esta textura ha sido descripta previamente en xenolitos de Laguna Fría y Prahuaniyeu en Patagonia norte por Bjerg et al. (2005).

Por otro lado, la interacción roca/fundido puede generarse directamente por el contacto del basalto hospedante con los cristales que componen los xenolitos o, 
mediante el ingreso de venillas de este basalto al interior de los mismos. Según Fisk (1986), la reacción del fundido basáltico al contacto con el ortopiroxeno de los nódulos ultramáficos, genera disolución de los ortopiroxenos y crecimiento de olivinos, dejando como residuo un fundido de composición andesítica en la zona del contacto. Los clinopiroxenos con coronas spongy hallados en varias muestras (Figura 9.1) es muy probable que se hayan generado a partir de la interacción con venillas de basalto hospedante, tal lo observado en la petrografía y en trabajos experimentales de interacción de harzburgitas y fundidos alcalinos subsaturados en sílice (Klügel 1998).

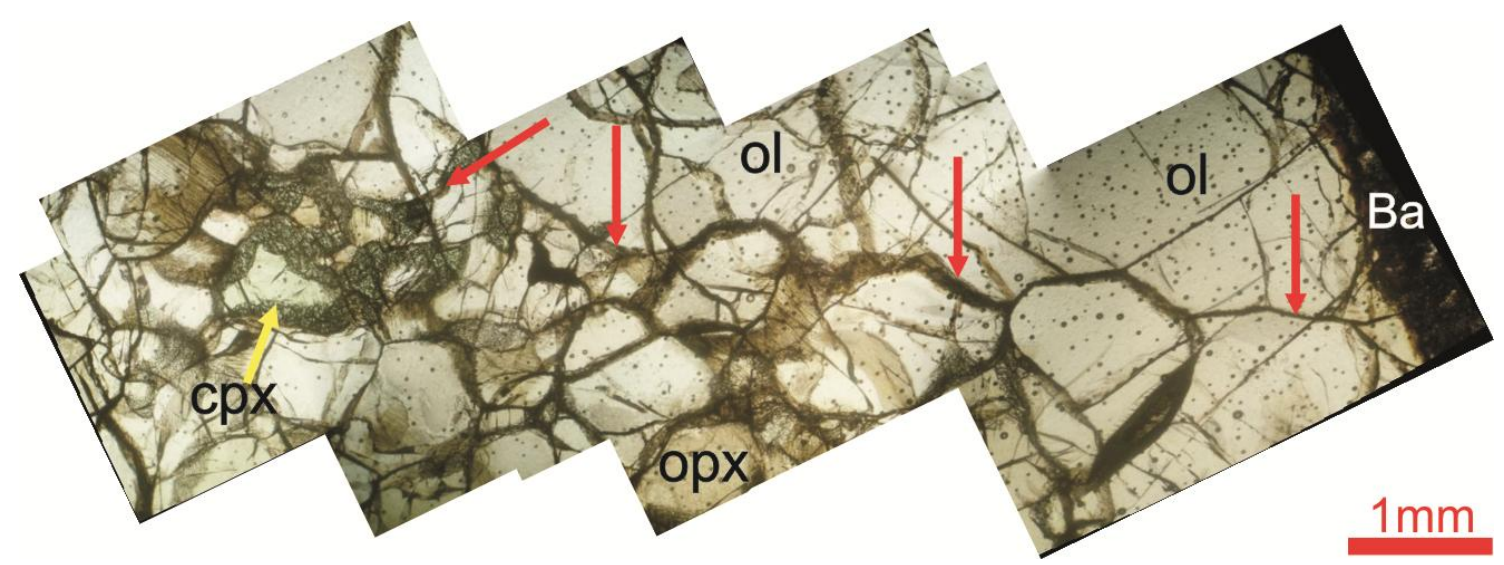

Figura 9.1. Fotomontaje de lherzolita Q96 donde se aprecia un cpx con corona de reacción conectado por una red de venilas con el basalto hospedante (b). Las flechas rojas indican el recorrido de la venilla principal de un xenolito. Imagen tomada de Ponce et al. (2015).

\subsection{ESTIMACIONES DE TEMPERATURA Y PRESIÓN}

Las temperaturas de equilibrio estimadas en xenolitos de Paso de Indios están basadas en los análisis de elementos mayores de núcleos de clinopiroxeno y ortopiroxeno. Las temperaturas estimadas en base al termómetro de Brey y Köhler (1990) basado en el intercambio de hierro, calcio y sodio entre ortopiroxeno y clinopiroxeno a una presión de 1,5 GPa dieron los siguientes resultados. En cerro Chenque, la temperatura promedio es de $973{ }^{\circ} \mathrm{C}$ y los valores varían entre $844{ }^{\circ} \mathrm{C}$ (websterita Q77) y $1087{ }^{\circ} \mathrm{C}$ (lherzolita Q96). En cerro Matilde el valor promedio es de $919{ }^{\circ} \mathrm{C}$, con valores entre $876{ }^{\circ} \mathrm{C}$ (lherzolita M53) y $950{ }^{\circ} \mathrm{C}$ (harzburgita M79). Las temperaturas estimadas en Cerro León varían de $919{ }^{\circ} \mathrm{C}$ (harzburgita L82a) a $1177{ }^{\circ} \mathrm{C}$ (harzburgita L37), con un valor promedio de $1033{ }^{\circ} \mathrm{C}$; mientras que para cerro Cortadera se obtuvo un valor de $867{ }^{\circ} \mathrm{C}$ (websterita C30a) y en Tapera Marín un único valor de $993{ }^{\circ} \mathrm{C}$ en una lherzolita (T18).

Comparado con las temperaturas previas estimadas para peridotitas de espinela de Patagonia (Bjerg et al. 2005, 2009, Rivalenti et al. 2004 y Bertotto, et al. 2013), 
utilizando el mismo geotermómetro $\left(\mathrm{T}^{\circ}{ }_{\mathrm{BK} 2 \mathrm{px}}\right.$, Brey y Köhler (1990)), las temperaturas de las muestras de Paso de Indios aquí estudiadas son relativamente más bajas (Figura 9.2). Temperaturas menores a $800{ }^{\circ} \mathrm{C}$ fueron obtenidas solamente en peridotitas del manto de Tres Lagos (Ntaflos et al. 2007). Aunque las peridotitas de Tres Lagos muestran una temperatura máxima de $1040{ }^{\circ} \mathrm{C}$, Bjerg et al. (2005) indicaron una $\mathrm{T}^{\circ}{ }_{\mathrm{BK} 2 \mathrm{px}}$ de $1030{ }^{\circ} \mathrm{C}$ para una harzburgita de Paso de Indios (CH16-A), mientras que Rivalenti et al. (2004) estimaron un intervalo de $\mathrm{T}^{\circ}{ }_{\mathrm{BK} 2 \mathrm{px}}$ de 839 a $1197{ }^{\circ} \mathrm{C}$ para 8 xenolitos peridotíticos de esta área.

Taylor (1998) determinó que el geotermómetro de 2 piroxenos de Brey y Köhler (1990) tiende a sobreestimar la temperatura en composiciones de peridotitas fértiles y propuso una nueva versión que incorpora correcciones para los contenidos de Ti, Fe y Na. De esta manera, Taylor (1998) demostró que su termómetro es aplicable a un rango más amplio de composiciones de peridotita fértiles durante un intervalo de presiones más amplio que los anteriores geotermómetros de dos piroxenos. Por su parte, Nimis y Grütter (2010) mostraron que el termómetro de dos piroxenos de Taylor (1998) y el termómetro de clinopiroxeno de Nimis y Taylor (2000) proporcionan las estimaciones de temperatura más fiables, porque estos reproducen las temperaturas de experimentos en una amplia variedad de sistemas peridotíticos naturales. El termómetro de Brey y Köhler (1990), basado en el contenido de Ca en Opx, muestra una buena concordancia con el de Taylor (1998) en el rango $1000-1400^{\circ} \mathrm{C}$, con un sesgo positivo a temperaturas más bajas (hasta $+90^{\circ} \mathrm{C}$ a $700^{\circ} \mathrm{C}$ ). Nimis y Grütter (2010) propusieron una corrección empírica para mejorar el termómetro de Ca en opx de Brey y Köhler (1990) y mostraron que la aplicación de la formulación corregida efectúa estimaciones similares a la de Taylor (1998). También, Nimis y Grüter (2010) demostraron que el termómetro de Brey y Köhler (1990) de dos piroxenos funciona bien en clinopiroxenos con contenidos de $\mathrm{Na} \sim 0,05$ átomos por fórmula de 6 oxígenos (apfu), pero muestra un sesgo positivo sistemático en relación con el de Taylor (1998) con el aumento del contenido de $\mathrm{Na}$ en clinopiroxeno $\left(+150^{\circ} \mathrm{C}\right.$ con un contenido de $\mathrm{Na}$ en $\mathrm{CPX}=0,25$ apfu). Los clinopiroxenos de Paso de Indios tienen entre 0,02 y 0,13 apfu, por lo tanto, se espera una sobreestimación de aproximadamente $50^{\circ} \mathrm{C}$ usando el termómetro de dos piroxenos de Brey y Köhler (1990) en relación al termómetro de Taylor (1998), de hecho las diferencias en el cálculo son de entre 18 y $80{ }^{\circ} \mathrm{C}$ (Tabla 9.1).

Las presiones de equilibrio de los xenolitos mantélicos de la región de Paso de Indios se estimaron en base al geobarómetro de clinopiroxeno de Mercier (1980) y varían entre 
1,6 y 2,2 GPa en Cerro Chenque; entre 1,7 y 2,0 GPa en Cerro Matilde; entre 1,7 y 2,1 GPa en Cerro León, mientras que para Cerro Cortadera y Tapera Marín se obtuvieron valores de 1,7 y 1,1 GPa respectivamente.

\begin{tabular}{|ccccccc|}
\hline Muestra & Roca & 2Px TY & 2Px ByK & Ca-ByK & Ca-NG & PMc \\
\hline Q58 & Harzburgita & 869 & 943 & 822 & 766 & 1,9 \\
Q65 & Lherzolita & 891 & 997 & 876 & 836 & 1,6 \\
Q77 & Websterita & 801 & 844 & 835 & 783 & 1,7 \\
Q80 & Harzburgita & 803 & & & & 1,7 \\
Q90 & Lherzolita & 945 & 1048 & 917 & 888 & 1,9 \\
Q96 & Lherzolita & 975 & 1087 & 983 & 968 & 1,9 \\
Q101 & Harzburgita & 846 & 937 & 868 & 826 & 1,8 \\
Q103 & Harzburgita & 941 & 986 & 916 & 886 & 2,0 \\
Q104 & Harzburgita & 883 & 993 & 888 & 851 & 1,8 \\
Q105 & Lherzolita & 880 & 968 & 879 & 840 & 1,7 \\
Q107 & Lherzolita & 863 & 973 & 893 & 858 & 1,6 \\
Q108 & Harzburgita & 939 & 947 & 857 & 812 & 2,2 \\
Q109 & Harzburgita & 893 & 966 & 878 & 838 & 2,0 \\
Qeug & Lherzolita & 859 & 955 & 890 & 854 & 1,8 \\
\hline M53 & Lherzolita & 802 & 876 & 871 & 830 & 1,7 \\
M55 & Harzburgita & 869 & 944 & 882 & 844 & 2,0 \\
M57 & Harzburgita & 814 & 924 & 885 & 847 & \\
M67 & Harzburgita & 793 & 912 & 856 & 810 & 1,8 \\
M76 & Harzburgita & & & 878 & 839 & \\
M79 & Harzburgita & 864 & 950 & 868 & 826 & 1,8 \\
Mh & Harzburgita & 826 & 909 & 909 & 878 & 1,7 \\
\hline L37 & Harzburgita & 1069 & 1177 & 1053 & 1048 & 2,1 \\
L38 & Harzburgita & 904 & 1022 & 947 & 924 & 1,9 \\
L82 & Dunita & 888 & 1014 & 893 & 858 & 1,7 \\
L82a & Harzburgita & 869 & 919 & 902 & 869 & 1,6 \\
\hline C5 & Lherzolita & 822 & & & & 1,7 \\
C30a & Websterita & 821 & 867 & 827 & 772 & \\
\hline T18 & Harzburgita & 869 & 993 & 928 & 901 & 1,1 \\
\hline
\end{tabular}

Tabla 9.1. Estimaciones de temperatura $\left({ }^{\circ} \mathrm{C}\right)$ y presión $(\mathrm{GPa})$. Referencias: $2 \mathrm{Px} \mathrm{TY}=$ termómetro de 2 piroxenos de Taylor (1998), 2Px ByK= termómetro de 2 piroxenos de Brey y Köhler (1990), Ca ByK= termómetro de Ca en opx de Brey y Köhler (1990), Ca NG= termómetro de Ca en opx de Nimis y Grüter (2010), y $\mathrm{PMc}=$ presión de Mercier (1980) sobre clinopiroxeno.

Se interpreta que el rango de variación de la temperatura de los xenolitos estudiados está netamente acotado ya que todos los geotermómetros utilizados muestran un intervalo relativamente bajo $\left(844-1177^{\circ} \mathrm{C}\right.$, con promedio de $\left.966^{\circ} \mathrm{C}\right)$. Esto último, junto a las presiones calculadas con el geobarómetro de Mercier (1980), el cual varía entre 1,1 y 2,2 GPa, con promedio de 1,8 GPa, sugiere que los xenolitos estudiados pertenecen a 
sectores restringidos del manto que abarca aproximadamente de los 40 a los $60 \mathrm{~km}$ de profundidad.

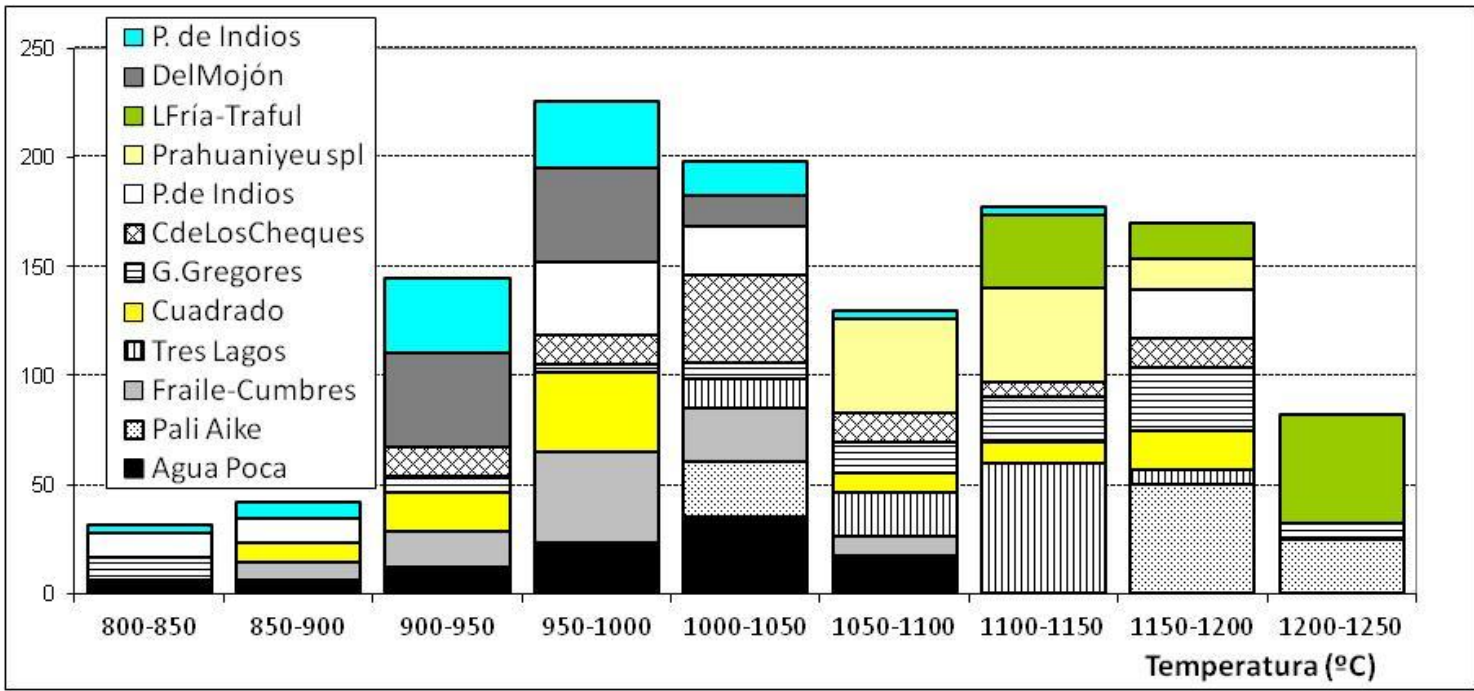

Figura 9.2. Comparación de variación de temperaturas obtenidas para Paso de Indios, respecto a otras localidades de Patagonia y oeste de La Pampa (Agua Poca). Las temperaturas se estimaron mediante el termómetro de 2 piroxenos de Brey y Köhler (1990).

Las estimaciones de temperaturas y presion nos permiten corroborar que las rocas ultramáficas de Paso de Indios provienen de niveles del manto de facies de espinela; esto según el diagrama de Melchiorre (2010) (Figura 9.3).

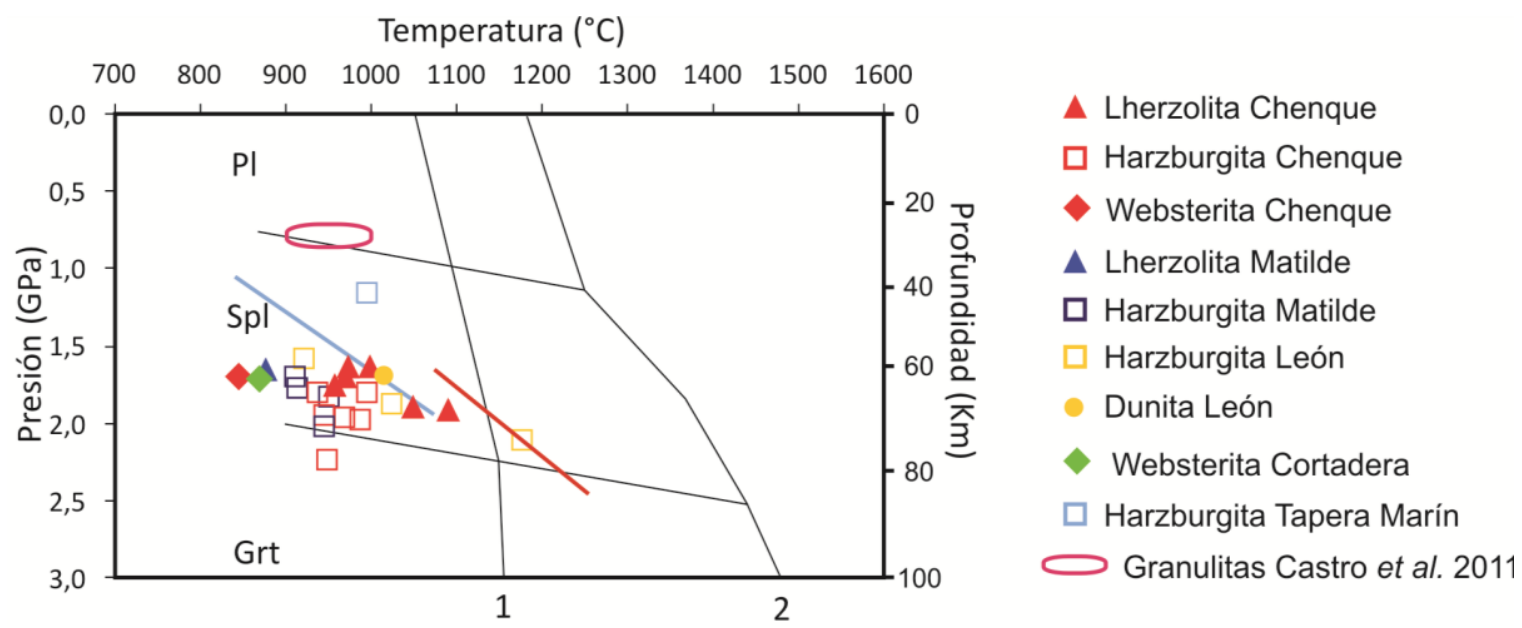

Figura 9.3. Estimaciones de presión (Mercier 1980) y temperatura (Brey y Köhler (1990) para xenolitos ultramáficos de Paso de Indios. 1: solidus hidratado y 2: solidus anhidro. Tomado de Melchiorre (2010). Línea roja: geoterma de Prahuaniyeu (Bjerg et al. 2009); línea celeste: geoterma Agua Poca (Bertotto et al. 2013). 


\subsection{FUSIÓN PARCIAL}

La abundancia (62\% en total) de harzburgitas y lherzolitas con menos de $6 \%$ de cpx en volumen, es una evidencia de que la columna del manto por debajo de la zona de Paso de Indios está significativamente empobrecida respecto de la composición modal de un manto fértil, como por ejemplo el manto primitivo propuesto por Johnson et al. (1990). Esta tendencia es un rasgo común compartido en la mayoría de los xenolitos mantélicos de Patagonia descriptos en trabajos previos (Bjerg et al. 2005, Laurora et al. 2001, Rivalenti et al. 2004a, Rivalenti et al. 2007) y se vincula a un empobrecimiento del manto de esta zona por fusión parcial.

Modalmente, las peridotitas en facies de espinela de las localidades estudiadas presentan un marcado empobrecimiento en el contenido de clinopiroxeno. Es posible estimar, entonces, el grado de empobrecimiento en cpx por fusión, en base a la relación entre el contenido modal de cpx vs. la relación modal cpx/opx (Rivalenti et al. 2000), partiendo de la relación teórica para un manto primitivo (Johnson et al. 1990). Si bien las muestras de las localidades estudiadas exhiben cierta dispersión, en su mayoría se ubican sobre o muy próximas al tren de empobrecimiento por fusión fraccionada no modal de un Manto Primitivo. De este modo, encontramos que los xenolitos de Cerro Chenque presentan un variable grado de empobrecimiento, con porcentajes de fusión que varían entre 10\% (Q103) y >24\%. En Cerro León, Cerro Matilde y Tapera Marín una muestra de cada uno presenta empobrecimiento menor (14, 16 y $17 \%)$ que el resto $(>20 \%$ ), mientras que las de Cerro Cortadera tienen valores mayores a $\sim 21 \%$ (Figura 9.4).

El carácter refractario de las asociaciones minerales se corresponde con las composiciones de elementos mayores de las fases minerales, las cuales son, en su mayoría, pobres en $\mathrm{Al}$ y ricas en $\mathrm{Mg}$ y $\mathrm{Cr}$ (ver capítulo 8.2).

El grado de fusión parcial también se estimó utilizando las ecuaciones empíricas de Hellebrand et al. (2001) y Batanova et al. (1998), en base al \#Cr de las espinelas. Con la primera ecuación, los resultados indican que las rocas mantélicas de Paso de Indios experimentaron los siguientes porcentajes de extracción de fundidos: Cerro Chenque 6 a 16\%; Cerro Matilde entre 14 y 16\%, a excepción de la harzburgita M57 que alcanza un valor de 21\%; Cerro León entre 7 y 16\%; Cerro Cortadera entre 8 y 18\% y 17\% la harzburgita T18 de Tapera Marín. Con la ecuación de Batanova, los porcentajes de fusión varían entre 8 y $18 \%$ en Cerro Chenque, entre 16 y $18 \%$ en Cerro Matilde, con excepción de la harzburgita M57 que alcanza el 23\%; entre 9 y 17\% en Cerro León; 
entre el 10 y 20\% en Cerro Cortadera y la harzburgita T18 de Tapera Marín tiene un valor de fusión del 19\%.

Ambas ecuaciones fueron aplicadas, también, en los análisis de espinelas de Paso de Indios previamente publicados (Rivalenti et al. 2004a). Esas muestras indican una extracción de fundido de 9 a 23\% y de 11 a 24\% con las ecuaciones de Hellebrand y Batanova, respectivamente.
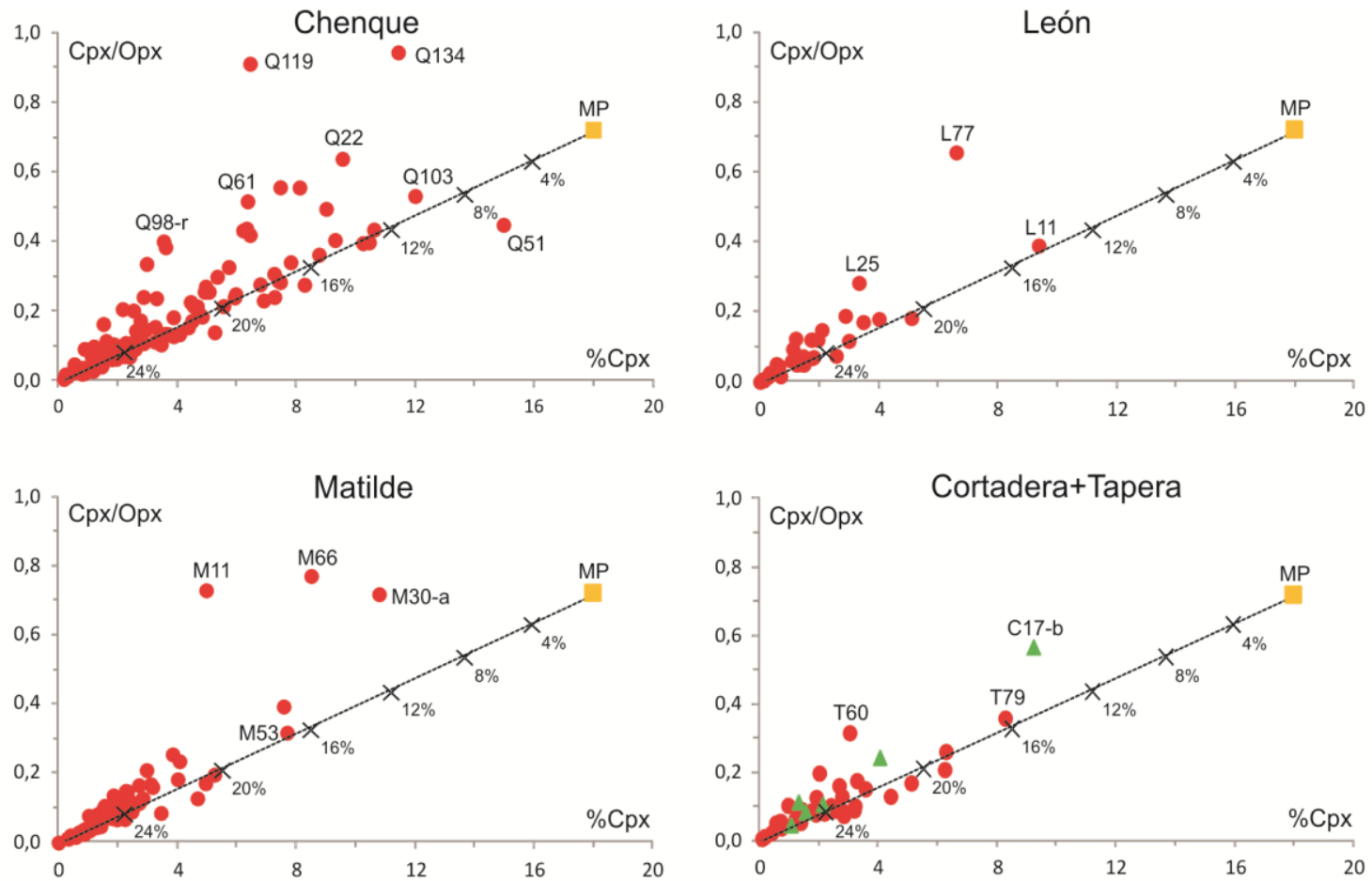

Figura 9.4. Relaciones modales de Cpx vs. Cpx/Opx de los xenolitos peridotíticos de los cerros Chenque, Matilde, León, Cortadera y Tapera Marín; las muestras de estas dos ultimas se graficaron juntas. La recta punteada negra representa el tren de empobrecimiento de clinopiroxeno por fusión fraccionada no modal de un Manto Primitivo (MP-Johnson et al. (1990), Rivalenti et al. (2000)), los intervalos separados con cruces (X) representan incrementos del 4\% de fusión. El cuadrado amarillo representa la relación del manto primitivo. En el gráfico inferior derecho, los xenolitos de cerro Cortadera se incdican con triánguos verdes, mientras que aquellos de Tapera Marín se indican con puntos rojos.

Se realizó otra estimación del grado de fusíon parcial, a partir del análisis de los patrones de REE normalizados a $\mathrm{C} 1$ de los clinopiroxenos de peridotitas de Paso de Indios. Los HREE son indicadores más estables del grado de fusión que los LREE ya que debido a sus coeficientes de partición, los LREE son más fácilmente enriquecidos por metasomatismo. Durante la circulación de pequeños volúmenes de fluidos/fundidos metasomatizantes se producirá enriquecimiento de los LREE, si estos volúmenes aumentan significativamente pueden también enriquecerse los HREE (Ozawa y Shimizu 1995, Ozawa 2001). Por otra parte, si el fluido/fundido metasomatizante es más pobre en HREE que una peridotita parcialmente fundida por la cual circula, los minerales residuales deberían empobrecerse en HREE (Ozawa 2001). Por esto es que, en esta tesis 
se realizan estimaciones de los porcentajes de fusión por varias vías. Las muestras con patrones más similares a los modelos de empobrecimiento por fusión son las lherzolitas Q107 y Q-PI46 (Grupo I) de Cerro Chenque las que exhiben concentraciones de HREE equivalentes a 10-12\% de fusión. Los mayores porcentajes de fusión se observan en las muestras con patrones en forma de "U" (Grupo V), los que alcanzan el 23\%.

Como es esperable, el contenido modal de cpx muestra correlación negativa con el grado de fusión $(\mathrm{F})$ estimado en base a la composición de espinela y correlación positiva con el contenido de $\mathrm{Al}_{2} \mathrm{O}_{3}$ de cpx (Figura 9.5 a y b). Junto con las correlaciones opuestas de $\mathrm{Ca}$ y $\mathrm{Na}$ respecto del contenido de $\mathrm{Al}$ en cpx y \#Mg vs. \#Cr en espinela (Figuras 8.3 y 8.5), esas relaciones son sugestivas de un tren de variación principal controlado por incrementos de fusión parcial de una fuente de manto fértil cerca de la composición de los xenolitos lherzolíticos de Agua Poca (Grupo 1 de Bertotto et al. 2013). En este aspecto las muestras de Cerro Matilde son las más deprimidas. El grupo 1 de los xenolitos de Agua Poca se eligieron porque registran composiciones de roca total y mineral más fértiles que la mayoría de las localidades de Patagonia.

Las muestras estudiadas fueron colectadas en una pequeña región $(<20 \mathrm{~km}$ de separación), pertenecientes a la misma época eruptiva. Las mismas son representativas de una pequeña porción del manto respecto de la escala de los procesos de fusión parcial que usualmente afectan una gran porción (cientos de kms) del manto astenosférico. La variabilidad composicional observada además, sugiere una variación del aparente grado de fusión que no puede ser justificado en términos de variaciones laterales de temperatura debido a la escasa distancia entre los centros eruptivos.

La fusión parcial puede ser optimizada localmente por una progresiva canalización de fundidos que incluye disolución de piroxenos imitando composicionalmente la tendencia de empobrecimiento por fusión (Kelemen 1990). Este proceso se propone en base a la fuerte variabilidad de opx modal, con varias muestras que contienen poco opx modal y consecuentemente alta relación Cpx/Opx (Figura 9.4). La presencia de dunitas puede ser interpretada como representativa de términos extremos de disolución de piroxenos debido a la canalización de fundidos subsaturados en sílice a relativamente baja presión (Mazzucchelli et al. 2009). La inestabilidad de piroxenos está confirmada por el estudio petrográfico, que presenta registros de olivino secundario reemplazando grandes opx en peridotitas ricas en olivino. 


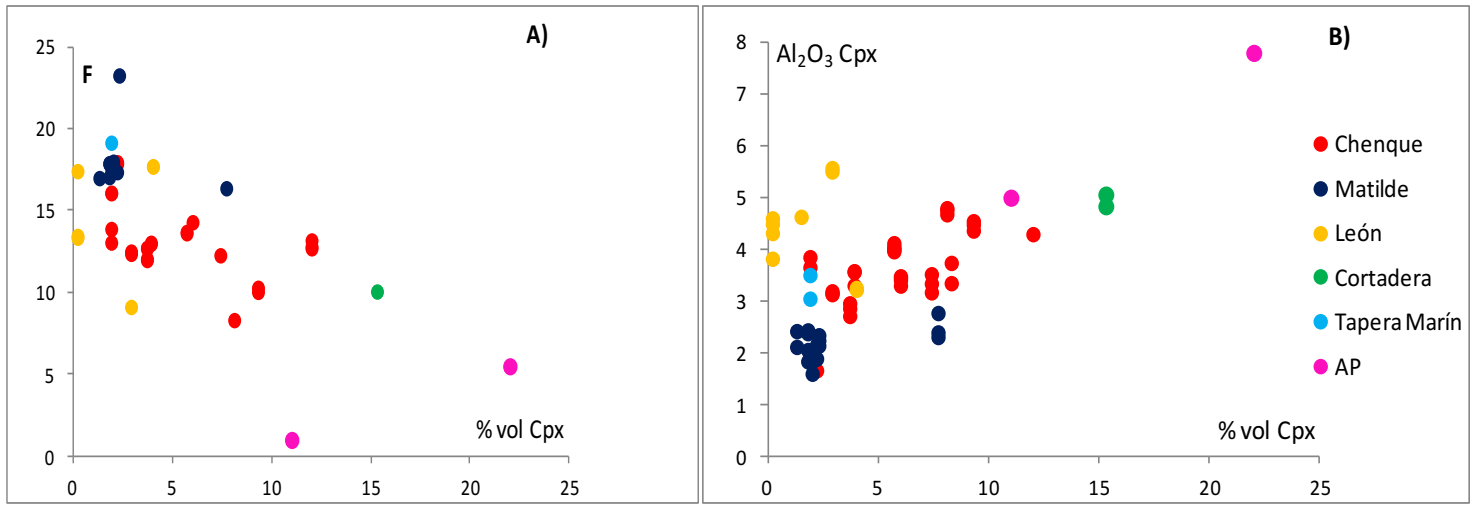

Figura 9.5. A: variación del porcentaje de fusión $\mathrm{F}$ (estimado en espinela) respecto del contenido modal de cpx. B: variación del contenido de $\mathrm{Al}_{2} \mathrm{O}_{3}$ en cpx, respecto al contenido modal de cpx. AP = Agua Poca (Bertotto et al. 2013).

Las variaciones composicionales indicadas muestran tendencias locales divergentes del tren principal asociado a fusión parcial. Esto se puede observar en el diagrama $\mathrm{Na}_{2} \mathrm{O}$ vs. $\mathrm{Al}_{2} \mathrm{O}_{3}$ de cpx (Figura 9.6) para las muestras de Chenque y Matilde. En el mismo sentido, el diagrama de $\mathrm{Na}_{2} \mathrm{O}$ vs. \#Cr en cpx (Figura 9.7) si tomamos todas las muestras en conjunto, muestra dispersión de las mismas hacia valores mas altos de $\mathrm{Na}_{2} \mathrm{O}$ con el aumento del \#Cr. En el residuo mantélico, el \#Cr en cpx se incrementa durante la fusión parcial debido a la relativa compatibilidad del $\mathrm{Cr}$ con respecto al Al. El $\mathrm{Na}$ es un elemento fuertemente incompatible por lo que debe decrecer durante la fusión parcial. El aumento de $\mathrm{Na}_{2} \mathrm{O}$ con el aumento del $\# \mathrm{Cr}$ en cpx de las muestras estudiadas es sugestivo de fusión en sistema abierto con infiltración de fundidos ricos en $\mathrm{Na}$ tal lo expuesto para peridotitas abisales de Brunelli et al. (2014).

Por último, las estimaciones de fusión parcial en base a la correlación del contenido de Fo de olivinos vs \#Cr de espinelas (Figura 8.6) nos indican, para la mayoría de las muestras, valores de fusión mayores al 20\%. De este mismo modo se observa que las peridotitas de Cerro Matilde son grupalmente las más empobrecidas de las muestreadas en la región de Paso de Indios. 


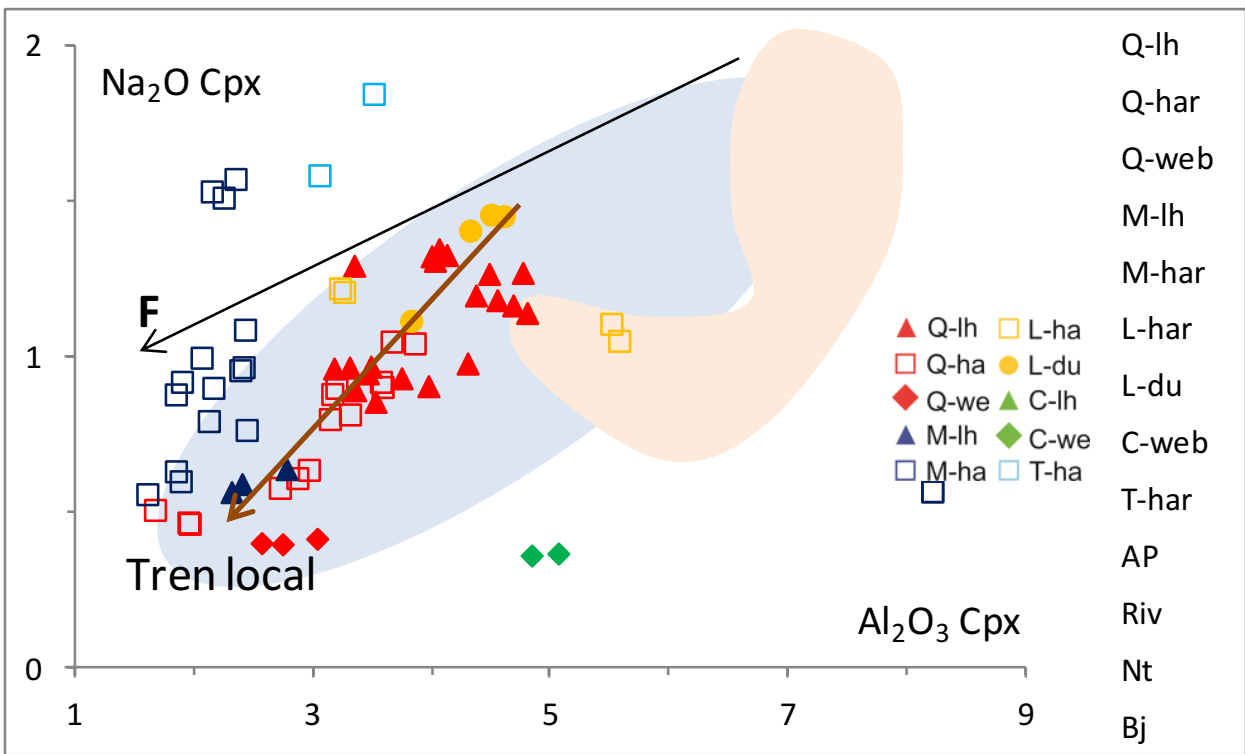

Figura 9.6. Diagrama de variación del contenido de $\mathrm{Na}_{2} \mathrm{O}$ respecto del contenido de $\mathrm{Al}_{2} \mathrm{O}_{3}$ en cpx. La flecha negra "F" muestra una variación relacionada a fusión parcial. La línea marrón muestra un tren de variación local observado en clinopiroxenos de Cerro Chenque.

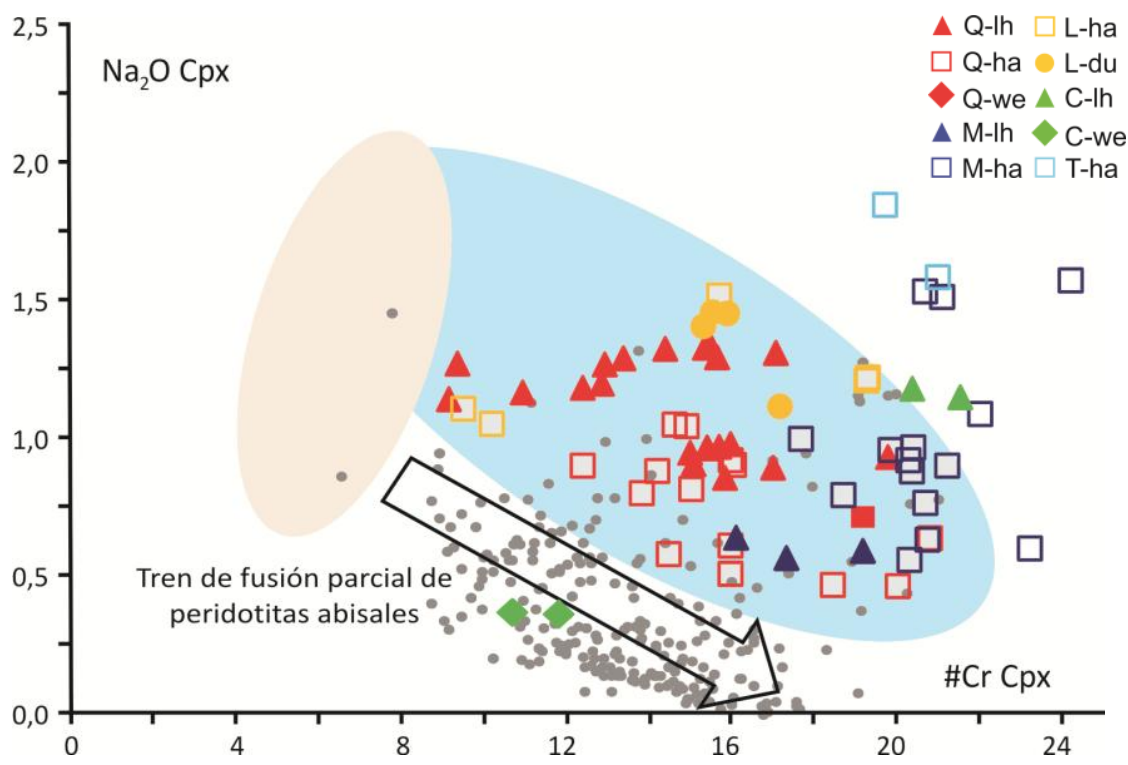

Figura 9.7. Variación del $\mathrm{Na}_{2} \mathrm{O}$ vs. \#Cr en clinopiroxenos. $\mathrm{El} \# \mathrm{Cr}$ aumenta durante la fusión mientras que el contenido de $\mathrm{Na}_{2} \mathrm{O}$ disminuye. Los puntos grises corresponden a muestras de peridotitas abisales, la flecha muestra la tendencia mundial para el manto suboceánico de la dorsal centro-atlántica (Brunelli et al. 2006) y de la dorsal del suroeste de India (Seyler et al. 2003). El campo rosa representa las muestras de Agua Poca de Bertotto et al. (2013). El campo celeste representa muestras de Patagonia.

\subsection{METASOMATISMO}

La columna del manto litosférico debajo de la región de Paso de Indios se vio afectada no solo por marcados eventos de empobrecimiento por fusión parcial, sino además por la influencia de distintos fundidos/fluidos que percolaron e interaccionaron a través de dicha columna. Estos fundidos/fluidos modificaron la impronta química de elementos traza, como podemos observar en el comportamiento que presentan los 
patrones de REE de los clinopiroxenos, en su mayoría claramente alejados de los trenes modelo de empobrecimiento por fusión (metasomatismo críptico). En base a estas modificaciones podemos realizar inferencias acerca de la composición de los agentes metasomatizantes.

Por otro lado, comparando estos patrones con los modelos de empobrecimiento por fusión parcial calculados para el manto primitivo, también es posible estimar el porcentaje de fusión parcial que sufrió una determinada porción del manto.

Los patrones de REE de cpx correspondientes al Grupo I (lherzolitas Q107 y Q-PI46) presentan empobrecimiento en HREE (aunque desplazados en LREE) que se correlacionan con los patrones teóricos propios para un manto primitivo empobrecido por aproximadamente $10 \%$ de fusión (Figura 8.13). Un patrón similar presentan los REE de clinopiroxenos del grupo 1 de Agua Poca de Bertotto et al. (2013) aunque en este caso sin desviarse del patrón modelo para los LREE.

Los patrones del Grupo II exhiben enriquecimiento uniforme de todos los REE (Figura 8.14). Este comportamiento sugiere un tiempo prolongado de interacción roca/fundido, lo que dio lugar a que el manto residual de esta región de Patagonia alcance un equilibrio relativo con dicho fundido. Estos patrones paralelos, casi horizontales, fueron también registrados por Rivalenti et al. (2007) en los cpx CD16 y CD21 de Cerro de los Chenques (160 km al SO de Paso de Indios) y Mundl et al. (2015) para los cpx CH1 y CH48 de cerro Chenque (norte de la meseta de Somuncurá).

Los Grupos III y IV presentan patrones de REE de cpx con fuerte enriquecimiento de LREE y, por otro lado, exhiben un fraccionamiento mínimo en MREE y HREE, donde alcanzan valores de 0,1 a 1 x C1. El contenido de HREE es consistente con 20-23\% de fusión parcial de un manto primitivo en facies de espinela, que luego interactuó, posiblemente, con un fundido alcalino que lo enriqueció en LREE (Figura 8.15 y 8.16). Patrones similares en Patagonia fueron registrados, entre otros, por Mundl et al. (2015) en clinopiroxenos de Puesto Díaz (norte de la meseta de Somuncurá) y en clinopiroxenos del Grupo 2 de Bjerg et al. (2009) de la localidad de Prahuaniyeu.

Las lherzolitas de Cerro Chenque que muestran patrones de REE con forma de "V" (Grupo V) (Figura 8.17) y algunas muestras del Grupo IV (Q101, MH, M67, M79 y MPI23), permiten inferir que sus contenidos de MREE y/o HREE están más fraccionados que lo esperado para una extracción de fundidos en facies de espinela, lo que podría sugerir un inicio de la fusión parcial en condiciones de facies de granate. Un comportamiento similar presentan algunos clinopiroxenos de Prahuaniyeu, Pra304 del 
Grupo 1 de Bjerg et al. (2009) y los cpx Pr301 y 303 de Mundl et al. (2015) del norte de la meseta de Somuncurá.

En otros casos, las lherzolitas (por ejemplo Q105) que presentan patrones de REE sinusoidales podrían ser el resultado de un proceso de refertilización producto de la interacción de fundidos enriquecidos en LREE con una peridotita empobrecida en LREE por fusión (Figura 8.18). Un comportamiento semejante presentan los REE de dos clinopiroxenos de Prahuaniyeu, Pral de Mundl et al. (2015) y Pra68 del Grupo 3 de Bjerg et al. (2009). Cabe destacar que Ozawa (2001) reprodujo patrones de este tipo a partir del influjo de fundidos tipo OIB ricos en LREE en un clinopiroxeno con 5\% de empobrecimiento por fusión parcial.

Ionov et al. (2002) propusieron un modelo de percolación por flujo unidireccional de fundidos/fluidos que atraviezan una columna de manto para explicar las modificaciones en los patrones de REE de los clinopiroxenos de las rocas ultramáficas de un manto que se empobrecía por fusión parcial.

Siguiendo esta idea, una posibilidad sería que los patrones de REE de los clinopiroxenos de Paso de Indios representan diferentes estadios de una columna de manto que fue variando su composición de elementos traza (Figura 9.7). En un principio el manto se empobreció por al menos $20 \%$ de extracción de fundidos, luego comenzó a ser atravezado por fundidos que lo enriquecieron levemente en LREE (ej. Grupo I); estadios más avanzados estarían plasmados por los patrones en "U" del grupo IV, donde se observa un alto enriquecimiento en LREE y por los extremos enriqecimientos de REE de las muestras M57, M-P-I14 y M-PI29 (Grupo III).

Otra posibilidad sería fusión asistida por fluidos/fundidos en sistema abierto con remanencia variable de líquidos en el sistema (Ozawa y Shimizu 1995, Ozawa 2001). En este caso los fluidos/fundidos podrían variar su composición (además de su volumen de remanencia) lo que explicaría los distintos patrones hallados. Siguiendo este concepto, los patrones enriquecidos en LREE (Grupos I, III, IV, V y VI) excepto los de las muestras M57, M-PI14 y M-PI29, son compatibles con enriquecimientos variables de una peridotita empobrecida por fusión, producidos por fundidos alcalinos tipo OIB. Las muestras M57, M-PI14 y M-PI29 del Grupo III, podrían haber adquirido ese patrón por interacción con fundidos "ultra-alcalinos" tipo kimberlitas. Finalmente los patrones planos del Grupo II son concordantes con interacción de la peridotita con un agente metasomatizante de composición similar a un fundido en equilibrio con hornblenda. 
Por otra parte, del análisis de los patrones extendidos resulta coherente sugerir que los agentes metasomatizantes tienen una impronta general dada por un ambiente de subducción. En relación a esto se calcularon los fundidos potenciales en equilibrio para todos los clinopiroxenos analizados. En estos también se repiten las características de basaltos de arco volcánico para la mayoría de las muestras, al igual que con los datos de elementos traza extendidos (Figura 9.9). En este sentido es importante destacar que las muestras con evidencia de importante tiempo/volumen de interacción con el agente metasomatizante (M57, Q77, M53) se encuentran dentro de las que exhiben un claro patrón relacionado a ambiente de subducción. Un detalle importante es que al comparar los fundidos potenciales con los basaltos de Paso de Indios (Alric 1996) no surge una buena concordancia composicional, ya que (si bien faltan datos de algunos elementos en los basaltos) no presentan anomalías negativas de Zr-Hf y Ta. Lo antes indicado permite por lo tanto, en principio, descartar que los xenolitos hayan sido metasomatizados por fundidos con composiciones similares a las que originaron los basaltos que los hospedan.

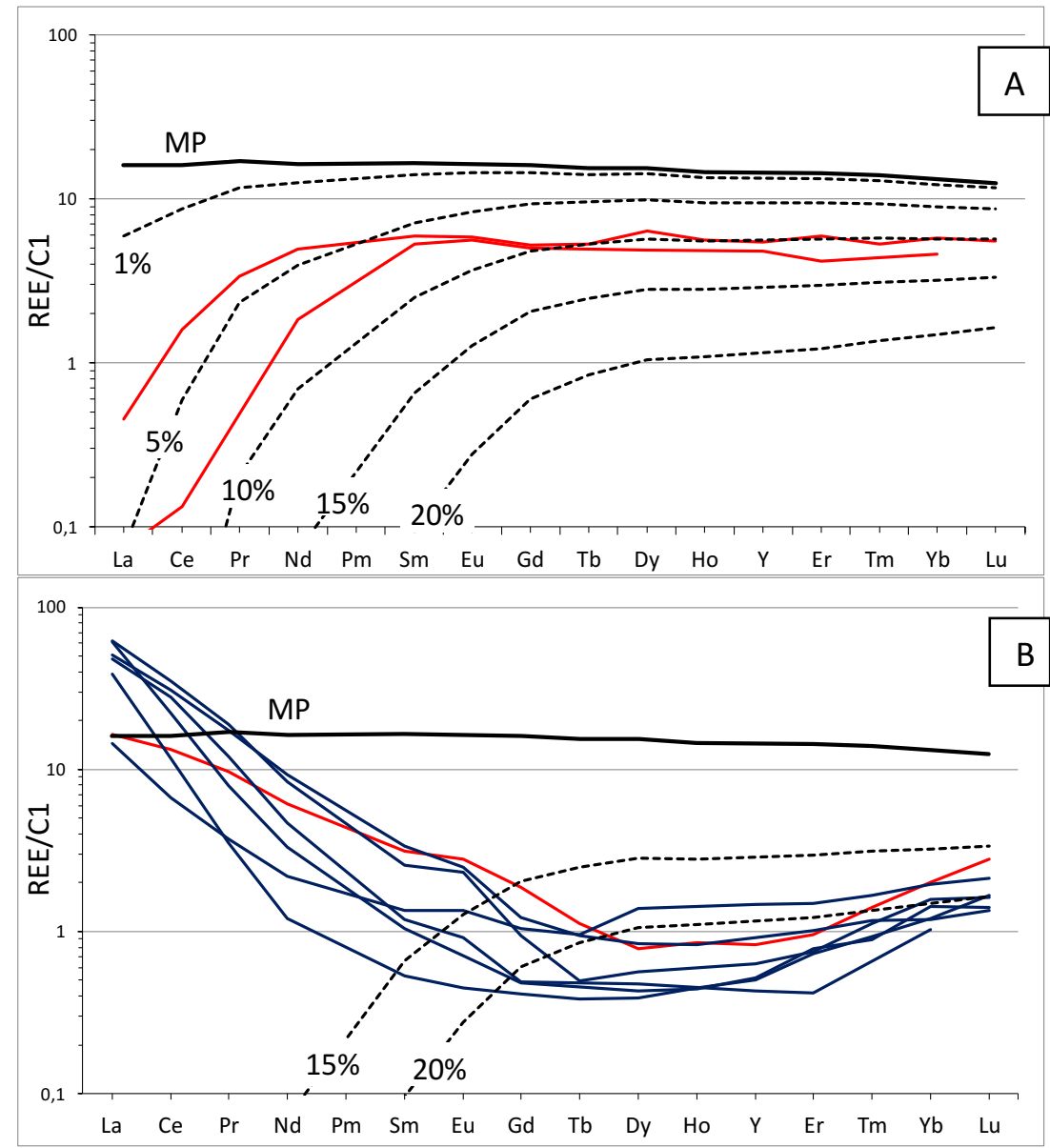

Figura 9.8. Patrones de REE normalizados a condrito $\mathrm{C} 1$ de clinopiroxenos de xenolitos de Paso de Indios. A: patrones de Grupo I; B: patrones del Grupo IV. MP: manto primitivo. 

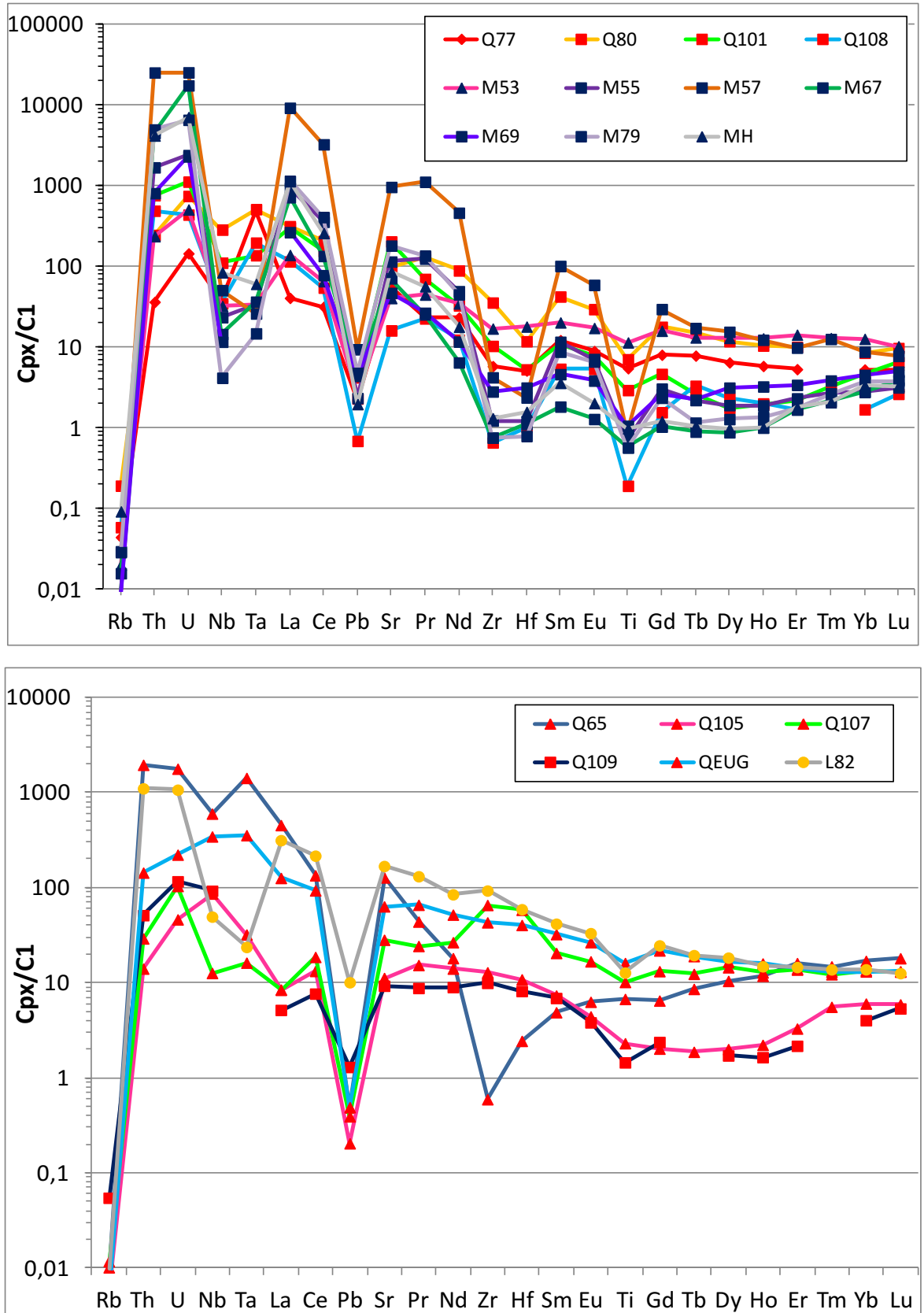

Figura 9.9. Patrones de elementos traza extendidos normalizados de fundidos potenciales. El gráfico de arriba muestra patrones similares a los de un arco volcánico típico; mientras que en el gráfico de abajo, los patrones no exhiben una típica impronta geoquímica de arco magmático. Q: Chenque; M: Matilde; L: León. Triángulo: lherzolita; cuadrado: harzburgita, círculo: dunita; rombo: websterita. 


\section{0- CONCLUSIONES}


Los xenolitos ultramáficos analizados para este trabajo de tesis doctoral muestran una asociación de minerales (olivino, ortopiroxeno, clinopiroxeno y espinela) típica del manto superior y texturas que documentan deformación astenosférica y/o litosférica. El tipo de roca dominante es harzburgita y las texturas presentes, en orden de abundancia son: porfiroclástica y la transición gruesa a porfiroclástica.

La abundancia de harzburgitas y lherzolitas con menos de $6 \%$ de clinopiroxeno en volumen (62\% en total), es una evidencia de que la columna del manto por debajo de la zona de Paso de Indios está significativamente empobrecida respecto de la composición modal de un manto primitivo. De acuerdo a las composiciones modales, el manto muestreado debajo de Cerro Matilde, Cerro León, Cerro Cortadera y Tapera Marín registra eventos de fusión parcial mayores al 20\%; mientras que los xenolitos con grado de empobrecimiento más variable ocurren en Cerro Chenque, donde se encuentran valores de entre $16 \%$ y $>24 \%$. Tales observaciones son confirmadas por estimaciones de fusión parcial basadas en el \#Cr de la espinela.

El tren de fusión común está parcialmente solapado por trenes locales (Cerro Chenque) que lo cortan. Estos podrían haber sido generados por procesos de fusión en sistema abierto y/o migración metasomática de fundidos exóticos ricos en $\mathrm{Na}-\mathrm{Cr}$ posteriores a la fusión parcial.

El estudio petrográfico evidencia, además, la ocurrencia de dos principales esquemas de reacción mineralógica debido a canalización y/o extracción/migración de fundidos en forma pervasiva. Esas son: 1) disolución de ortopiroxeno y segregación de nuevos olivinos en peridotitas ricas en olivino, y 2) reemplazo de olivino primario por clinopiroxeno y ortopiroxeno en peridotitas ricas en piroxeno. Tales esquemas mineralógicos se consideran relacionados a migración de fundidos con diferente saturación en sílice. De hecho una mayor disolución de piroxenos está atribuida a canalización de fundidos subsaturados en sílice, mientras que el reemplazo de olivino primario por ortopiroxeno \pm clinopiroxeno sugiere reacciones con fundidos saturados en sílice. Reacciones coroníticas finales involucrando piroxenos y espinelas están frecuentemente ligadas a venillas conectadas con el basalto hospedante. La ocurrencia de texturas simplectíticas en opx y spl podría ser el resultado de una reacción de desestabilización de granate producto de una descompresión por ascenso del manto litosférico (upwelling).

Las muestras del manto estudiadas presentan temperaturas más bajas que las estimadas para otros sectores de Patagonia mediante xenolitos ultramáficos. Todos los 
geotermómetros utilizados indican un rango relativamente bajo $\left(844-1177{ }^{\circ} \mathrm{C}\right.$, con promedio de $966{ }^{\circ} \mathrm{C}$ ) de variación. Esto último, junto al ámbito de variación de las presiones calculadas (1,1-2,2 GPa, con promedio de 1,8 GPa), sugiere que los xenolitos estudiados pertenecen a sectores restringidos del manto que abarcan aproximadamente de los 40 a los $75 \mathrm{~km}$ de profundidad.

Toda la información expuesta indica que la columna del manto superior debajo de Paso de Indios registra una refertilización incompleta (metasomatismo) de protolitos fuertemente empobrecidos por fusión. Esto representa un ejemplo valioso para la región patagónica, donde, con frecuencia, el manto en facies de espinela está completamente afectado por múltiples etapas de migración de fundidos.

A partir de los patrones de elementos de tierras raras se infiere que los agentes metasomatizantes presentaron características similares a fundidos alcalinos (tipo OIB), ultra-alcalinos (tipo kimberlitas) y de composición similar a un fundido en equilibrio con hornblenda. Asimismo, es notable la impronta de ambiente de subducción en los mismos. 


\section{1- BIBLIOGRAFÍA}


Acevedo, R. D. y Quartino, B. J. 2004. Basalto alcalino portador de xenolitos ultramáficos en Tierra del Fuego. Rev. Asoc. Geol. Argentina 59, 411-415.

Alric V., Labudía C., Iglesias C., Pardo M. 1993. Xenolitos lherzolíticos en basaltos alcalinos del centro de la provincia del Chubut. Actas $12^{\circ}$ Congreso Geológico Argentino y $2^{\circ}$ Congreso de Exploración de Hidrocarburos, Mendoza, Argentina. Asociación Geológica Argentina. 4: 249-255.

Alric V. 1996. Los basaltos portadores de xenolitos aflorantes en las localidades Paso de Indios y Cerro Cóndor, departamento de Paso de Indios, provincia del Chubut. Tesis doctoral, Universidad Nacional de la Patagonia San Juan Bosco, Argentina. Inédito.

Alric, V., Haller, M., Féraud, G. y Betrand, H. 2002. Volcanismo Alcalino Paleógeno en los alrededores de Paso de Indios, provincia del Chubut. Actas $15^{\circ}$ Congreso Geológico Argentino, El Calafate (Santa Cruz), Argentina. 2: 101-106.

Anders, E. y Grevesse, N. 1989. Abundances of the elements: meteoric and solar. Geochimica et Cosmochimica Acta 53: 197-214.(89) 90286.

Anderson, D. 1967. Phase changes in the upper mantlle. Science. 157: 1165-1173.

Anselmi, G., Gamba, M. y Panza, J. 2004. Descripción geológica de la Hoja 4369-IV, Los Altares, Provincia del Chubut. Servicio Geológico Minero Argentino. Boletín No 313, Buenos Aires, Argentina.

Aragón, E., Aguilera, Y., Cavarozzi, C. y Ribot, A. 2005. Basaltos Alcalinos en el Complejo Volcánico-Piroclastico del Río Chubut medio. Actas $16^{\circ}$ Congreso Geológico Argentino, La Plata (Buenos Aires), Argentina. Asociación 1: 485-486.

Aragón, E., D'Eramo, F., Castro, A., Pinotti, L., Brunelli, D., Rabbia, O., Rivalenti, G., Varela, R., Spakman, W., Demartis, M., Cavarozzi, C., Aguilera, Y., Mazzucchelli, M. y Ribot, A. 2011. Tectono-magmatic response to major convergence changes in the north Patagonian suprasubduction system: The Paleogene subduction-transcurrent plate margin transition. Tectonophysics. 509: 218-237.

Aragón, E., Pinotti, L., D’Eramo, F., Castro, A., Rabbia, O., Coniglio, J., Demartis, M., Hernando, I., Cavarozzi, C. y Aguilera, Y. 2013. The Farallón-Aluk ridge collisison with South America: Implications for the geochemical changes of slab window magmas from fore- to back-arc. Geoscience Frontiers. 4: 377-388. 
Arai, S. 1994. Characterization of spinel peridotites by olivine-spinel compositional relationships: Review and interpretation, Chem. Geol. 113: 191-204.

Ardolino, A. y Franchi, M. 1993. El vulcanismo cenozoico de la meseta de Somún Cura, provincias de Río Negro y Chubut. $12^{\circ}$ Congreso Geológico Argentino. Actas 4:225235. Buenos Aires.

Barbieri, M.A., Rivalenti, G., Cingolani, C., Vanucci, R. y Kempton P. 1999. Geochemical and isotope constraints on the composition of the mantle lithosphere in Patagonia (Argentina, Chile). South American Symposium on Isotope Geology, Actas. 2: 163-166. Carlos Paz.

Batanova, V., Suhr, G. y Sobolev, A. 1998. Origin of geochemical heterogeneity in the mantle peridotites from the Bay of Islands Ophiolite, Newfoundland, Canada; ion probe study of clinopyroxenes. Geochim. Cosmochim. Ac. 62: 853-866.

Bertotto, G.W. 2000. Cerro Agua Poca, un cono basáltico cuaternario portador de xenolitos ultramáficos, en el oeste de la provincia de La Pampa, Argentina. Revista de la Asociación Geológica Argentina, 55(1-2): 59-71.

Bertotto, G.W., 2002a. Cerro Huanul (37 $17^{\circ}$ S; 68 32'O), nueva localidad con xenolitos ultramáficos en basanitas cenozoicas del sur de Mendoza. 15 Congreso Geológico Argentino, Actas. 3: 66-70, El Calafate.

Bertotto, G.W. 2002b. Xenolitos ultramáficos en el cerro De la Laguna, volcanismo basáltico de retroarco en el sureste de la provincia de Mendoza, Argentina. Revista de la Asociación Geológica Argentina, 57(4): 445-450.

Bertotto, G.W., Mazzucchelli, M., Zanetti, A. y Vannucci, R. 2013. Petrology and geochemistry of the back-arc lithospheric mantle beneath eastern Payunia (La Pampa, Argentina): Evidence from Agua Poca peridotite xenoliths, Geochem. J. 47: 219-234.

Bjerg, E.A., Labudía, C. y Cesaretti, N. 1991. Mineralogy, texture and stress measurements of mantle xenoliths from Southern Argentina. Berichte der Deutschen Mineralogischen Gesellschaft. Beihefte zum: Eur. J. Mineral. 3: 31.

Bjerg, E.A., Ntaflos, Th., Kurat, G., Dobosi, G. y Labudia, C. 2005. The upper mantle beneath Patagonia, Argentina, documented by xenoliths from alkali basalts. J. S. Am. Earth Sci. 18: 125-145. 
Bjerg, E.A., Ntaflos, Th., Thöni, M., Aliani, P. y Labudia, C. 2009. Heterogeneous lithospheric mantle beneath Northern Patagonia: evidence from Prahuaniyeu garnet- and spinel-peridotites. J. Petrol. 50: 1267-1298.

Bottazzi, P., Tiepolo, M., Vanucci, R., Zanetti, A., Brumm, R., Foley, S. y Oberti, R. 1999. Distinct site preferences for heavy and light REE in amphibole and the prediction of Amph/LDREE: Contributions to Mineralogy and Petrology, v. 137, p. 36-45.

Brey, G., Köhler, T. 1990. Geothermobarometry in four-phase lherzolites II. New thermobarometers, and practical assessment of existing thermobarometers. J. Petrol. 31: 1353-1378.

Brunelli, D., Seyler, M., Cipriani, A., Ottolini, L. y Bonatti, E. 2006. Discontinuous melt extraction and weak refertilization of mantle peridotites at the vema lithospheric section (Mid-Atlantic Ridge). J. Petrol. 47: 745-771.

Brunelli, D., Paganelli, D. y Seyler, M. 2014. Percolation of enriched melts during incremental open-system melting in the spinel field: A REE approach to abyssal peridotites from the Southwest Indian Ridge. Geochim. Cosmochim. Ac. 127: 190-203.

Castro, A., Aragón, E., Díaz-Alvarado, J., Blanco, I., García-Casco, A., Vogt, K. y Liu, D. 2011. Age and composition of granulite xenoliths from Paso de Indios, Chubut province, Argentina. J. S. Am. Earth Sci. 32: 567-574.

Codignotto, J., Nullo, F., Panza, J. y Proserpio, C. 1978. Estratigrafía del Grupo Chubut entre Paso de Indios y Las Plumas, Provincia del Chubut, $7^{\circ}$ Congreso Geológico Argentino (Neuquén), Actas 1: 471-480.

Cortés, J. 1988. Descripción geológica de la Hoja 46d "Meseta del Canquel" (escala 1:200.000), provincia del Chubut. Facultad de Ciencias Exactas y Naturales, Universidad de Buenos Aires, Tesis doctoral: 179p. Inédito.

Dawson, J. 1984. The Mantle and Crust-Mantle Relationships. Kimberlites II: Elsevier, Holland, pp. 289-294.

De Ignacio, C., Lopéz, I., Oyarzun, R., and Márquez, A., 2001. The northern Patagonian Somuncura plateau basalts: a product of slab-induced, shallow asthenospheric upwelling, Terra Nova, 13: 117-121. 
Douglas, B., Saul, S. y Stern, C. 1987. Rheology of the upper mantle beneath southernmost South America inferred from peridotite xenoliths. J. Geology. 95: 241-253.

Fígari, E. y Courtade, S. 1993. Evolución tectosedimentaria de la cuenca de Cañadón Asfalto. Chubut. Argentina. $12^{\circ}$ Congreso Geológico Argentino y $2^{\circ}$ Congreso de Exploración de Hidrocarburos, Actas 1:66-77. Buenos Aires.

Fisk, M.R. (1986). Basalt magma interaction with harzburgite and the formation of high-magnesium andesites. Geophysical Research Letters. issn: 0094-8276.

Gelós, E. y Hayase, K. 1979. Estudio de las inclusiones peridotíticas en un basalto de la región de Comallo y de otras localidades de las provincias de Río Negro y Chubut. Proceedings of the $6^{\circ}$ Congreso Geológico Argentino, Bahía Blanca (Buenos Aires), Argentina. Asociación Geológica Argentina, Buenos Aires. 2: 69-82.

Giacosa, A. y Márquez, M. 1999. Jurásico y Cretácico de la Cordillera Patagónica septentrional y Precordillera patagónica. Instituto de Geología y Recursos minerales. Geología Argentina. Anales 29 (6): 444-459.

Green, D. H. y Falloon, T.J, 1998. Pyrolite: A Ringwood concept and its current expression. En: Jackson, I. (ed) The Earth's mantle: composition, structure and evolution. Cambridge University Press, 311-378, Cambridge.

Hama, J. y Suito, K. 2001 Thermoelastic models of minerals and the composition of the Earth's lower mantle. Phys. Earth Planet. Inter. 125, 147-166.

Harte, B. 1977. Rock nomenclature with particular relation to deformation and recrystallization textures in olivine bearing xenoliths. The Journal of Geology, Vol. 85, No. 3, pp. 279-288.

Harte, B. 1983. Mantle peridotites and processes-The kimberlite sample. Continental basalts and mantle xenoliths, 46-91. Shiva, Nantwich.

Helffrich, G. y Wood, B. 2001. The Earth's mantle. Nature 412: 501-507.

Hellebrand, E., Snow, J., Dick, H. y Hofmann, A. 2001. Coupled major and trace elements as indicators of the extent of melting in mid-ocean-ridge peridotites. Nature. 410: 677681. 
Hirose, K. y Kushiro, I. 1993. Partial melting of dry peridotites at high pressures: determination of compotions of melts segregated from peridotite using aggregates of diamonds. Earth and Planetary Science Letters, 114:477-489.

Ionov, D. A., Bodinier, J. -L., Mukasa, S. B., Zanetti, A. (2002). Mechanisms and sources of mantle metasomatism: Major and trace element compositions of peridotite xenoliths from Spitsbergen in the context of numerical modelling. Journal of Petrology 43, p. 2219-2259.

Ito, E., Harris, M. y Anderson, T. 1983. Alteration of oceanic crust and geologic cycling of chlorine and water. Geochimica et Cosmochimica Acta 47, 1613-24.

Ito, E. y Takahashi, E. 1989. Postspinel transformations in the system Mg2SiO4-Fe2SiO4 and some geophysical implications. Journal of Geophysical Research 94: 0148-0227.

Jalowitzki, T. L. R., Conceição, R. V., Orihashi, Y., Bertotto, G. W., Nakai, S. y Schilling, M. 2010. Evolução geoquímica de Peridotitos e Piroxenitos do Manto Litosférico Subcontinental do vulcão Agua Poca, Terreno Cuyania, Argentina. Pesq. Geoc. 37, $143-167$.

Johnson, K., Dick, H. y Shimizu, N. 1990. Melting in oceanic upper mantle: an ion microprobe study of diopsides in abyssal peridotites. J. Geophys. Res. 95: 2661-2678.

Kay, S. M., 2002. Magmatic sources, setting and causes of eocene to recent Patagonian plateau magmatism $\left(36^{\circ} \mathrm{S}\right.$ to $52^{\circ} \mathrm{S}$ latitude). $\mathrm{XV}^{\circ}$ Congreso Geológico Argentino, Actas 3: 95-100.

Kay, S., Gorring, M. y Ramos, V. 2004. Magmatic sources, setting and causes of Eocene to Recent Patagonian plateau magmatism $\left(36^{\circ} \mathrm{S}\right.$ to $52^{\circ} \mathrm{S}$ latitude). Revista de la Asociación Geológica Argentina 59: 556-558.

Kay, S., Ardolino, A., Gorring, M. y Ramos, V. 2007. The Somuncura Large Igneous Province in Patagonia: Interaction of a Transient Mantle Thermal Anomaly with a Subducting Slab. Journal of Petrology 48: 43-77.

Kelemen, P. B. (1990). Reaction between ultramafic rock and fractionating basaltic magma I. Phase relations, the origin of calc-alkaline magma series, and the formation of discordant dunite. Journal of Petrology 31, p. 51-98. 
Kelemen, P., Whitehead, J., Aharonov, E. y Jordahl, K. 1995. Experiments on flow focusing in soluble porous media. With aplicationsto melt extraction from the mantle. Journal of Geophysical Research. 100: 475-496.

Kempton, P., Hawkesworth, C., Lopez-Escobar, L., Pearson, D.G. y Ware, A.J. 1999. Spinel \pm garnet lherzolite xenoliths from Pali Aike: part 2. Trace element and isotopic evidence bearing on the evolution of lithospheric mantle beneath southern Patagonia. 7th Int. Kimberlite Conf. Dawson Volume. 1: 415-428.

Klügel, A. (1998). Reactions between mantle xenoliths and host magma beneath La Palma (Canary Islands): constraints on magma ascent rates and crustal reservoirs. Contribution to Mineralogy and Petrology 131, p. 237-257.

Köhler, T. y Brey, G. 1990. Calcium exchange between olivine and clinopyroxene calibrated as a geothermobarometer for natural peridotites from 2 to $60 \mathrm{~kb}$ with applications. Geochimica et Cosmochimica Acta 54, 2375-2388.

Labudía, C. 1994. Petrología y geoquímica de xenolitos lherzolíticos de las localidades de Lenzaniyeu y Paso de Indios - Comarca Nordpatagónica. II Jornadas de Mineralogía, Petrografía y Metalogénesis de Rocas Ultrabásicas, Universidad Nacional de La Plata, La Plata, Argentina. 3: 523-532.

Larrea, M., Martig, S., Castro, S., Aliani, P. y Bjerg, E.A. 2010. Rock.AR - A Point Counting Application for Petrographic Thin Sections. Paper presented at the 26th Spring Conference on Computer Graphics, Budmerice, Slovakia, 13-15 May, 2010.

Laurora, A., Mazzucchelli, M., Rivalenti, G., Vannucci, R., Zanetti, A., Barbieri, M.A. y Cingolani C.A. 2001. Metasomatism and melting in carbonated peridotite xenoliths from the mantle wedge: the Gobernador Gregores case (southern Patagonia). J. Petrol. 42: 69-87.

Le Maitre, R. W., editor, Streckeisen, A., Zanettin, B., Le Bas, M.J., Bonin, B., Bateman, P., Bellieni, G., Dudek, A., Efremova, S., Keller, J., Lameyre, J., Sabine, P.A., Schmid, R., Sørensen, H., Woolley, A.R., 2002. Igneous Rocks. A Classification and Glossary of Terms. Recommendations of the International Union of Geological Sciences Subcommission on the Systematics of Igneous Rocks, 2nd ed. xvi +236 pp. Cambridge, New York, Melbourne: Cambridge University Press, 236 p., Cambridge. 
Lesta, P. J. 1968. Estratigrafía de la cuenca del Golfo San Jorge. Jornadas Geología Argentina (Buenos Aires), Actas 1: 251-289, Buenos Aires.

Lesta, P. J. y Ferello, R. 1972. Región Extraandina de Chubut y norte de Santa Cruz. Dir. Geol. Reg. Arg., Acad. Nac. Ciencias. Córdoba.

Liu, L. 1976. The high-pressure phase of MgSiO3. Earth Planet. Sci. Lett. 31, 200-208.

Lizuain, A. y Silva Nieto, D. 1993. Hoja Geológica 4369-I, Gastre, provincia del Chubut. Dirección Nacional del Servicio Geológico (informe inédito). Buenos Aires.

Mazzucchelli, M., Rivalenti, G., Brunelli, D., Zanetti, A., Boari, E., 2009. Formation of Highly Refractory Dunite by Focused Percolation of Pyroxenite-Derived Melt in the Balmuccia Peridotite Massif (Italy). Journal of Petrology, 50: 1205-1233.

Melchiorre, M. 2010. Petrology of suprasubductive mantle xenoliths from Estancia Sol de Mayo (Central Patagonia, Argentina). Universitá degli studi di Ferrara. Tesi dottorale.

McDonough, W. F. 1990. Constraints on the composition of the continental lithospheric mantle. Earth and Planetary Science Letters 101, 1-18.

Menzies, M.A. y Hawkesworth, C.J. 1987. Mantle Metasomatism. Academic Press, 422 p., Londres.

Mercier, J.-C.C. 1980. Single-pyroxene thermobarometry. Tectonophysics 70: 1-37.

Mercier, J-C. C. y Nicolas, A. 1975. Textures and fabrics of upper mantle peridotites as illustrated by basalts xenoliths. Journal of Petrology 16(2): 454-487.

Morimoto, N. 1988. Nomenclature of pyroxenes. Canadian Mineralogists 16: 501-520.

Mundl, A., Ntaflos, T., Ackerman, L., Bizimis, M. y Bjerg, A. 2015. Geochemical and OsHf-Nd-Sr Isotopic Characterization of North Patagonian Mantle Xenoliths: Implications for Extensive Melt Extraction and Percolation Processes. Journal of Petrology. Journal of Petrology, 2015, 1-3. doi: 10.1093/petrology/egv048.

Nielson Pike, J.E., y Schwarzman, E.G. 1977. Classification of textures in ultramafic xenoliths. Journal of Geology, v. 85, p. 49-61.

Nimis, P. y Grütter, H. 2010. Internally consistent geothermometers for garnet peridotites and pyroxenites. Contrib. Mineral. Petr. 159: 411-427. 
Nimis, P. y Taylor, W. R. 2000. Single clinopyroxene thermobarometry for garnet peridotites. Part I. Calibration and testing of a Cr-in-Cpx barometer and an enstatite-inCpx thermometer. Contributions to Mineralogy and Petrology, 139: 541-544.

Niu, Y. 1997. Mantle melting and mantle extraction processes beneath ocean ridges: evidence from abyssal peridotites. Journal of Petrology. 38:1047-1074.

Ntaflos, Th., Bjerg, E.A., Labudía, C.H., Thöni, M., Frisicale, C. y Günther, M. 2001. Garnet-bearing xenoliths: evidence of plume activity in northern Patagonia. Proceedings of the 11th Annual Goldschmidt Conf. abstract \#3126.

Ntaflos, Th. y Bjerg, E.A. 2006. Garnet-bearing xenoliths from Prahuaniyeu N-Patagonia: a LA-ICP-MS study. $16^{\circ}$ Annual VM Goldschmidt Conference August-September 2006, Geochimica et Cosmochimica Acta, 70 (18), Supplement 1, Page A450.

Nullo, F. 1983. Descripción geológica de la Hoja 45c "Pampa de Agnia" (escala 1:200.000), prov. del Chubut. Servicio Geológico Nacional, Boletín Nº 199: 1-94.

Ozawa, K. (2001) Mass balance equations for open magmatic systems: Trace element behavior and its application to open system melting in the upper mantle. J. Geophys. Res. 106, 13407-13434.

Ozawa, K. and Shimizu, N. (1995) Open-system melting in the upper mantle: Constraints from the Hayachine-Miyamori ophiolite, northeastern Japan. J. Geophys. Res. 100, $22315-22335$

Page, R. y Page, S. 1993. Petrología y significado tectónico del Jurásico volcánico del Chubut central. Revista de la Asociación Geológica Argentina. 48(1):41-58. Buenos Aires.

Palme, H. y Nickel, K.G. 1985. Ca/Al ratio and composition of the Earth's upper mantle. Geochemica et Cosmochemica Acta 49: 2123-2132.

Palme, H. y O’Neill, H.C. 2014. Cosmochemical estimates of mantle composition. In: Carlson, R.W. (Ed) The mantle and core, Treatise on Geochemistry, 2nd edition, 3, 139.

Panza, J.L. 1981. Descripción geológica de las Hojas 46e "Gran Laguna Salada" y 47f "Meseta Cuadrada" (escala 1:100.000), provincia del Chubut. Dirección Nacional del Servicio Geológico, Informe inédito: 241p. 
Piccardo, G.B., Müntener, O., Zanetti, A., 2004. Alpine-Apennine ophiolitic peridotites: new concepts on their composition and evolution. Ofioliti 29 (1), 63-74.

Ponce, A., Bertotto, G., Zanetti, A., Brunelli, D., Giovanardi, T., Aragón, E., Bernardi, M., Hémond, C. y Mazzuchelli, M. 2015. Short-scale variability of the SCLM beneath the extra-Andean back arc (Paso de Indios, Argentina): Evidence from spinel-facies mantle xenoliths. Open Geosciences. 7: 362-385.

Proserpio, C.A. 1987. Descripción Geológica de la Hoja 44e, Valle General Racedo (1:200.000), provincia del Chubut. Dirección Nacional de Minería y Geología, Boletín $\mathrm{N}^{\mathrm{o}}$ 201: 1-102.

Ramos, V. 1999. Las Provincias Geológicas del Territorio Argentino. Geología Argentina, Instituto de Geología y Recursos Minerales, Anales 29 (3): 41 - 96 , Buenos Aires. ISSN: 0328-2325.

Ringwood, A.E. y Major, A. 1966. High-pressure transformations in pyroxenes. Earth and Planetary Science Letters 1: 241-245.

Rivalenti, G., Mazzuchelli, M., Laurora, A., Ciuffi, C. A., Zanetti, A., Vannucci, R., Cingolani,C. A. (2004a). The back arc mantle lithosphere in Patagonia, South America. Journal of South American Earth Sciences 17, p. 121-152.

Rivalenti, G., Zanetti, A., Mazzuchelli, M., Vannucci, R., Cingolani, C. A. (2004b). Equivocal carbonatite markers in the mantle xenoliths of the Patagonia backarc: the Gobernador Gregores case (Santa Cruz Province, Argentina). Contributions to Mineralogy and Petrology 147, p. 647-670.

Rivalenti, G., Mazzucchelli, M., Zanetti, A., Vannucci, R., Bollinger, C., Hémond, C. y Bertotto G.W. 2007. Xenoliths from Cerro de los Chenques (Patagonia): An example of slab-related metasomatism in the backarc lithospheric mantle. Lithos. 99: 45-67.

Rollinson, H. 2007. Early Earth Systems. A Geochemical Approach. 285 p. Oxford, Malden, Carlton: Blackwell Publishing.

Selverstone, J. 1982. Fluid inclusions as petrogenetic indicators in granulite xenoliths, PaliAike volcanic field, Chile. Contributions to Mineralogy and Petrology. 79, 28, 1-36. 
Seyler, M., Cannat, M. y Mével, C. 2003. Evidence for major-element heterogeneity in the mantle source of abyssal peridotites from the Southwest Indian Ridge ( $52^{\circ}$ to $68^{\circ} \mathrm{E}$ ), Geochem. Geophy. Geosy. 4(2), 9101.

Silva Nieto, D.G. 2005. Descripción geológica de la Hoja 4369-III, Paso de Indios, Provincia del Chubut. Servicio Geológico Minero Argentino, Boletín N²67, Buenos Aires.

Simpson, G.G. 1941. The Eogene of Patagonia. American Museum of Natural History, Novitates 1120: 15p., New York.

Somoza, R. y Ghidella, M. 2005, Convergencia en el margen occidental de América del Sur durante el Cenozoico: subducción de las placas de Nazca, Farallón y Aluk: Revista de la Asociación Geológica Argentina, v. 60, no. 4, p. 797-809.

Skewes, M.A. y Stern, C.R. 1979. Petrology and geochemistry of alkali basalts and ultramafic inclusions from the Pali-Aike volcanic field in southern Chile and the origin of the Patagonian plateau lavas. J. Volcanol. Geoth. Res. 6: 3-25.

Stern, C.R., Saul, S., Skewes, M.A. y Futa, K. 1989. Garnet peridotite xenoliths from the Pali Aike basalts of southernmost South America. Kimberlites and Related Rocks. Geological Society of Australia. Spec. Publ. 14(2), 735-744.

Stern, C.R., Frey, F.A., Futa, K., Zartman, R.E., Peng, Z. y Kyser, K.T. 1990. Traceelement and $\mathrm{Sr}, \mathrm{Nd}, \mathrm{Pb}$, and $\mathrm{O}$ isotopic composition of Pliocene and Quaternary alkali basalts of the Patagonian Plateau lavas of southernmost South America. Contrib. Mineral. Petr. 104: 294-308.

Stipanicic, P.N., Rodrigo, F., Baulies, O. y Martinez, C. 1968. Las formaciones presenonianas en el denominado Macizo Nord patagónico y regiones adyacentes. Revista Asociación Geológica Argentina, 23(2): 67-95, Buenos Aires.

Sun, S. y McDonough, W. F. 1989. Chemical and isotopic systematics of oceanic basalts; implications for mantle composition and processes. En: Magmatism in the Ocean Basins (Saunders, A. y Norry, M., eds.), Geol. Soc. Spec. Publ. 42, 313-345.

Taylor, W.R. 1998. An experimental test of some geothermometer and geobarometer formulations for upper mantle peridotites with application to the thermobarometry of fertile lherzolite and garnet websterite. Neues Jb. Miner. Abh. 172: 381-408. 
Turner, J.C. 1983. Descripción geológica de la Hoja 44d, Colan Conhue, provincia de Chubut. Boletín 197, 78 p. Serv. Geol. Nacional, Buenos Aires.

Vannucci, R., Zanetti, A., Kempton, P.D., Ciuffi, S., Mazzucchelli, M. y Cingolani, C.A. 2002. The chemical history of young lithospheric mantle in a backarc region: the spinel \pm garnet peridotite xenoliths from Pali Aike (south Patagonia). $15^{\circ}$ Congreso Geológico Argentino, Actas 3: 71-74, El Calafate.

Walter, M.J., Kohn, S.C., Araujo, D., Bulanova, G.P., Smith, C.B., Gaillou, E., Wang, J., Steele, A., Shirey, S.B., 2011. Deep Mantle Cycling of Oceanic Crust: Evidence from Diamonds and Their Mineral Inclusions. Science 334: 54-57.

Whitney, D. y Evans, B. 2010. Abbreviations for names of rock-forming minerals. American Mineralogist, Volume 95, pages 185-187

Wilson, M. 1989. Igneous petrogenesis: a global tectonic Approach. Unwin Hyman, London-UK., 466p. 


\section{2- ANEXO}


Tabla 12.1. Composición modal y textura de los xenolitos ultramáficos de $\mathrm{C}^{\circ}$ Chenque (Q), $\mathrm{C}^{\circ}$ Matilde $(\mathrm{M}), \mathrm{C}^{\circ}$ León (L), $\mathrm{C}^{\circ}$ Cortadera (C), Tapera Marín (T) y Estancia La Primavera (P). Los valores representan $\%$ en volumen. Gruesa/porfi = transición gruesa a porfiroclástica; porfi = porfiroclástica; porfi mosaico $=$ porfiroclástica en mosaico y granulo $=$ granuloblástica. Oli $=$ olivínica. Parche $=$ zonas de reacción con fundido.

\begin{tabular}{|c|c|c|c|c|c|c|c|c|c|}
\hline Muestra & OI & Opx & Cpx & Sp & Vetas & Parches & Total & Roca & Textura \\
\hline Q1-a & 79,3 & 15,9 & 1,7 & 2,5 & 0,6 & 0,0 & 100 & harzburgita & porfi \\
\hline Q2-b & 0,0 & 29,2 & 68,8 & 1,4 & 0,6 & 0,0 & 100 & websterita & granulo \\
\hline Q3 & 57,8 & 37,1 & 0,8 & 2,6 & 1,7 & 0,0 & 100 & harzburgita & porfi \\
\hline Q5 & 80,7 & 16,5 & 0,5 & 2,0 & 0,3 & 0,0 & 100 & harzburgita & porfi \\
\hline Q6 & 66,8 & 27,7 & 2,6 & 1,4 & 1,4 & 0,0 & 100 & harzburgita & granulo \\
\hline Q7 & 64,2 & 28,3 & 0,2 & 5,0 & 2,3 & 0,0 & 100 & harzburgita & granulo \\
\hline Q9 & 67,0 & 8,7 & 20,9 & 2,6 & 0,8 & 0,0 & 100 & Iherzolita & porfi \\
\hline Q11 & 64,5 & 27,1 & 3,5 & 3,4 & 1,4 & 0,0 & 100 & harzburgita & porfi mosaico \\
\hline Q13 & 73,1 & 20,7 & 1,7 & 3,0 & 1,6 & 0,0 & 100 & harzburgita & granulo \\
\hline Q14 & 87,9 & 7,1 & 0,5 & 4,3 & 0,2 & 0,0 & 100 & dunita & porfi \\
\hline Q15 & 63,9 & 28,7 & 2,0 & 4,2 & 1,1 & 0,0 & 100 & harzburgita & porfi mosaico \\
\hline Q16 & 75,8 & 21,1 & 0,8 & 1,2 & 1,1 & 0,0 & 100 & harzburgita & gruesa/porfi \\
\hline Q18 & 73,4 & 22,2 & 2,6 & 1,5 & 0,2 & 0,0 & 100 & harzburgita & porfi \\
\hline Q19 & 64,1 & 29,1 & 2,3 & 0,8 & 3,6 & 0,0 & 100 & harzburgita & granulo \\
\hline Q20 & 59,3 & 23,5 & 7,2 & 2,8 & 7,1 & 0,0 & 100 & Iherzolita & porfi \\
\hline Q21 & 59,9 & 34,2 & 2,4 & 2,0 & 1,5 & 0,0 & 100 & harzburgita & porfi \\
\hline Q22 & 67,9 & 14,9 & 9,5 & 3,5 & 4,1 & 0,0 & 100 & Iherzolita & porfi \\
\hline Q23 & 80,7 & 13,8 & 3,3 & 1,6 & 0,6 & 0,0 & 100 & harzburgita & porfi \\
\hline Q24 & 74,7 & 20,6 & 2,3 & 1,7 & 0,7 & 0,0 & 100 & harzburgita & porfi \\
\hline Q25 & 52,3 & 39,4 & 1,2 & 0,7 & 6,4 & 0,0 & 100 & harzburgita & porfi \\
\hline Q26 & 64,1 & 25,3 & 2,3 & 3,6 & 4,7 & 0,0 & 100 & harzburgita & granulo \\
\hline Q27 & 76,0 & 21,2 & 0,3 & 0,6 & 1,8 & 0,0 & 100 & harzburgita & porfi \\
\hline Q28 & 61,5 & 26,2 & 2,9 & 3,6 & 5,8 & 0,0 & 100 & harzburgita & porfi \\
\hline Q29 & 86,9 & 3,3 & 6,1 & 1,1 & 2,6 & 0,0 & 100 & dunita & gruesa/porfi \\
\hline Q30 & 79,4 & 14,4 & 0,5 & 2,4 & 3,2 & 0,0 & 100 & harzburgita & porfi mosaico \\
\hline Q31 & 79,1 & 9,2 & 1,5 & 3,6 & 6,5 & 0,0 & 100 & harzburgita & porfi mosaico \\
\hline Q32 & 70,2 & 26,2 & 1,6 & 1,0 & 1,0 & 0,0 & 100 & harzburgita & porfi mosaico \\
\hline Q33 & 72,3 & 19,7 & 5,1 & 1,5 & 1,5 & 0,0 & 100 & Iherzolita & porfi \\
\hline Q34 & 76,3 & 13,4 & 7,5 & 1,9 & 1,0 & 0,0 & 100 & Iherzolita & porfi \\
\hline Q35 & 85,2 & 8,8 & 3,0 & 1,9 & 1,2 & 0,0 & 100 & harzburgita & gruesa/porfi \\
\hline Q36 & 83,3 & 11,9 & 1,2 & 3,1 & 0,5 & 0,0 & 100 & harzburgita & porfi \\
\hline Q37 & 83,7 & 12,4 & 2,5 & 1,0 & 0,5 & 0,0 & 100 & harzburgita & gruesa/porfi \\
\hline Q38 & 73,8 & 21,7 & 1,5 & 2,2 & 0,9 & 0,0 & 100 & harzburgita & porfi \\
\hline Q39 & 59,3 & 37,6 & 0,9 & 1,6 & 0,7 & 0,0 & 100 & harzburgita & porfi \\
\hline Q40 & 86,4 & 11,0 & 0,5 & 0,7 & 1,4 & 0,0 & 100 & harzburgita & gruesa/porfi \\
\hline Q41 & 66,5 & 21,7 & 0,8 & 6,7 & 4,4 & 0,0 & 100 & harzburgita & porfi mosaico \\
\hline Q42 & 38,9 & 25,8 & 10,2 & 24,0 & 1,0 & 0,0 & 100 & Iherzolita & granulo \\
\hline Q44 & 67,6 & 25,9 & 4,5 & 1,9 & 0,1 & 0,0 & 100 & harzburgita & porfi mosaico \\
\hline Q45 & 74,7 & 19,5 & 4,4 & 1,1 & 0,3 & 0,0 & 100 & harzburgita & porfi \\
\hline Q46 & 76,7 & 18,9 & 1,5 & 2,4 & 0,5 & 0,0 & 100 & harzburgita & gruesa/porfi \\
\hline Q47 & 87,2 & 12,0 & 0,2 & 0,3 & 0,2 & 0,0 & 100 & harzburgita & porfi mosaico \\
\hline Q48 & 80,9 & 16,2 & 1,1 & 0,8 & 1,0 & 0,0 & 100 & harzburgita & gruesa/porfi \\
\hline Q50 & 0,1 & 91,9 & 1,8 & 1,2 & 5,0 & 0,0 & 100 & ortopiroxenita & gruesa/porfi \\
\hline Q51 & 48,1 & 33,3 & 15,0 & 3,6 & 0,0 & 0,0 & 100 & Iherzolita & porfi \\
\hline Q52 & 63,7 & 24,4 & 6,8 & 1,6 & 3,5 & 0,0 & 100 & Iherzolita & porfi mosaico \\
\hline Q53 & 63,5 & 24,1 & 8,8 & 2,2 & 1,4 & 0,0 & 100 & Iherzolita & porfi mosaico \\
\hline Q54 & 71,1 & 19,1 & 4,9 & 2,6 & 2,3 & 0,0 & 100 & Iherzolita & porfi \\
\hline Q55 & 61,2 & 30,9 & 2,2 & 3,4 & 2,3 & 0,0 & 100 & harzburgita & gruesa/porfi \\
\hline
\end{tabular}




\begin{tabular}{|c|c|c|c|c|c|c|c|c|c|}
\hline Muestra & OI & Opx & Cpx & Sp & Vetas & Parches & Total & Roca & Textura \\
\hline Q56 & 64,8 & 25,7 & 5,5 & 1,2 & 2,7 & 0,0 & 100 & Iherzolita & porfi \\
\hline Q57 & 70,8 & 20,9 & 3,2 & 2,6 & 2,5 & 0,0 & 100 & harzburgita & porfi \\
\hline Q58-m & 77,9 & 19,2 & 1,3 & 1,3 & 0,3 & 0,0 & 100 & harzburgita & porfi \\
\hline Q58 & 65,3 & 30,2 & 1,9 & 2,3 & 0,3 & 0,0 & 100 & harzburgita & porfi \\
\hline Q59 & 53,8 & 37,4 & 5,2 & 3,6 & 0,0 & 0,0 & 100 & Iherzolita & porfi \\
\hline Q60 & 71,7 & 21,0 & 3,9 & 3,3 & 0,2 & 0,0 & 100 & harzburgita & porfi \\
\hline Q61 & 76,0 & 12,3 & 6,4 & 2,0 & 3,4 & 0,0 & 100 & Iherzolita & porfi \\
\hline Q62 & 66,8 & 27,3 & 1,3 & 2,4 & 2,3 & 0,0 & 100 & harzburgita & porfi mosaico \\
\hline Q63 & 56,0 & 34,1 & 1,5 & 4,3 & 4,3 & 0,0 & 100 & harzburgita & porfi \\
\hline Q64 & 73,7 & 14,3 & 6,2 & 1,3 & 4,5 & 0,0 & 100 & Iherzolita & porfi \\
\hline Q65 & 62,8 & 22,9 & 9,3 & 3,9 & 1,1 & 0,0 & 100 & Iherzolita & porfi mosaico \\
\hline Q65.1 & 67,2 & 22,8 & 7,8 & 1,2 & 1,0 & 0,0 & 100 & Iherzolita & porfi mosaico \\
\hline Q67 & 0,0 & 21,5 & 73,9 & 0,1 & 3,4 & 1,0 & 100 & websterita & granulo \\
\hline Q68 & 0,0 & 24,0 & 71,9 & 1,6 & 2,5 & 0,0 & 100 & websterita & granulo \\
\hline Q69 & 56,1 & 24,3 & 10,6 & 4,6 & 4,1 & 0,3 & 100 & Iherzolita & porfi mosaico \\
\hline Q70 & 67,7 & 21,0 & 4,5 & 3,2 & 3,0 & 0,5 & 100 & harzburgita & porfi \\
\hline Q72 & 68,5 & 24,9 & 1,9 & 1,1 & 3,6 & 0,0 & 100 & harzburgita & gruesa/porfi \\
\hline Q75 & 77,8 & 15,8 & 2,8 & 2,1 & 1,7 & 0,0 & 100 & harzburgita & porfi \\
\hline Q77 & 0,0 & 65,9 & 34,0 & 0,0 & 0,0 & 0,0 & 100 & websterita & gruesa \\
\hline Q80 & 78,0 & 17,6 & 1,9 & 1,4 & 1,1 & 0,0 & 100 & harzburgita & porfi \\
\hline Q81 & 64,0 & 28,4 & 1,8 & 1,3 & 4,4 & 0,1 & 100 & harzburgita & gruesa/porfi \\
\hline Q82 & 60,1 & 29,8 & 6,9 & 0,9 & 2,1 & 0,2 & 100 & Iherzolita & porfi \\
\hline Q83 & 70,6 & 20,1 & 1,7 & 1,9 & 5,7 & 0,0 & 100 & harzburgita & porfi \\
\hline Q84 & 81,4 & 9,4 & 3,6 & 0,7 & 5,0 & 0,0 & 100 & harzburgita & gruesa/porfi \\
\hline Q85 & 71,2 & 17,9 & 2,6 & 1,5 & 6,8 & 0,0 & 100 & harzburgita & porfi \\
\hline Q86 & 75,1 & 13,9 & 1,6 & 7,4 & 2,0 & 0,0 & 100 & harzburgita & granulo \\
\hline Q87 & 66,6 & 28,1 & 1,2 & 1,1 & 3,0 & 0,0 & 100 & harzburgita & gruesa/porfi \\
\hline Q88 & 0,0 & 34,4 & 59,6 & 0,0 & 3,1 & 2,9 & 100 & websterita & gruesa \\
\hline Q89 & 0,0 & 51,5 & 46,7 & 0,1 & 1,7 & 0,0 & 100 & websterita & gruesa/porfi \\
\hline Q90 & 74,1 & 14,6 & 8,1 & 2,8 & 0,4 & 0,0 & 100 & Iherzolita & gruesa/porfi \\
\hline Q91 & 3,0 & 26,3 & 68,5 & 1,4 & 0,9 & 0,0 & 100 & websterita & granulo \\
\hline Q92 & 58,0 & 30,1 & 4,1 & 3,0 & 4,7 & 0,1 & 100 & harzburgita & porfi \\
\hline Q93 & 67,7 & 21,5 & 1,7 & 3,7 & 5,4 & 0,0 & 100 & harzburgita & porfi \\
\hline Q95 & 2,8 & 38,7 & 56,7 & 0,2 & 1,4 & 0,2 & 100 & websterita & gruesa/porfi \\
\hline Q96 & 59,5 & 29,9 & 8,3 & 2,2 & 0,2 & 0,0 & 100 & Iherzolita & gruesa/porfi \\
\hline Q98-t & 73,7 & 10,9 & 11,5 & 2,7 & 1,2 & 0,0 & 100 & Iherzolita & porfi \\
\hline Q98-r & 78,1 & 8,8 & 3,5 & 1,3 & 6,9 & 1,3 & 100 & harzburgita & porfi \\
\hline Q98-v & 24,8 & 1,2 & 61,2 & 11,5 & 1,2 & 0,0 & 100 & clinopiroxenita oli & gruesa/porfi \\
\hline Q99 & 83,7 & 9,4 & 0,9 & 1,2 & 4,8 & 0,0 & 100 & harzburgita & porfi \\
\hline Q100 & 63,7 & 26,1 & 4,8 & 1,7 & 3,3 & 0,5 & 100 & Iherzolita & porfi \\
\hline Q101 & 78,6 & 11,8 & 2,9 & 4,5 & 2,3 & 0,0 & 100 & harzburgita & gruesa/porfi \\
\hline Q102 & 76,6 & 15,3 & 6,4 & 1,6 & 0,0 & 0,0 & 100 & Iherzolita & porfi \\
\hline Q103 & 61,7 & 22,5 & 12,0 & 3,8 & 0,0 & 0,0 & 100 & Iherzolita & porfi mosaico \\
\hline Q104-m & 70,7 & 24,5 & 2,8 & 2,0 & 0,1 & 0,0 & 100 & harzburgita & porfi \\
\hline Q104 & 63,9 & 29,9 & 3,9 & 2,3 & 0,0 & 0,0 & 100 & harzburgita & porfi \\
\hline Q105 & 63,1 & 25,5 & 7,4 & 3,5 & 0,6 & 0,0 & 100 & Iherzolita & porfi \\
\hline Q105 & 72,7 & 17,8 & 5,3 & 4,1 & 0,1 & 0,0 & 100 & Iherzolita & porfi \\
\hline Q106 & 55,9 & 26,2 & 10,4 & 2,8 & 4,7 & 0,0 & 100 & Iherzolita & gruesa/porfi \\
\hline Q107 & 73,4 & 17,4 & 5,7 & 2,6 & 0,9 & 0,0 & 100 & Iherzolita & gruesa \\
\hline Q108 & 82,5 & 10,4 & 2,2 & 2,0 & 2,9 & 0,0 & 100 & harzburgita & porfi \\
\hline Q109 & 63,1 & 27,5 & 3,7 & 2,8 & 2,9 & 0,0 & 100 & harzburgita & porfi \\
\hline Q110 & 0,0 & 31,4 & 67,3 & 1,3 & 0,0 & 0,0 & 100 & websterita & granulo \\
\hline Q111 & 10,9 & 78,6 & 4,3 & 1,8 & 4,5 & 0,0 & 100 & ortopiroxenita oli & gruesa \\
\hline
\end{tabular}




\begin{tabular}{|c|c|c|c|c|c|c|c|c|c|}
\hline Muestra & OI & Opx & Cpx & Sp & Vetas & Parches & Total & Roca & Textura \\
\hline Q112 & 62,8 & 28,8 & 3,5 & 1,1 & 3,9 & 0,0 & 100 & harzburgita & porfi \\
\hline Q113 & 70,9 & 24,6 & 0,8 & 1,1 & 2,6 & 0,0 & 100 & harzburgita & porfi \\
\hline Q114 & 65,0 & 24,6 & 5,9 & 1,6 & 2,9 & 0,0 & 100 & Iherzolita & gruesa/porfi \\
\hline Q115 & 61,0 & 32,8 & 3,5 & 1,5 & 1,3 & 0,0 & 100 & harzburgita & porfi \\
\hline Q117 & 68,4 & 23,7 & 4,7 & 1,6 & 1,7 & 0,0 & 100 & harzburgita & gruesa/porfi \\
\hline Q119 & 79,4 & 7,1 & 6,4 & 1,9 & 5,0 & 0,2 & 100 & Iherzolita & gruesa/porfi \\
\hline Q120 & 37,1 & 37,0 & 21,4 & 2,8 & 1,5 & 0,2 & 100 & websterita oli & porfi mosaico \\
\hline Q122 & 91,6 & 1,0 & 3,0 & 4,2 & 0,2 & 0,0 & 100 & dunita & gruesa \\
\hline Q123 & 70,1 & 21,4 & 2,2 & 2,3 & 3,9 & 0,0 & 100 & harzburgita & gruesa \\
\hline Q125 & 66,9 & 14,3 & 14,7 & 1,7 & 2,1 & 0,2 & 100 & Iherzolita & porfi \\
\hline Q126 & 73,2 & 18,2 & 4,9 & 1,9 & 1,8 & 0,0 & 100 & Iherzolita & porfi \\
\hline Q127 & 66,3 & 26,4 & 3,6 & 3,6 & 0,0 & 0,0 & 100 & harzburgita & gruesa/porfi \\
\hline Q128 & 61,7 & 26,2 & 7,5 & 3,1 & 1,6 & 0,0 & 100 & Iherzolita & porfi \\
\hline Q129 & 70,8 & 18,2 & 9,0 & 1,3 & 0,8 & 0,0 & 100 & Iherzolita & granulo \\
\hline Q130 & 70,6 & 14,4 & 6,3 & 3,8 & 4,8 & 0,1 & 100 & Iherzolita & porfi \\
\hline Q131 & 50,7 & 25,9 & 19,7 & 2,7 & 1,0 & 0,0 & 100 & Iherzolita & granulo \\
\hline Q132 & 70,5 & 25,8 & 1,0 & 2,0 & 0,7 & 0,0 & 100 & harzburgita & gruesa/porfi \\
\hline Q134 & 73,8 & 12,1 & 11,4 & 2,1 & 0,5 & 0,0 & 100 & Iherzolita & porfi mosaico \\
\hline Q135 & 63,9 & 28,2 & 4,4 & 0,7 & 2,7 & 0,2 & 100 & harzburgita & porfi \\
\hline Q140 & 70,8 & 19,8 & 2,9 & 0,9 & 5,5 & 0,0 & 100 & harzburgita & porfi \\
\hline Q141 & 0,4 & 7,4 & 61,3 & 23,3 & 6,2 & 1,3 & 100 & websterita & granulo \\
\hline Q142 & 0,0 & 14,6 & 81,7 & 0,3 & 3,5 & 0,0 & 100 & websterita & gruesa/porfi \\
\hline Q143b & 0,0 & 39,4 & 58,9 & 0,4 & 1,4 & 0,0 & 100 & websterita & granulo \\
\hline Q144 & 30,8 & 45,2 & 15,6 & 4,7 & 2,1 & 1,6 & 100 & websterita oli & granulo \\
\hline Q145 & 0,0 & 25,0 & 72,0 & 3,0 & 0,0 & 0,0 & 100 & websterita & gruesa/porfi \\
\hline Q146 & 65,7 & 21,7 & 4,7 & 2,3 & 5,7 & 0,0 & 100 & Iherzolita & porfi \\
\hline Q147 & 53,0 & 30,0 & 7,3 & 4,7 & 4,2 & 0,9 & 100 & Iherzolita & porfi \\
\hline Q148 & 73,4 & 19,4 & 0,5 & 1,1 & 5,6 & 0,0 & 100 & harzburgita & porfi \\
\hline Qeug & 65,5 & 23,9 & 6,0 & 4,2 & 0,6 & 0,0 & 100 & Iherzolita & gruesa \\
\hline Qeug-pu & 66,0 & 28,6 & 3,2 & 2,1 & 0,0 & 0,0 & 100 & harzburgita & porfi \\
\hline M1 & 76,1 & 20,4 & 0,0 & 0,6 & 2,9 & 0,0 & 100 & harzburgita & gruesa \\
\hline M2 & 61,4 & 35,7 & 0,6 & 0,9 & 1,4 & 0,0 & 100 & harzburgita & gruesa \\
\hline M3 & 69,1 & 23,3 & 0,7 & 2,1 & 4,9 & 0,0 & 100 & harzburgita & porfi \\
\hline M4 & 88,7 & 7,4 & 0,6 & 1,2 & 2,2 & 0,0 & 100 & dunita & gruesa/porfi \\
\hline M6 & 67,8 & 28,2 & 0,8 & 2,2 & 1,0 & 0,0 & 100 & harzburgita & gruesa/porfi \\
\hline M7 & 66,7 & 27,6 & 2,5 & 1,3 & 2,0 & 0,0 & 100 & harzburgita & gruesa/porfi \\
\hline M8 & 67,2 & 26,4 & 0,5 & 0,9 & 5,0 & 0,0 & 100 & harzburgita & porfi \\
\hline M9 & 90,9 & 3,8 & 2,7 & 0,9 & 1,7 & 0,0 & 100 & dunita & porfi \\
\hline M11 & 83,2 & 6,8 & 5,0 & 2,0 & 3,1 & 0,0 & 100 & Iherzolita & porfi \\
\hline M13 & 64,6 & 30,1 & 1,4 & 1,8 & 2,1 & 0,0 & 100 & harzburgita & gruesa/porfi \\
\hline M14 & 76,0 & 19,7 & 2,4 & 1,5 & 0,4 & 0,0 & 100 & harzburgita & gruesa/porfi \\
\hline M15 & 75,1 & 21,1 & 1,5 & 0,7 & 1,6 & 0,0 & 100 & harzburgita & porfi \\
\hline M16 & 81,4 & 13,1 & 1,0 & 2,8 & 1,7 & 0,0 & 100 & harzburgita & porfi \\
\hline M17 & 71,4 & 23,6 & 2,7 & 1,4 & 0,9 & 0,0 & 100 & harzburgita & porfi \\
\hline M18 & 89,6 & 5,4 & 0,5 & 1,3 & 3,3 & 0,0 & 100 & dunita & porfi \\
\hline M19 & 77,1 & 15,0 & 3,8 & 1,6 & 2,4 & 0,0 & 100 & harzburgita & gruesa/porfi \\
\hline M20 & 75,7 & 16,3 & 2,7 & 1,6 & 3,7 & 0,0 & 100 & harzburgita & porfi \\
\hline M21 & 72,9 & 22,7 & 0,8 & 1,1 & 2,5 & 0,0 & 100 & harzburgita & porfi \\
\hline M22 & 79,7 & 14,1 & 3,0 & 1,0 & 2,2 & 0,0 & 100 & harzburgita & porfi \\
\hline
\end{tabular}




\begin{tabular}{|c|c|c|c|c|c|c|c|c|c|}
\hline Muestra & 이 & Opx & Cpx & $S p$ & Vetas & Parches & Total & Roca & Textura \\
\hline M24 & 71,6 & 24,5 & 0,3 & 0,5 & 2,7 & 0,4 & 100 & harzburgita & porfi \\
\hline M25 & 70,8 & 22,8 & 0,9 & 3,2 & 2,3 & 0,0 & 100 & harzburgita & gruesa/porfi \\
\hline M29 & 71,4 & 16,0 & 1,3 & 0,5 & 8,2 & 2,6 & 100 & harzburgita & porfi \\
\hline M30-a & 62,4 & 15,0 & 10,8 & 2,1 & 4,7 & 5,0 & 100 & Iherzolita & porfi \\
\hline M30-b & 70,9 & 4,6 & 6,4 & 3,1 & 8,3 & 6,7 & 100 & Iherzolita & porfi \\
\hline M31 & 65,3 & 21,9 & 4,0 & 5,5 & 3,3 & 0,0 & 100 & harzburgita & gruesa \\
\hline M31 & 56,3 & 36,5 & 4,7 & 1,9 & 0,5 & 0,0 & 100 & harzburgita & gruesa \\
\hline M31-b & 63,3 & 28,8 & 4,9 & 1,6 & 1,4 & 0,0 & 100 & Iherzolita & gruesa \\
\hline M31.4 & 70,4 & 22,2 & 2,8 & 0,7 & 3,9 & 0,0 & 100 & harzburgita & porfi \\
\hline M36 & 62,6 & 19,7 & 0,4 & 2,3 & 11,7 & 3,2 & 100 & harzburgita & porfi \\
\hline M37 & 63,9 & 29,5 & 1,0 & 2,3 & 3,2 & 0,0 & 100 & harzburgita & porfi \\
\hline M41 & 78,2 & 17,5 & 1,2 & 1,8 & 1,3 & 0,0 & 100 & harzburgita & gruesa/porfi \\
\hline M50-a & 76,6 & 17,3 & 4,1 & 0,4 & 1,3 & 0,2 & 100 & harzburgita & porfi mosaico \\
\hline M53 & 63,9 & 24,2 & 7,7 & 2,5 & 1,8 & 0,0 & 100 & Iherzolita & porfi mosaico \\
\hline M53-b & 69,6 & 19,2 & 7,6 & 1,5 & 2,1 & 0,0 & 100 & Iherzolita & porfi \\
\hline M55 & 74,3 & 20,1 & 2,0 & 2,1 & 1,4 & 0,0 & 100 & harzburgita & gruesa/porfi \\
\hline M55-b & 85,8 & 1,0 & 2,9 & 0,6 & 6,3 & 3,4 & 100 & dunita & porfi \\
\hline M55-c & 76,3 & 15,6 & 2,3 & 1,7 & 4,0 & 0,0 & 100 & harzburgita & gruesa \\
\hline M57 & 77,2 & 15,1 & 2,3 & 3,1 & 2,2 & 0,0 & 100 & harzburgita & porfi \\
\hline M61 & 74,3 & 18,6 & 2,3 & 0,5 & 3,4 & 0,9 & 100 & harzburgita & gruesa \\
\hline M62 & 74,8 & 16,3 & 1,7 & 0,6 & 4,5 & 2,0 & 100 & harzburgita & gruesa \\
\hline M65-r & 74,7 & 13,5 & 1,8 & 1,4 & 6,5 & 2,0 & 100 & harzburgita & porfi \\
\hline M65 & 70,1 & 17,7 & 1,6 & 0,3 & 7,5 & 2,8 & 100 & harzburgita & porfi \\
\hline M66 & 72,0 & 11,0 & 8,5 & 6,6 & 1,9 & 0,0 & 100 & Iherzolita & porfi \\
\hline M67-a & 70,2 & 23,6 & 1,7 & 4,3 & 0,2 & 0,0 & 100 & harzburgita & gruesa/porfi \\
\hline M67-b & 68,4 & 25,1 & 1,8 & 4,0 & 0,7 & 0,0 & 100 & harzburgita & porfi \\
\hline M68.2 & 75,1 & 18,3 & 3,1 & 1,4 & 2,1 & 0,0 & 100 & harzburgita & porfi \\
\hline M69 & 68,8 & 22,3 & 2,8 & 1,4 & 4,8 & 0,0 & 100 & harzburgita & porfi \\
\hline M71 & 59,8 & 34,7 & 0,9 & 3,8 & 0,8 & 0,0 & 100 & harzburgita & porfi \\
\hline M73 & 75,5 & 18,1 & 1,1 & 3,0 & 2,3 & 0,0 & 100 & harzburgita & porfi \\
\hline M74 & 80,3 & 15,4 & 1,5 & 2,1 & 0,7 & 0,0 & 100 & harzburgita & gruesa \\
\hline M75 & 68,7 & 28,7 & 1,3 & 0,6 & 0,7 & 0,0 & 100 & harzburgita & porfi \\
\hline M75.2 & 67,4 & 29,2 & 2,0 & 0,6 & 0,8 & 0,0 & 100 & harzburgita & porfi \\
\hline M76 & 64,8 & 29,4 & 0,3 & 2,3 & 3,1 & 0,0 & 100 & harzburgita & porfi \\
\hline M77 & 64,8 & 26,7 & 5,2 & 2,3 & 1,0 & 0,0 & 100 & Iherzolita & porfi \\
\hline M79 & 60,8 & 32,7 & 2,2 & 1,5 & 2,8 & 0,0 & 100 & harzburgita & porfi \\
\hline M79-a & 52,9 & 40,3 & 3,4 & 3,2 & 0,2 & 0,0 & 100 & harzburgita & gruesa/porfi \\
\hline M79-b & 79,4 & 17,4 & 2,0 & 1,2 & 0,0 & 0,0 & 100 & harzburgita & gruesa \\
\hline M79.2 & 71,1 & 20,4 & 2,0 & 4,2 & 2,3 & 0,0 & 100 & harzburgita & gruesa/porfi \\
\hline MA & 75,8 & 18,1 & 1,5 & 1,4 & 3,2 & 0,0 & 100 & harzburgita & gruesa/porfi \\
\hline MB & 75,8 & 19,6 & 3,2 & 0,9 & 0,5 & 0,0 & 100 & harzburgita & porfi \\
\hline ME & 76,3 & 19,2 & 1,7 & 0,2 & 2,6 & 0,0 & 100 & harzburgita & porfi \\
\hline $\mathrm{MH}$ & 67,9 & 27,9 & 1,3 & 2,0 & 0,9 & 0,0 & 100 & harzburgita & gruesa/porfi \\
\hline $\mathrm{MI}$ & 78,4 & 14,5 & 1,6 & 0,6 & 4,9 & 0,0 & 100 & harzburgita & porfi \\
\hline L6 & 87,3 & 9,7 & 1,2 & 0,3 & 1,5 & 0,0 & 100 & harzburgita & gruesa/porfi \\
\hline
\end{tabular}




\begin{tabular}{|c|c|c|c|c|c|c|c|c|c|}
\hline Muestra & 이 & Opx & Cpx & Sp & Vetas & Parches & Total & Roca & Textura \\
\hline L8 & 83,2 & 13,6 & 0,6 & 0,8 & 1,7 & 0,0 & 100 & harzburgita & porfi \\
\hline L9 & 79,5 & 16,7 & 0,6 & 1,4 & 1,8 & 0,0 & 100 & harzburgita & porfi \\
\hline L11 & 65,0 & 24,0 & 9,4 & 0,8 & 0,8 & 0,0 & 100 & Iherzolita & porfi \\
\hline L12 & 82,5 & 1,3 & 11,9 & 1,7 & 2,6 & 0,0 & 100 & Wherlita & porfi \\
\hline L13 & 85,8 & 12,1 & 0,1 & 0,4 & 1,6 & 0,0 & 100 & harzburgita & gruesa \\
\hline L14 & 70,1 & 26,2 & 0,1 & 0,7 & 2,9 & 0,0 & 100 & harzburgita & porfi \\
\hline L16 & 86,7 & 10,8 & 0,5 & 0,8 & 1,2 & 0,0 & 100 & harzburgita & gruesa \\
\hline L17 & 89,4 & 5,9 & 2,1 & 1,6 & 0,9 & 0,0 & 100 & dunita & porfi \\
\hline L18 & 81,8 & 13,8 & 0,0 & 0,3 & 4,1 & 0,0 & 100 & harzburgita & porfi \\
\hline L20 & 85,4 & 11,8 & 1,1 & 1,3 & 0,5 & 0,0 & 100 & harzburgita & gruesa/porfi \\
\hline L22 & 83,2 & 12,6 & 0,3 & 1,8 & 2,0 & 0,0 & 100 & harzburgita & porfi \\
\hline L23 & 91,4 & 1,9 & 3,1 & 1,9 & 1,7 & 0,0 & 100 & dunita & porfi \\
\hline L24 & 95,8 & 2,6 & 0,1 & 1,4 & 0,2 & 0,0 & 100 & dunita & porfi \\
\hline L25 & 80,1 & 11,8 & 3,3 & 1,7 & 3,1 & 0,0 & 100 & harzburgita & porfi \\
\hline L28 & 81,6 & 14,2 & 1,7 & 0,7 & 1,8 & 0,0 & 100 & harzburgita & gruesa/porfi \\
\hline L30 & 69,1 & 25,3 & 0,1 & 2,3 & 3,2 & 0,0 & 100 & harzburgita & porfi \\
\hline L31 & 92,3 & 0,6 & 0,7 & 5,0 & 1,4 & 0,0 & 100 & dunita & gruesa \\
\hline L32 & 89,4 & 1,9 & 4,1 & 2,2 & 2,5 & 0,0 & 100 & dunita & porfi mosaico \\
\hline L33 & 78,0 & 18,4 & 0,3 & 1,8 & 1,6 & 0,0 & 100 & harzburgita & porfi mosaico \\
\hline L34 & 84,1 & 5,0 & 8,5 & 1,1 & 1,3 & 0,0 & 100 & Iherzolita & porfi \\
\hline L35 & 74,6 & 20,3 & 3,5 & 1,3 & 0,4 & 0,0 & 100 & harzburgita & porfi \\
\hline L36 & 91,4 & 1,1 & 4,9 & 1,2 & 1,3 & 0,0 & 100 & dunita & porfi \\
\hline L37 & 79,9 & 15,2 & 2,9 & 1,0 & 1,0 & 0,0 & 100 & harzburgita & porfi mosaico \\
\hline L38 & 72,2 & 22,2 & 4,0 & 1,1 & 0,4 & 0,0 & 100 & harzburgita & porfi \\
\hline L39 & 95,9 & 0,1 & 1,2 & 0,7 & 2,0 & 0,0 & 100 & dunita & porfi \\
\hline L40 & 84,4 & 13,3 & 0,1 & 0,7 & 1,5 & 0,0 & 100 & harzburgita & gruesa \\
\hline L41 & 94,9 & 0,6 & 2,7 & 1,0 & 0,9 & 0,0 & 100 & dunita & porfi \\
\hline L42 & 91,5 & 1,7 & 1,0 & 4,6 & 1,2 & 0,0 & 100 & dunita & gruesa/porfi \\
\hline L44 & 83,3 & 12,8 & 0,1 & 2,0 & 1,8 & 0,0 & 100 & harzburgita & porfi mosaico \\
\hline L45 & 80,3 & 16,8 & 0,3 & 0,5 & 2,2 & 0,0 & 100 & harzburgita & porfi \\
\hline L46 & 94,7 & 0,8 & 0,1 & 3,4 & 1,0 & 0,0 & 100 & dunita & gruesa \\
\hline L47 & 86,8 & 10,1 & 0,2 & 1,7 & 1,2 & 0,0 & 100 & dunita & porfi \\
\hline L48 & 72,2 & 24,0 & 1,4 & 1,6 & 0,9 & 0,0 & 100 & harzburgita & porfi \\
\hline L49 & 93,3 & 3,6 & 1,7 & 0,8 & 0,6 & 0,0 & 100 & dunita & porfi \\
\hline L50 & 96,2 & 0,4 & 0,0 & 0,7 & 2,7 & 0,0 & 100 & dunita & porfi \\
\hline L51 & 0,0 & 79,1 & 7,7 & 7,9 & 5,3 & 0,0 & 100 & ortopiroxenita & granu \\
\hline L52 & 86,6 & 10,2 & 0,3 & 0,9 & 2,0 & 0,0 & 100 & dunita & gruesa/porfi \\
\hline L55 & 53,0 & 43,5 & 0,7 & 2,0 & 0,8 & 0,0 & 100 & harzburgita & gruesa/porfi \\
\hline L56 & 80,3 & 14,0 & 2,1 & 1,2 & 2,4 & 0,0 & 100 & harzburgita & porfi mosaico \\
\hline L58 & 72,6 & 16,5 & 0,6 & 2,9 & 7,4 & 0,0 & 100 & harzburgita & porfi \\
\hline L59-a & 67,9 & 25,5 & 3,0 & 1,5 & 2,1 & 0,0 & 100 & harzburgita & porfi \\
\hline L59-b & 67,4 & 25,4 & 1,8 & 1,5 & 3,8 & 0,0 & 100 & harzburgita & granu \\
\hline L60-a & 62,6 & 29,9 & 1,5 & 0,9 & 4,2 & 0,9 & 100 & harzburgita & porfi \\
\hline L61 & 5,6 & 86,6 & 5,2 & 0,7 & 1,9 & 0,0 & 100 & websterita oli & gruesa \\
\hline L62 & 87,4 & 0,0 & 0,0 & 6,0 & 6,2 & 0,5 & 100 & dunita & gruesa \\
\hline
\end{tabular}




\begin{tabular}{|c|c|c|c|c|c|c|c|c|c|}
\hline Muestra & OI & Opx & Cpx & Sp & Vetas & Parches & Total & Roca & Textura \\
\hline L63 & 70,9 & 22,0 & 1,4 & 5,5 & 0,3 & 0,0 & 100 & harzburgita & gruesa \\
\hline L64 & 5,3 & 86,7 & 5,2 & 1,4 & 1,4 & 0,0 & 100 & websterita oli & gruesa \\
\hline L65 & 91,2 & 2,8 & 0,0 & 0,1 & 6,0 & 0,0 & 100 & dunita & porfi \\
\hline L68 & 60,2 & 34,2 & 2,6 & 2,3 & 0,6 & 0,0 & 100 & harzburgita & porfi \\
\hline L69 & 74,4 & 19,9 & 1,5 & 3,3 & 0,8 & 0,0 & 100 & harzburgita & gruesa/porfi \\
\hline $\mathrm{L} 70$ & 94,1 & 0,7 & 0,0 & 0,0 & 4,6 & 0,6 & 100 & dunita & gruesa \\
\hline L72-a & 80,0 & 14,4 & 1,7 & 0,7 & 3,1 & 0,0 & 100 & harzburgita & porfi \\
\hline L72-a' & 76,4 & 17,8 & 1,1 & 1,7 & 3,0 & 0,0 & 100 & harzburgita & porfi \\
\hline L72-b & 72,2 & 16,1 & 1,9 & 0,2 & 5,4 & 4,2 & 100 & harzburgita & porfi \\
\hline L72-e & 93,3 & 1,1 & 0,1 & 0,0 & 3,7 & 1,8 & 100 & dunita & gruesa \\
\hline L73 & 65,8 & 27,9 & 5,1 & 1,2 & 0,0 & 0,0 & 100 & Iherzolita & porfi mosaico \\
\hline L75 & 64,5 & 4,7 & 25,8 & 1,3 & 3,6 & 0,0 & 100 & wherlita & gruesa \\
\hline $\mathrm{L} 76$ & 87,7 & 8,6 & 0,8 & 2,4 & 0,5 & 0,0 & 100 & dunita & porfi \\
\hline L77 & 79,9 & 10,0 & 6,6 & 2,8 & 0,7 & 0,0 & 100 & Iherzolita & gruesa/porfi \\
\hline $\mathrm{L} 78$ & 69,2 & 24,9 & 1,2 & 0,8 & 3,7 & 0,2 & 100 & harzburgita & gruesa \\
\hline L80 & 67,1 & 25,8 & 1,8 & 0,5 & 4,9 & 0,0 & 100 & harzburgita & porfi mosaico \\
\hline L81 & 79,8 & 8,5 & 0,0 & 0,1 & 9,5 & 2,1 & 100 & dunita & porfi \\
\hline L82 & 89,0 & 1,8 & 0,2 & 3,2 & 5,8 & 0,0 & 100 & dunita & gruesa/porfi \\
\hline $\mathrm{L} 82 \mathrm{a}$ & 39,0 & 57,2 & 1,5 & 2,0 & 0,3 & 0,0 & 100 & harzburgita & porfi \\
\hline $\mathrm{C} 1$ & 65,8 & 18,7 & 1,5 & 2,9 & 9,4 & 1,6 & 100 & harzburgita & porfi-mosaico \\
\hline C3-c & 0,0 & 36,9 & 57,0 & 0,3 & 2,4 & 3,4 & 100 & websterita & porfi-mosaico \\
\hline C5 & 49,3 & 6,9 & 42,5 & 0,8 & 0,5 & 0,0 & 100 & Iherzolita & gruesa/porfi \\
\hline c9-a & 53,9 & 3,6 & 32,9 & 2,9 & 6,3 & 0,4 & 100 & wherlita & granu \\
\hline C12-a & 1,8 & 29,7 & 59,5 & 0,9 & 4,2 & 3,9 & 100 & websterita & gruesa \\
\hline C13 & 0,0 & 43,4 & 49,5 & 0,6 & 3,6 & 2,9 & 100 & websterita & gruesa \\
\hline C14-b & 0,5 & 33,7 & 61,2 & 0,3 & 2,1 & 2,2 & 100 & websterita & gruesa \\
\hline C15 & 78,2 & 11,7 & 1,3 & 0,9 & 3,5 & 4,5 & 100 & harzburgita & porfi \\
\hline C17-b & 68,9 & 16,3 & 9,2 & 1,6 & 3,6 & 0,3 & 100 & Iherzolita & porfi \\
\hline C17-c & 72,1 & 20,1 & 2,1 & 2,1 & 2,9 & 0,7 & 100 & harzburgita & gruesa/porfi \\
\hline C18-a & 71,7 & 16,7 & 4,0 & 2,8 & 3,5 & 1,2 & 100 & harzburgita & porfi \\
\hline C18-b & 19,6 & 65,2 & 8,0 & 3,7 & 3,4 & 0,1 & 100 & websterita oli & porfi \\
\hline C18-b.1 & 0,0 & 76,7 & 17,2 & 2,4 & 3,9 & 0,0 & 100 & websterita & porfi \\
\hline C18-b.2 & 0,0 & 29,8 & 59,3 & 0,9 & 5,7 & 4,4 & 100 & websterita & gruesa/porfi \\
\hline C19 & 0,0 & 83,8 & 10,2 & 1,4 & 4,7 & 0,0 & 100 & websterita & gruesa/porfi \\
\hline$c 23-b$ & 0,0 & 85,1 & 5,3 & 0,3 & 3,3 & 5,9 & 100 & ortopiroxenita & gruesa \\
\hline C23-d & 0,0 & 83,0 & 13,6 & 0,9 & 2,2 & 0,4 & 100 & websterita & porfi \\
\hline C25-a & 0,0 & 22,7 & 72,9 & 0,7 & 3,7 & 0,0 & 100 & websterita & gruesa/porfi \\
\hline $\mathrm{C} 25-\mathrm{b}$ & 2,1 & 62,8 & 28,8 & 0,3 & 4,0 & 2,0 & 100 & websterita & porfi \\
\hline $\mathrm{C} 26$ & 0,0 & 43,9 & 53,6 & 0,2 & 2,3 & 0,1 & 100 & websterita & porfi \\
\hline C28-a & 20,6 & 68,5 & 3,6 & 2,0 & 3,2 & 2,1 & 100 & ortopiroxenita oli & porfi \\
\hline $\mathrm{C} 28-\mathrm{C}$ & 66,8 & 23,7 & 1,1 & 0,8 & 7,4 & 0,5 & 100 & harzburgita & gruesa/porfi \\
\hline C30-a & 4,4 & 75,1 & 15,3 & 1,1 & 3,5 & 0,5 & 100 & websterita & porfi \\
\hline $\mathrm{C} 30-\mathrm{b}$ & 4,5 & 86,5 & 7,0 & 1,1 & 0,9 & 0,0 & 100 & websterita & gruesa/porfi \\
\hline C31-a & 0,6 & 26,4 & 66,3 & 1,8 & 2,7 & 2,2 & 100 & websterita & porfi/granu \\
\hline $\mathrm{c} 28-\mathrm{b}$ & 18,8 & 59,6 & 14,8 & 1,5 & 3,1 & 2,2 & 100 & websterita oli & porfi \\
\hline
\end{tabular}




\begin{tabular}{|c|c|c|c|c|c|c|c|c|c|}
\hline Muestra & OI & Opx & Cpx & Sp & Vetas & Parches & Total & Roca & Textura \\
\hline $\mathrm{T} 7$ & 0,0 & 15,0 & 80,0 & 3,0 & 2,0 & 0,0 & 100 & websterita & granu \\
\hline $\mathrm{T} 10$ & 69,7 & 20,3 & 0,7 & 1,4 & 4,5 & 3,3 & 100 & harzburgita & porfi \\
\hline T15 & 61,8 & 30,4 & 5,1 & 1,3 & 1,4 & 0,0 & 100 & Iherzolita & porfi \\
\hline T16 & 76,8 & 16,7 & 2,7 & 0,5 & 3,1 & 0,3 & 100 & harzburgita & porfi \\
\hline T16 & 70,0 & 23,7 & 2,4 & 0,6 & 3,3 & 0,0 & 100 & harzburgita & porfi \\
\hline $\mathrm{T} 16-\mathrm{b}$ & 72,2 & 20,4 & 1,8 & 0,4 & 4,1 & 1,3 & 100 & harzburgita & porfi \\
\hline T18 & 71,4 & 24,6 & 1,9 & 0,9 & 1,2 & 0,0 & 100 & harzburgita & porfi \\
\hline $\mathrm{T} 18.2$ & 66,1 & 28,8 & 2,5 & 1,7 & 0,8 & 0,0 & 100 & harzburgita & porfi \\
\hline T19-a & 83,3 & 9,4 & 0,5 & 0,7 & 5,1 & 0,9 & 100 & casi dunita & gruesa/porf \\
\hline T19-b & 90,0 & 9,5 & 0,5 & 0,0 & 0,0 & 0,0 & 100 & dunita & gruesa \\
\hline T22 & 74,6 & 18,8 & 3,3 & 2,5 & 0,9 & 0,0 & 100 & harzburgita & porfi \\
\hline T23-a & 79,2 & 10,8 & 0,5 & 1,2 & 4,8 & 3,4 & 100 & harzburgita & porfi \\
\hline T23-b & 78,5 & 15,3 & 0,1 & 0,8 & 5,2 & 0,1 & 100 & harzburgita & porfi \\
\hline T31 & 74,5 & 16,1 & 1,4 & 2,8 & 5,2 & 0,0 & 100 & harzburgita & gruesa/porf \\
\hline T32 & 55,9 & 36,1 & 3,2 & 2,7 & 2,0 & 0,1 & 100 & harzburgita & granu \\
\hline T32.2 & 56,3 & 34,3 & 4,4 & 3,6 & 1,4 & 0,0 & 100 & harzburgita & granu \\
\hline T35-a & 83,3 & 10,2 & 2,0 & 0,8 & 3,7 & 0,0 & 100 & harzburgita & gruesa/porfi \\
\hline T37 & 69,2 & 8,0 & 13,7 & 1,3 & 4,4 & 3,3 & 100 & Iherzolita & porfi \\
\hline $\mathrm{T} 45$ & 58,8 & 32,0 & 3,2 & 1,8 & 4,2 & 0,0 & 100 & harzburgita & porfi \\
\hline T51 & 71,3 & 24,6 & 1,1 & 1,3 & 1,8 & 0,0 & 100 & harzburgita & gruesa/porfi \\
\hline $\mathrm{T} 51-\mathrm{b}$ & 60,8 & 34,1 & 2,8 & 1,1 & 1,1 & 0,0 & 100 & harzburgita & porfi-mosaico \\
\hline T51-j & 69,5 & 26,6 & 1,4 & 1,1 & 1,4 & 0,0 & 100 & harzburgita & porfi \\
\hline T53 & 57,2 & 39,1 & 2,8 & 0,6 & 0,3 & 0,0 & 100 & harzburgita & porfi \\
\hline T53-a & 69,1 & 19,0 & 1,2 & 1,8 & 7,2 & 1,7 & 100 & harzburgita & gruesa/porfi \\
\hline T60 & 81,6 & 9,6 & 3,0 & 1,6 & 3,9 & 0,2 & 100 & harzburgita & porfi \\
\hline T60-a & 76,7 & 15,2 & 1,9 & 0,8 & 5,4 & 0,0 & 100 & harzburgita & porfi \\
\hline T61-a & 82,4 & 9,4 & 1,0 & 2,0 & 5,3 & 0,2 & 100 & harzburgita & gruesa/porfi \\
\hline T63-a & 70,3 & 23,7 & 3,6 & 0,6 & 1,8 & 0,0 & 100 & harzburgita & gruesa/porfi \\
\hline T63-b & 72,4 & 21,5 & 2,8 & 2,0 & 1,3 & 0,0 & 100 & harzburgita & gruesa/porfi \\
\hline T64 & 61,5 & 27,4 & 2,2 & 1,3 & 1,4 & 6,3 & 100 & harzburgita & porfi \\
\hline T66 & 76,8 & 16,5 & 0,2 & 0,6 & 2,3 & 3,7 & 100 & harzburgita & porfi \\
\hline T71 & 77,8 & 18,3 & 0,4 & 0,5 & 3,0 & 0,0 & 100 & harzburgita & porfi \\
\hline T73-a & 59,9 & 30,1 & 6,2 & 2,2 & 1,2 & 0,4 & 100 & Iherzolita & porfi \\
\hline T73-b & 65,1 & 24,2 & 6,3 & 0,8 & 3,2 & 0,4 & 100 & Iherzolita & porfi \\
\hline $\mathrm{T} 74$ & 82,4 & 12,7 & 0,7 & 0,3 & 2,8 & 1,1 & 100 & harzburgita & porfi \\
\hline T79 & 62,8 & 23,1 & 8,3 & 2,6 & 2,4 & 0,8 & 100 & Iherzolita & porfi \\
\hline $\mathrm{P} 4$ & 0,0 & 63,9 & 29,9 & 3,4 & 2,8 & 0,0 & 100 & websterita & granulo \\
\hline P13-a & 0,0 & 72,5 & 25,0 & 0,4 & 2,2 & 0,0 & 100 & websterita & gruesa/porfi \\
\hline P42 & 0,0 & 94,3 & 2,8 & 0,4 & 2,5 & 0,0 & 100 & ortopiroxenita & gruesa \\
\hline P44 & 0,0 & 80,1 & 19,4 & 0,0 & 0,4 & 0,0 & 100 & websterita & granulo \\
\hline P57 & 0,0 & 81,6 & 14,2 & 1,4 & 2,8 & 0,0 & 100 & websterita & gruesa \\
\hline
\end{tabular}


Tabla 12.2a. Análisis de microsonda de cristales de olivino de xenolitos de $\mathrm{C}^{\circ}$ Chenque $(\mathrm{Q}) ; \mathrm{C}^{\circ}$ Matilde (M); $\mathrm{C}^{\circ}$ León (L); Cortadera (C) y Tapera Marín (T). d.l.d = debajo de límite de detección.

\begin{tabular}{|c|c|c|c|}
\hline 萑 & 要罗思 & 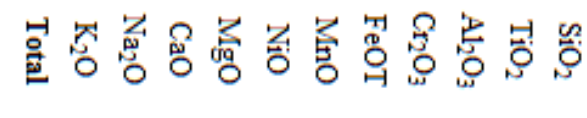 & 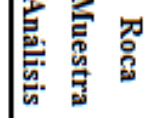 \\
\hline 号 & 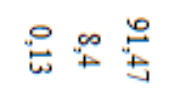 & 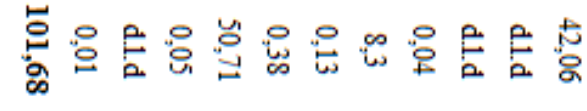 & 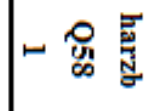 \\
\hline : & 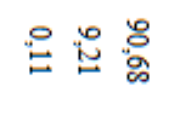 & 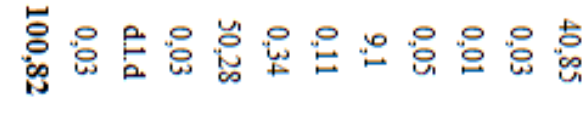 & N 요 \\
\hline $\overrightarrow{8}$ & 욤용 & 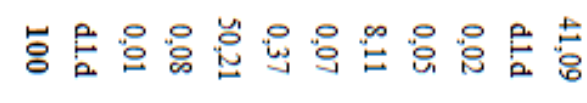 & $\omega$ \\
\hline \%ू & 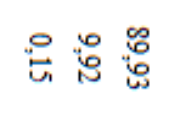 & 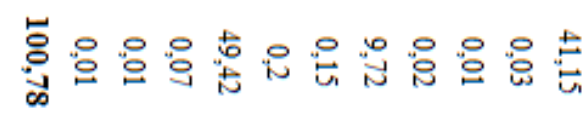 & - \\
\hline (: & 인 怘总 & 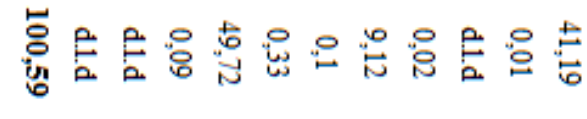 & N \\
\hline 良 & 욤 & 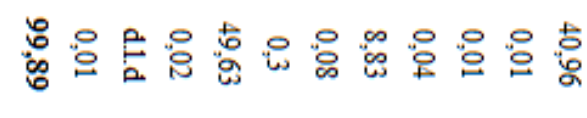 & $\omega$ \\
\hline 䍐 & 谂总菜 & 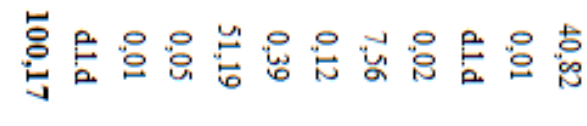 & \\
\hline 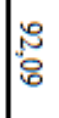 & 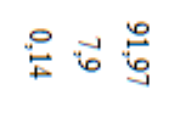 & 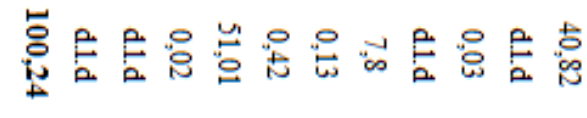 & w \\
\hline 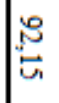 & 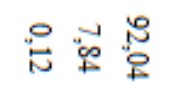 & 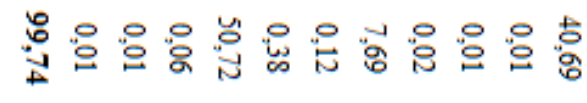 & \\
\hline 总 & 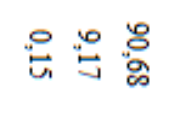 & 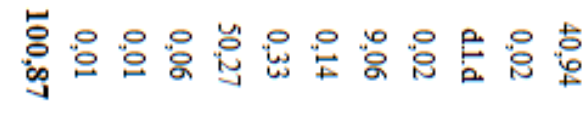 & - \\
\hline : & 을 & 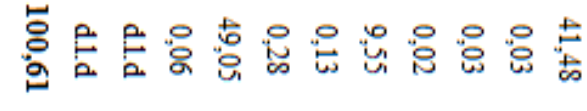 & No \\
\hline$\stackrel{3}{\circ}$ & 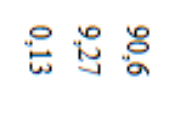 & 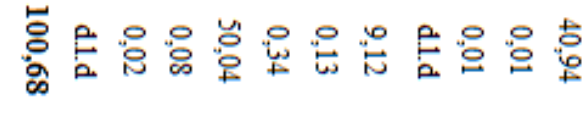 & \\
\hline 号 & 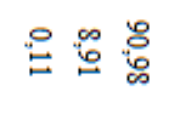 & 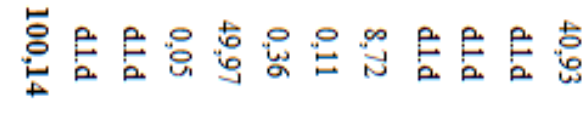 & 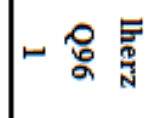 \\
\hline 疍 & 은 & 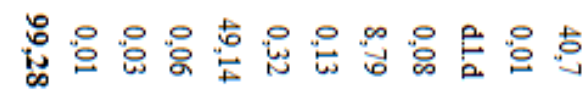 & $\omega$ \\
\hline$\stackrel{0}{\square}$ & 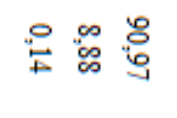 & 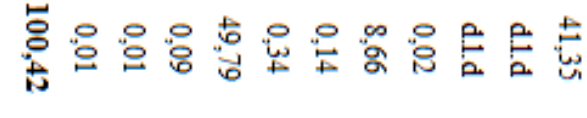 & \\
\hline 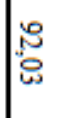 & 잉 范总 & 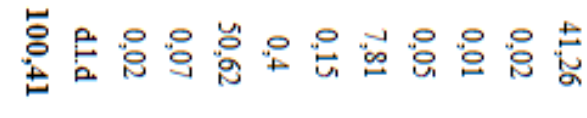 & \\
\hline$\stackrel{\circ}{\circ}$ & $\because \infty \stackrel{\circ}{\stackrel{\circ}{\circ}}$ & 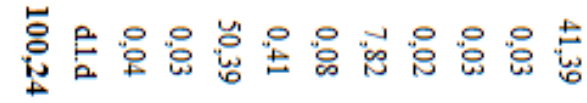 & $\xi$ \\
\hline
\end{tabular}


Tabla 12.2a. Continuación.

\begin{tabular}{|c|c|c|c|}
\hline 萫 & 要 & 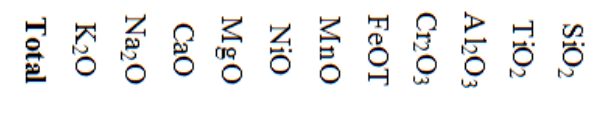 & 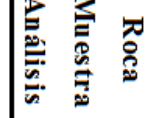 \\
\hline ". & 品楞总 & 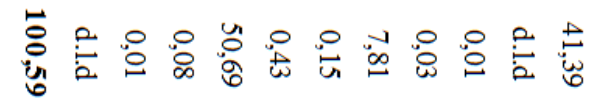 & $\sim \stackrel{\circ}{\stackrel{8}{g}}$ \\
\hline$\underset{\substack{\infty \\
\infty}}{\stackrel{\infty}{\infty}}$ & 임 & 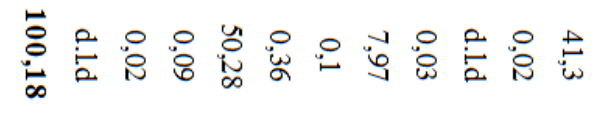 & $\omega \stackrel{\rho}{\stackrel{\rho}{g}}$ \\
\hline 苫 & 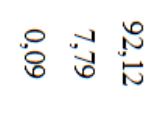 & 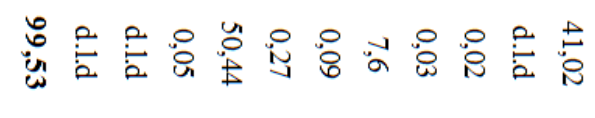 & 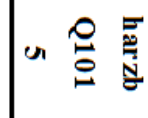 \\
\hline $\begin{array}{l}8 \\
: \\
\infty \\
\infty\end{array}$ & : & 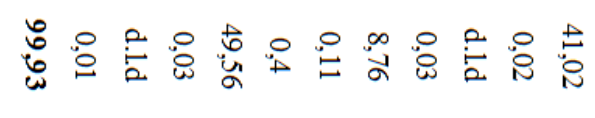 & 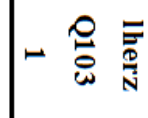 \\
\hline $\mathscr{W}_{\text {L }}^{\circ}$ & : & 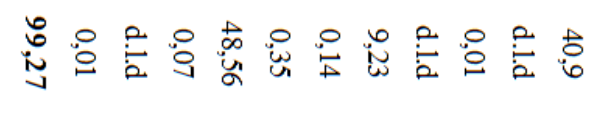 & 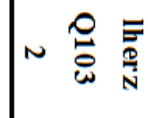 \\
\hline$\stackrel{\circ}{\circ}$ & 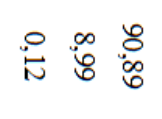 & 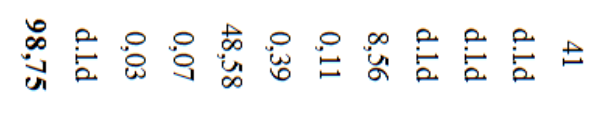 & 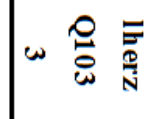 \\
\hline 䓌 & 윰 & 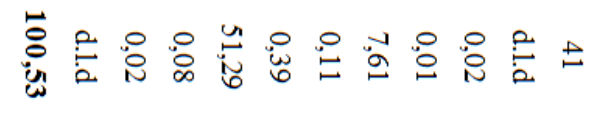 & - \\
\hline 必 & 윰욤 & 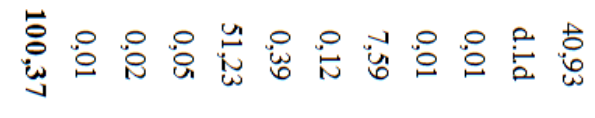 & 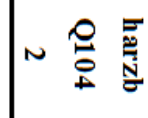 \\
\hline 总 & 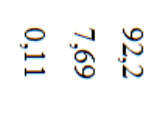 & 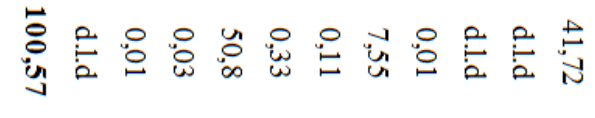 & $\omega \stackrel{\circ}{\circ}$ \\
\hline 总 & 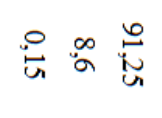 & 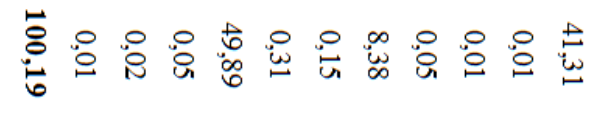 & $+\stackrel{8}{\circ}$ \\
\hline 索 & 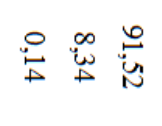 & 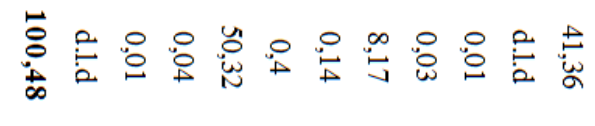 & - \\
\hline 号 & 号染芯 & 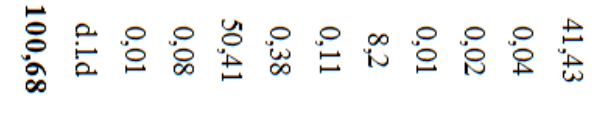 & N 葛 $\overline{0}$ \\
\hline 常 & 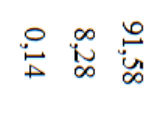 & 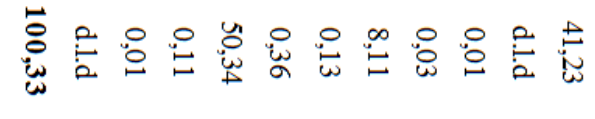 & 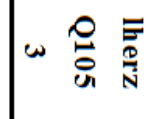 \\
\hline 蒙 & $\stackrel{\infty}{\infty} \underset{\infty}{\infty} \bullet$ & 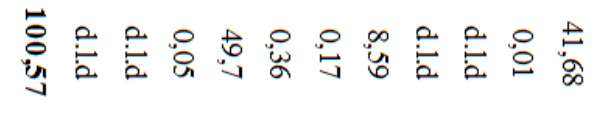 & - \\
\hline 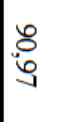 & 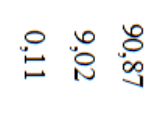 & 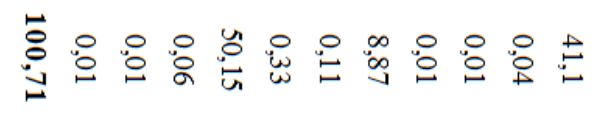 & N \\
\hline 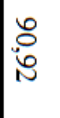 & : & 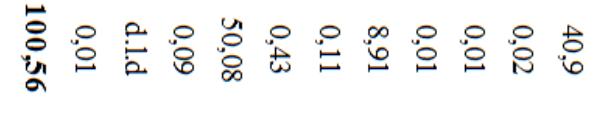 & 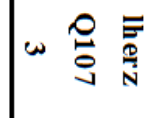 \\
\hline 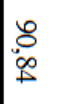 & 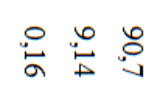 & 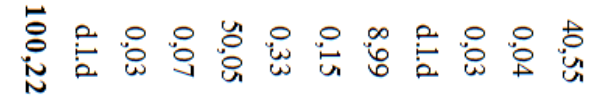 & 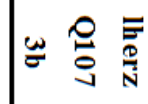 \\
\hline
\end{tabular}


Tabla 12.2a. Continuación.

\begin{tabular}{|c|c|c|c|}
\hline 蒡 & 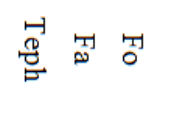 & 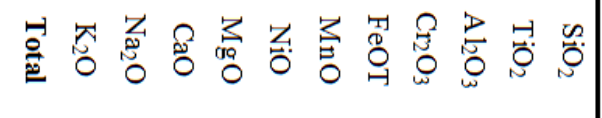 & 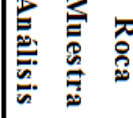 \\
\hline 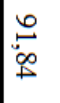 & 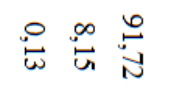 & 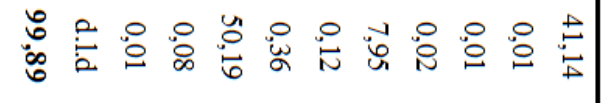 & $\sim \stackrel{0}{\stackrel{0}{*}}$ \\
\hline 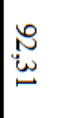 & 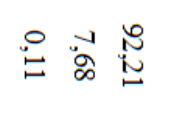 & 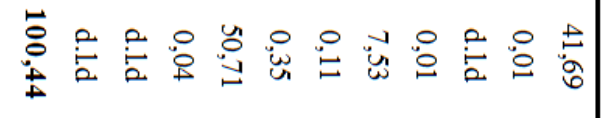 & 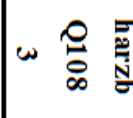 \\
\hline 勇 & $\because \underset{1}{0}$ & 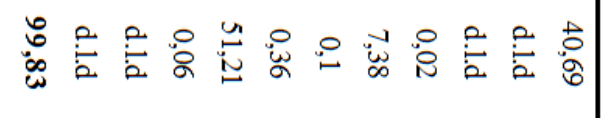 & $-\stackrel{\circ}{\circ}$ \\
\hline 总 & $\stackrel{0}{\infty} \stackrel{\infty}{\infty} \stackrel{0}{:}$ & 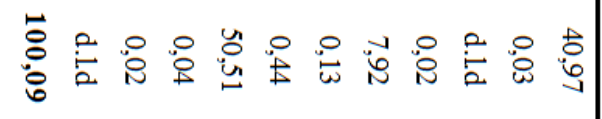 & 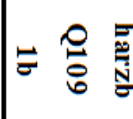 \\
\hline 雚 & 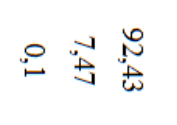 & 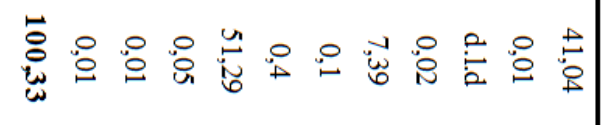 & N \\
\hline$\stackrel{0}{\circ}$ & 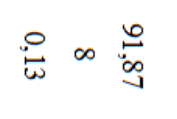 & : & $\approx \stackrel{0}{8}$ \\
\hline 垈 & 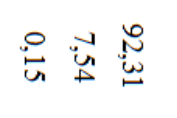 & 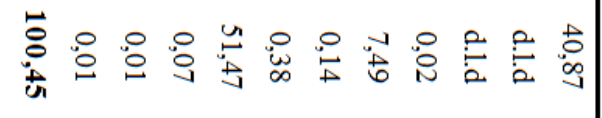 & $\omega \stackrel{0}{0}$ \\
\hline $\begin{array}{l}\overbrace{0} \\
i \\
i\end{array}$ & 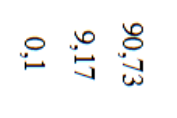 & 离点 & - 謩宽 \\
\hline 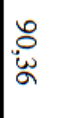 & 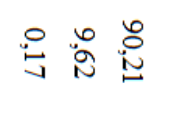 & 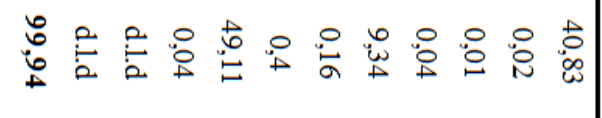 & 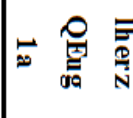 \\
\hline $\begin{array}{l}\mathscr{l}_{\infty} \\
\substack{\infty \\
\infty}\end{array}$ & 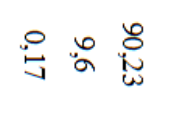 & 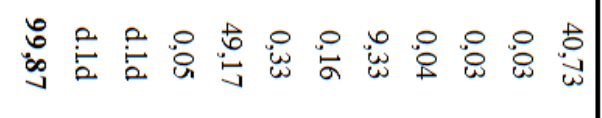 & N \\
\hline 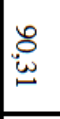 & 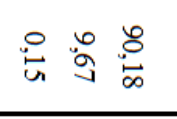 & 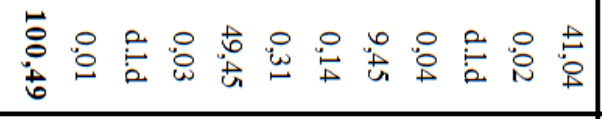 & 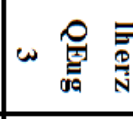 \\
\hline \begin{tabular}{ll}
8 \\
$:$ \\
\hdashline \\
\hdashline
\end{tabular} & 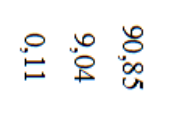 & 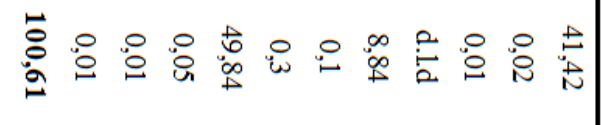 & - 空高 \\
\hline : & 원 & 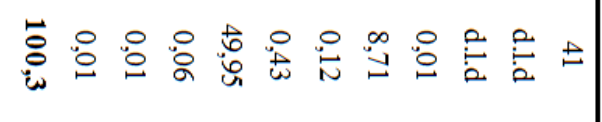 & N空高 \\
\hline$\stackrel{\circ}{\circ}$ & 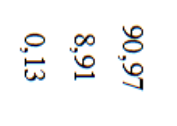 & 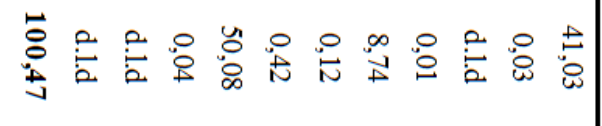 & $\omega$ 空高 \\
\hline$\stackrel{\circ}{\circ}$ & 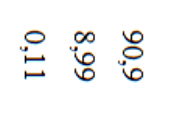 & 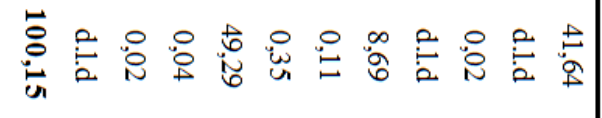 & 岕堂高 \\
\hline 总 & 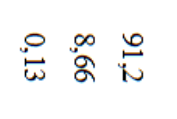 & 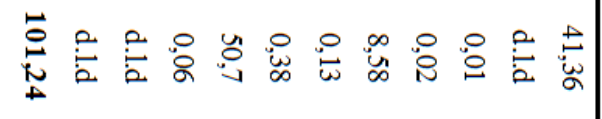 & - 䆓 \\
\hline 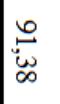 & 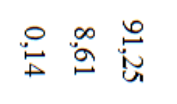 & 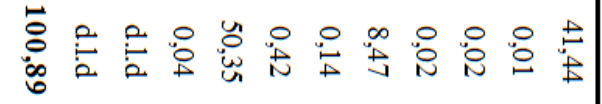 & N 䆓 \\
\hline
\end{tabular}


Tabla 12.2a. Continuación.

\begin{tabular}{|c|c|c|c|}
\hline 茎 & 要团团 & 불 杂芯 & 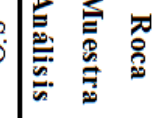 \\
\hline $\mathbb{N}$ & 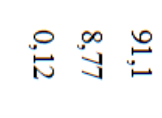 & 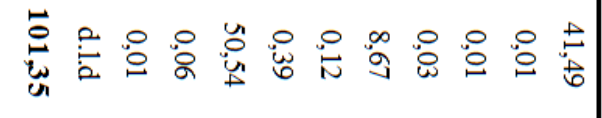 & w 空 \\
\hline 惫 & 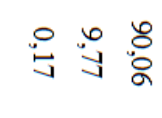 & 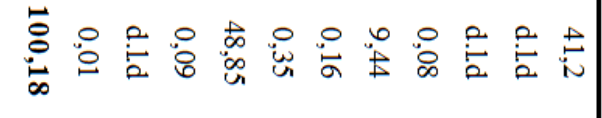 & - 学 \\
\hline 6 & 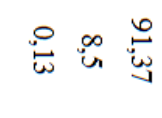 & 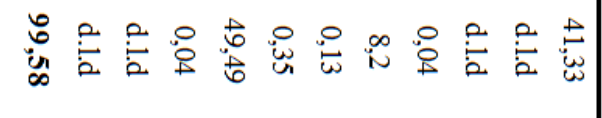 & N 岁 \\
\hline 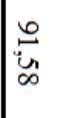 & 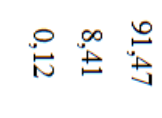 & 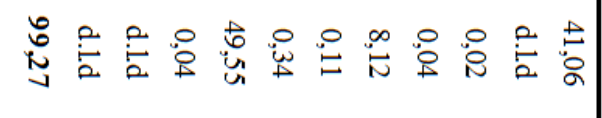 & w 窎 \\
\hline$\sqrt{6}$ & 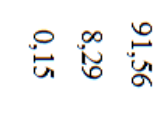 & 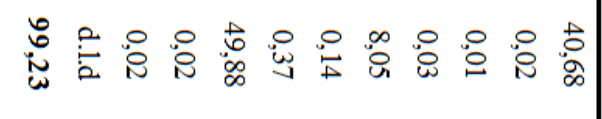 & - हू \\
\hline$\underset{\infty}{\sim}$ & 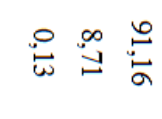 & 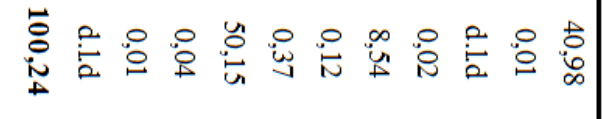 & : \\
\hline 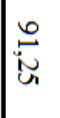 & $\because \stackrel{\infty}{*} \stackrel{0}{+}$ & 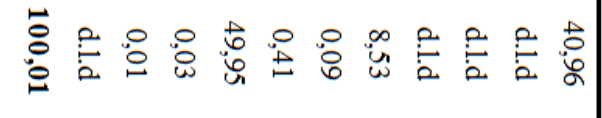 & ? \\
\hline$\frac{0}{6}$ & 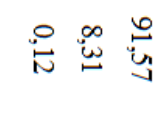 & 怘总菅 & 는 \\
\hline$\frac{\tilde{\omega}}{\infty}$ & 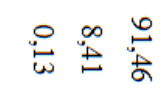 & 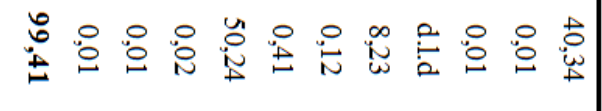 & w 光 \\
\hline$\frac{0}{0}$ & 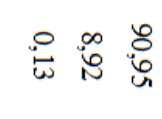 & 这 & w \\
\hline$\frac{0}{6}$ & $\stackrel{\circ}{\infty} \underset{\infty}{\infty} \stackrel{0}{\circ}$ & 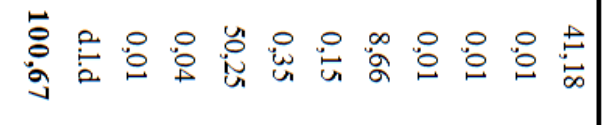 & N 光 \\
\hline$\frac{0}{E_{n}}$ & 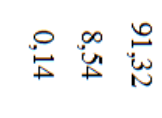 & 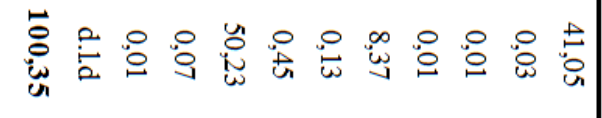 & - Зู \\
\hline 总 & 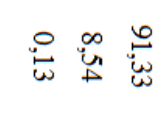 & 总莣 & N \\
\hline 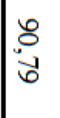 & 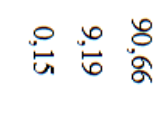 & 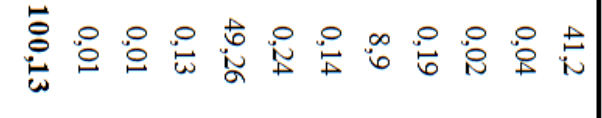 & $\omega$ 党 \\
\hline שِ & : & 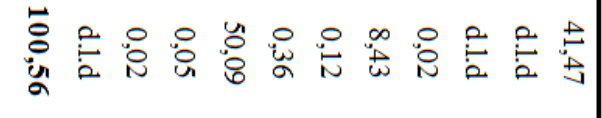 & 一血蛋 \\
\hline 常 & 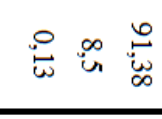 & 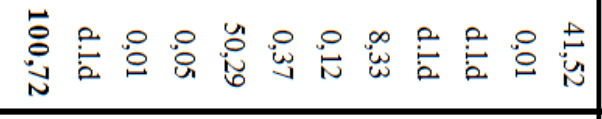 & N甶害 \\
\hline 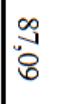 & 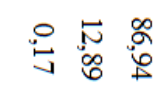 & 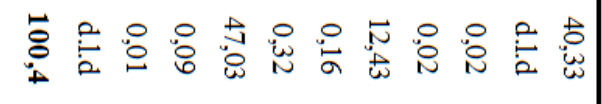 & $\sim \varpi^{2}$ \\
\hline
\end{tabular}


Tabla 12.2a. Continuación.

\begin{tabular}{|c|c|c|c|}
\hline 荧 & 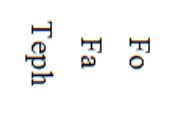 & 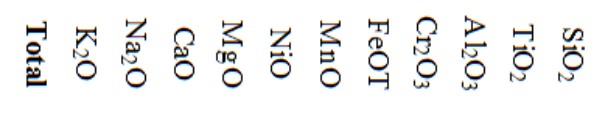 & 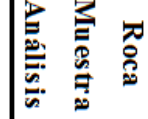 \\
\hline \pm & 品离总 & 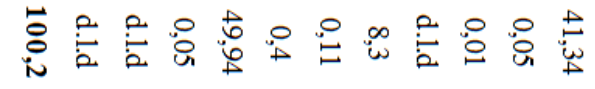 & $-\underbrace{5}_{\infty}$ \\
\hline 峁 & 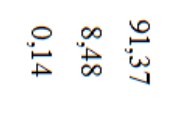 & 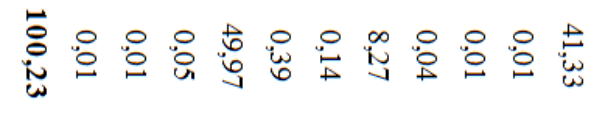 & $\sim \underbrace{5}_{\infty}$ \\
\hline 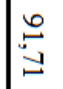 & 号点苔 & 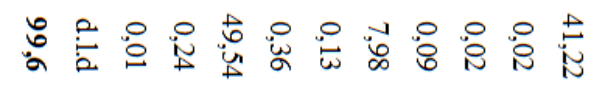 & 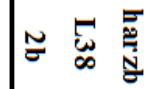 \\
\hline 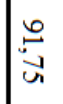 & 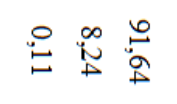 & 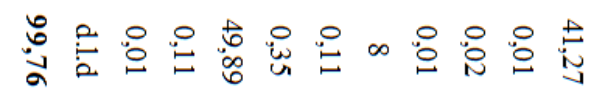 & $\approx D_{\infty}^{5}$ \\
\hline ( & 怘点怘 & 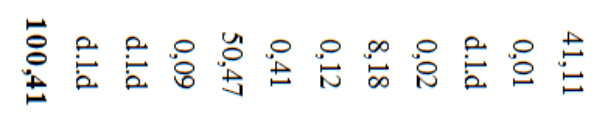 & - $\underset{\sim}{\infty}$ \\
\hline 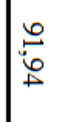 & 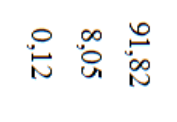 & 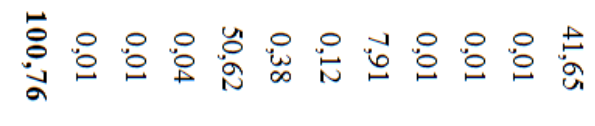 & $\sim \underset{\sim}{<}$ \\
\hline 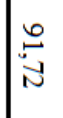 & 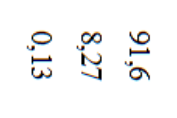 & 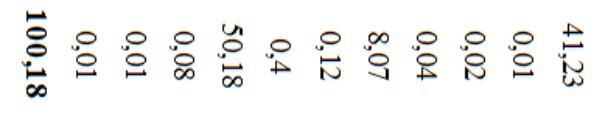 & 당 \\
\hline 旁 & : & 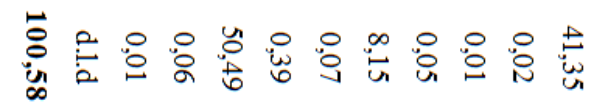 & 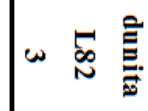 \\
\hline $\begin{array}{ll}0 \\
:\end{array}$ & 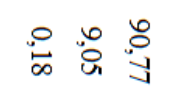 & 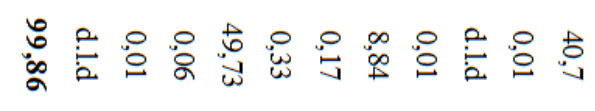 & $-\approx \frac{\bar{D}}{\mathrm{~N}}$ \\
\hline 萬 & 茪 & 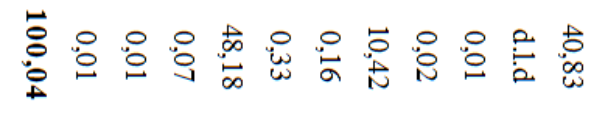 & $F$ in \\
\hline 这 & $\ddot{8}: \stackrel{8}{8}$ & 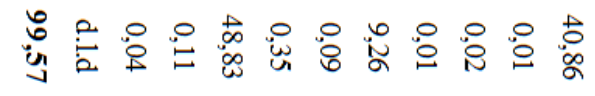 & $\sim \approx \overline{\frac{D}{n}}$ \\
\hline$\underbrace{\infty}_{\infty}$ & 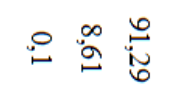 & 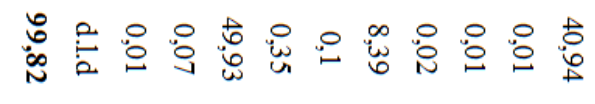 & $-\vec{\infty}$ \\
\hline 常 & 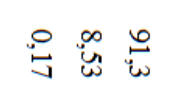 & 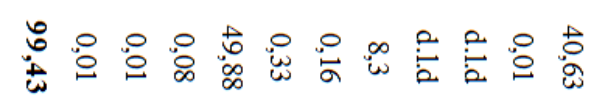 & $\sim \underset{\infty}{\exists}$ \\
\hline : & 怘总怘 & 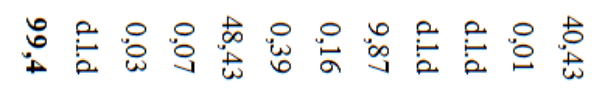 & $+\underset{\infty}{\theta}$ \\
\hline
\end{tabular}


Tabla 12.2b. Análisis de microsonda de cristales de ortopiroxeno de xenolitos de $\mathrm{C}^{\circ}$ Chenque (Q); $\mathrm{C}^{\circ}$ Matilde (M); $\mathrm{C}^{\circ}$ León (L); Cortadera (C) y Tapera Marín (T). d.l.d = debajo de límite de detección.

\begin{tabular}{|c|c|c|c|}
\hline 蒡 & 車田を & 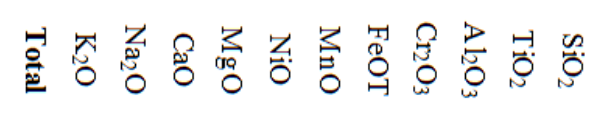 & 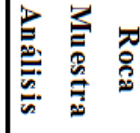 \\
\hline is & 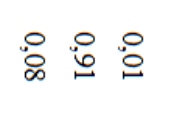 & 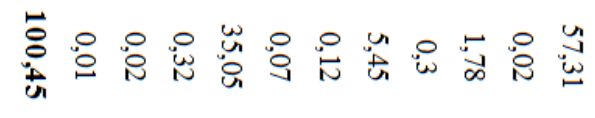 & $-\infty$ \\
\hline is & $\because \stackrel{\circ}{\circ} \because$ & 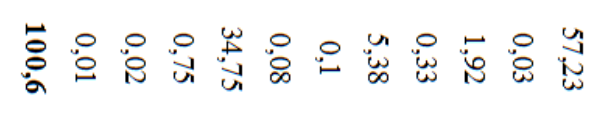 & 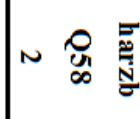 \\
\hline is & $\because \ddot{\circ}: 0$ & 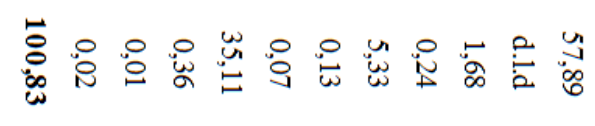 & w \\
\hline :ْ & 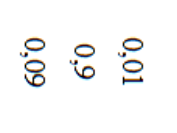 & 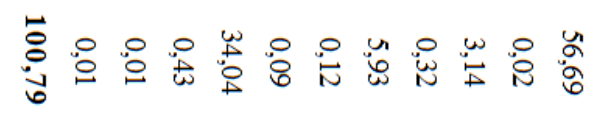 & - 용 \\
\hline ஜ̊ & 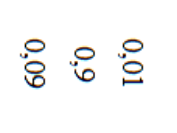 & 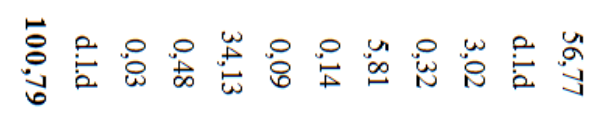 & N \\
\hline ஜٌ & 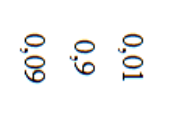 & 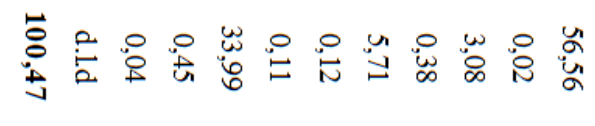 & w \\
\hline $\begin{array}{l}\infty \\
\infty \\
\infty\end{array}$ & 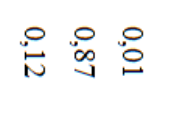 & 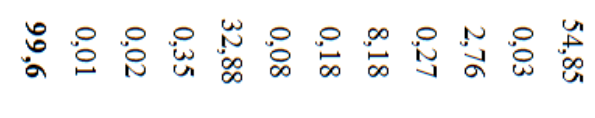 & - 억 兽 \\
\hline$\stackrel{\infty}{\infty}$ & 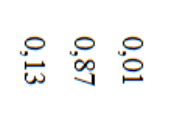 & 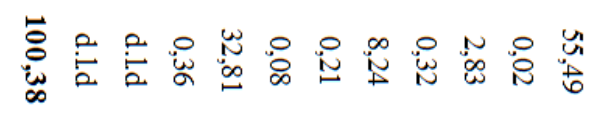 & N 억 兽 \\
\hline $\begin{array}{l}\infty \\
\infty \\
\infty\end{array}$ & $\stackrel{i}{\circ} \stackrel{-\infty}{0}$ & 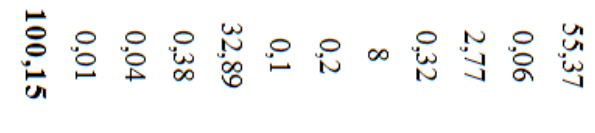 & 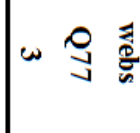 \\
\hline is & 용 웅 & : & $+\infty$ \\
\hline 운 & 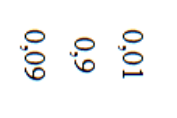 & 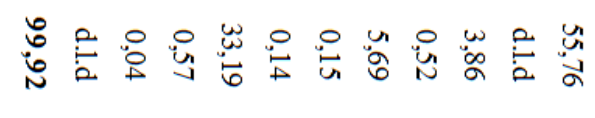 & 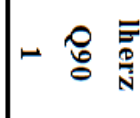 \\
\hline 。ํํㅇ & 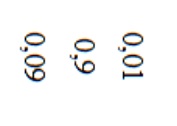 & 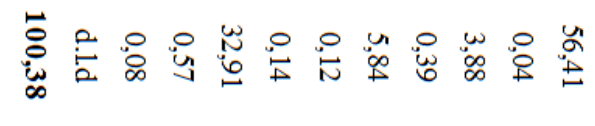 & $\approx$ : \\
\hline 品 & 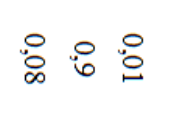 & 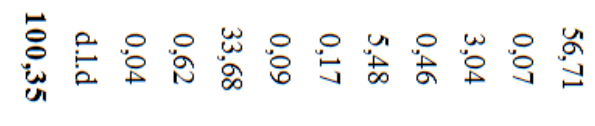 & - م : \\
\hline 웅 & $\because \because \%$ & 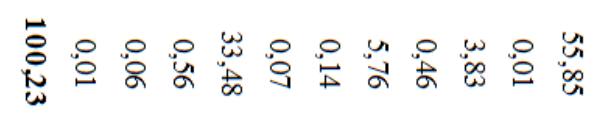 & N \\
\hline i⿺ & $\therefore$ & 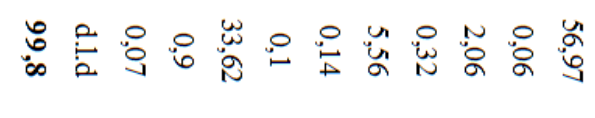 & $\omega \stackrel{\circ}{\circ}$ \\
\hline i⿱宀 & 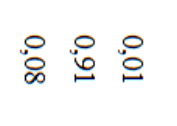 & 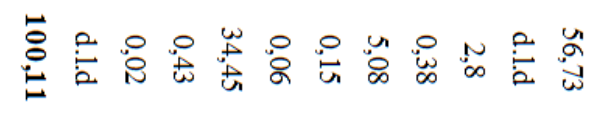 & $-\stackrel{8}{\circ}$ \\
\hline : & 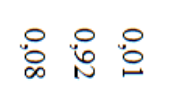 & 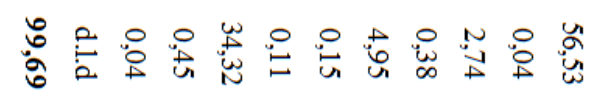 & 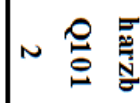 \\
\hline
\end{tabular}


Tabla 12.2b. Continuación.

\begin{tabular}{|c|c|c|c|}
\hline & 果田贯 & 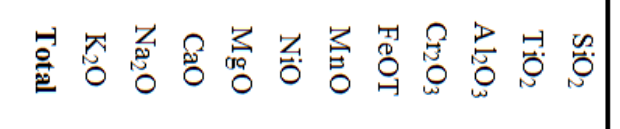 & 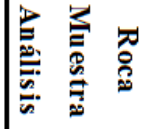 \\
\hline 8 & : 용: & 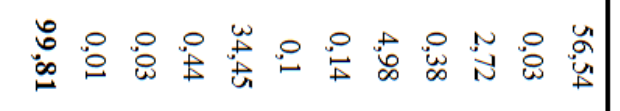 & $\cong \stackrel{8}{\circ}$ \\
\hline & $\therefore:$ & 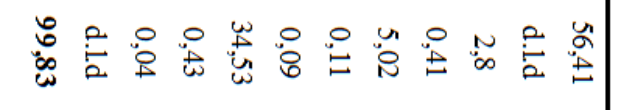 & 的 \\
\hline ic & 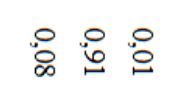 & $\begin{array}{l}0 \\
0 \\
0\end{array}$ & $-\stackrel{\mathscr{B}}{\mathrm{E}}$ \\
\hline$x$ & $\because: \circ:$ & 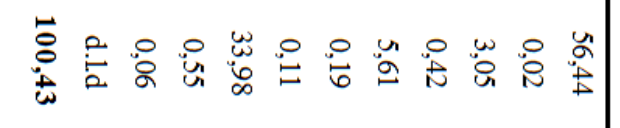 & $\sim$ \\
\hline$\stackrel{8}{\circ}$ & $\because: 0$ & 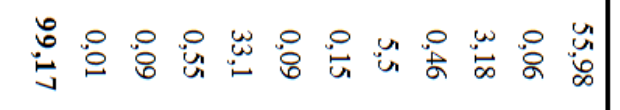 & $\omega \stackrel{8}{\stackrel{\Xi}{\leftrightarrows}}$ \\
\hline$\stackrel{8}{8}$ & : 용: & 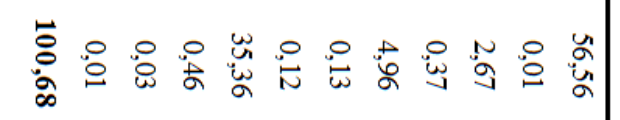 & $-\stackrel{\varrho}{+}$ \\
\hline ¿̊ & 品兑: & 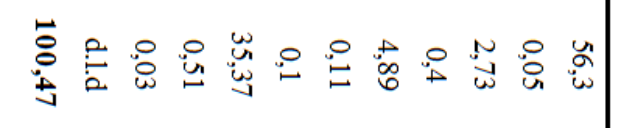 & 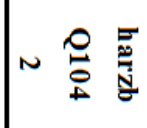 \\
\hline is & $\therefore$ & 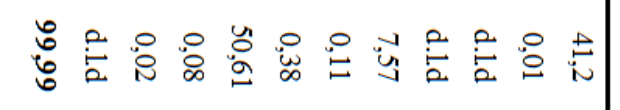 & $\omega \stackrel{9}{!}$ \\
\hline io & 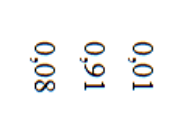 & 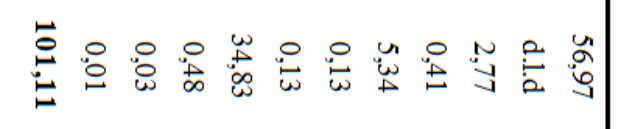 & $-\stackrel{\ominus}{\square}$ \\
\hline i̊ & $\therefore:$ & 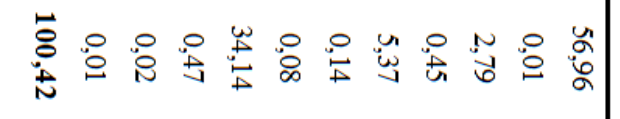 & $\stackrel{8}{8}$ \\
\hline io & 용 웅 & 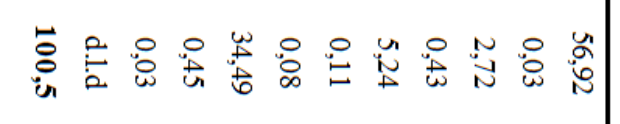 & $\omega \stackrel{\circ}{\stackrel{0}{0}}$ \\
\hline 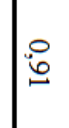 & $\because: \circ:$ & 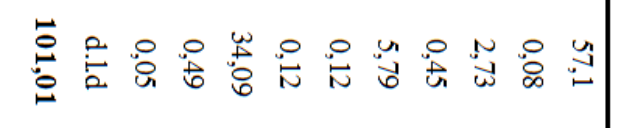 & $-\stackrel{8}{g}$ \\
\hline :̊ & 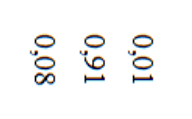 & 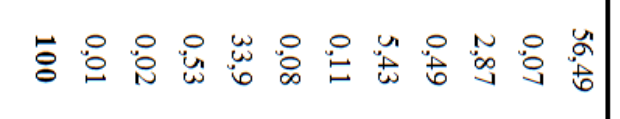 & $=\stackrel{9}{g}$ \\
\hline : & 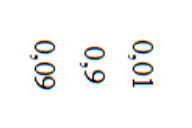 & 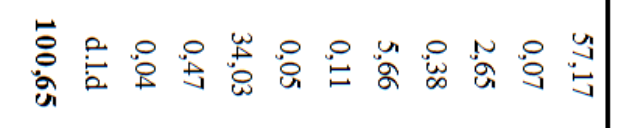 & $\sim \stackrel{8}{9}$ \\
\hline \& & $\because: 0$ & 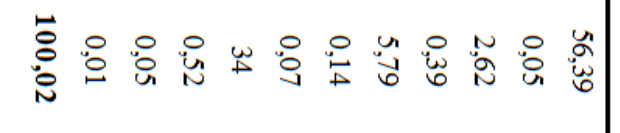 & $\omega \stackrel{\ominus}{\stackrel{0}{*}}$ \\
\hline is & $: \stackrel{0}{\circ}: \stackrel{\circ}{\circ}$ & 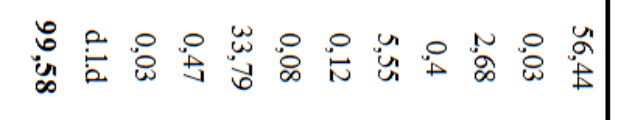 & $+\stackrel{8}{9}$ \\
\hline : & 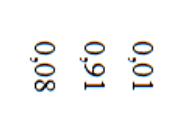 & 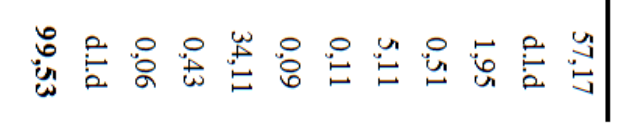 & $\sim \cong$ \\
\hline
\end{tabular}


Tabla 12.2b. Continuación.

\begin{tabular}{|c|c|c|c|}
\hline & 車四艺 & 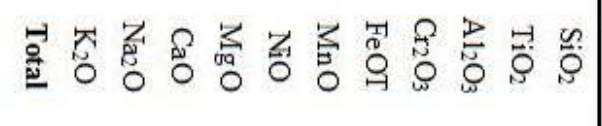 & 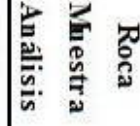 \\
\hline & 웅 is "웅 & 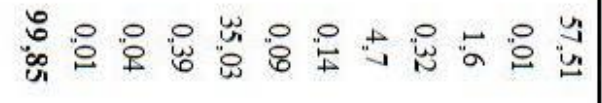 & $\omega \stackrel{\circ}{\stackrel{0}{\circ}}$ \\
\hline & 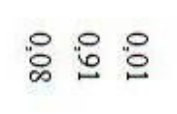 & 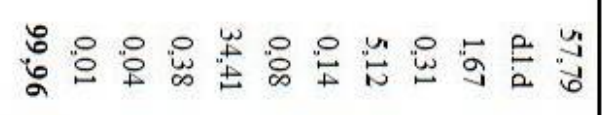 & $\underset{\infty}{\infty} \stackrel{?}{\circ}$ \\
\hline & 옹 : 웅 & 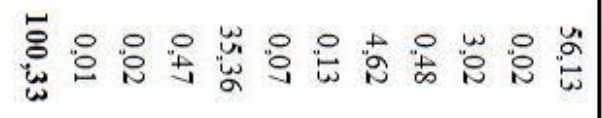 & $-\stackrel{\circ}{8}$ \\
\hline & "is is "웅 & 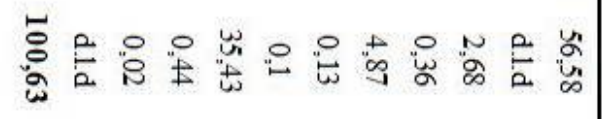 & N \\
\hline & 웅 is: & 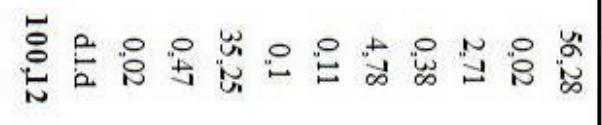 & $\omega \stackrel{\circ}{\circ}$ \\
\hline & 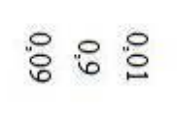 & 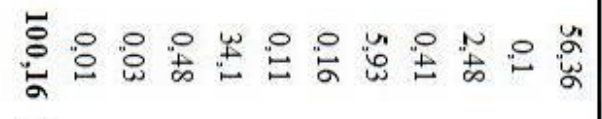 & 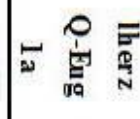 \\
\hline & $\therefore: \circ$ & 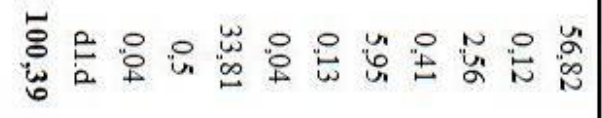 & N 畩 \\
\hline & :8: & 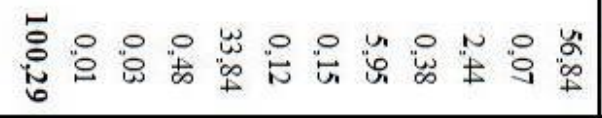 & 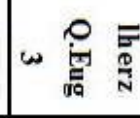 \\
\hline & : 융 & 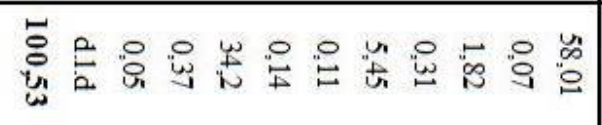 & $\approx$ 岕 \\
\hline & "융ㅇㅇ & 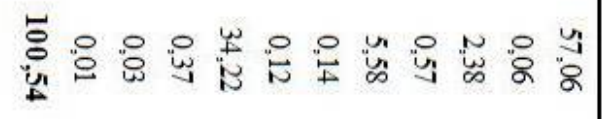 & - 党 \\
\hline & $\because 8:$ & 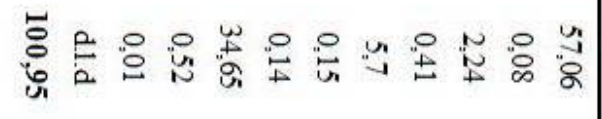 & N 莞 \\
\hline 8 & $\therefore$ 응 & 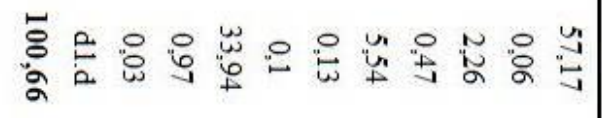 & 㝒 \\
\hline is & :융요 & 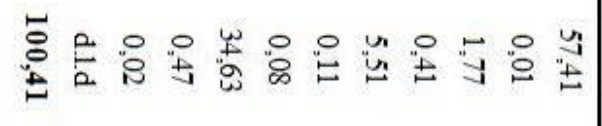 & 一䒺 \\
\hline is & ஃ용요 & 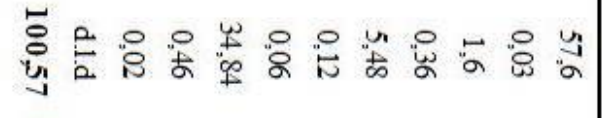 & 心否 \\
\hline 这 & 용 & 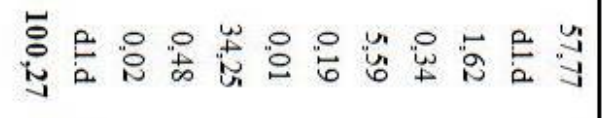 & 山忿 \\
\hline 웅 & "유" & 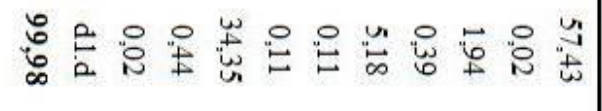 & 一耍 \\
\hline & ". & 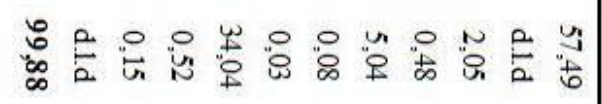 & 心光 \\
\hline
\end{tabular}


Tabla 12.2b. Continuación.

\begin{tabular}{|c|c|c|c|}
\hline & আ & 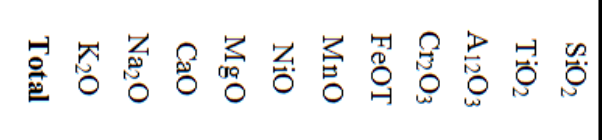 & 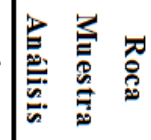 \\
\hline & $\because \stackrel{\circ}{\circ} \cong$ & 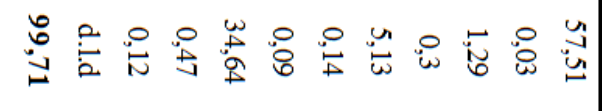 & + 窎 \\
\hline & 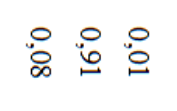 & 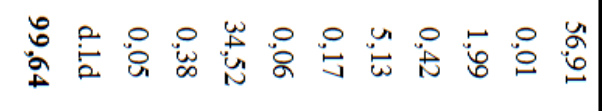 & - \\
\hline & ¿ & 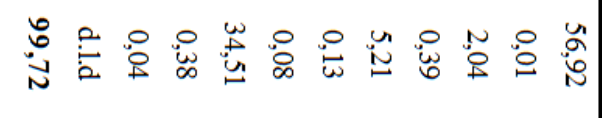 & N 学 \\
\hline & $\ddot{\infty}: \circ$ & 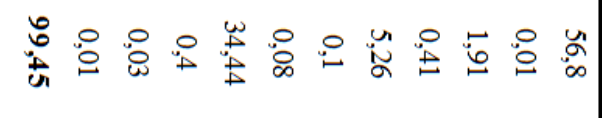 & w \\
\hline & ¿ & 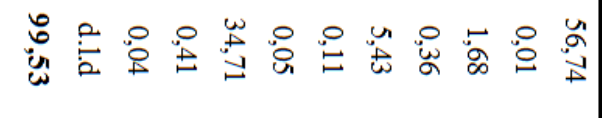 & - 学 \\
\hline & $\therefore$ & 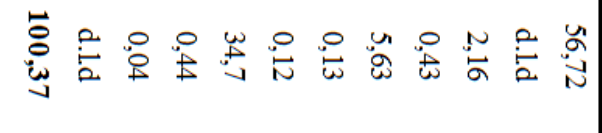 & N \\
\hline & $\because \ddot{\infty}:$ & 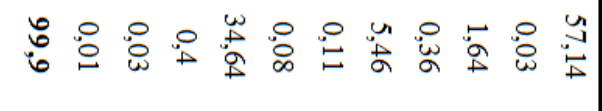 & w 并 \\
\hline & 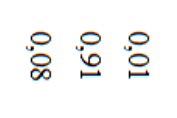 & 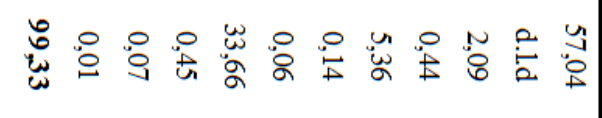 & +3 \\
\hline & $\therefore$ & 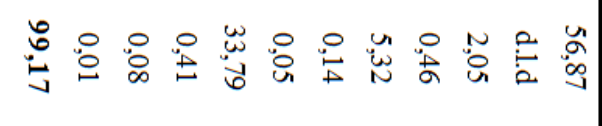 & \# 쳑 \\
\hline & $\because \ddot{\circ}:$ & 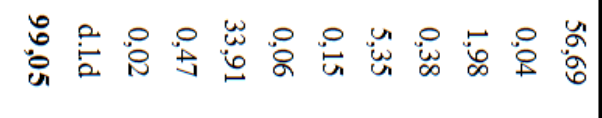 & म \\
\hline & 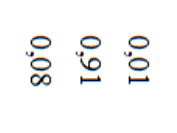 & 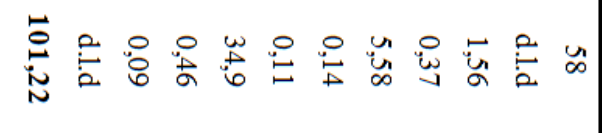 & 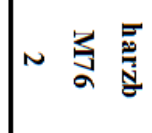 \\
\hline & $\because \ddot{\infty}: 0$ & 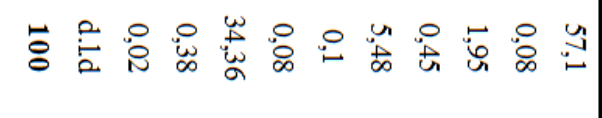 & 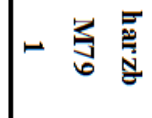 \\
\hline & 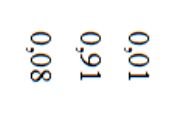 & 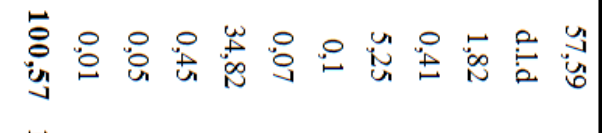 & N 㝍 \\
\hline & $\because \stackrel{\circ}{\circ}:$ & 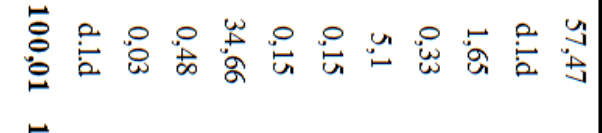 & $\omega$ क \\
\hline & $\because \stackrel{\infty}{\circ}:$ & 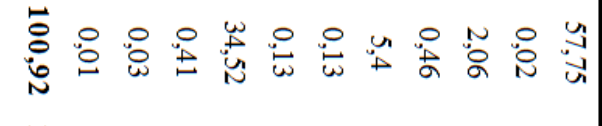 & 一当光 \\
\hline & 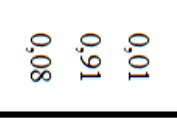 & 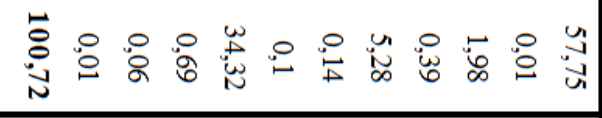 & 几名党 \\
\hline & 离祭总 & 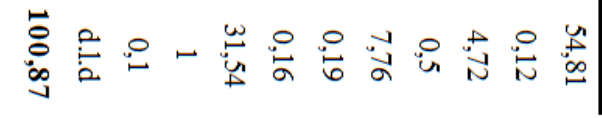 & $-\sqrt[5]{-5}$ \\
\hline
\end{tabular}


Tabla 12.2b. Continuación.

\begin{tabular}{|c|c|c|c|}
\hline & T्र & 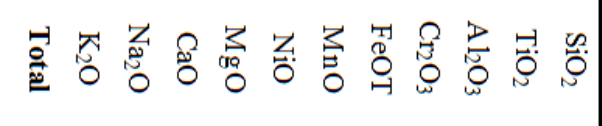 & 焉 \\
\hline & 选 品 & 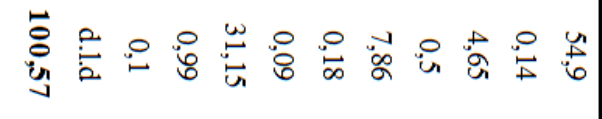 & $N \underset{\omega}{5}$ \\
\hline & 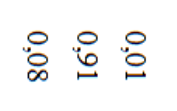 & 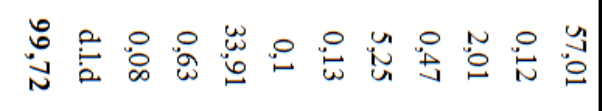 & $-\Sigma_{\infty}^{5}$ \\
\hline & 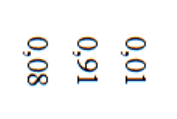 & 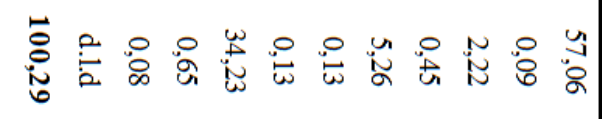 & $\sim \underset{\infty}{\sim}$ \\
\hline & : & 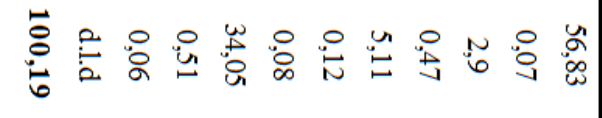 & $-\underset{N}{\infty}$ \\
\hline & ஃ & 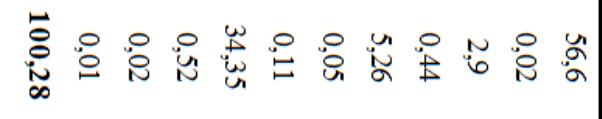 & $\approx \underset{\sim}{\stackrel{\infty}{N}}$ \\
\hline & 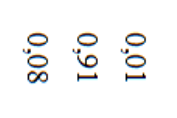 & 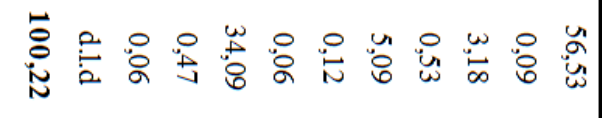 & $\sim \infty$ \\
\hline & 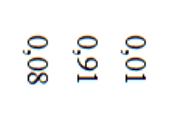 & 官: & 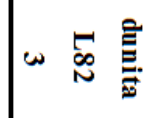 \\
\hline & $\therefore \stackrel{\circ}{\infty}:$ & 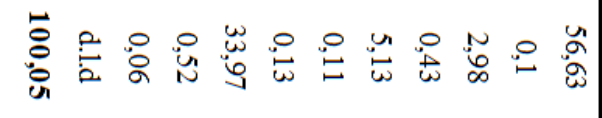 & $+\underset{\substack{\infty \\
N}}{\stackrel{\infty}{N}}$ \\
\hline & $\therefore \stackrel{\circ}{\circ}:$ & 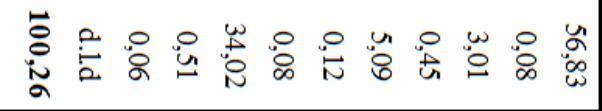 & 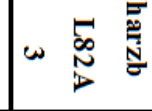 \\
\hline & 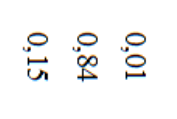 & 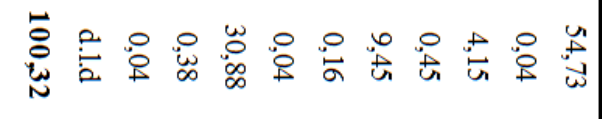 & 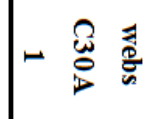 \\
\hline & 品品怘 & 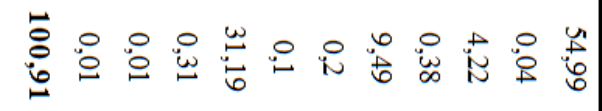 & $N \underset{\mathscr{D}}{\mathscr{D}}$ \\
\hline & $\because 0$ & 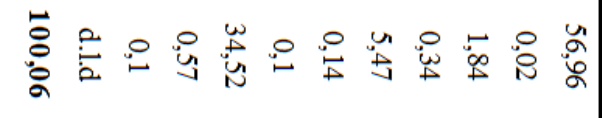 & $-\vec{\infty}$ \\
\hline & ¿̊口 & 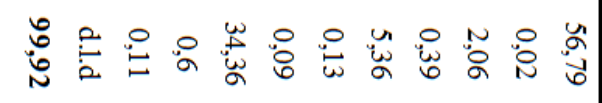 & $\sim \underset{\infty}{\vec{G}}$ \\
\hline
\end{tabular}


Tabla 12.2c). Análisis de microsonda de cristales de clinopiroxeno de xenolitos de $\mathrm{C}^{\circ}$ Chenque (Q); $\mathrm{C}^{\circ}$ Matilde (M); $\mathrm{C}^{\circ}$ León (L); Cortadera (C) y Tapera Marín (T). d.l.d = debajo de límite de detección.

\begin{tabular}{|c|c|c|c|c|}
\hline & 柋 & & 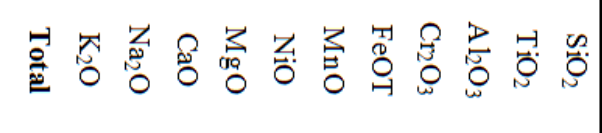 & 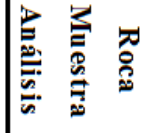 \\
\hline & $\stackrel{0}{\circ}$ & 足 & 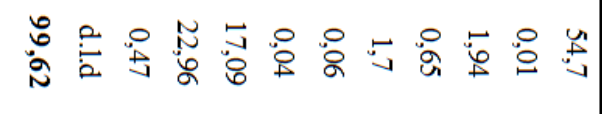 & $-\underset{\infty}{0}$ \\
\hline & $\stackrel{\circ}{\circ}$ & $\stackrel{\circ}{\infty}$ & 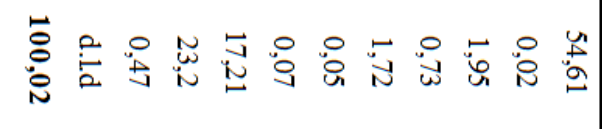 & $\omega$ \\
\hline & $\stackrel{\circ}{\circ}$ & $\begin{array}{l}\infty \\
\infty \\
\infty\end{array}$ & 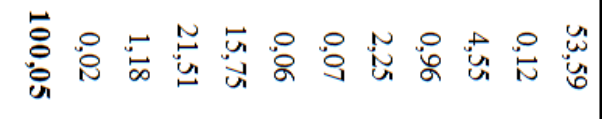 & - \& \\
\hline & 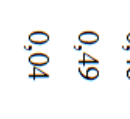 & & 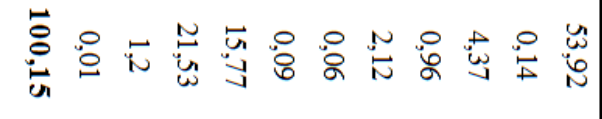 & N \\
\hline & $\stackrel{\circ}{\circ}$ & $\stackrel{\circ}{\infty}$ & 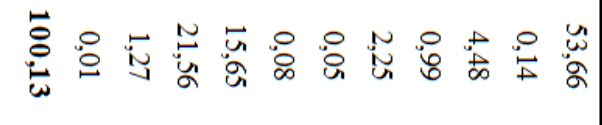 & w \\
\hline & $\stackrel{\circ}{\circ}$ & $\begin{array}{l}0 \\
\infty \\
\infty\end{array}$ & 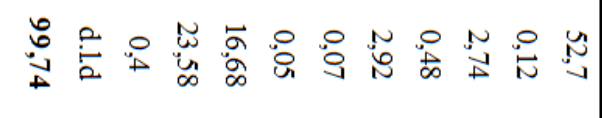 & - 엉 \\
\hline & $\stackrel{\circ}{\circ}$ & $\stackrel{0}{\infty}$ & 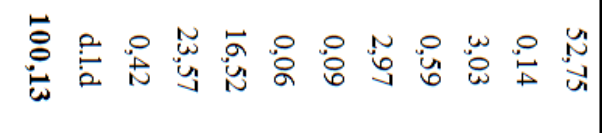 & 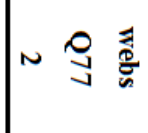 \\
\hline & $\therefore$ & $\stackrel{\infty}{\infty}$ & 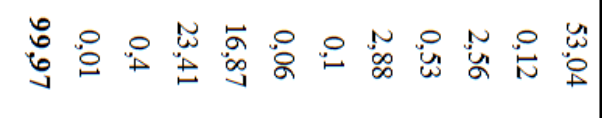 & 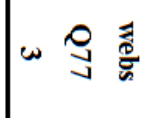 \\
\hline & $\because i_{i}:$ & $\stackrel{\circ}{\oplus}$ & 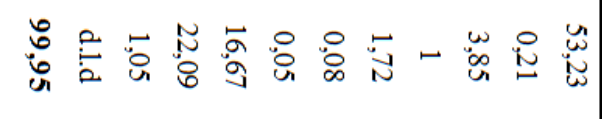 & $-\infty$ \\
\hline & $\therefore$ & $\stackrel{\infty}{\infty}$ & 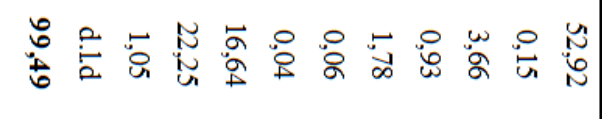 & $\omega \stackrel{\&}{0}$ \\
\hline & $\therefore \circ$ & 足 & 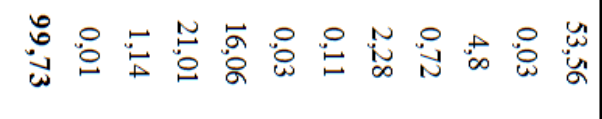 & - : : \\
\hline & $\because$ & $\stackrel{\circ}{ \pm}$ & 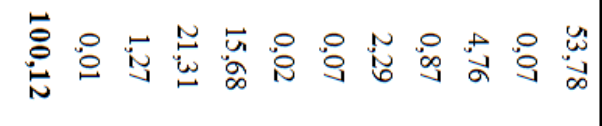 & $\approx:$ \\
\hline & $\therefore$ in & 吕 & 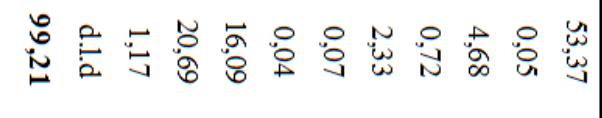 & $\omega:$ \\
\hline & $\because 8$ & 今 & 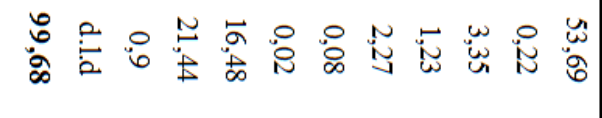 & - : : \\
\hline & $\therefore$ : & $\stackrel{\circ}{\circ}$ & 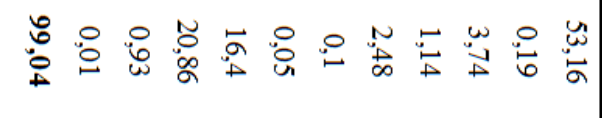 & $\omega \stackrel{\circ}{\circ}$ \\
\hline & $\therefore$ & $\begin{array}{l}\infty \\
\infty\end{array}$ & 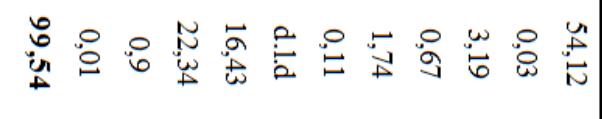 & $-\stackrel{?}{\stackrel{0}{\bullet}}$ \\
\hline & $\therefore$ & $\stackrel{\circ}{\infty}$ & 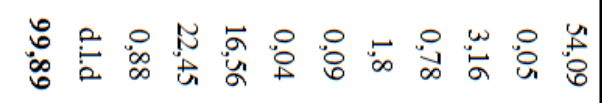 & $\sim \stackrel{\circ}{\stackrel{\theta}{\ominus}}$ \\
\hline
\end{tabular}


Tabla 12.2c). Continuación.

\begin{tabular}{|c|c|c|c|}
\hline & 承凹 & 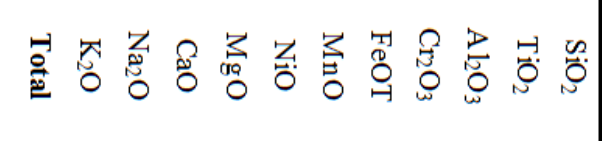 & 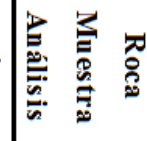 \\
\hline & 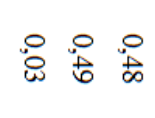 & 离 : & $\omega \stackrel{\circ}{\circ}$ \\
\hline & 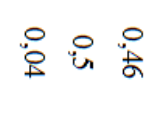 & 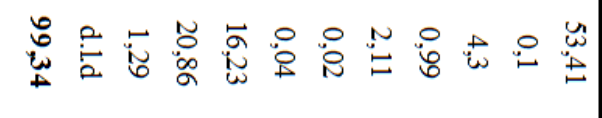 & $-\underset{0}{0}$ \\
\hline & $\stackrel{\circ}{\circ}$ in & 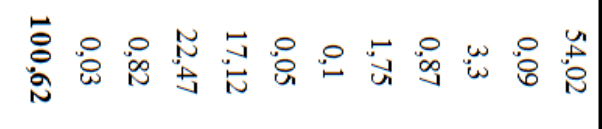 & $-\stackrel{0}{\circ}$ \\
\hline & 品 in & 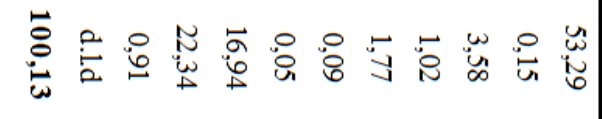 & N $\underset{0}{0}$ \\
\hline & $\stackrel{\circ}{\circ}$ in $\stackrel{\circ}{*}$ & 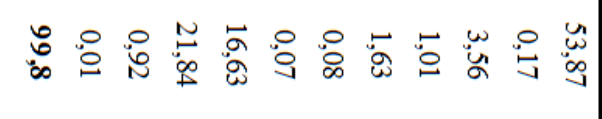 & $\omega \stackrel{0}{\infty}$ \\
\hline & 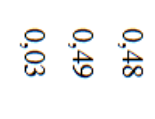 & 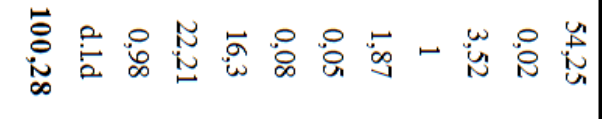 & $-\stackrel{0}{\stackrel{0}{0}}$ \\
\hline & 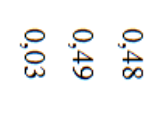 & 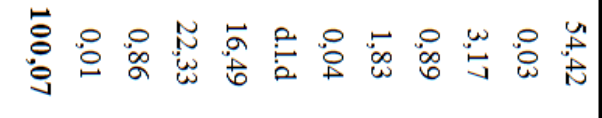 & W \\
\hline & 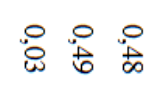 & 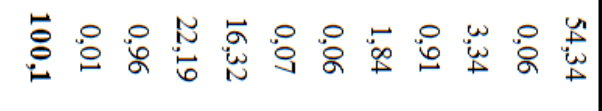 & 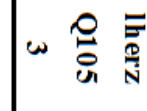 \\
\hline & 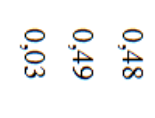 & 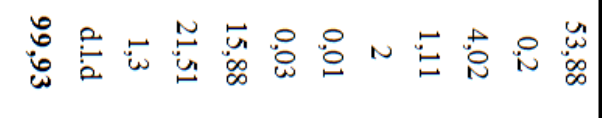 & - \\
\hline & 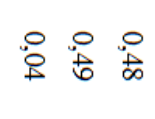 & 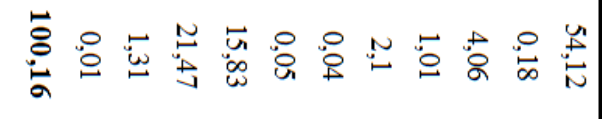 & 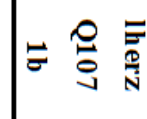 \\
\hline & 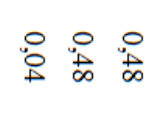 & 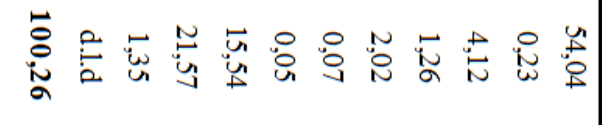 & N $\stackrel{0}{\stackrel{0}{0}}$ \\
\hline & $\therefore$ & 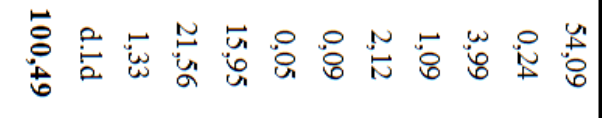 & $\omega \stackrel{0}{g}$ \\
\hline & 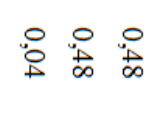 & 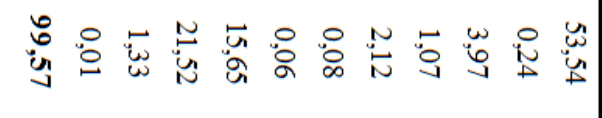 & $+\stackrel{\circ}{\stackrel{0}{\circ}}$ \\
\hline & 品品 & 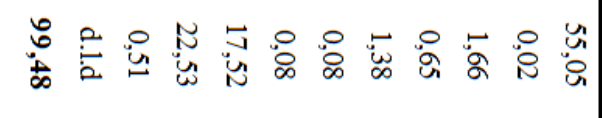 & $\omega$ \\
\hline & $\stackrel{\circ}{\circ} \stackrel{\circ}{\circ} \stackrel{\circ}{*}$ & 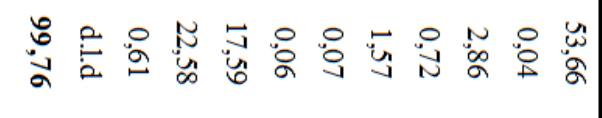 & - \\
\hline & $\stackrel{\circ}{8}$ in & 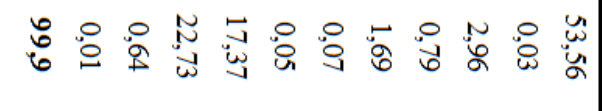 & 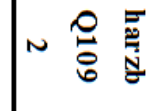 \\
\hline & $\stackrel{\circ}{\circ} \stackrel{\circ}{\circ}$ & 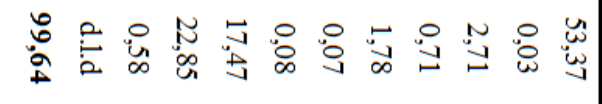 & $\omega \stackrel{?}{?}$ \\
\hline
\end{tabular}


Tabla 12.2c). Continuación.

\begin{tabular}{|c|c|c|c|}
\hline 蒦 & 到思 & 恶思若 & 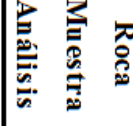 \\
\hline ¿̊. & $\stackrel{\circ}{\circ}$ in & 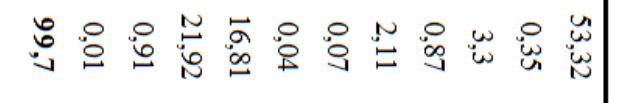 & - 番高 \\
\hline io & 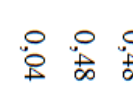 & 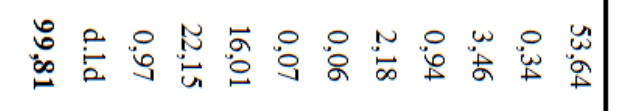 & 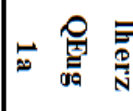 \\
\hline is & 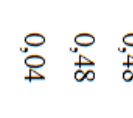 & 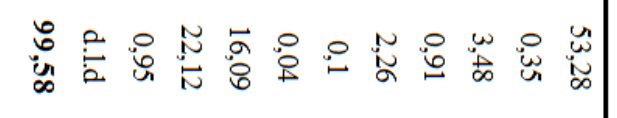 & N \\
\hline ¿̊ & 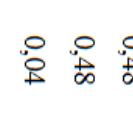 & 总芒 & w \\
\hline 品 & $\therefore$ & 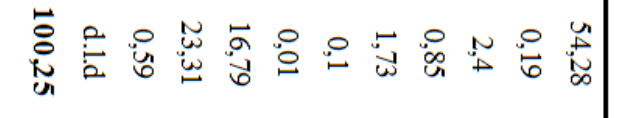 & 一否高 \\
\hline :̊ & $\stackrel{\circ}{\circ} \stackrel{\circ}{\infty}$ & 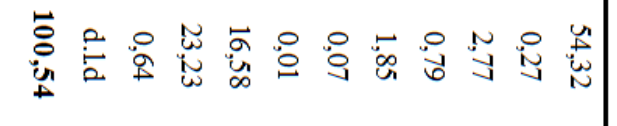 & N勇高 \\
\hline$\ddot{\circ}$ & $\therefore$ & 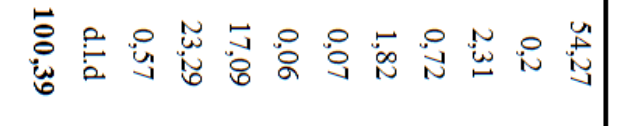 & $\omega$ 忿高 \\
\hline$\ddot{\circ}$ & $\therefore$ & 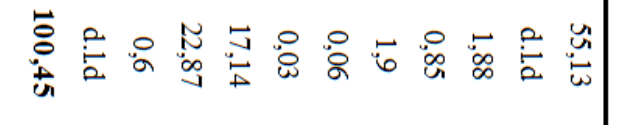 & 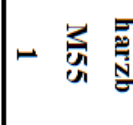 \\
\hline ¿̊ & $\stackrel{8}{\circ}$ & 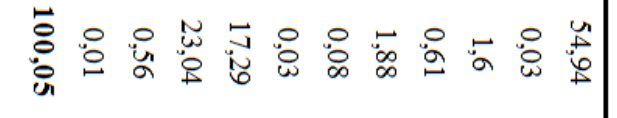 & 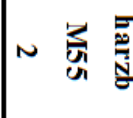 \\
\hline ஜ & $\therefore$ & 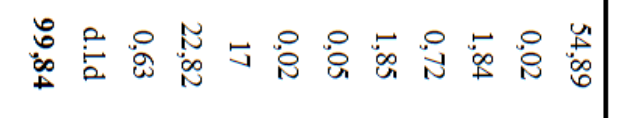 & 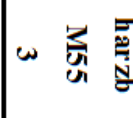 \\
\hline $\begin{array}{l}\circ \\
\stackrel{2}{\circ} \\
+\end{array}$ & 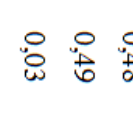 & 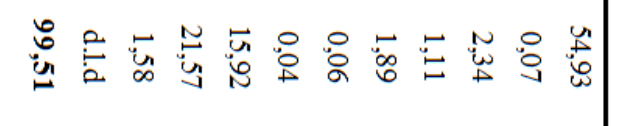 & - 宗产 \\
\hline i⿺ & $\therefore$ 品 & 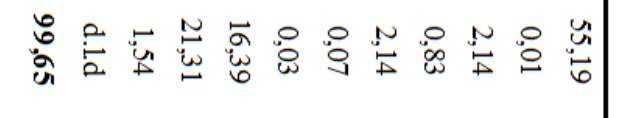 & 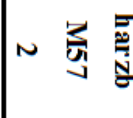 \\
\hline id & $\because$ 品字 & 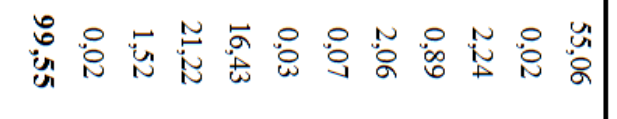 & + 宗产 \\
\hline 兑 & $\therefore$ 道 & 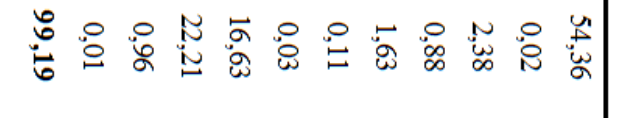 & - 년 \\
\hline$\because$ & 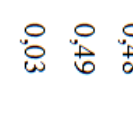 & 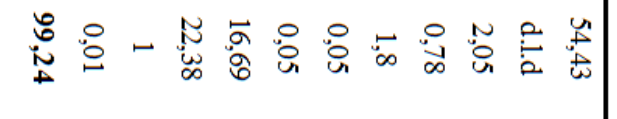 & $\approx$ 学 \\
\hline : & $\therefore$ & 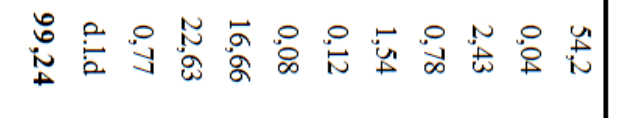 & N 容 \\
\hline : & 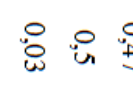 & 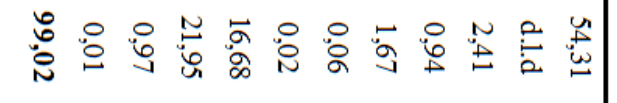 & 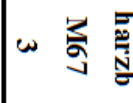 \\
\hline
\end{tabular}


Tabla 12.2c). Continuación.

\begin{tabular}{|c|c|c|c|}
\hline 蒡 & 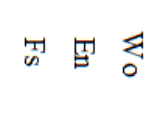 & 总忩若 & 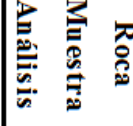 \\
\hline ¿̊ & 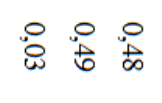 & 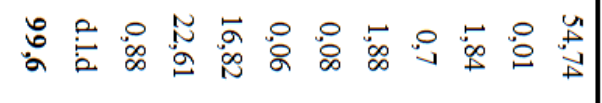 & ๘ \\
\hline$\stackrel{0}{0}$ & 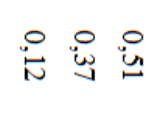 & 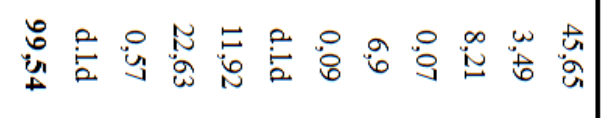 & + 는 \\
\hline$\stackrel{8}{\circ}$ & $\ddot{8}$ in & 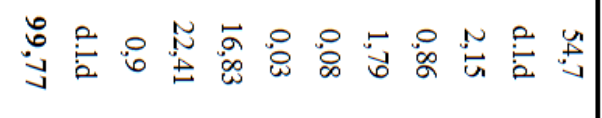 & - \\
\hline 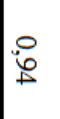 & $\therefore$ 品茟 & 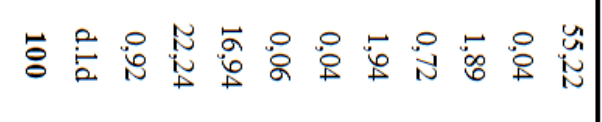 & N 光产 \\
\hline 品 & 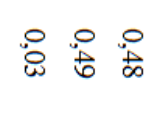 & 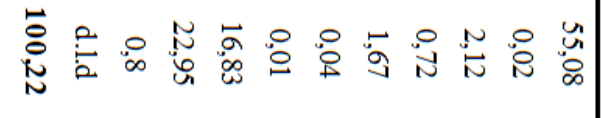 & 一宣宽 \\
\hline :̊ & $\therefore$ & 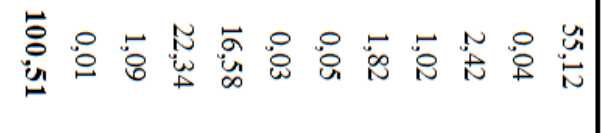 & 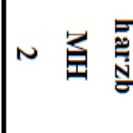 \\
\hline 文 & $\because \stackrel{\circ}{\circ} \stackrel{\circ}{+}$ & 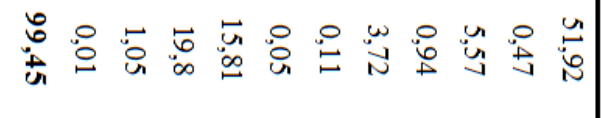 & $-\underbrace{5}$ \\
\hline 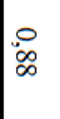 & 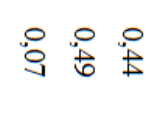 & 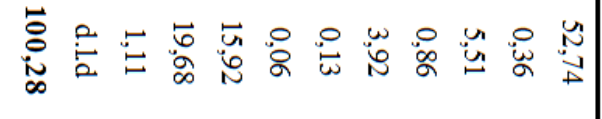 & N 点 \\
\hline 遂 & $\because 0$ & 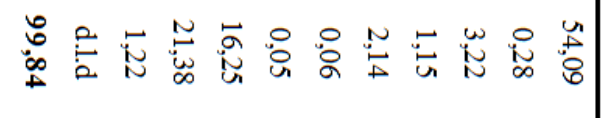 & $-\sum_{\infty}$ \\
\hline ¿̊ & 品望 & 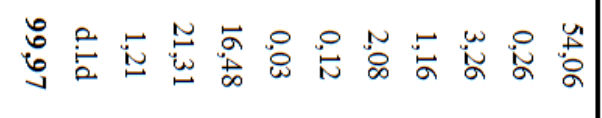 & $\sim \underset{\infty}{5}$ \\
\hline 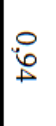 & $\because \stackrel{\circ}{\circ} \stackrel{\circ}{\oplus}$ & 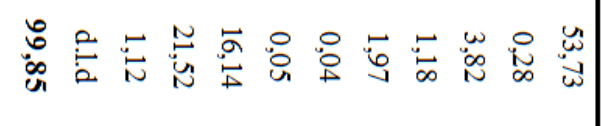 & - \\
\hline : & $\because \stackrel{8}{\circ}$ & 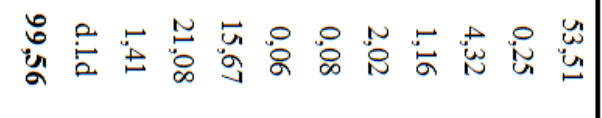 & N 点 \\
\hline i⿺ & 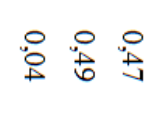 & 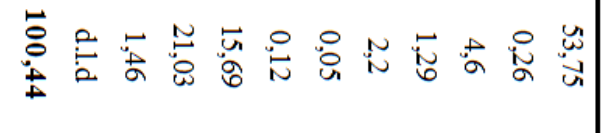 & $\approx \underset{\sim}{\infty}$ \\
\hline : & 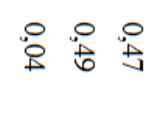 & 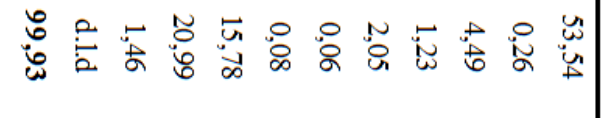 & 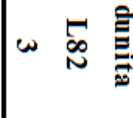 \\
\hline ¿ & 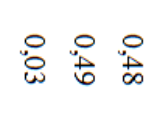 & 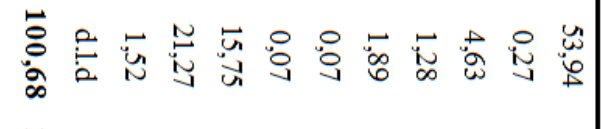 & 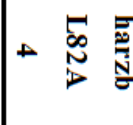 \\
\hline : & 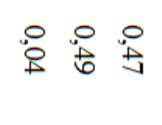 & 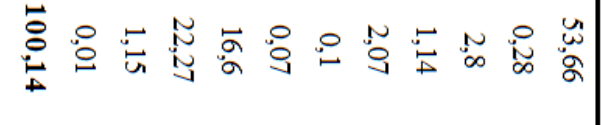 & $-\Omega_{1} \overline{\frac{D}{n}}$ \\
\hline i: & $\therefore$ & : & $\approx \Omega_{1} \overline{\frac{D}{N}}$ \\
\hline
\end{tabular}


Tabla 12.2c). Continuación.

\begin{tabular}{|c|c|c|c|}
\hline 藻 & 雨 & 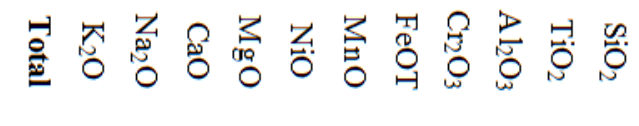 & 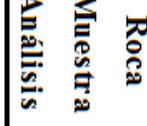 \\
\hline : & : & 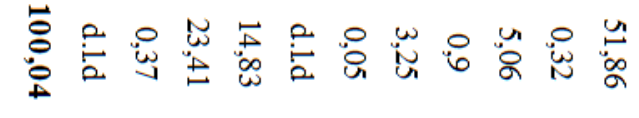 & 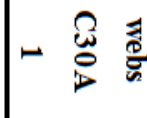 \\
\hline : & 号 i in & 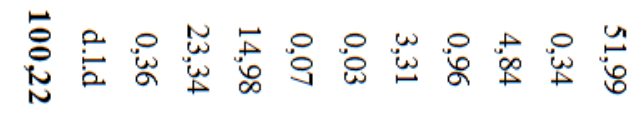 & 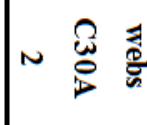 \\
\hline : & $\stackrel{\circ}{\circ}$ in & 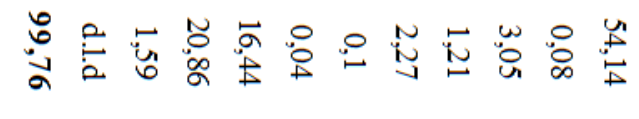 & 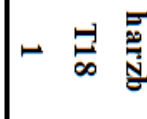 \\
\hline \&̊ & $\begin{array}{l}\circ \\
0 \\
\circ\end{array}$ & 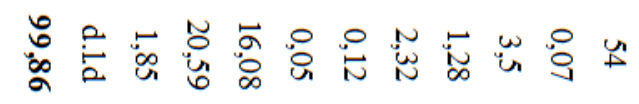 & N $\underset{\infty}{\vec{g}}$ \\
\hline
\end{tabular}


Tabla12.2d. Análisis de microsonda de cristales de espinela de los xenolitos de $\mathrm{C}^{\circ}$ Chenque (Q); $\mathrm{C}^{\circ}$ Matilde (M); $\mathrm{C}^{\circ}$ León (L); Cortadera (C) y Tapera Marín (T). d.l.d = debajo de límite de detección. n.a $=$ no analizado.

\begin{tabular}{|c|c|c|c|}
\hline 蒦蕰 & 을 & 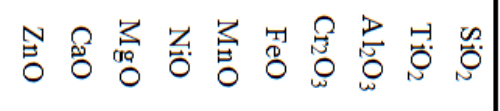 & 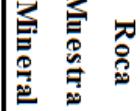 \\
\hline$\stackrel{\omega}{\circ}$ & 㝘 & 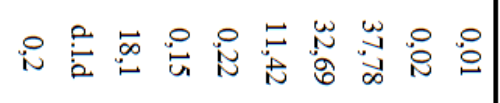 & $-\infty$ \\
\hline \begin{tabular}{l}
$\circ$ \\
\hdashline \\
$\infty$
\end{tabular} & : & 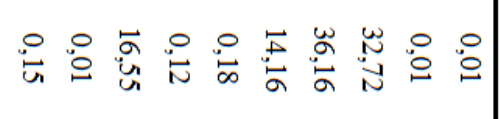 & $\sim$ 灾 \\
\hline 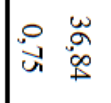 & $\begin{array}{l}\infty \\
\infty \\
\infty \\
\infty\end{array}$ & 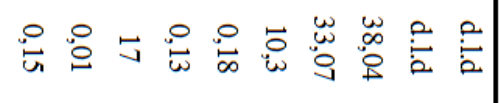 & $\omega$ 屈 \\
\hline$\stackrel{0}{0}$ & $\stackrel{\vec{\circ}}{\circ}$ & 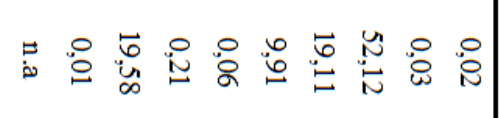 & - 串 \\
\hline 品 : & 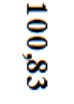 & 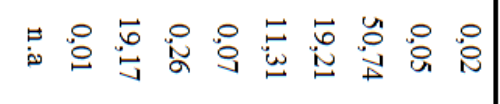 & + 央 \\
\hline 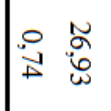 & 宫 & 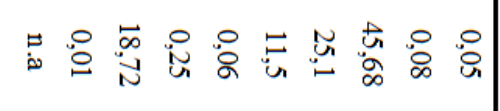 & 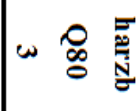 \\
\hline$\because ّ$ & : & 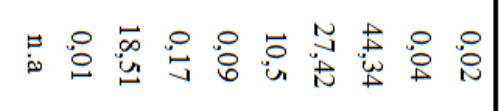 & $+\infty \stackrel{\square}{8}$ \\
\hline 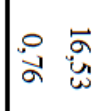 & $\stackrel{\vec{\circ}}{\dot{\Xi}}$ & 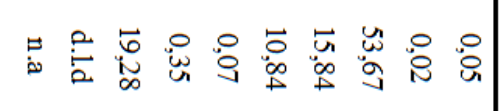 & $\sim$ : \\
\hline 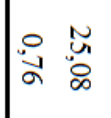 & $\stackrel{\overrightarrow{0}}{\stackrel{N}{N}}$ & 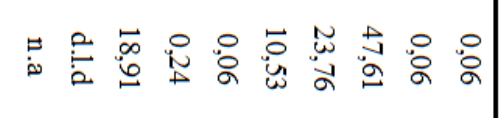 & N \\
\hline \begin{tabular}{ll}
0 \\
\hdashline
\end{tabular} & $\stackrel{\vec{s}}{\circ}$ & 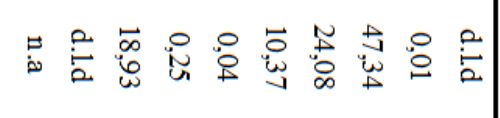 & $+\stackrel{0}{\theta}$ \\
\hline$\stackrel{0}{0}$ & $\underset{\infty}{\stackrel{5}{\infty}}$ & 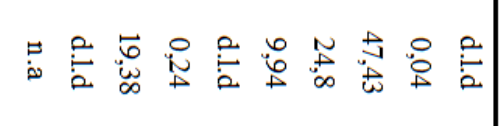 & 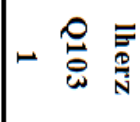 \\
\hline 웍 & $\begin{array}{l}0 \\
: \\
\infty \\
\infty \\
0\end{array}$ & 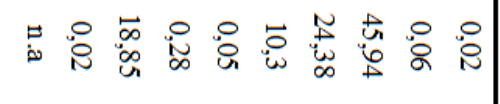 & 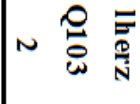 \\
\hline 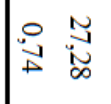 & $\begin{array}{l}0 \\
: \\
\infty \\
\infty \\
0\end{array}$ & 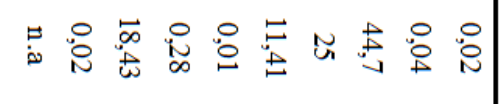 & 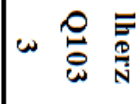 \\
\hline $\begin{array}{ll}0 \\
\infty \\
\infty\end{array}$ & $\stackrel{s}{\stackrel{s}{\omega}}$ & 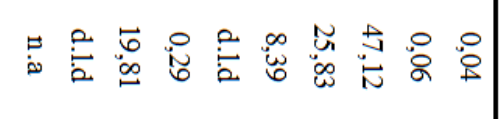 & $-\stackrel{0}{\circ}$ \\
\hline$\stackrel{\circ}{0.0}$ & : & 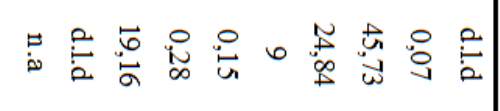 & 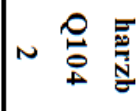 \\
\hline 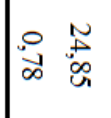 & 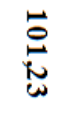 & 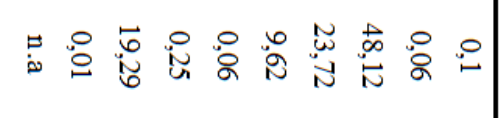 & - 号 \\
\hline 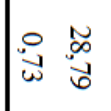 & $\stackrel{\bullet}{\stackrel{\infty}{\infty}}$ & 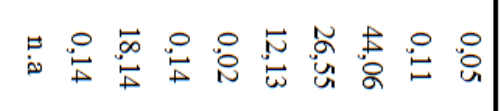 & $\omega \stackrel{0}{\circ}$ \\
\hline
\end{tabular}


Tabla12.2d. Continuación.

\begin{tabular}{|c|c|c|c|}
\hline 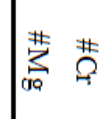 & $\stackrel{\overrightarrow{0}}{\ddot{E}}$ & 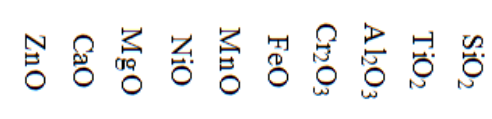 & 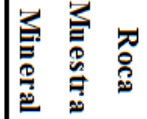 \\
\hline 舟总 & $\stackrel{s}{\vec{b}}$ & 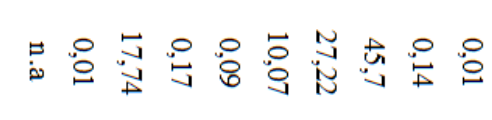 & w \\
\hline 원 & $\begin{array}{l}0 \\
:\end{array}$ & 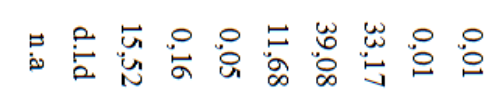 & 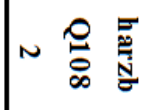 \\
\hline 实苦 & $\begin{array}{l}0 \\
: \\
\vdots \\
\vdots\end{array}$ & 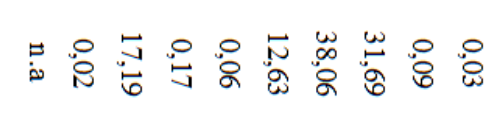 & $\omega \stackrel{\circ}{\circ}$ \\
\hline 宓莒 & \begin{tabular}{l}
$\infty$ \\
$\infty$ \\
\hdashline \\
$o n$
\end{tabular} & 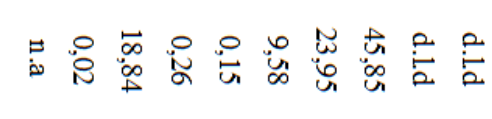 & $-\frac{0}{8}$ \\
\hline 赵赵 & $\stackrel{\vec{g}}{\mathrm{~s}}$ & 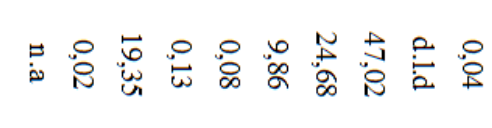 & $=\frac{8}{8}$ \\
\hline 品党 & \begin{tabular}{l} 
高 \\
$\vdots$ \\
\multirow{2}{a}{}
\end{tabular} & 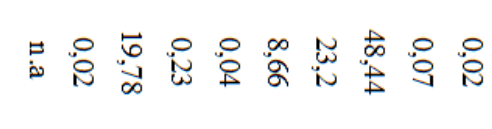 & $\sim \stackrel{P}{\circ}$ \\
\hline$\stackrel{0}{\infty}$ & 总 & 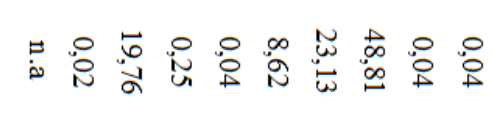 & $\cong$ 串 \\
\hline 요 & 悹 & 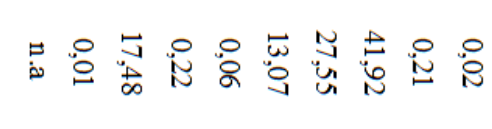 & - 兽高 \\
\hline 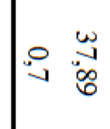 & 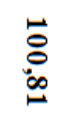 & 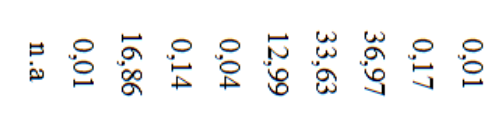 & $\omega$ 空言 \\
\hline$\therefore$ & 宫 & 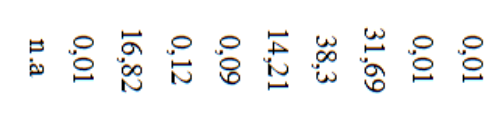 & - 慈哀 \\
\hline 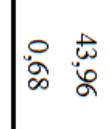 & $\stackrel{\vec{g}}{\Delta}$ & 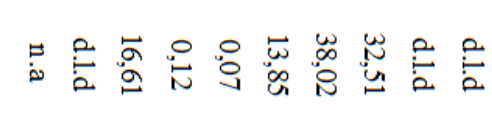 & N 窇总 \\
\hline 용 & $\underset{\substack{\circ \\
\infty}}{+\infty}$ & 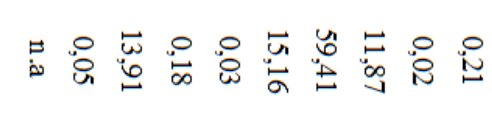 & 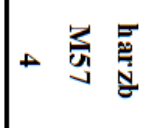 \\
\hline 客喜 & : & 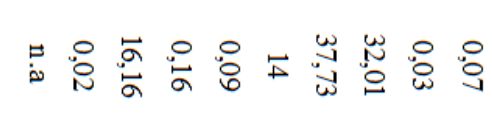 & - - 参 \\
\hline 웅 & $\stackrel{\circ}{\circ}$ & 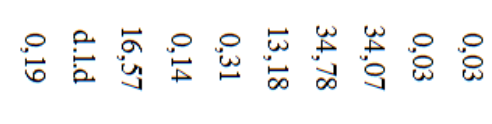 & $\omega$ 察 \\
\hline$\therefore$ 声 & 总 & 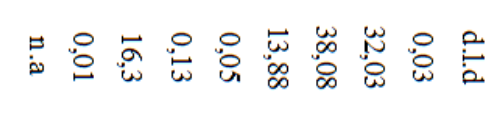 & w 寄 \\
\hline 号苫 & $\begin{array}{c}\text { Dे } \\
\text { on } \\
\text { का }\end{array}$ & 芦苔 & 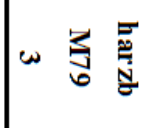 \\
\hline$\stackrel{8}{7}$ & $\stackrel{\vec{g}}{+}$ & 品菅岕总 & 一宣言 \\
\hline
\end{tabular}


Tabla12.2d. Continuación.

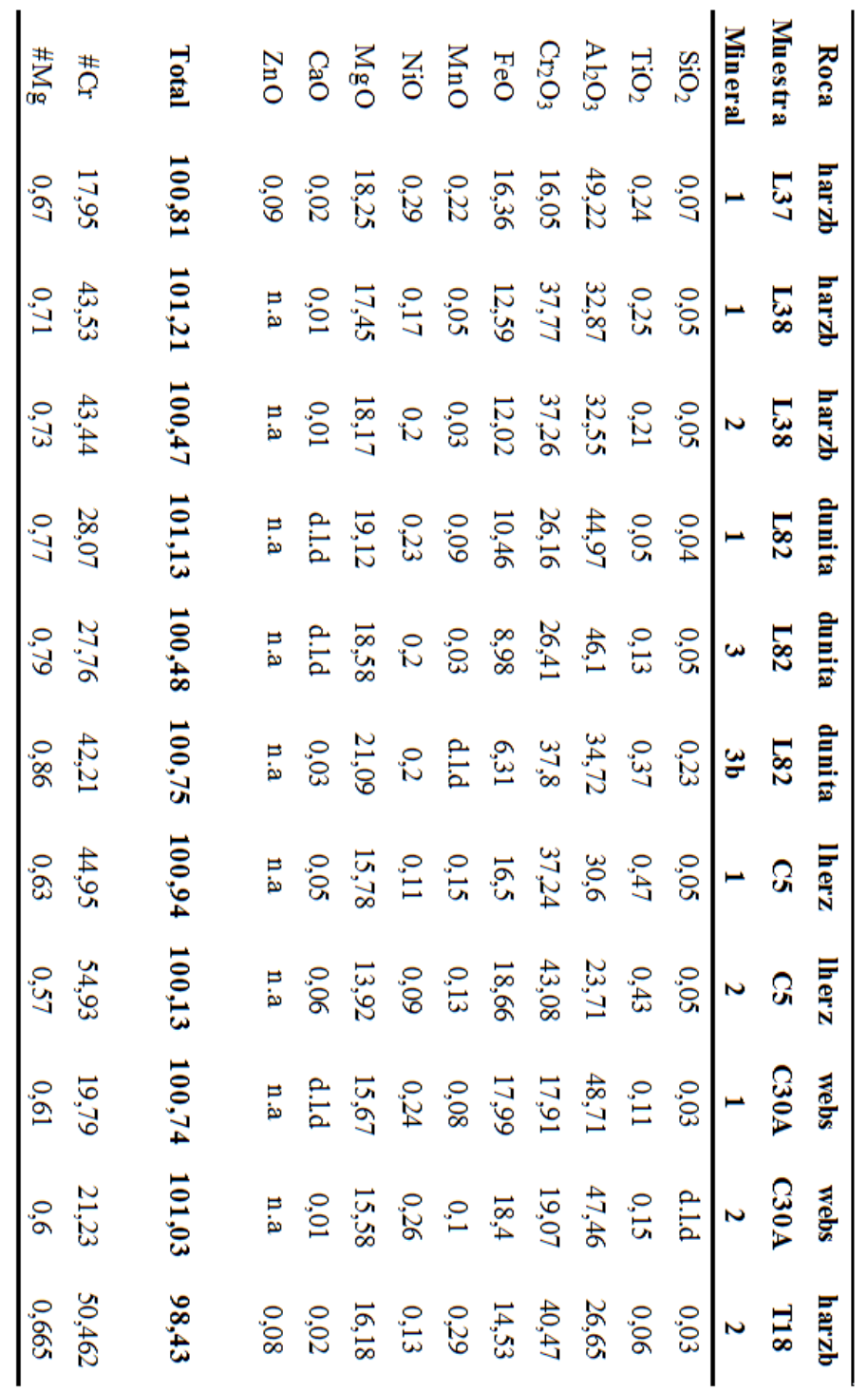


Tabla 12.3. Contenido de elementos traza en clinopiroxenos de los xenolitos de $\mathrm{C}^{\circ}$ Chenque (Q); $\mathrm{C}^{\circ}$ Matilde (M); $\mathrm{C}^{\circ}$ León (L) obtenido mediante ablación laser. ). d.1.d = debajo de límite de detección. Valores expresados en ppm.

\begin{tabular}{cccccccccc}
\hline Muestra & Q65 & Q77 & Q77.2 & Q80 & Q101 & Q105 & Q107 & Q108 & Q109 \\
\hline $\mathrm{Rb}$ & 0,054 & d.l.d & 0,234 & 1,014 & 0,051 & 0,032 & 0,062 & 0,31 & 0,289 \\
$\mathrm{Sr}$ & 127,288 & 56,325 & 56,638 & 97,567 & 203,368 & 11,160 & 28,156 & 25,19 & 9,247 \\
$\mathrm{Y}$ & 8,173 & 3,440 & 3,368 & 6,728 & 1,303 & 1,681 & 8,526 & 1,2045 & 1,037 \\
$\mathrm{Zr}$ & 0,304 & 2,685 & 2,977 & 18,257 & 5,297 & 6,570 & 33,522 & 0,469 & 5,082 \\
$\mathrm{Nb}$ & 1,133 & d.1.d & 0,071 & 0,541 & 0,210 & 0,164 & 0,024 & 0,089 & 0,175 \\
$\mathrm{Cs}$ & 0,011 & d.l.d & 0,015 & 0,013 & 0,005 & $\mathrm{~d} .1 . \mathrm{d}$ & $\mathrm{d} .1 . \mathrm{d}$ & 0,01965 & 0,009 \\
$\mathrm{Ba}$ & 0,113 & d.l.d & 0,202 & 1,053 & 0,036 & 0,038 & 0,201 & 18,66 & 0,316 \\
$\mathrm{La}$ & 5,742 & 0,529 & 0,516 & 3,995 & 3,850 & 0,107 & 0,106 & 2,7385 & 0,065 \\
$\mathrm{Ce}$ & 6,967 & 1,606 & 1,644 & 10,733 & 8,005 & 0,687 & 0,965 & 5,1665 & 0,397 \\
$\mathrm{Pr}$ & 0,542 & 0,276 & 0,290 & 1,636 & 0,868 & 0,190 & 0,300 & 0,481 & 0,109 \\
$\mathrm{Nd}$ & 1,528 & 1,860 & 1,970 & 7,530 & 2,777 & 1,186 & 2,248 & 1,8745 & 0,758 \\
$\mathrm{Sm}$ & 0,209 & 0,550 & 0,522 & 1,812 & 0,458 & 0,313 & 0,876 & 0,485 & 0,295 \\
$\mathrm{Eu}$ & 0,123 & 0,191 & 0,175 & 0,579 & 0,156 & 0,086 & 0,328 & 0,154 & 0,075 \\
$\mathrm{Gd}$ & 0,509 & 0,615 & 0,632 & 1,404 & 0,366 & 0,159 & 1,036 & 0,201 & 0,187 \\
$\mathrm{~Tb}$ & 0,134 & 0,105 & 0,122 & 0,234 & 0,040 & 0,029 & 0,192 & 0,105 & $\mathrm{~d} .1 . \mathrm{d}$ \\
$\mathrm{Dy}$ & 1,116 & 0,696 & 0,692 & 1,266 & 0,189 & 0,214 & 1,552 & 0,381 & 0,184 \\
$\mathrm{Ho}$ & 0,287 & 0,134 & 0,142 & 0,255 & 0,047 & 0,054 & 0,312 & 0,07465 & 0,040 \\
$\mathrm{Er}$ & 1,111 & 0,340 & 0,369 & 0,696 & 0,152 & 0,228 & 0,948 & 0,127 & 0,150 \\
$\mathrm{Tm}$ & 0,155 & d.1.d & $\mathrm{d} .1 . \mathrm{d}$ & $\mathrm{d} .1 . \mathrm{d}$ & 0,034 & 0,058 & 0,128 & 0 & $\mathrm{~d} .1 . \mathrm{d}$ \\
$\mathrm{Yb}$ & 1,183 & 0,359 & 0,369 & 0,594 & 0,325 & 0,421 & 0,940 & 0,119 & 0,281 \\
$\mathrm{Lu}$ & 0,187 & 0,060 & 0,055 & 0,101 & 0,068 & 0,061 & 0,135 & 0,0172 & 0,055 \\
$\mathrm{Hf}$ & 0,051 & 0,084 & 0,107 & 0,246 & 0,110 & 0,225 & 1,212 & 0,0277 & 0,170 \\
$\mathrm{Ta}$ & 0,404 & $\mathrm{~d} .1 . \mathrm{d}$ & 0,137 & 0,145 & 0,039 & 0,009 & 0,005 & 0,068 & $\mathrm{~d} .1 . \mathrm{d}$ \\
$\mathrm{Pb}$ & 0,086 & 0,411 & 0,382 & 0,410 & 0,748 & 0,036 & 0,070 & 0,1705 & 0,230 \\
$\mathrm{Th}$ & 0,688 & 0,012 & 0,013 & 0,087 & 0,269 & 0,005 & 0,010 & 0,37025 & 0,018 \\
$\mathrm{U}$ & 0,148 & $\mathrm{~d} .1 . \mathrm{d}$ & 0,012 & 0,062 & 0,094 & 0,004 & 0,009 & 0,081 & 0,010 \\
\hline & & & & & & & & &
\end{tabular}


Tabla 12.3. Continuación.

\begin{tabular}{cccccccccc}
\hline Muestra & Qeug & M53 & M55 & M57 & M67 & M69 & M79 & MH & L82 \\
\hline $\mathrm{Rb}$ & 0,032 & 0,106 & 0,049 & 0,156 & 0,083 & 0,046 & 0,152 & 0,487 & 0,052 \\
$\mathrm{Sr}$ & 63,216 & 40,422 & 114,687 & 963,513 & 70,901 & 46,882 & 180,595 & 85,556 & 168,055 \\
$\mathrm{Y}$ & 8,878 & 7,983 & 1,430 & 10,143 & 0,789 & 2,292 & 0,994 & 0,803 & 9,757 \\
$\mathrm{Zr}$ & 22,010 & 8,690 & 0,630 & 2,160 & 0,387 & 1,441 & 0,387 & 0,672 & 47,587 \\
$\mathrm{Nb}$ & 0,652 & 0,061 & 0,044 & 0,096 & 0,027 & 0,022 & 0,008 & 0,160 & 0,094 \\
$\mathrm{Cs}$ & $\mathrm{d} .1 . \mathrm{d}$ & 0,006 & $\mathrm{~d} . \mathrm{I} . \mathrm{d}$ & 0,009 & 0,011 & $\mathrm{~d} . \mathrm{I} . \mathrm{d}$ & 0,011 & 0,006 & 0,004 \\
$\mathrm{Ba}$ & 0,045 & 0,335 & 0,203 & 46,827 & 1,746 & 0,083 & 9,765 & 0,817 & 0,128 \\
$\mathrm{La}$ & 1,596 & 1,758 & 11,904 & 117,177 & 9,118 & 3,368 & 14,553 & 14,392 & 3,988 \\
$\mathrm{Ce}$ & 4,836 & 3,400 & 18,517 & 169,090 & 6,985 & 4,041 & 21,163 & 13,438 & 11,210 \\
$\mathrm{Pr}$ & 0,814 & 0,554 & 1,543 & 13,867 & 0,314 & 0,330 & 1,682 & 0,702 & 1,625 \\
$\mathrm{Nd}$ & 4,386 & 2,938 & 4,173 & 39,117 & 0,545 & 0,990 & 3,805 & 1,510 & 7,165 \\
$\mathrm{Sm}$ & 1,382 & 0,865 & 0,498 & 4,337 & 0,078 & 0,198 & 0,375 & 0,154 & 1,782 \\
$\mathrm{Eu}$ & 0,521 & 0,338 & 0,140 & 1,158 & 0,025 & 0,075 & 0,130 & 0,040 & 0,649 \\
$\mathrm{Gd}$ & 1,712 & 1,253 & 0,240 & 2,327 & 0,081 & 0,205 & 0,185 & 0,095 & 1,935 \\
$\mathrm{~Tb}$ & 0,295 & 0,205 & 0,034 & 0,268 & 0,014 & 0,035 & 0,018 & 0,016 & 0,303 \\
$\mathrm{Dy}$ & 1,772 & 1,393 & 0,205 & 1,660 & 0,094 & 0,338 & 0,138 & 0,105 & 1,962 \\
$\mathrm{Ho}$ & 0,388 & 0,313 & 0,046 & 0,301 & 0,025 & 0,079 & 0,033 & 0,024 & 0,362 \\
$\mathrm{Er}$ & 0,966 & 0,987 & 0,161 & 0,681 & 0,116 & 0,236 & 0,120 & 0,124 & 1,010 \\
$\mathrm{Tm}$ & 0,136 & 0,136 & 0,028 & 0,132 & 0,022 & 0,040 & 0,027 & 0,022 & 0,144 \\
$\mathrm{Yb}$ & 0,914 & 0,884 & 0,194 & 0,613 & 0,197 & 0,316 & 0,258 & 0,233 & 0,964 \\
$\mathrm{Lu}$ & 0,136 & 0,106 & 0,033 & 0,081 & 0,041 & 0,052 & 0,040 & 0,034 & 0,130 \\
$\mathrm{Hf}$ & 0,839 & 0,374 & 0,025 & 0,049 & 0,023 & 0,066 & 0,016 & 0,033 & 1,229 \\
$\mathrm{Ta}$ & 0,101 & 0,009 & 0,010 & 0,007 & 0,010 & $\mathrm{~d} . \mathrm{I} . \mathrm{d}$ & 0,004 & 0,017 & 0,007 \\
$\mathrm{~Pb}$ & 0,087 & 0,460 & 0,415 & 1,669 & 0,890 & 0,781 & 0,850 & 0,350 & 1,792 \\
$\mathrm{Th}$ & 0,051 & 0,084 & 0,596 & 8,923 & 1,590 & 0,285 & 1,757 & 1,476 & 0,389 \\
$\mathrm{U}$ & 0,018 & 0,042 & 0,200 & 2,122 & 1,461 & 0,192 & 0,547 & 0,592 & 0,089 \\
\hline & & & & & & & & &
\end{tabular}


Lic. Alexis D. Ponce

Director: Dr. Gustavo W. Bertotto

Co-director: Dr. Carlos A. Cingolani 